INTERNATIONAL PHASE OF OCEAN DRILLING (IPOD)

DEEP SEA DRILLING PROJECT

DEVELOPMENT ENGINEERING

TECHNICAL REPORT NO. 20

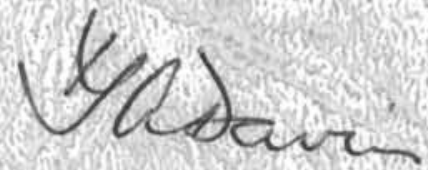

\title{
DESIGN AND OPERATION OF AN EXTENDED CORE BARREL
}

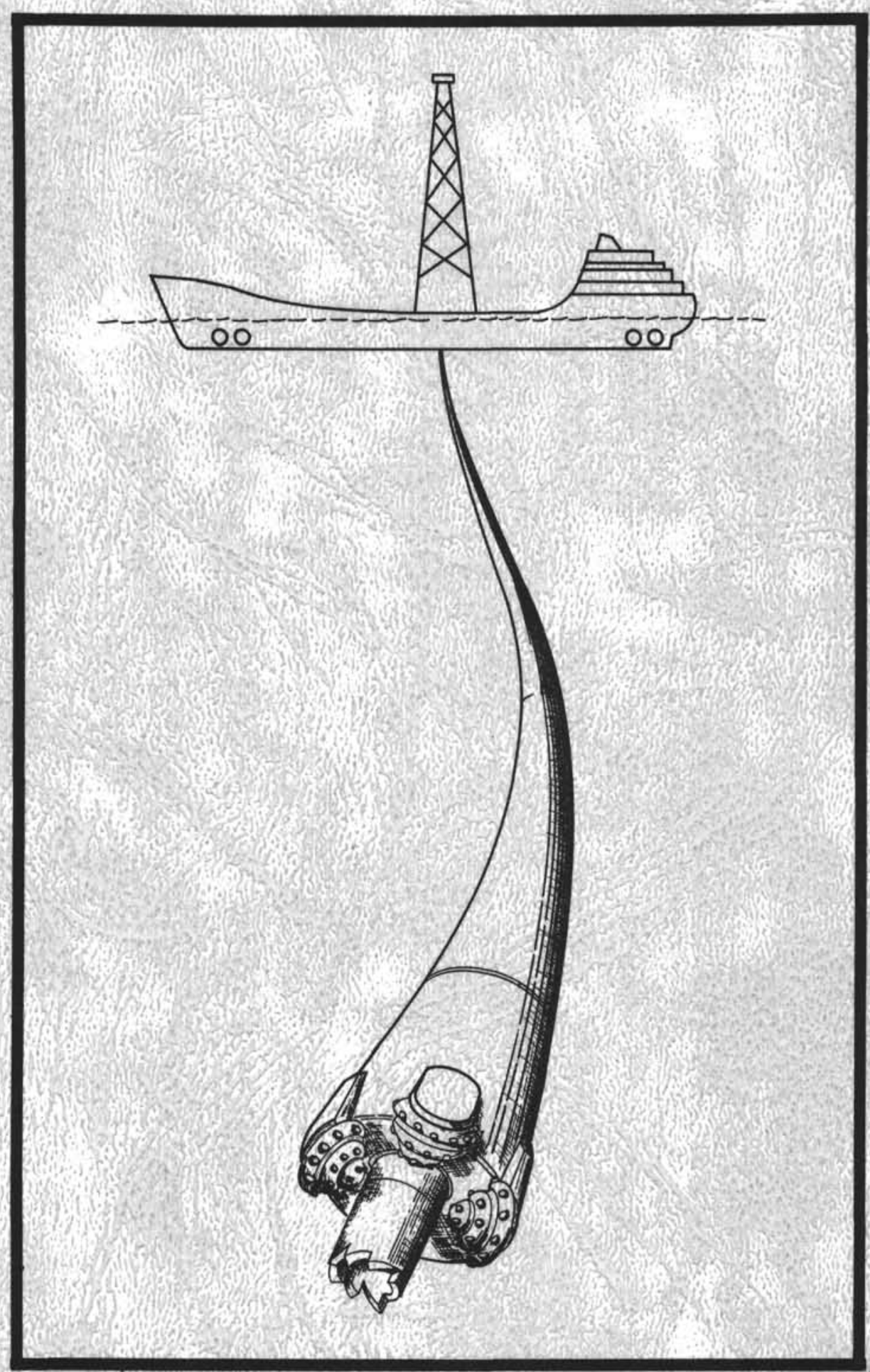

SCRIPPS INSTITUTION OF OCEANOGRAPHY UNIVERSITY OF CALIFORNIA AT SAN DIEGO 


\section{DISCLAIMER}

This report was prep̧ared by the Deep Sea Drilling Project, University of California, San Diego as an account of work sponsored by the United States Government's National Science Foundation. Neither the University nor any of their employees, nor any of their contractors, subcontractors, or their employees, makes any warranty, express or implied, or assumes any legal

liability or responsibility for the accuracy, completeness or usefulness of any information, apparatus, product or process disclosed, or represents that its use would not infringe privacely owned rights. 


\section{THE COVER ILLUSTRATION}

The Extended Core Barrel is shown protruding from a roller-cone core bit at the bottom of the drill string. The drag-type extended Cutting Shoe will core ahead of the bit to capture relatively undisturbed soft sediments. Stiffer formations will force the Shoe to retract flush with the bit.

-iii- 
TECHNICAL REPORT NO. 20

Design and Operation of an

Extended Core Barrel

\author{
Prepared for the \\ National Science Foundation \\ National Ocean Sediment Coring Program \\ Under Contract C-482
}

by the

\author{
University of California \\ Scripps Institution of Oceanography \\ Prime Contractor for the Project
}

August 1984

W.A. Nierenberg, Director

Scripps Institution of Oceanography
M. N. A. Peterson

Principal Investigator and Project Manager

Scripps Institution of Oceanography 


\section{$\underline{\text { INTRODUCTION }}$}

\section{DEEP SEA DRILLING PROJECT}

The Deep Sea Drilling Project (DSDP) began coring in August, 1968, under the auspices of the National Science Foundation's (NSF) Ocean Sediment Coring Program to increase man's knowledge of the earth's development through the exploration of the ocean floor. The prime contract for the Project was executed in 1966 between NSF and the Board of Regents of the University of California (UC). Scripps Institution of Oceanography in La Jolla, California, which is part of the UC system, is responsible for the management and operation of the Project. Global Marine, Inc. (GMI) of Los Angeles, owner, designer, and builder of the GLOMAR CHALLENGER, subcontracted with Scripps to provide the drilling vessel for the drilling and coring program.

To plan the scientific objectives of the program, major oceanographic institutions in the United States (including Woods Hole Oceanographic Institution, Lamont-Doherty Geological Observatory of Columbia University, Rosenstiel School of Marine Sciences of the University of Miami, the University of Washington and Scripps), joined in an agreement to mutually support such a program of deep ocean drilling. This association is called the Joint Oceanographic Institutions for Deep Earth Sampling (JOIDES) and provides scientific guidance for the Deep Sea Drilling Project. The group was later enlarged to include nine American institutions.

\section{INTERNATIONAL PHASE OF OCEAN DRILLING}

Prompted by the vast scientific and technical successes of the first seven years, the Project increased the scope of the coring program to include even deeper penetrations into the ocean floor. International interest in the Project increased. Several foreign scientific institutions, excited by past scientific results and confident of future successes, were interested in becoming members of JOIDES. These institutions were willing to contribute financially to the Projection exchange for a greater role in the scientific planning. In 1975, the "International Phase of Ocean Drilling", known as IPOD, was born. IPOD was an initial three year Deep Crustal coring Porgram supported both scientifically and financially by the governments of France, Germany, Japan, England, and Russia.

\section{D/V GLOMAR CHALLENGER}

The GLOMAR CHALLENGER, with its unique coring procedures, has long been recognized as a major technical achievement in its own right. The 10,500 metric ton drill ship utilized an advanced on board computer and dual bow and stern thrusters to dynamically position itself. The CHALLENGER operated as far north as 76 degrees latitude; as far south as $\mathbf{7 7}$ degrees latitude and has the capability to maintain its station in 30-knot winds and 7-10 foot seas. Similar to conventional drillships, the vessel incorporated a 43-meter derrick amidship with a hookload capacity of 450 metric tons 
and could deploy a $7000 \mathrm{~m}$ drill string. The CHALLENGER utilized an automatic pipe racker capable of handling 7,300 meters of 5-inch S-135 drill pipe, and was equipped with a drill pipe heave compensation system.

Most coring operations were conducted in very deep water and all sites were carefully screened to ensure that there was no possibility of encountering gas or hydrocarbons. For these reasons no riser or blow-out prevention equipment was used. Circulation while coring was provided by two National 1600 mud pumps and consisted of seawater without return circulation. Core barrels were retrieved by wireline utilizing a coring winch equipped with up to $7900 \mathrm{~m}$ of $6 \times 16$ wire rope. Well equipped shipboard scientific laboratories were utilized to conduct comprehensive core analyses.

\section{ABSTRACT/TECHNICAL REPORT NO. 20}

This Deep Sea Drilling Technical Report discusses the design, development and operation of the DSDP Extended Core Barrel (XCB). Test reports are included in the Appendices along with detailed machine drawings of the most current version.

The XCB was successfully operated by DSDP on the Glomar Challenger during Legs 90-96. It is one part of a totally new coring system that can take deep ocean cores from the soft mudline to basalt basement. It has been developed to core the sediment interval below the depth limit (sediment stiffness limit) of the Advanced Piston Corer and into basalt basement without tripping the drill string.

The XCB concept is not new and was used successfully on Legs 18 and 30 of DSDP, when a commercial model produced by Christensen Diamond Products was adapted for use with the DSDP wireline coring system. Initially it was intended as a specialized tool to improve core recovery in alternately hard and soft interbedded strata. The emergence of the hydraulic piston coring technology stimulated new interest in the XCB. It was redesigned to be an integral component of a dual - barrel system which may obsolete the standard rotary core barrel.

The XCB can extend up to 7 inches below the Core Bit, or retract flush with the Bit. The extension is maintained by a spring force of up to $2000 \mathrm{lbs}$. The retractibility prevents overload damage to the tool. Other features include a non-rotating core liner and a secondary circulation system which diverts some of the drill string circulating water to the extended Cutting Shoe. 


\section{ACKNOWLEDGEMENTS}

The DSDP Extended Core Barrel system is a logical extension of the Advanced Piston Coring System in that it allows continued coring to basement without tripping the drill string.

Early efforts were geared toward adapting a commercial model produced by Christensen Diamond Products, Inc. Building upon that past experience a totally new system was developed by Mr. B.W. Adams and Mr. D.H. Cameron of DSDP. Significant design contributions were made by M.A. Storms and D.P. Huey of DSDP. Overall guidance was provided by Mr. S.T. Serocki, Principal Development Engineer at DSDP.

This report was prepared by Mr. D.H. Cameron, Associate Development Engineer at DSDP.

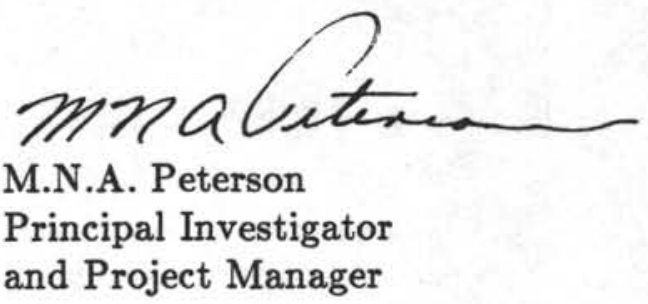




\section{CONTENTS}

I. Background

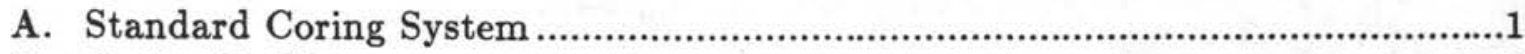

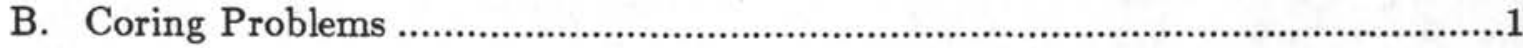

C. Benefits of an Extended Core Barrel ....................................................................

II. Design and Development

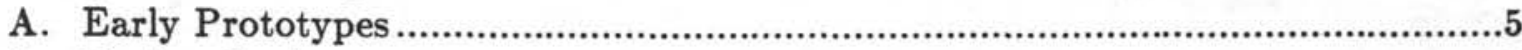

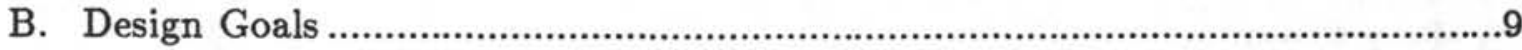

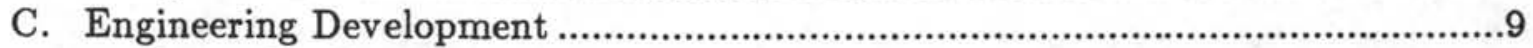

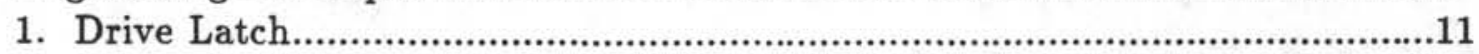

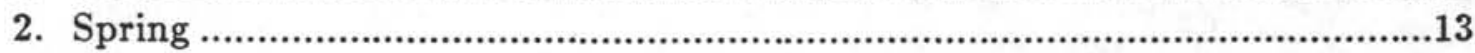

3. Telescoping Section...................................................................................

4. Core Barrel with Non-Rotating Core Liner .................................................15

5. Cutting Shoe Development...........................................................................15

6. Cutting Shoe Circulation .................................................................................21

III. Current XCB Description and Operator

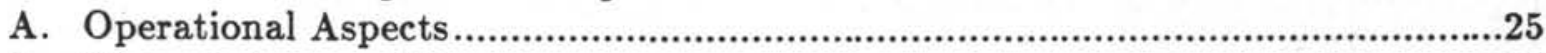

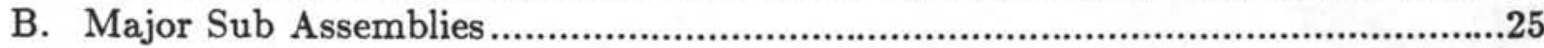

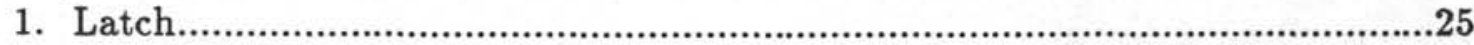

2. Hex-Splined Scoping Section........................................................................29

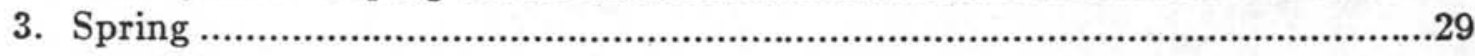

4. Quick Release Mechanism ............................................................................29

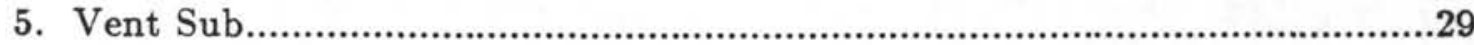

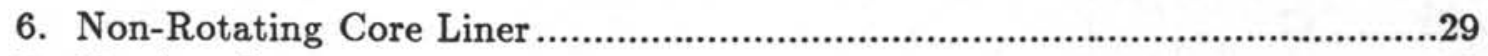

7. Cutting Shoe .......................................................................................................

IV. BHA Configuration and Specific Assemblies

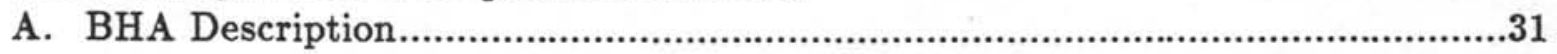

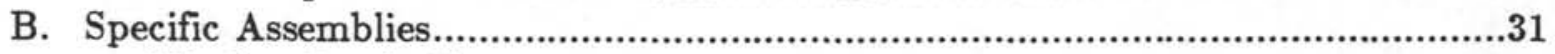

1. Window Latch Sleeve .....................................................................................

2. Padded Flapper ...........................................................................................

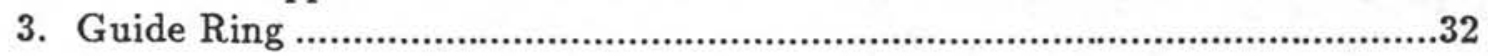

V. Performance Evaluation

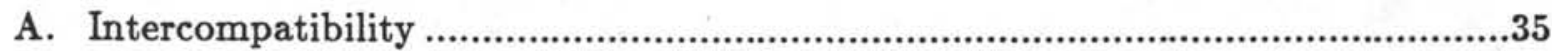

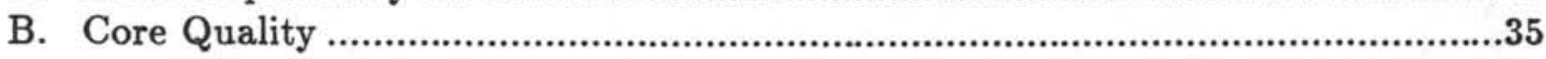

C. Floating Core Liner/Liner Failures ....................................................................35

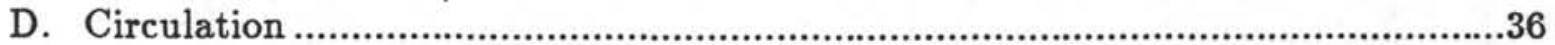


VI. XCB Assembly Instructions

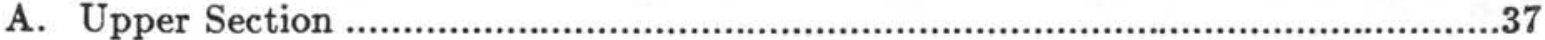

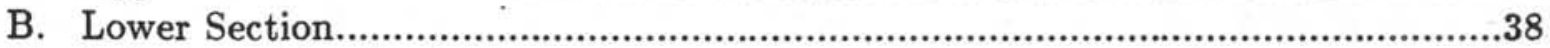

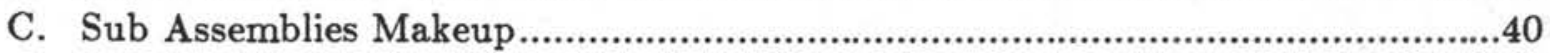

1. Quick Release Assembly ..........................................................................40

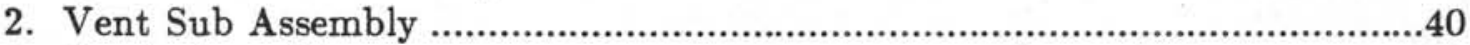

3. Latch Assembly …........................................................................................

4. Acker Core Lifter Assembly ....................................................................41

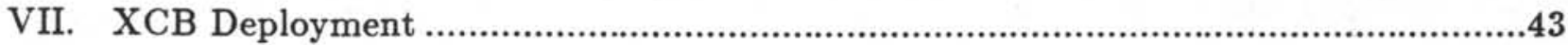

VIII. Appendices

A. Results of Extended Core Barrel Test - Salt Lake City, May 5-7, 1981 .............47

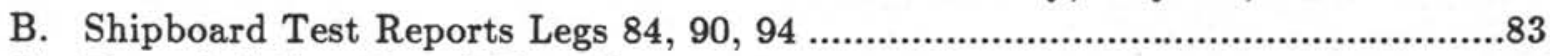

C. Extended Core Barrel Flow Tests...............................................................117

D. Assembly Instructions for XCB as used on Legs 94-96 .....................................133

E. Parts List and Machine Drawings.....................................................................139 


\section{LIST OF FIGURES}

1. Deep Sea Drilling Project Wireline Coring System ...................................2

2. Double Fingered Latch (P/N B-OP3019) ................................................

3. Splined Inner Sub Used to Drive Prototype XCB ......................................

4. Double Finger Latch Driven By Latch Sleeve ..............................................10

5. XCB Latch Dog Showing Excessive Wear...................................................12

6. Origional Stratpax Cutting Shoe With Exploded

View of Core Catcher Package.........................................................................16

7. Second Generation Hard and Soft Formation Cutting Shoes .......................18

8. Hard Formation Shoe Destroyed on Leg 91 ..............................................19

9. Acker Hard Formation Cutting Shoe ..........................................................20

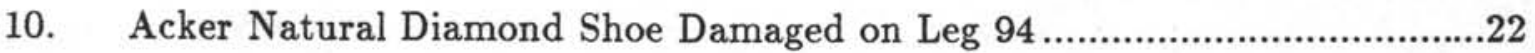

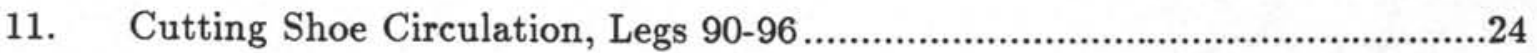

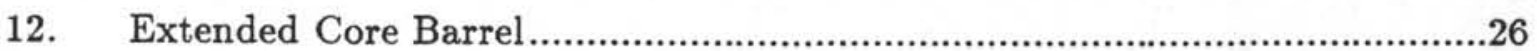

13. XCB Spacing Comparison Chart...............................................................27

14. Alternate XCB Spring Assemblies............................................................28

15. Bottom Hole Assembly for XCB and APC................................................33

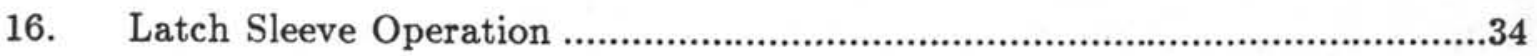

\section{LIST OF TABLES}

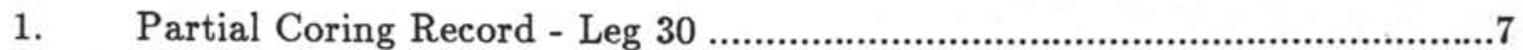




\section{BACKGROUND}

\section{A. Standard Coring System}

The Deep Sea Drilling Project (DSDP) adopted a non-rotating wireline core barrel system developed by the Hycalog Company. It proved to be an excellent tool and it remained, with few changes, the standard DSDP coring system for the past 15 years. A schematic of the system is shown in Fig. 1. The core barrel is about $10 \mathrm{~m}$. long and accepts a $9.5 \mathrm{~m}$ long $\times 6.3 \mathrm{~cm}$. (2.5") diameter core in a section lined with a removable butyrate core liner.

In operation the core barrel is landed on a support bearing at the bottom of the drill string so that the bottom of the barrel is positioned just above the core guide in the core bit. The support bearing and the swivel (located below the latch at the upper end of the core barrel) allow the barrel to remain non-rotating as the drill string and bit are rotated and lowered to cut the core and force it into the barrel. During the coring operation salt water* is normally circulated down the drill pipe, around the core barrel, and out through four bit jets and the restricted annulus between the core barrel and the throat of the bit. A bit seal was devised to minimize the flow through the bit throat to protect the core from unnecessary erosion.

\section{B. Coring Problems}

Proper circulation flow was essential to good core recovery. Too little flow would cause the core to hard-pack in the core catcher and inhibit further recovery. Too much flow might excessively erode the sediment cores or wash them away entirely. In the large scale dynamics of the drill string/drill hole system, an adequate circulation was needed to maintain an acceptable penetration rate and to clear away cuttings lest the bit become stuck in the hole. Drilling techniques for various lithologies were developed through trial and error. But it was not uncommon to have to compromise with circulation and accept a less-than-optimal core recovery in order to maintain the hole.

One type of lithology which was especially frustrating to core was alternating hard and soft interbeds. The high circulation rate (and weight) necessary to penetrate a hard sedimentary layer would blast away the underlying soft layer once the bit punched through, so that only the hard layers were recovered.

The tungsten carbide toothed roller cone core bit was an excellent tool for coring stiff and indurated sediments and basalt. But the relatively unconsolidated sediments

"Drilling muds are occasionally circulated depending upon hole conditions. 


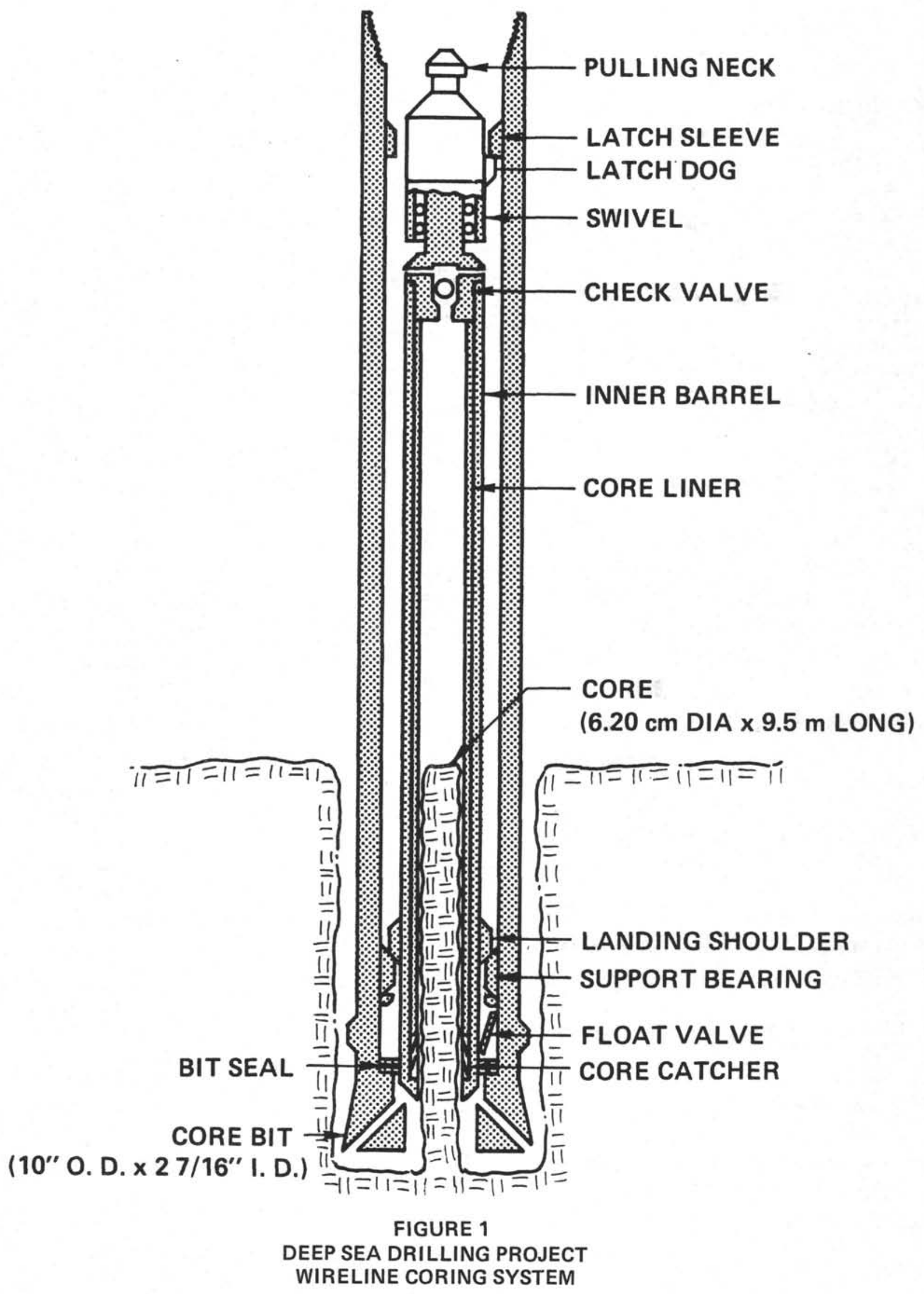


generally suffered excessive disturbance from the grinding, crushing action of the roller cones.

\section{Benefits of an Extended Core Barrel}

It was believed that the quality and quantity of core recovery could be increased in certain types of sediment if the core barrel were allowed to protrude several inches through the core bit. It could then capture soft or water-sensitive sediments before they come within range of the powerful bit jets. It would permit generally higher circulation rates in all types of sediment to increase penetration rates. In addition, the drag bit action of the extended bit ahead of the roller bit should produce less core disturbance in the softer materials.

Perhaps the most important requisition for a through-the-bit extended core barrel owed to the debut of the Hydraulic Piston Corer (HPC) in January 1979. The HPC began a new era in sub ocean sediment studies. It was able to take virtually undisturbed cores through relatively unconsolidated sediments (generally characteristic of the upper $100 \mathrm{~m}$ - $200 \mathrm{~m}$ of ocean floor) by hydraulically injecting a core barrel through the bit and 15' (later expanded to up to 30') into the sediment. The HPC and its successors, the Variable Length Hydraulic Piston Corer (VLHPC) and the Advanced Piston Corer (APC), became an integral part of the coring program; in many instances early drill sites were re-occupied years later in order to obtain less disturbed lithologies of the upper sections previously unattainable. Since it worked through the bit, the 3.5" barrel O.D. required the use of a special core bit with a $35 / 8$ " I.D. gage. It was thus incompatable with the rotary coring system, and the drill string had to be tripped to change the bit if it was desired to penetrate beyond HPC capability. An extended core barrel was a natural choice to follow the HPC and continue the hole into indurated sediments and basement. Tripping the drill pipe would not be required since a common bottom hole assembly and bit could be used by both systems. 


\section{DESIGN AND DEVELOPMENT}

\section{A. Early Prototypes}

An extended core barrel produced by Christensen Diamond Products, Inc. was part of the original core barrel system purchased for the D/V Glomar Challenger and not utilized previously. An external compression spring operated over a splined telescoping shaft to force the tool into full extension through the bit. It was capable of retracting back into the core bit when sediment resistance overcame the spring force to protect the tool from overload damage.

In June 1971 the Christensen spring/scoping section was mated to a standard DSDP core barrel to create the first Extended Core Barrel (XCB) to be used aboard the Glomar Challenger. At the upper end of the barrel a Double Fingered Latch (Fig. 2) served the dual purpose of latching down the tool and transmitting torque from the drill string. The lower end of the XCB terminated in a Cutting Shoe with tungsten carbide coated serrations on the cutting edge. A special roller cone bit was fabricated with an inner gage hole of $35 / 8^{\prime \prime}$ to allow the $31 / 2^{\prime \prime}$ O.D. Cutting Shoe to protrude $4 "$ through the bit.

The XCB was used to core two sites during DSDP Leg 18 with moderate success. It was not used again until Leg 30, two years later. One reason for the hiatus was the disadvantage of having to commit an entire hole to an unproven tool, since the largergage XCB core bit was not compatible with the standard core barrel. For Leg 30 a small diameter Cutting Shoe was devised which permitted the XCB to be used with a standard bit so that both standard, non-rotary barrels and XCB barrels could be alternated if desired. The resulting core size was $13 / 4$ dia. instead of the standard $21 / 2 "$. Table 1 presents a partial coring record for Site 289. The formation consisted of soft clay sand oozes. The XCB consistently recovered more than adjacent standard cores; though in both cases the cores were greatly disturbed. The smaller core diameter frustrated many established sampling procedures, and was unpopular.

Perhaps the major disadvantage with the original tool was the fact that the barrel rotated around the core to cause more core disturbance than a standard non-rotating core barrel, where the core is cut entirely by the core bit. Two new features were incorporated by a new protoype built in May 1976:

1. A non-rotating Core Liner. The inner-inner barrel (Core Liner) was decoupled from the rotation of the core barrel. The liner was fabricated from aluminum tubing for rigidity. It was supported by a combination of roller bearings and bushings which greatly reduced frictional drag.

2. A Bottom Drive Sub. A splined sub (Fig. 3) was added to the lower inner barrel; the splines engaged two drive lugs on a sleeve which fit inside the bit sub. A mule shoe lead-in ensured that the splines would always engage the 


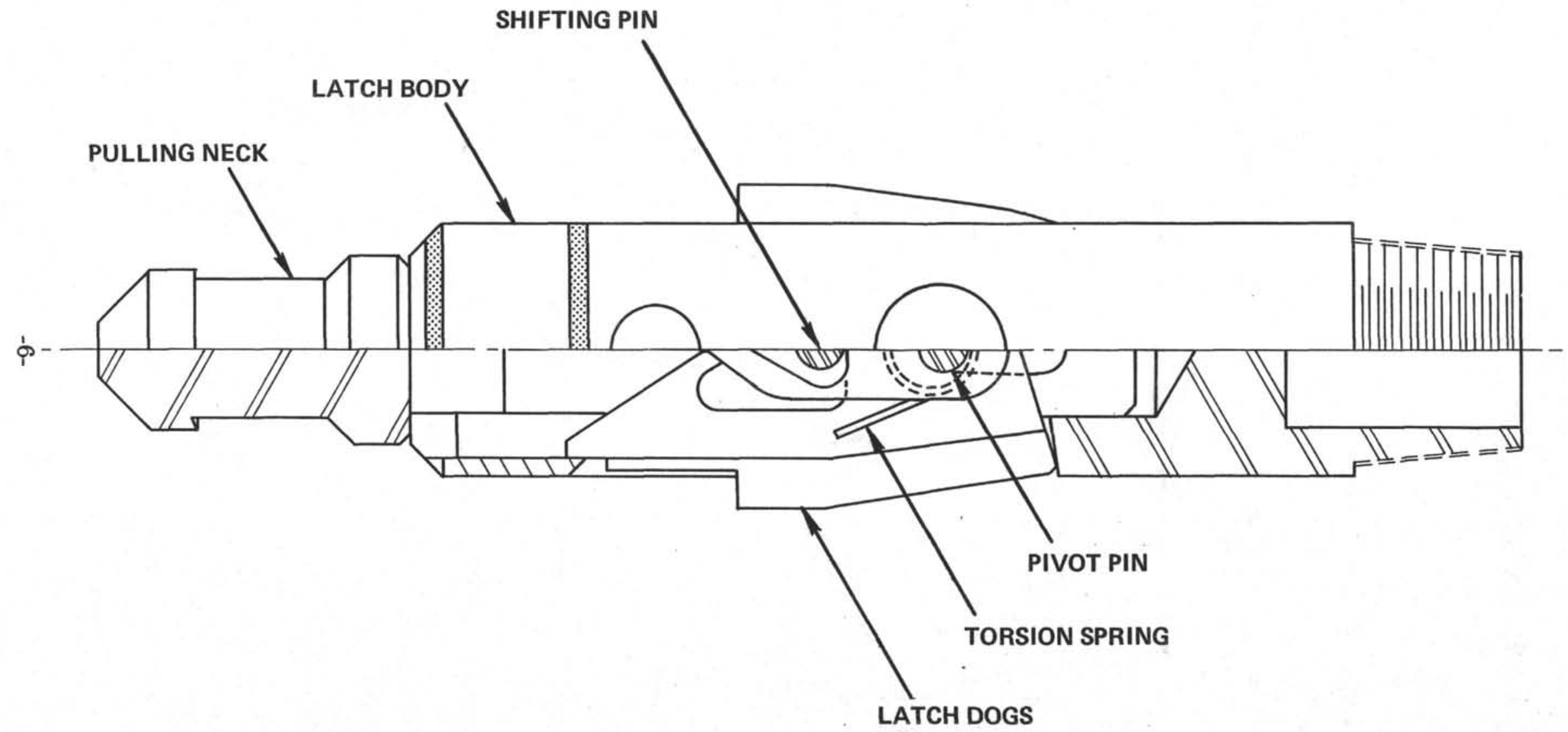

FIGURE 2

DOUBLE FINGERED LATCH

(P/N B-OP 3019) 
TABLE 1

PARTIAL CORING RECORD - LEG 30

\begin{tabular}{cccccc}
$\begin{array}{c}\text { Core } \\
\text { No }\end{array}$ & $\begin{array}{c}\text { Meters } \\
\text { Cored }\end{array}$ & $\begin{array}{c}\text { Meters } \\
\text { Recovered }\end{array}$ & $\begin{array}{c}\text { SPM } \\
\text { Pump }\end{array}$ & $\begin{array}{c}\text { Time } \\
\text { Interval }\end{array}$ & $\begin{array}{c}\text { Type Of } \\
\text { Core Barrel }\end{array}$ \\
\hline 87 & 9.5 & 1.8 & 0 & 20 & Non-Rotating \\
88 & 9.5 & 3.3 & 0 & 22 & Non-Rotating \\
\hline 89 & 9.5 & 6.2 & 10 & 12 & Extended \\
\hline 90 & 9.5 & 3.7 & 0 & 20 & Non-Rotating \\
\hline 91 & 9.5 & 7.0 & 8 & 15 & Extended \\
\hline 92 & 9.5 & 1.2 & 6 & 12 & Non-Rotating \\
\hline 93 & 9.5 & -5.4 & 8 & 12 & Extended \\
\hline 94 & 9.5 & 4.8 & 0 & 14 & Non-Rotating \\
95 & 9.5 & 1.8 & 0 & 20 & Non-Rotating
\end{tabular}




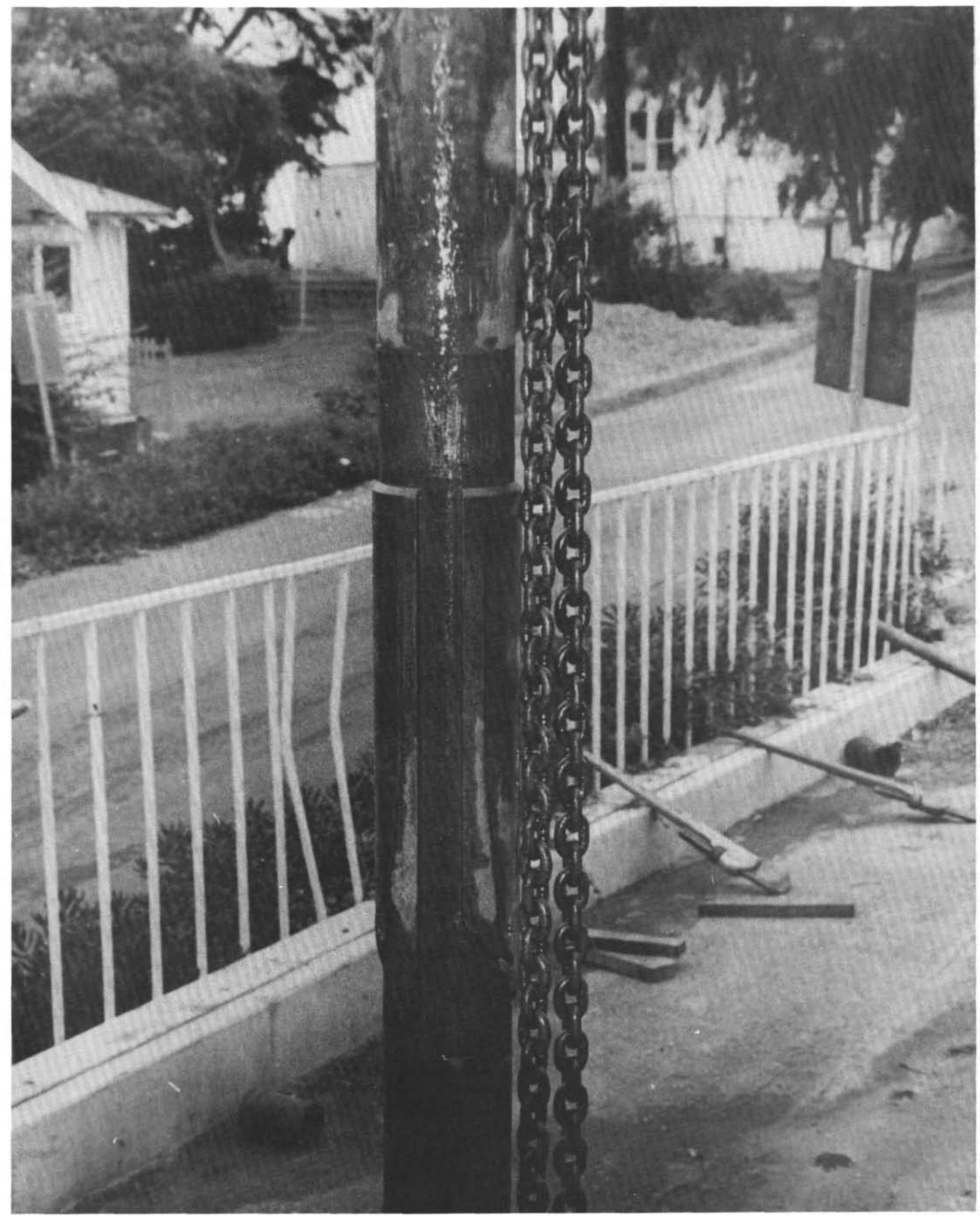

FIGURE 3

SPLINED INNER SUB USED TO

DRIVE PROTOTYPE XCB 
drive lugs and transmit the driving torque directly to the Cutting Shoe rather than to the Latch, $30 \mathrm{ft}$. away.

Unfortunately the bottom drive system did not survive shore based drop tests. Repeated impact loading caused both the splines and the lugs to deform and/or chip, and ultimately caused the barrel to jam in the bit sub. Neither did the aluminum liner progress beyond the test phase. It was awkward to handle, easily damaged, and created new problems for core processing and storage. However, the general concept for a "floating" core liner was not abandoned.

\section{B. Design Goals}

In February 1979 after a thorough study of the XCB's past performance and a reevaluation of its potential in the light of the advent of the HPC, a new aggressive development program was initiated. Four major design goals were established:

1 The Core Liner should be non-rotating and standard sized.

2. Cutting Shoe effectiveness should be improved; probably several types of Shoes were needed for different sediment and rock types.

3. Circulation flow to the Cutting Shoe was needed. Though the extended barrel concept was designed to keep excessive circulation flow away from the core, it appeared that not enough flow was getting to the Shoe in the extended mode. Some type of controlled flow was needed instead of an all-or-nothing situation.

4. The XCB should be able to operate in the same Bottom Hole Assembly (BHA) as the new HPC.

\section{Engineering Development}

The $\mathrm{XCB}$ was essentially redesigned from scratch, but the major components remained, from top to bottom, the Drive Latch Mechanism, the Spring/Extension Assembly, the Core Barrel with non-rotating Core Liner, and the Cutting Shoe. The developing prototype was tested several times at a full scale test laboratory in Salt Lake City, Utah. (See Appendix A). The first sea trials were conducted on Leg 84 in January 1982. After Leg 90 the XCB was made fully operational, though developmental improvements continued. Test reports for Legs 84, 90, and 94 are reproduced in the Appendix B. 


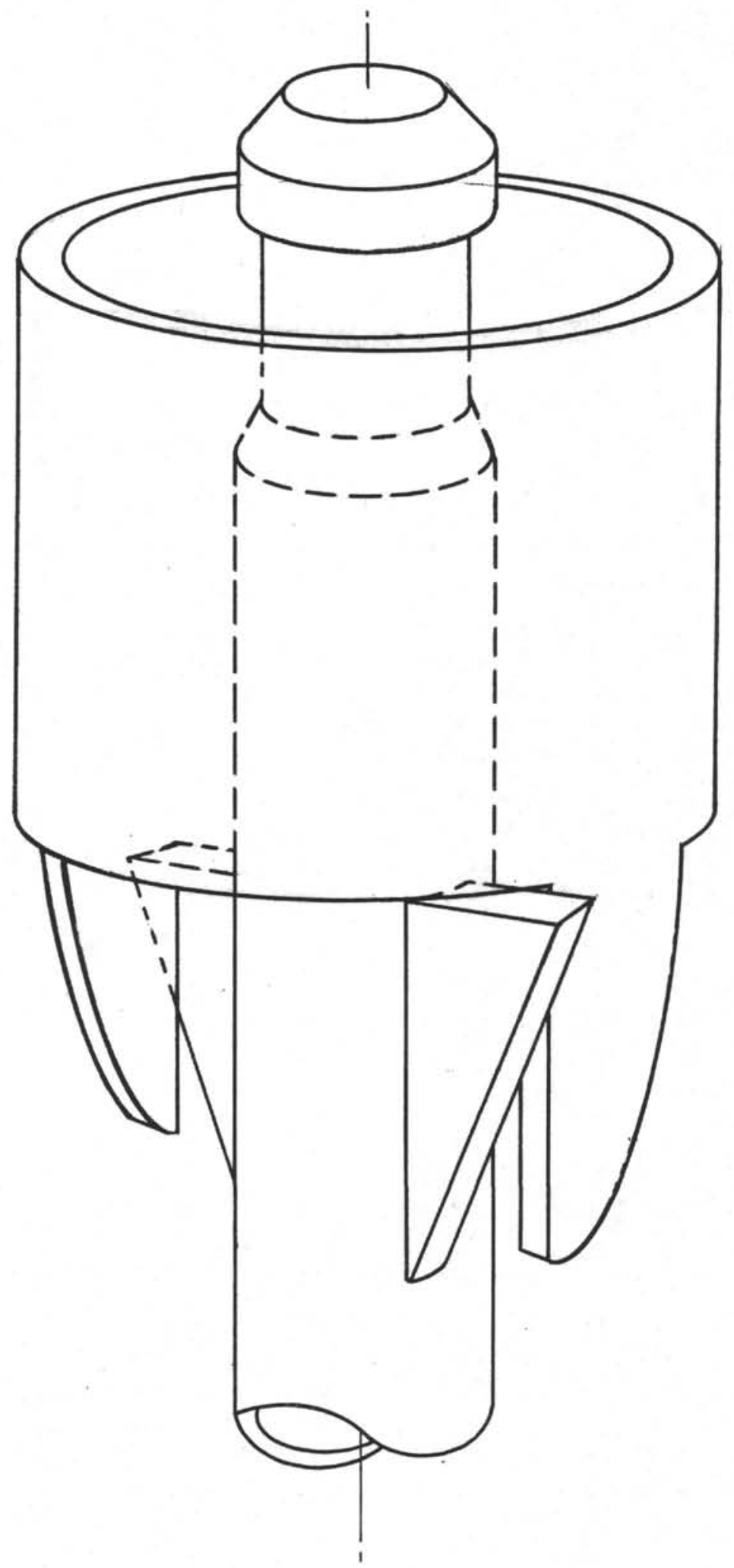

FIGURE 4

DOUBLE FINGER LATCH

DRIVEN BY LATCH SLEEVE 


\section{Drive Latch}

The splined bottom-drive system was abandoned in favor of the original topdrive system where a Double Finger Latch provided both the hold-down function and transmitted the driving torque from the Latch Sleeve. The two Latch Dogs engaged the two lugs on the Latch Sleeve as shown in Figure 4. The early tests in Salt Lake City disclosed a curious defect: When subjected to high torque, the lugs levered over the Latch Dogs to cause premature release. The problem was partially solved by driving the Latch with a single-lugged Latch Sleeve so that only one Latch Dog was loaded at any one time. Thus when the loaded Dog cammed-in the opposite Dog was still locked out to hold down the tool. The resulting slip-spin action was still undesirable and had a detrimental effect on core recovery, as was demonstated during the sea trials on Leg 84.

A new Latch was designed for the second set of sea trials on Leg 90. It employed a totally different operating principle: Two substantial Latch Dogs were free to shift up and in to allow downward motion of the XCB in the drill pipe. Once the Dogs landed opposite the expanded inner diameter below the Latch Sleeve a restoring spring forced them out to lock under the Latch Sleeve. The Dogs remained positively locked against $\cdot$ lifting or torquing forces until an inner Pulling Neck was intentionally shifted by wireline pull out from under the Dogs. An unforseen dimensional problem caused the new Latch to occasionally snag in the expanded diameter of one of the bumper subs located some distance above the Latch Sleeve. The problem was solved by lengthening the Dogs and increasing their "locked out" diameter so that they could not fully expand and lock in any but the intended inner profile under the Latch Sleeve.

In order to prevent the possibility that the Latch Dogs would land directly opposite the Latch Sleeve lugs (which would prevent them from popping out to lock down the tool), the XCB was spaced out so that the Latch Dogs landed completely below the lugs. They engaged only when the XCB was lifted by sediment resistance as the drill bit was lowered. However, it was discovered that during coring the Latch continuously jumped in and out of engagement with the Latch Sleeve due to the dynamic interacting forces caused by circulation pressure, ship's heave, and sediment resistance. This often allowed the lugs to spin over the tops of the Dogs and cause accelerated wear (Fig. 5).

A new Window Latch Sleeve was recently designed to work with the new Latch. Described in Section IV, it has not yet been tested at sea. 


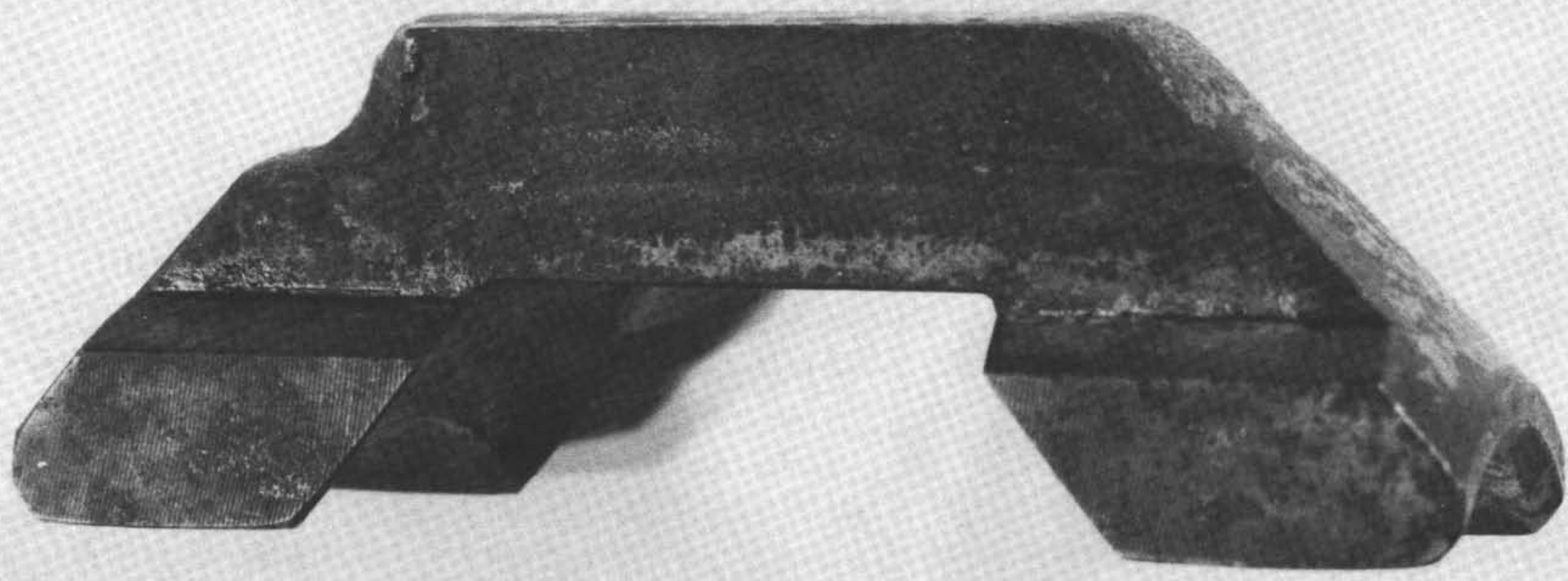

FIGURE 5

XCB LATCH DOG SHOWING EXCESSIVE WEAR ON ONE END 


\section{2. $\quad$ Spring}

Disc Springs were selected to replace the original compression spring because of their high damping characteristic and easily modifiable spring rate. A single Disc Spring could be deflected about 0.1" under a $1240 \mathrm{lb}$ load. Series stacking of the springs will increase the total deflection without increasing the load. Parallel stacking will increase the load without increasing the deflection. Thus any number of spring rates could be achieved. In the laboratory drilling tests 100 to 200 Disc Springs were stacked over the Spring Shaft in several seriesparallel combinations to achieve spring rates of 170 to $480 \mathrm{lbs} /$ in. The total available stroke decreased with increasing spring rate because of the necessity to add-in more Disc Springs which increased the solid height of the stack. The stiffest spring stack applied a force of about $2400 \mathrm{lbs}$ at full retraction and did not cause any damage to the XCB. In fact, due to the greater cutting efficiency of the drag-type Cutting Shoe, it extended ahead of the roller cone bit while cutting through solid basalt in one of the tests. The necessity for the spring was demonstrated, however, when the Cutting Shoe was intentionally locked out 2 " below the core bit and was structurally damaged after being subjected to loads of up to $24000 \mathrm{lbs}$ while coring through sandstone.

The Disc Spring configuration used in all of the XCB runs on DSDP Legs 8496 consisted of a series-parallel stacking of 200 springs; 50 sets of 2 nested discs were stacked with the concave side alternately facing up, then down. Each group of 40 springs was separated by a spacer to minimize hysterisis. Because of the inherent hysterisis build-up caused by the length of the stack and the parallel stacking the spring rate was more progressive than linear - and well damped. The total force was equal to about $2400 \mathrm{lbs}$ at 7 " deflection.

The Disc Springs frequently cracked in use; sometimes as many as $\mathbf{5 0}$ springs had to be replaced at one time. Although the stack functioned acceptably even with a number of cracked springs, the expense and inconvenience of continually having to replace them prompted further design analysis. The fatigue resistance of the Springs might have been lowered due to the chemical and thermal environment at the ocean floor, or they could have been overstressed due to unpredictable localized forces. (Very little industrial data exists for long stacks or for parallel stacked discs). New, possibly exotic, metals would have to be field tested at in situ conditions. If an acceptable metal were found, the cost of producing 200 units per tool would probably be quite high. Therefore, the design work concentrated on devising a compression spring to do the job.

The XCB had evolved so much from the early days that the original compression spring could not be used. The new spring had to fit within a 1 1/4" I.D. $x 27 / 8$ " O.D. annulus, and have a rate comparable to the Disc Springs. It was fabricated from chrome silicon and specially treated to withstand the high torsional stress induced at the maximum load of $2400 \mathrm{lbs}$. 
The primary reason for choosing the Disc Springs was to prevent surging; this possibility was also eliminated in the new Compression Spring because the natural frequency of the Spring was over 20 times the frequency of the applied load at operating conditions:

$$
\begin{aligned}
& \text { Spring natural frequency } \approx \frac{13900 d}{n D^{2}}=36 \text { cycles } / \mathrm{sec}, \\
& \text { where } \quad d=\text { wire diameter }=0.522 \text { inches, } \\
& n=\text { active coils }=46, \\
& D=\text { Mean Spring diameter }=2.1 \text { inches. }
\end{aligned}
$$

The reintroduction of the Compression Spring required making ancillary modifications to several other components. The latest system has not yet been field tested; for that reason the version incorporating the Disc Springs has not yet been obsoleted, and machine drawings for both versions are included in the Appendix.

\section{Telescoping Section}

Two alternative telescoping mechanisms were originally designed. The Clutch Drive System involved a jaw clutch assembly which, in the extended mode, decoupled the core barrel from the continuously driven upper section. The core barrel was driven only when the tool was fully retracted to engage the jaws. The second option, designated the Locked Drive System, consisted of two mating hex-splined components which engaged to rotate the core barrel at all times, whether extended or retracted.

It was originally assumed that the Clutch Drive design would be used most often, since the barrel would punch through the softer cores without rotating to induce the least core disturbance. However, the Salt Lake City test proved the Locked Drive to be the superior of the two - so much so that the Clutch Drive development was discontinued. The problem with the Clutch Drive was that it tended to chatter between the engaged and decoupled modes when coring hard material resulting in frequent core jams and excessive wear in the clutch jaws. Apparently the tool would retract just enough for the jaws to partially engage to cause the Cutting Shoe to rotate with the bit. Penetrating faster than the bit, the Shoe repeatedly worked its way out of engagement, then fell back to engage when it was not driven. Ultimately the clutch jaws simply spun from tip to tip, causing accelerated wear and inducing a stop-go rotation in the core barrel. Eventually an oversize piece of core would break off and jam in the throat of the Cutting Shoe. 


\section{Core Barrel With Non-Rotating Core Liner}

In developing this system it was desired to retain the standard 2.6" I.D. $\times 2.8^{\prime \prime}$ O.D. butyrate Core Liner since all of the core processing procedures had been standardized to that size. The regular core barrel (2 $7 / 8^{\prime \prime}$ I.D. $\times 3$ 1/2" O.D.) did not allow enough clearance to "float" the Core Liner, so a new barrel was designed with the radial dimensions increased to $31 / 8$ " I.D. $x 33 / 4$ " O.D. Inside, the Liner was suspended from a Bearing Shaft and was free to spin on roller bearings. The non rigid Liner was supported only at the extreme ends, hence it could buckle and rub the inner barrel wall which created some extra drag resistance. Even so, the system worked quite well through Leg 93.

The development of the APC created a new compatibility problem for the XCB. The APC required the inclusion of a 3.80" I.D. Seal Bore Drill Collar in the BHA. (The normal I.D. is $41 / 8^{\prime \prime}$ ). The XCB, with its $33 / 4$ " upsets at the core barrel connections, would have presented a critical flow restriction in that section. Since the bore could not be widened the core barrel O.D. had to be reduced. The core barrel design was restricted by a minimum 3" I.D. necessary to continue to float the core barrel as before. A barrel measuring $3^{\prime \prime}$ I.D. $\times 31 / 2$ " O.D. would be ideal, but the $1 / 4^{\prime \prime}$ wall thickness did not leave enough room for the DSDP stub acme pin thread.

Since the box thread could still be cut in the thinner wall, two $15 \mathrm{ft}$. long inner barrels measuring 3 " I.D. $x 31 / 2$ " O.D. were fabricated with box threads at either end. They were assembled together with a short double pin sub which reduced the I.D. at the center of the long section to $27 / 8$ ". The internal upset served as a midpoint bushing to support the non-rotating Core Liner.

\section{Cutting Shoe Development}

DSDP worked with Sandia National Laboratories to fabricate a new cutting Shoe using Stratpax ${ }^{\circledR}$ diamond cutters. Stratapax is the trade name for a polycrystalline diamond compact (PDC), usually cast into the form of a small disc. Sandia had done a great deal of early evaluation and development of design criteria for PDC's for the U.S. Government. (References 1,2,3). Some of their conclusions were that the PDC's - which cut by shearing through the rock - have potential for significantly increasing the drilling rate over roller bits which crush the rock, or natural diamond bits which grind the rock. Another advantage over natural diamonds is their ability to maintain a good cutting edge while wearing. In the initial design 8 PDC cutters were brazed into slots cut into the end of the Shoe (Fig. 6). Bottom discharge ports carried circulation flow to the cutters. They were moderately successful when used on Leg 84. Unfortunately other problems with the prototype XCB made it impossible to fairly test the PDC's. Though core recovery was low, the PDC's were

(B) General Electric registered trademark. 


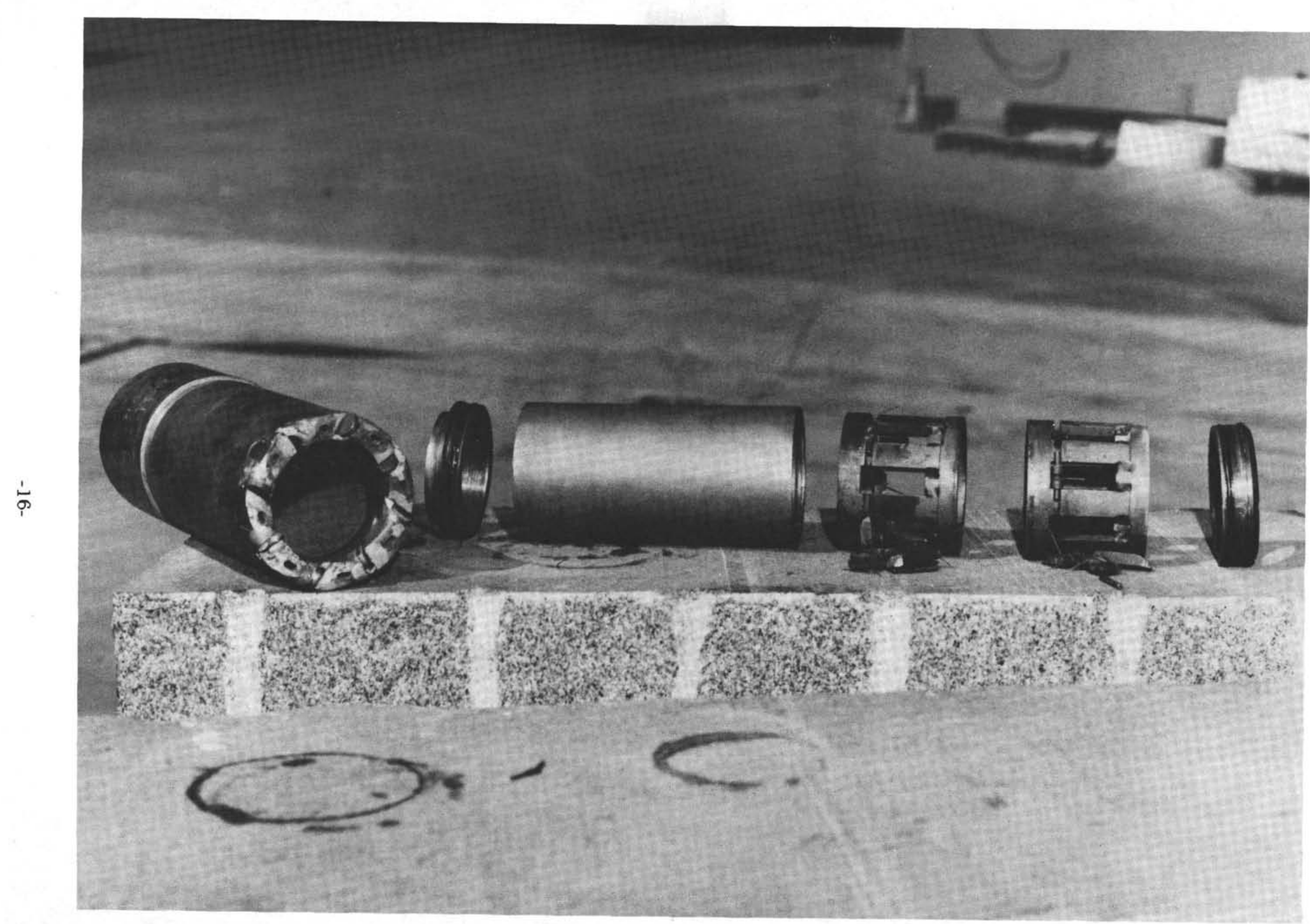

FIGURE 6

ORIGIONAL STRATAPAX CUTTING SHOE

WITH FXPI ONFD WIFW OF CORF CATCHFR DACK ACF 
undamaged after cutting several clayey cores. When the formation became rubble, the PDC's chipped and fractured. Because of their brittleness the cutters were known to be vulnerable in such formations (also in chert) where impact loading is inevitable.

Two new prototype Cutting Shoes were made available for Leg 90. The two on the left in Figure 7 were designated "Hard Formation Shoes". They still incorporated PDC cutters, which were now brazed to the faces of tungsten carbide studs, which were in turn brazed into slots in the Shoe. The twofold advantage over the previous Shoe was that more of the PDC was exposed for cutting, and more surface area was used for the bonding, thus effecting a stronger bond between the cutters and the Shoe. Their unsuitability for rubble-type drilling remained unchanged, so a second "Soft Formation Shoe" was developed (the two right-most Shoes in Figure 7). It incorporated a high relief sawtooth profile with waterways to aid circulation flow. The serrations were coated with a coarse grit tube-borium layer which both provided wear protection and abrasiveness to aid in cutting. The Soft Formation Shoe was very effective in mud, clay, ooze and chalk, and cored 20 meters of volcanogenic rock on Leg 90 . Its competence in all types of formations was exhibited during ensuing Legs.

One of the two Hard Formation Cutting Shoes was destroyed while coring broken basalt on Leg 91 . The impact loading destroyed the tungsten carbide studs; all of them were lost while coring chert and basalt rubble on Site 596 . Several had fractured, and a few had popped out of their welds (Figure 8). Assessment of the cause of damage was complicated by the fact that one of the core bit's four cutter legs had broken free in the hole sometime during the $\mathrm{XCB}$ coring period and may have battered against the Shoe. The other Shoe was destroyed on Leg 92 while coring basalt rubble. The coring conditions in both cases were extremely harsh, nevertheless, the failures underscored the need for a more dependable hard formation shoe.

An industry search was conducted which led to a line of Cutting Shoes produced by Acker Drill Company, Inc. Their HQWL size shoes were adaptable to the XCB; they cut a $2.5^{\prime \prime}$ gage core and were slim enough to pass through the $3.800 "$ restriction in the BHA. The opportunity to experiment with offthe-shelf equipment was a tremendous asset, and offered a means of maximizing hard core recovery at minimum expense. Three types of Cutting Shoes were available (Fig. 9):

a) The Natural Diamond Shoe consisted of diamonds set in a hard metal matrix. Options include diamond size and grade, matrix hardness, number of waterways, choice of two face contours, and with or without bottom discharge jets. 


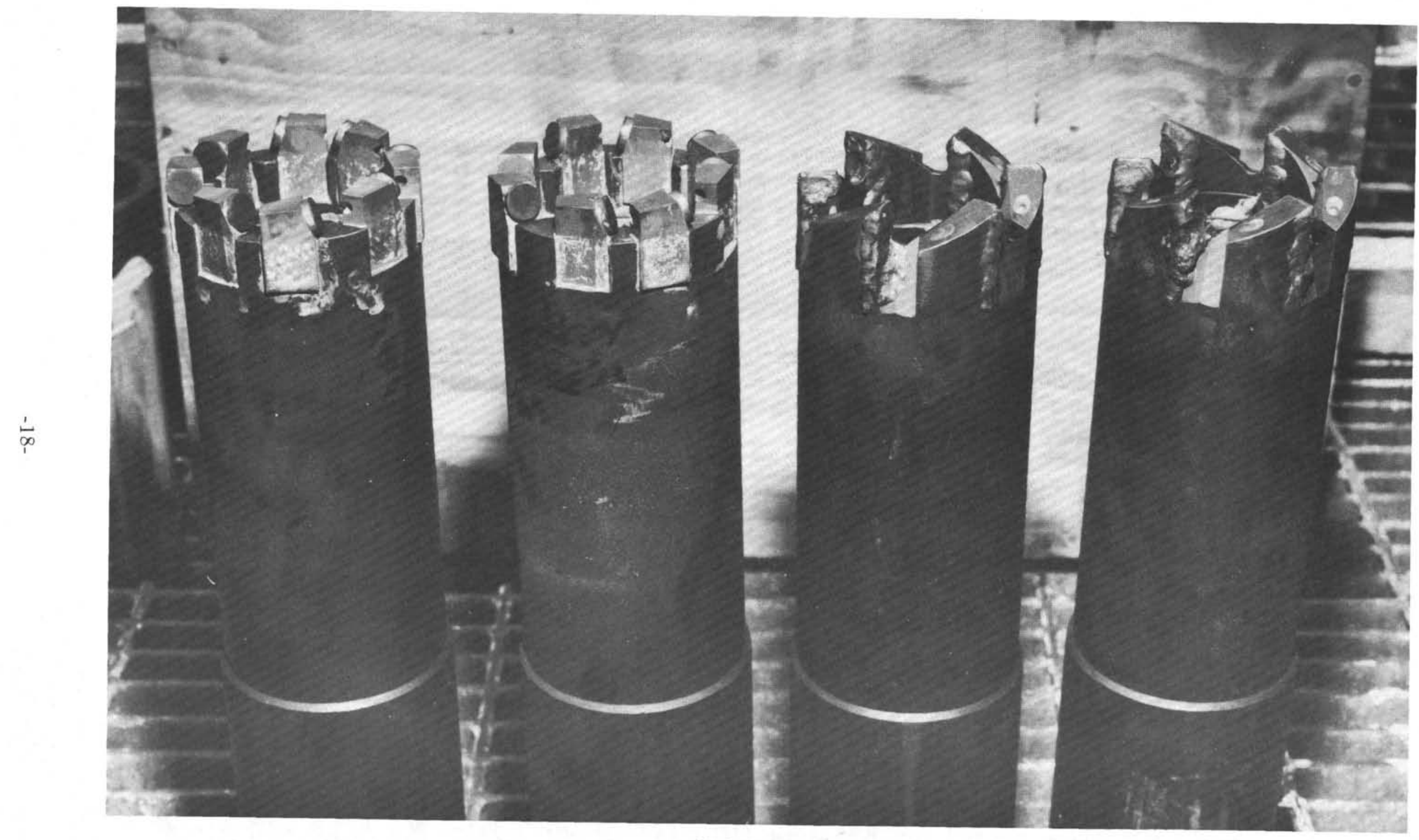

FIGURE 7

SECOND GENERATION HARD AND SOFT FORMATION CUTTING SHOES 


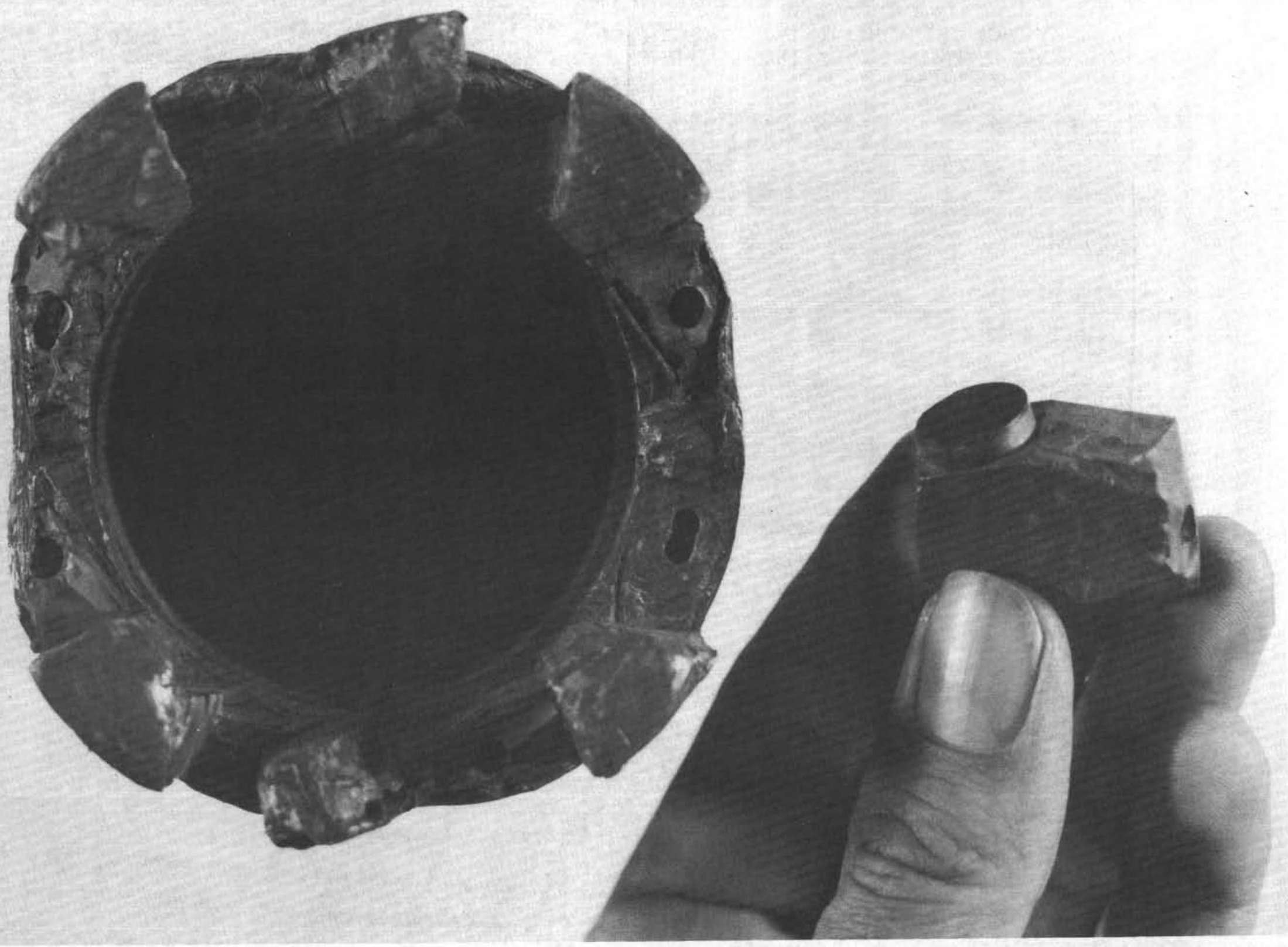

FIGURE 8

HARD FORMATION SHOE

DESTROYED ON LEG 91 


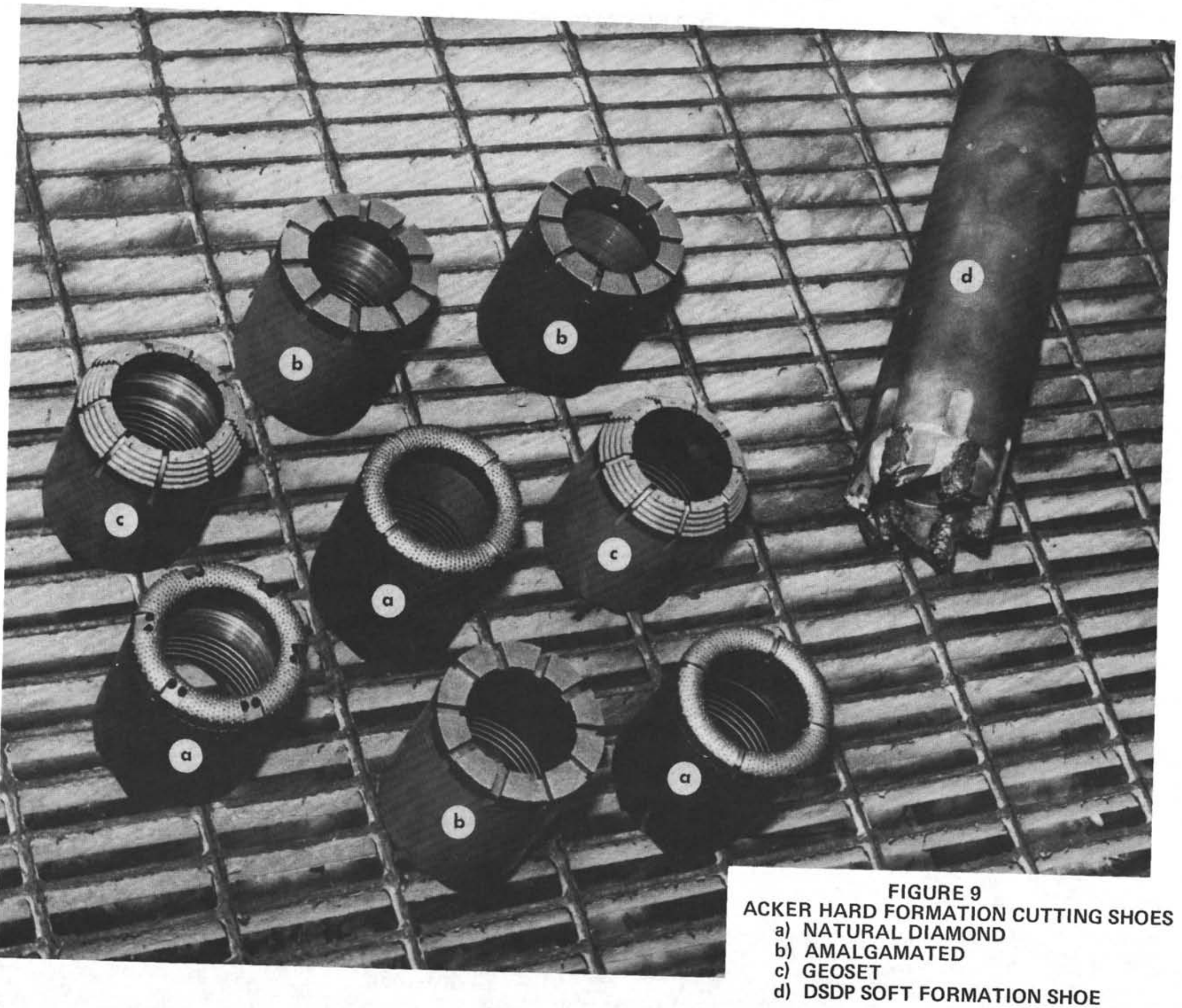


b) The Amalgamated ${ }^{\circledR}$ Diamond Shoes incorporated small natural and synthetic chips impregnated into a hard metal matrix to produce as sand paper - like texture. They were designed to be used in broken formations and/or very hard formations.

c) The Geoset ${ }^{\circledR}$ Synthetic Diamond Shoe used triangular-shaped PDC's instead of natural diamonds. The PDC's were embedded in a relatively soft metal matrix; as the metal wore away new PDC's were continually exposed to maintain an efficient cutting surface. The Geoset Shoe's intended range of use was similar to that of the Stratapax Shoes; that is, coring hard solid formations up to and including massive basalt, but not broken formations.

On Leg 94 the Geoset Shoe was used a few times in hard chalky sediments, but did not impress its users. The core recovery was always less than neighboring cores taken with the Soft Formation Cutting Shoe. The Natural Diamond Shoe was tried for two cores in basalt. Both attempts achieved low recovery. The Shoe was badly damaged during the last attempt (Fig. 10). The Amalgamated Shoe was not used (and has never been used yet). The chief problem with the Acker Shoes was determined to be the lack of clearance between the nominal core diameter and the core catchers. An attempt was made in the field to increase I.D. of the core catchers, but there were too few chances to effectively test the modifications. New Acker Shoes have been custom built to cut a $23 / 8$ " I.D. core to increase the clearance and hopefully improve their effectiveness in hard rock.

\section{Cutting Shoe Circulation}

In the standard coring system the circulation flow travels through the drill string, around the core barrel, and out four jet holes in the core bit. The bit seal seals around the core barrel to limit the flow out the center of the bit.

In the earliest $\mathrm{XCB}$ system the circulation was also directed away from the core barrel entrance, even though the extended barrel had to do its own core cutting. It was later determined that some circulation to the Cutting Shoe was necessary to wash the cutters and lubricate the passage of the core through core catcher.

A circulation diversion system was designed which utilized the back pressure generated above the bit to propel a portion of the flow into the annulus between the Core Liner and core barrel, and out several discharge holes at the bottom of the Cutting Shoe. Several pluggable flow inlet holes were drilled into the core barrel, far enough above the Cutting Shoe so that they remained above the choke (core guide) when the XCB was fully extended through the

(®) Trademark of Acker Drill Co.

(B) Geoset is a Trademark of the General Electric Company. 


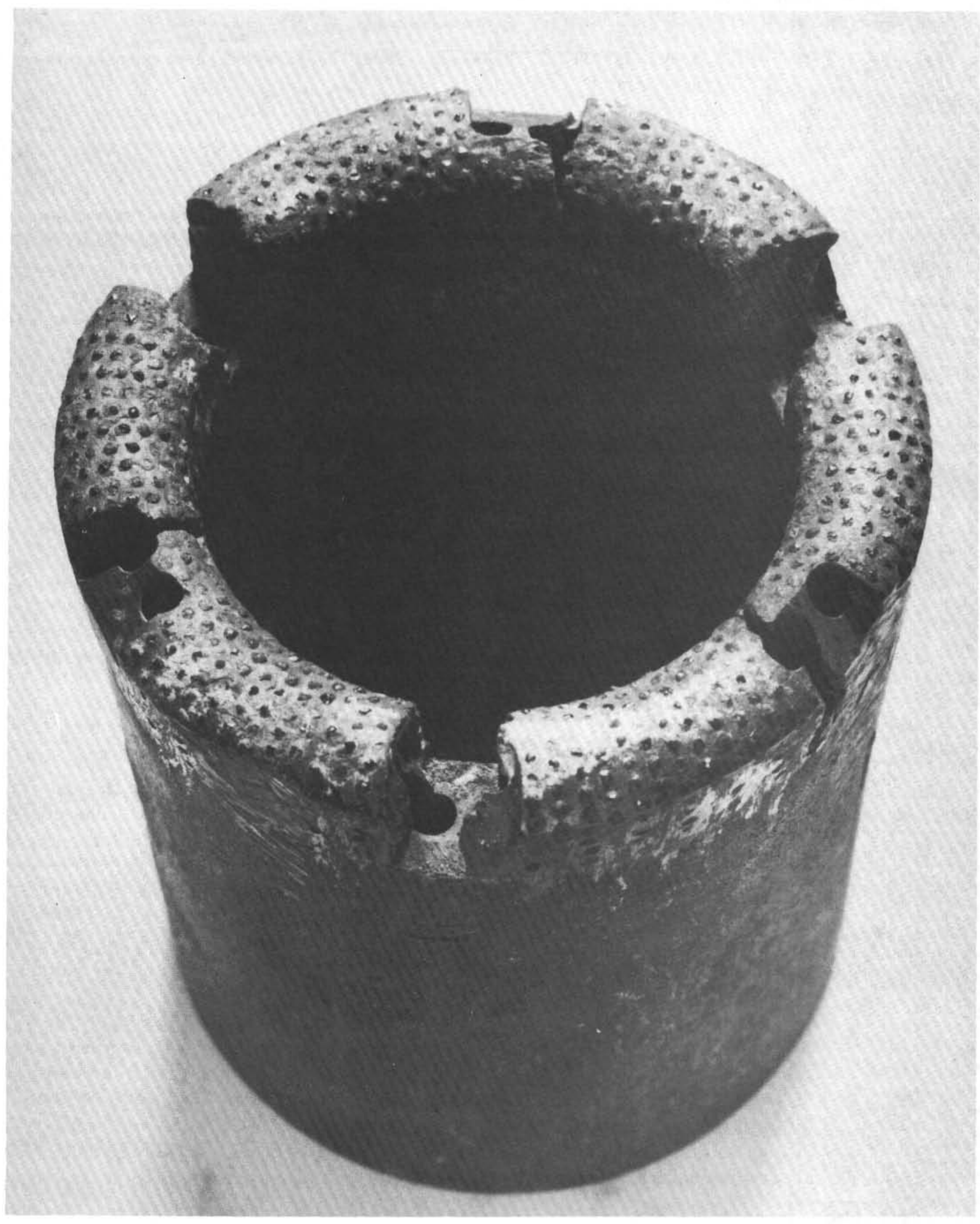

FIGURE 10

ACKER NATURAL DIAMOND SHOE

DAMAGED ON LEG 94 
bit. The total circulation flow rate was geared to the drilling conditions and could vary from 0-500 GPM. The resulting back pressure $(\triangle \mathrm{P})$ was calculated to vary from 0-200 psi. The pressure drop into the Cutting Shoe could be controlled by the number of inlet holes left open, but these could only be adjusted on deck.

The circulation system was first tested on Leg 84. The XCB Core Liner collapsed during every test. It appeared that the pressure differential was causing it to implode. Subsequent static pressure tests demonstrated that the Core Liner failed when subjected to a pressure differential of 28-38 psi. It had been assumed from an early calculation that the Liner could withstand up to 110 psi.

Flow tests were later conducted on a mock-up of the XCB circulation system (See Appendix C). The results showed that the annulus pressure (between the Core Liner and the core barrel) often rose above the critical pressure at all but the lowest flow rates. It was apparent that the Liner either had to be strengthened or isolated from the circulation flow.

The latter solution was chosen. The Cutting Shoe was modified to incorporate a steel Isolation Sleeve which created a pressure tight annulus from the area of the inlet holes to the discharge holes (Fig. 11). 


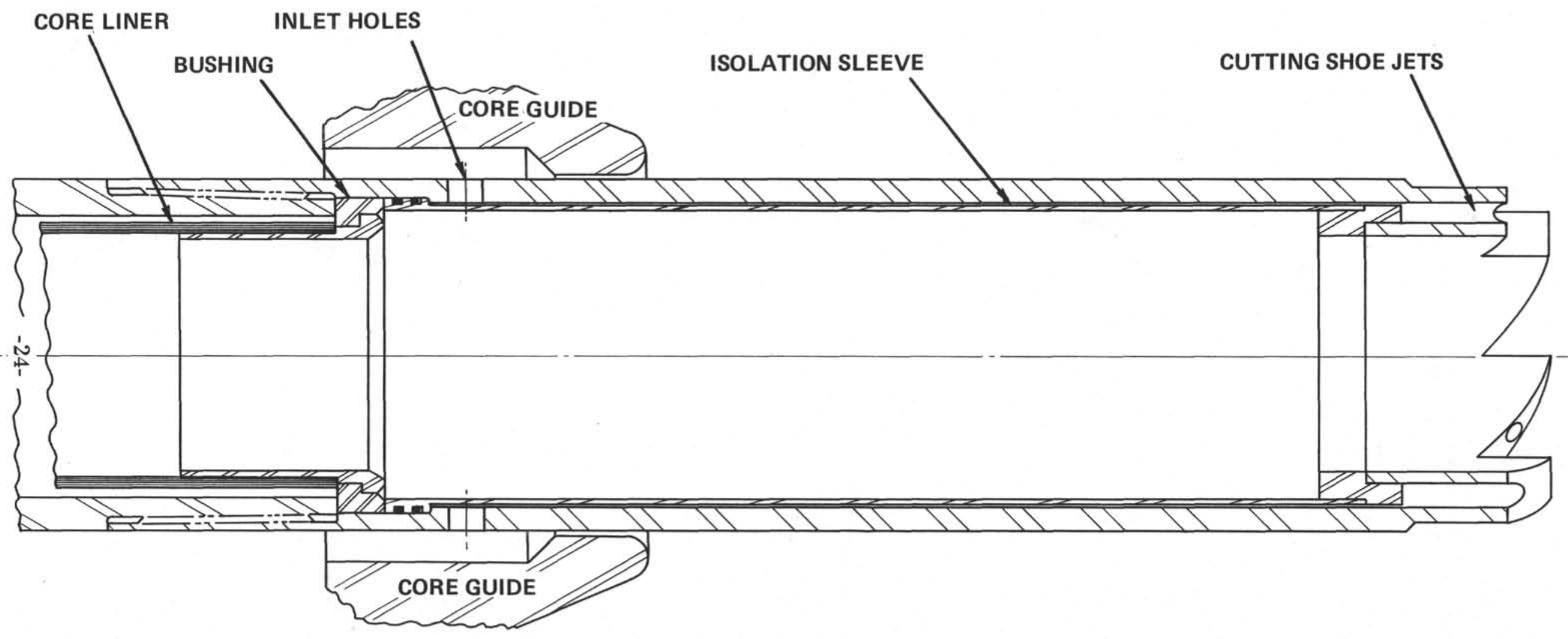

FIGURE 11

CUTTING SHOE CIRCULATION

LEGS 90 - 96 


\section{CURRENT XCB DESCRIPTION AND OPERATION}

\section{A. Operational Aspects}

The XCB was developed to recover undisturbed cores in sedimentary zones where the sediment was too hard to piston core. Working through the core bit, the spring loaded extension allows the $\mathrm{XCB}$ to protrude up to $7 "$ below the bit to capture soft sediments before they can be disturbed by the water jets (Fig. 12). Harder sediments will force the barrel to retract back through the bit to protect the tool against overload (buckling) failure. In addition the spring loaded extension tends to reduce undesirable impact loading due to heaving motions of the bit, so that the XCB may be superior to rotary coring even in most indurated sediments and basalt. Its chief advantage, though, is that it can continue in the same hole, using the same BHA and bit, after the Advanced Piston Corer (APC) has reached its limit. Previously the drill string would have had to have been tripped to change to a BHA suitable for rotary coring.

The current XCB space out length is $13.4 \mathrm{~m}(44.1 \mathrm{ft})$ from the bottom of the Cutting Shoe to the top of the Latch Dog. Figure 13 compares the relative spacing of past and present XCB configurations within the Bottom Hole Assembly. The Leg 96 version was the last to be used by DSDP aboard the Glomar Challenger. The ODP version will be used by the Ocean Drilling Project beginning in 1985. It can be assembled with either the Compression Spring or the Disc Spring stack (Fig. 14). The Disc Spring stack is slated for obsolescence, and has been retained only as a backup in case unforseen problems develop with the untried Compression Spring.

\section{B. Major Sub-Assemblies}

The major components from the top down include the Latch, Hex Splined Scoping Section, Spring Shaft with helical Compression Spring, Quick Release, Vent Sub, Core Barrel with Non-Rotating Core Liner, and Cutting Shoe.

1. Latch

The Latch was developed specifically for use with the XCB but may be used with any other tool which requires a hold down or driving mechanism. The Latch Body is $33 / 4^{\prime \prime}$ in diameter. The two Latch Dogs lock out to $5^{\prime \prime}$ diameter. When the XCB enters the pipe the Latch Dogs are forced up against the spring (rate $=100 \mathrm{lb} /$ in) until they fall into the pulling neck detents. The Dogs remain depressed in the $41 / 8^{\prime \prime}$ bore as the tool travels down the pipe. The pipe bore widens to $51 / 2^{\prime \prime}$ I.D. below the Latch Sleeve in the BHA; when the XCB is landed the latch is positioned in this section. The spring forces the Dogs to lock out over the high points on the Pulling Neck. At this point the tool is locked in under the Latch Sleeve since the Dogs cannot not shift if an upward force is applied to the tool (downward force on top of Dogs). When it is desired to release the tool for retrieval. An overshot is lowered by wireline to lock onto the head of the Pulling Neck. A pull on the wireline 

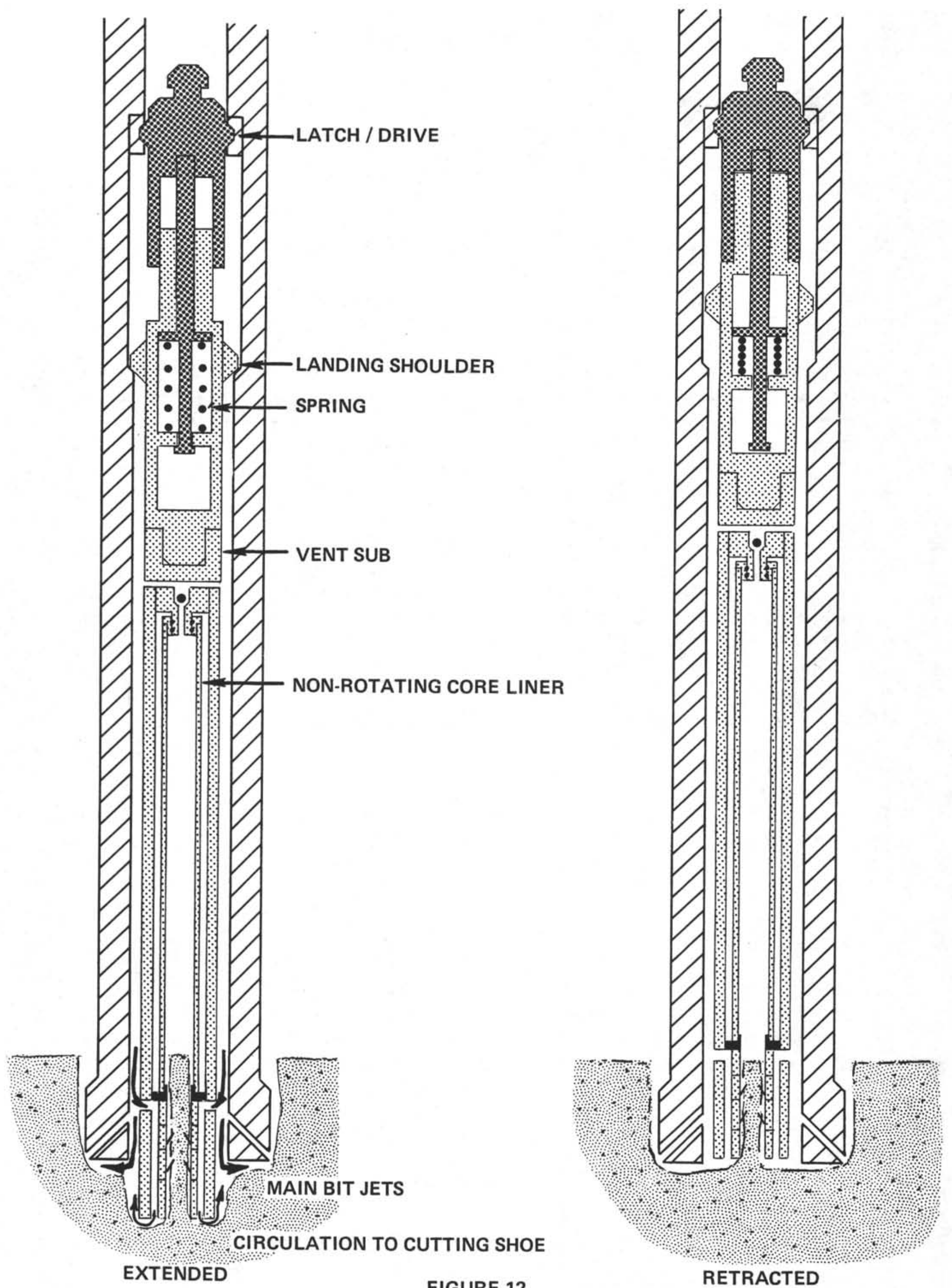

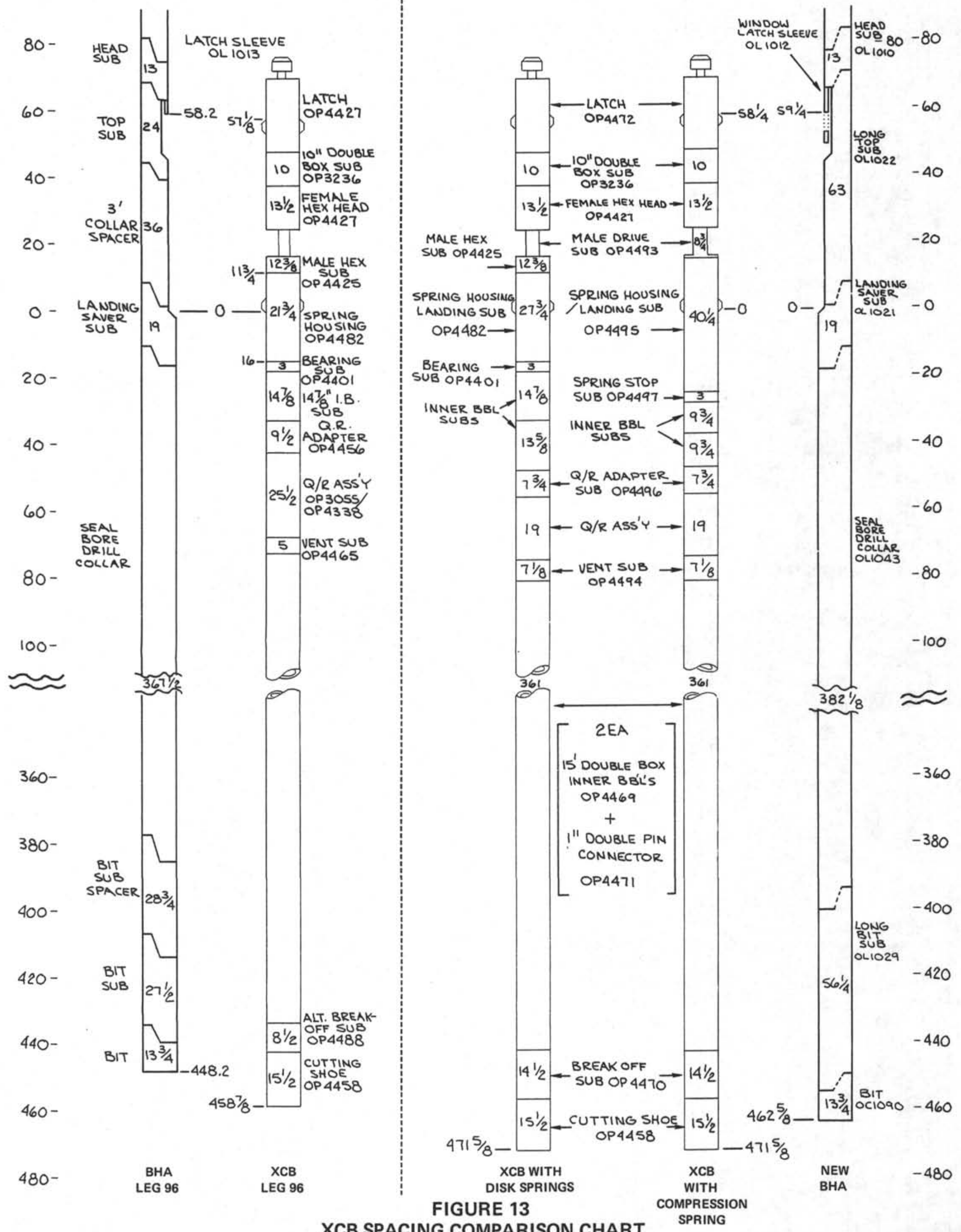


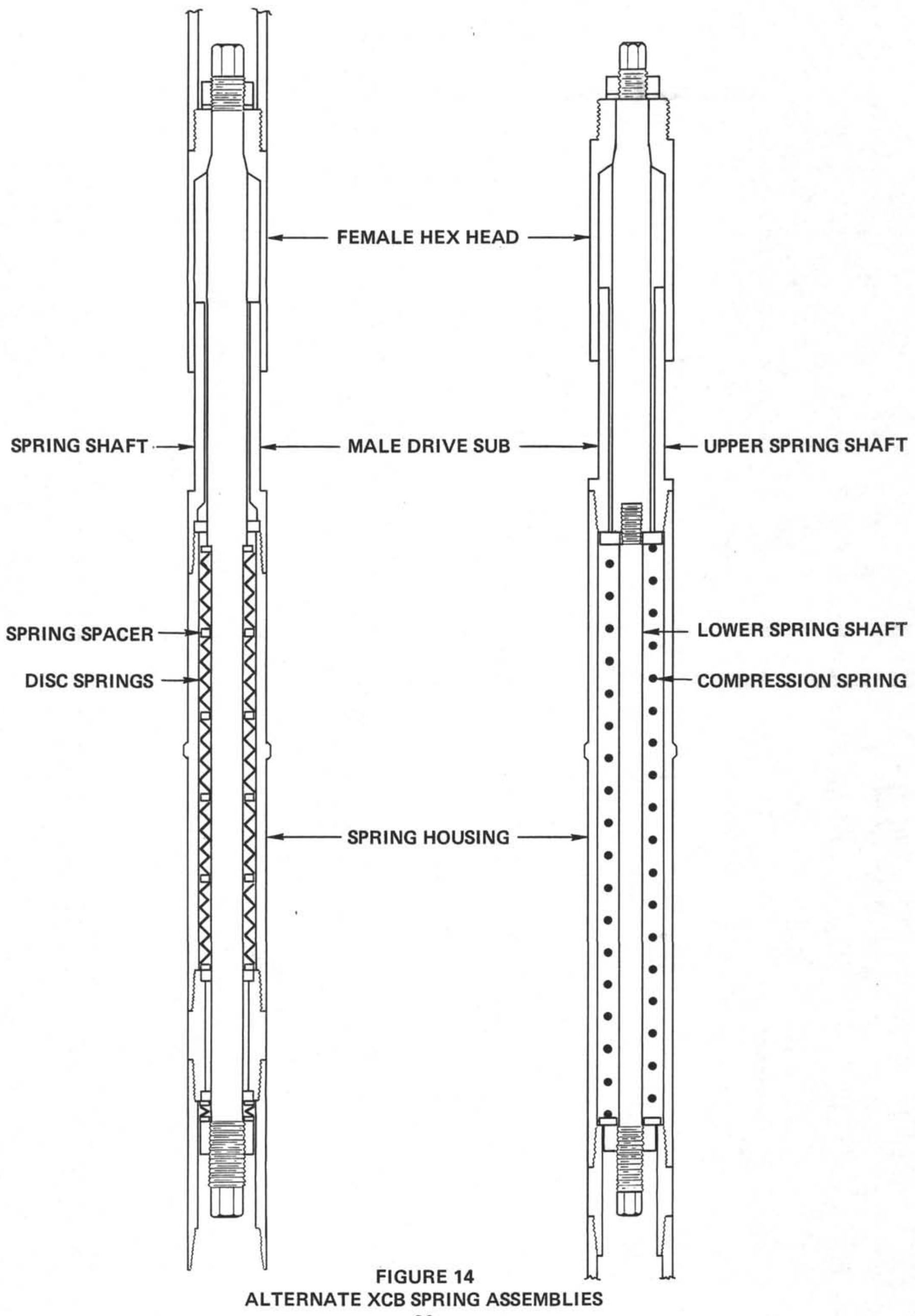


shifts the Pulling Neck out from under the locking Dogs, and the Dogs fall in to release the tool from under the Latch Sleeve.

\section{Hex Splined Scoping Section}

The hex shaped shaft of the Male Drive Sub engages a similar profile in the Female Hex Head to provide for up to $8^{\prime \prime}$ of axial displacement while continually transmitting torque.

\section{3. $\quad$ Spring}

A 34 " long helical Compression Spring with a spring rate of $250 \mathrm{lb} /$ in initially maintains the XCB at full extension. A compression force of $2000 \mathrm{lbs}$ will cause the tool to compress $8 "$ at which point the Male Drive Sub shoulders on the Female Hex Head.

\section{Quick Release Mechanism}

Currently used on both the XCB and APC, the Quick Release reduces the turn around time between successive cores by providing a rapid means of connecting and disconnecting the core barrel from the upper section the tool. The male and female sections engage and rotate $90^{\circ}$ to lock together.

\section{Vent Sub}

The Vent Sub is fitted with a one way check valve to allow fluid to exhaust from the core barrel into the drill string annulus as the core enters, but prevents flow in the opposite direction to protect the core from being washed out during retrieval.

\section{Non-Rotating Core Liner}

Up to 9.8 meters $(32.1 \mathrm{ft}$.) of core can be recovered in the standard butyrate Core Liner. The lower end of the Vent Sub provides the inner race for a bearinged device called the Liner Hanger, which is the upper support for the Core Liner. The Liner is also supported at its center where the inner barrel I.D. drops from 3 " to $27 / 8$ " for a 6 " span, and at the bottom where it rides on a low friction bushing. The 2.817" O.D. liner is not rigid and is free to buckle until it contacts the inner barrel wall in any number of places. This extra induced drag was considered to be a minor problem compared to the complications which would arise from using a non-standard liner. 


\section{Cutting Shoe}

Three types of Cutting Shoes are available for use depending upon the nature of the sediment or rock to be cored.

a) The Soft Formation Cutting Shoe - also useful in hard formations employs a serrated cutting profile hardfaced with tungsten carbide grit. A portion of the circulation flow to the core bit is diverted to directly lubricate the extended Cutting Shoe; entering through the inlet holes at the top of the Shoe, it is directed through an annulus created by the Isolation Sleeve and out small jet holes at the bottom of the Shoe (Fig.11).

b) The Acker Natural Diamond Shoe consists of premium grade natural diamonds set in a hard metal matrix. It is used to core solid basalt. Circulation flow to the cutting edge is similarly diverted down an internal annulus, but exits directly onto the core.

c) The Acker "Amalgamated" Diamond Shoe is composed of artifical diamond chips set in a hard metal matrix. It is used to core through fractured basalt and cherts. Both of the hard formation shoes are produced by Acker Drilling Company, Inc. to DSDP specifications. 


\section{BHA CONFIGURATION AND SPECIFIC ASSEMBLIES}

\section{A. BHA Description}

The lower BHA has been designed to accomodate both the XCB and the APC. The assembly shown in Fig. 15 is the most current version. It differs from the one last used aboard the Glomar Challenger: the Long Top Sub and the Long Bit Sub each consolidate two previous components, thereby reducing the number of connections in the BHA. Both the XCB and APC employ the $117 / 16^{\prime \prime} \times 3.8^{\prime \prime}$ roller cone core bit. The 3.8" diameter hole through the bit allows passage of a barrel of up to $33 / 4$ " diameter. Three of the components required specifically for XCB work are described below.

B. Specific Assemblies

1. Window Latch Sleeve (OL1012)

The two-fold function of the Latch Sleeve is to hold down the XCB and transmit torque during coring. The windows in the Sleeve allow the Latch Dogs room to pop out and lock. The upper set of windows is offset $90^{\circ}$ from the lower set. Ideally the XCB Latch Dogs will land opposite the lower set of windows (Fig. 16c). In that position the tool is latched in with the correct spacing relative to the Bit. However if the tool initially lands with the Dogs not opposite the lower windows (Fig. 16a), one of two things will happen: 1) when the drill string is rotated the Latch Sleeve may spin relative to the Latch until the lower windows align opposite the Dogs which then pop out and lock. 2) When the drill string is lowered into the sediment the resisting load will push the XCB up until the Latch Dogs are opposite the upper set of windows in the Latch Sleeve; they will pop out and lock against further upward movement, but will allow the tool to fall into the lower set of windows as soon as the load is momentarily removed (ships heave, etc). In either case the tool will ultimately be correctly positioned with the Latch Dogs locked out in the lower set of windows of the Latch Sleeve.

2. $\quad$ Padded Flapper (OL1504)

At the bottom of its drop down the drill pipe, the XCB cutting shoe impacts upon and noses open a Baker Float Valve flapper in the Bit Sub. In order to minimize the risk of impact damage to the relatively brittle cutting edge structure, a polyurethane padded flapper is used in place of the standard one in the Float Valve. 
3. Guide Ring (OL1031)

The Guide Ring provides a 3.800 " bore positioned just above the core guide to centralize the XCB Cutting Shoe (O.D. = 3.75) and minimize wobble. 


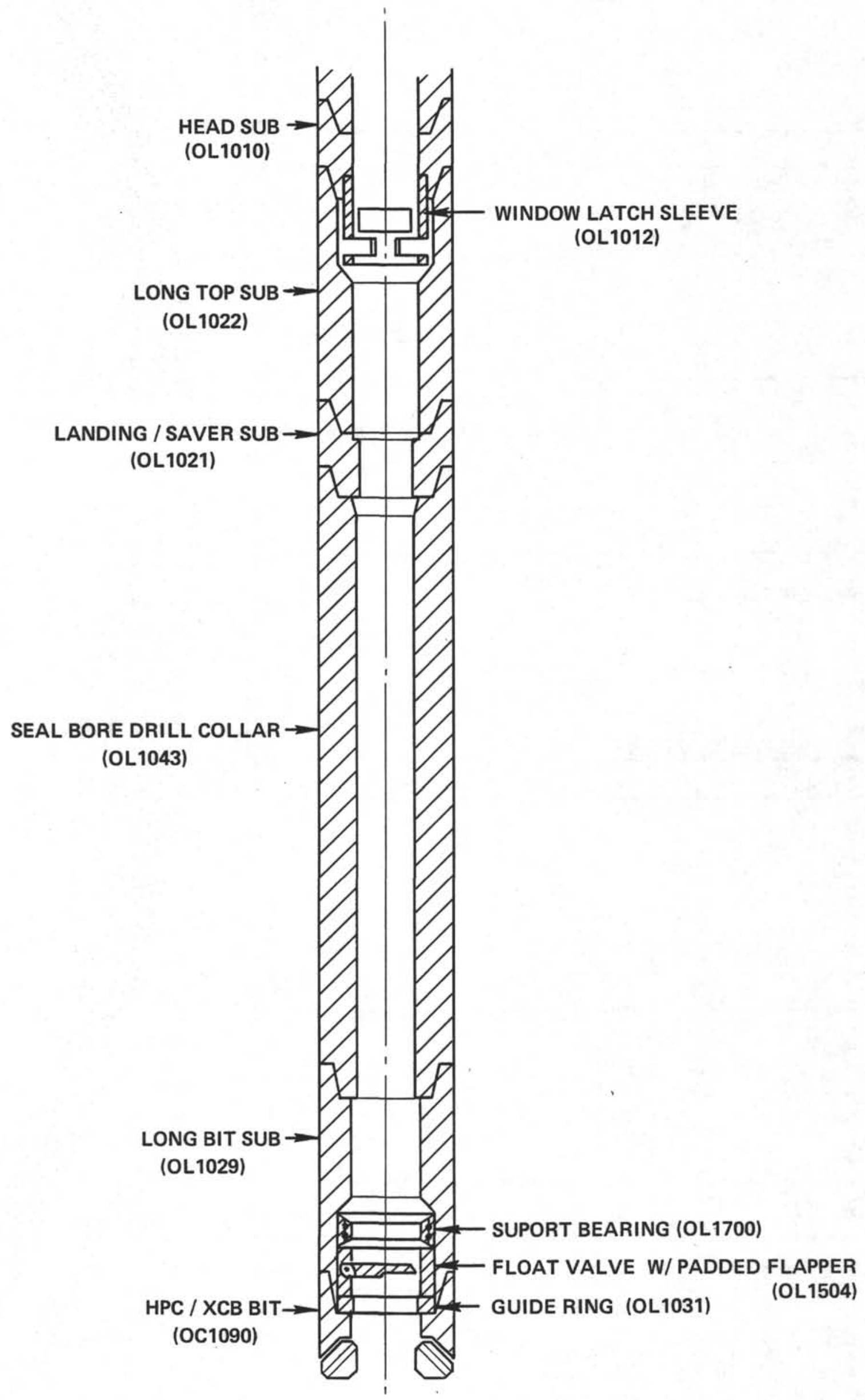

FIGURE 15

BOTTOM HOLE ASSEMBLY FOR XCB AND APC 


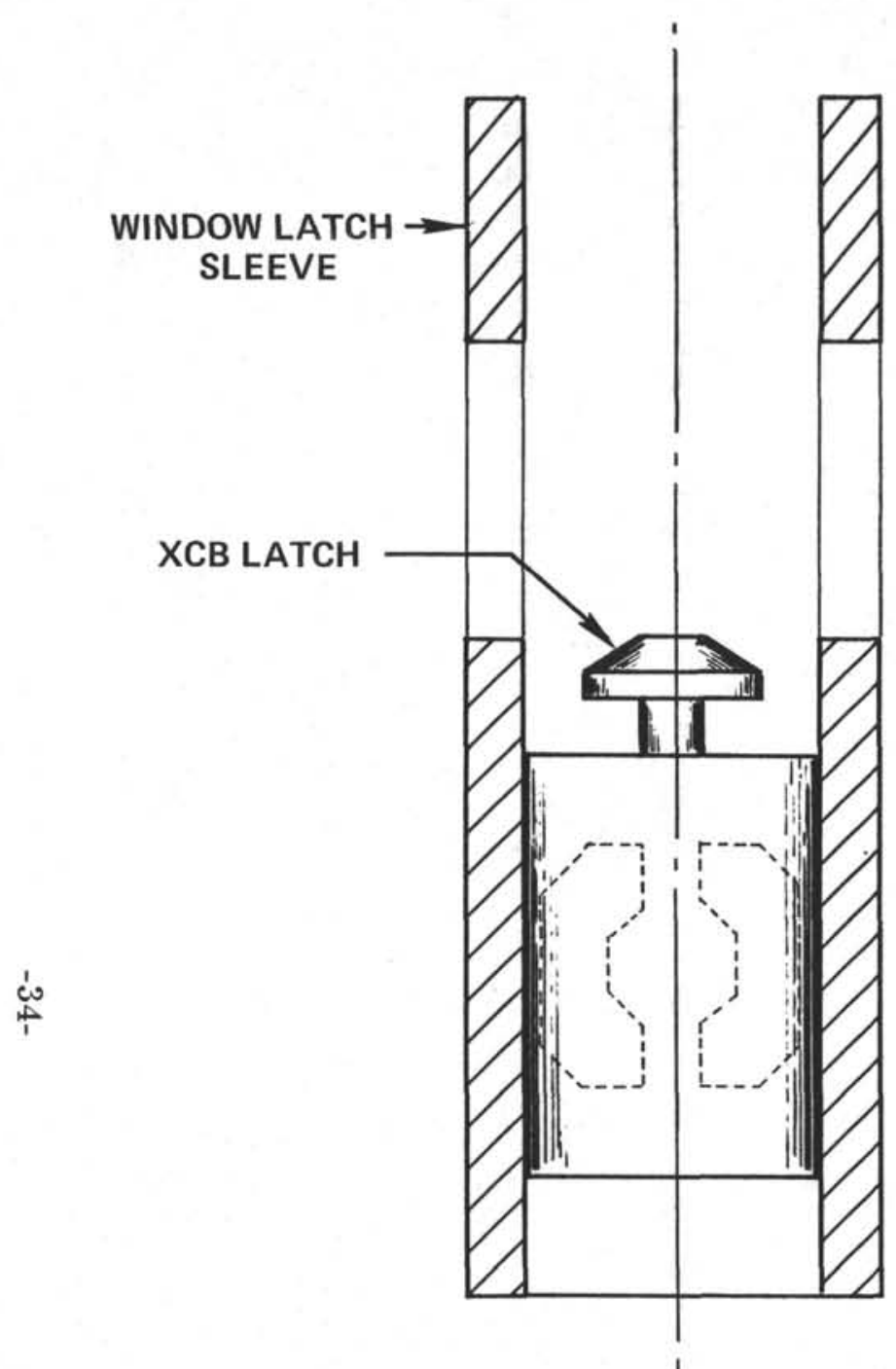

A. LATCH DOGS OFFSET FROM LOWER WINDOWS. TOOL IS NOT LATCHED IN.

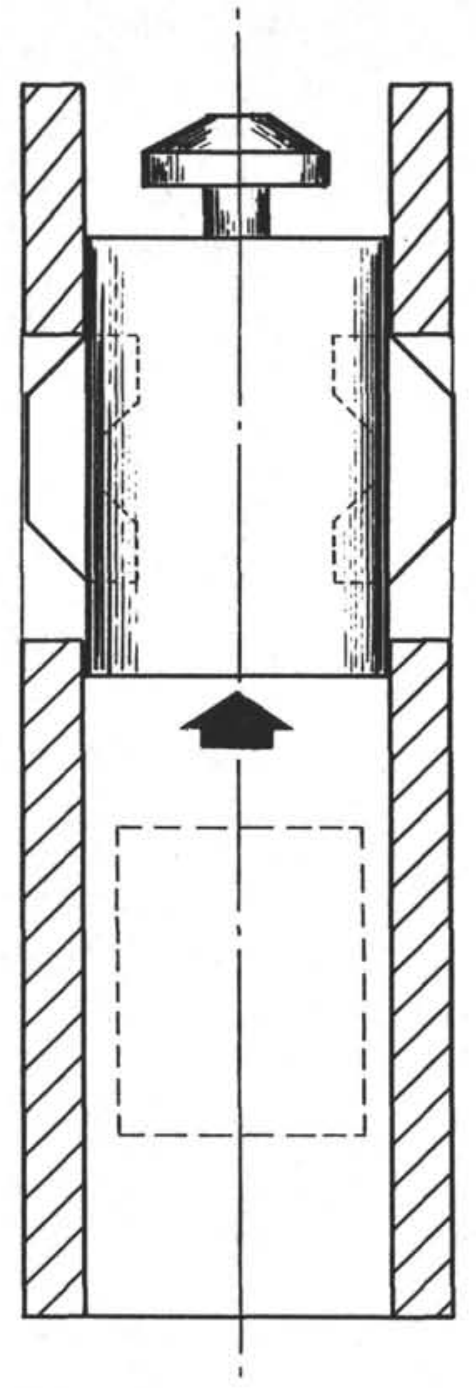

B. TOOL CAN BE FORCED UPWARD ONLY UNTIL DOGS LOCK OUT OPPOSITE UPPER WINDOWS. TOOL CAN STILL FALL LOWER IF UPWARD FORCE REMOVED.

FIGURE 16 LATCH SLEEVE OPERATION

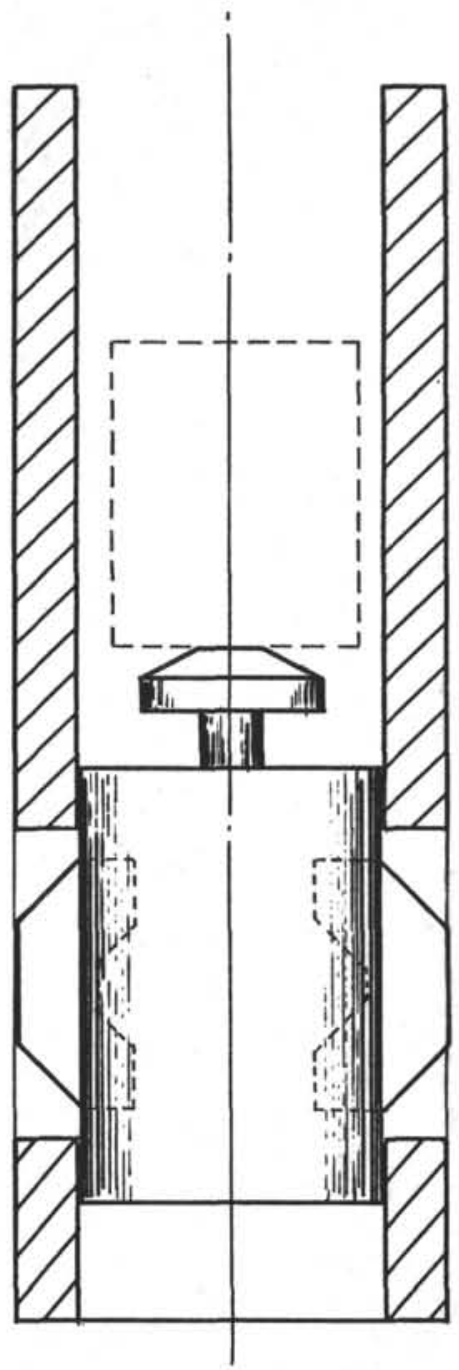

C. THROUGH COMBINATION OF SHIP'S HEAVE AND DRILL STRING ROTATION, DOGS WILL EVENTUALLY LOCK OUT OPPOSITE LOWER WINDOWS 


\section{PERFORMANCE EVALUATION}

A. Intercompatibility

The XCB was deployed successfully as an operational tool during DSDP Legs 90-96. Its overall performance has been rated very good. Its most important contribution is that, in conjunction with the VLHPC or APC, it has made it possible to continuously core from surface to basement using either tool as necessary to obtain the best core. Previously the upper sediments were piston cored to refusal (sediment too stiff to achieve full stroke); if it was desired to penetrate deeper, the drill string had to be tripped to change to a standard coring bit. Then a new hole had to be drilled through the piston cored sections before finally resuming coring at the desired depth. A tremendous time savings was achieved by eliminating numerous round trips of the drill pipe.

\section{B. Core Quality}

The quality of the XCB cores has been excellent at times. Usually cores taken just below the piston core refusal point were as undisturbed as the previous piston cores. Induced coring disturbance, while still evident in many cores, was no worse than that observed in standard cores of similar lithologies.

In spite of the problems described below the overall XCB core quality was better in most soft sediments and comparable in indurated sediments to the standard cores. The only advantage the standard core barrel now holds over XCB is in hard rock coring. The array of available Cutting Shoes includes specialized ones for hard rock coring, but these have not yet demonstrated their reliability. The most common problem has been the tendency for rock chunks to jam in the throat of the Shoe or in the core catchers. The clearance between the cutter gage and the core catcher I.D. has been increased, but the modification has not yet been tested at sea.

\section{Floating Core Liner/Liner Failures}

A key element in providing for a free-floating liner is using an over-size core barrel which allows clearance outside the Core Liner. This, however, removes a source of mechanical support to the Liner, making it more prone to failure by a number of failure modes. The XCB Liner often failed by the following mechanisms: implosion (collapse), explosion (shattering or splitting), axial overload (crumpling), or torsion overload (twist off). The isolation of the Core Liner from the circulation to the Cutting Shoe reduced the number of failures due to implosion, but failures in the other modes still occur. Though sometimes an entire hole can be cored without a single Liner failure, at other times they fail on every core. Variations in sea state, hole depth, lithology and drilling techniques all appear to affect the frequency of the Liner failures, but no apparent consistency has yet been discerned. 


\section{Circulation}

It is doubtful that the circulation diversion system has ever worked as well as was intended. The $\mathrm{XCB}$ core barrels usually returned to deck with clogged Cutting Shoe discharge ports. In fact, the only times they did not clog were in some indurated sediments or rock, where the cuttings comprised discrete grains rather than sticky clays and muds.

Since in most cases the core quality was good, the plugging might be occurring only after most of the core had been cut. Or a break in the circulation flow might allow a plug to form which cannot be dislodged once the flow is reestablished. An attempt was made to shield the discharge ports to prevent their clogging so easily: For Leg 90 the discharge ports were modified to jet horizontally, each water jet impinging on the following cutter tooth rather than straight down into the formation. The clogging still routinely occurred, and the right angle bend made the clogged ports even harder to clean out between runs. The inlet hole area has been maximized to reduce pressure loss. But the annular area between the inside of the Shoe and Isolation Sleeve is currently restricted to 0.44 in $^{2}$ because of dimensional limitations. 


\section{XCB ASSEMBLY INSTRUCTIONS}

\section{A. Upper Section}

Components:

OP4432 Compression Spring

OP4489 Spring Shaft

OP4498 Spring Stop Washer

OP4414 Nut (2 ea)

OD7160 Cotter Pin (2 ea)

OP4493 Male Drive Sub

OP4495 Spring Housing

OP4427 Female Head Hex Drive
OP4407 Spring Shaft Washer

OP3236 10" Double Box Sub

OP4472 Latch

OP4497 Spring Stop Sub

OP3230 9-3/4" Inner Barrel Sub (2 ea)

OP4496 Quick Release Adaptor

OP4825 Male Quick Release

OP4752 Quick Release Nut

OP4753 Quick Release Dogs (2 ea)

1. Slip the Compression Spring over the lower end of the Shaft. Then install the Spring Stop Washer, Nut, and Cotter Pin to retain the Spring.

2. Make-up the Male Drive Sub to the upper end of the Spring Housing. (Make sure that the correct end of the Spring Housing is up. The landing shoulder is 16 " from the upper connection). Slip this assembly over the Spring Shaft so that the spring housing encloses the Spring, and the Male Drive Sub encloses the larger diameter section of the Spring Shaft.

3. Install the Female Head Hex Drive over the Shaft and Male Drive Sub. Then install the Spring Shaft Washer, Nut, and Cotter Pin onto the Spring Shaft.

4. Make-up the 10" Double Box Sub and the Latch (see Section "C") to the Female Head Hex Drive Sub.

5. To the lower end of the Spring Housing make-up the Spring Stop Sub, 2 ea. 9-3/4" Inner Barrel Subs, and the Quick Release Adapter Sub.

6. Assemble the Quick Release Dogs and Quick Release Nut onto the Male Quick Release. Then make-up the Male Quick Release to the Quick Release Adapter Sub. This completes the assembly of the upper section. Attach a handling clamp under the Latch and lift it to a vertical position for assembly to the lower section. 
B. Lower Section

Components:

OP4469 15' Double Box Inner Barrel

OP4471 Double Pin Connection

OP4464 Liner Hanger

OD2330 O-Ring \#2-330 (2 ea)

OP4494 Vent Sub

OD7220 Stainless Steel Balls, 5/16"

Dia. (30 ea)

OP3107 Check Ball

Soft Formation System:

OP4458 Soft Formation Cutting Shoe

OP4460 Bushing

OP4459 Isolation Sleeve

OD2042 O-Ring \#2-042

OR7020 8-Finger Core Catcher

OR7010 10-Finger Core Catcher

OP4481 Core Catcher Spacer
OP3108 Valve Seat Retainer

OP4827 Female Quick Release

OP4470 Break off Sub

OP3400 Core Liner

OP4416 Liner Support Sleeve

OP4415 Retainer Ring

OD6586 Set Screw for Liner Hanger (2 ea)

$\underline{\text { Hard Formation System: }}$

OP4445 Diamond Cutting Shoe

OP4447 Amalgamated Cutting Shoe

OP4449 Lifter

OP4448 Lifter Case

OP4450 Stop Ring

OP4487 Modified Core Catcher

OP4484 Core Lifter Adapter

OD2335 O-Ring \#2-335

OP4485 Cutting Shoe Adapter

1. Connect the two 15' Double Box Inner Barrels with the Double Pin Connector. NOTE: one of the barrels should already have the Double Pin Connector Baker-Locked onto it.

2. Install two O-rings \#2-330 onto the Liner Hanger, which is a part of the Vent Sub Assembly. (see section "C" for vent sub assembly).

3. Ensure that the Check Ball and Valve Seat Retainer are installed into the lower end of the Vent Sub, then make-up the Vent Sub to the upper end of the Inner Barrel assembly.

4. Make-up the Female Quick Release to the Vent Sub.

5. Make-up the Breakoff Sub to the lower end of the Inner Barrel assembly.

6. Bevel the upper inside lip of a Core Liner with a shaping tool, then insert the Liner through the core barrel. NOTE: the Liner must slip over both O-rings on the Liner Hanger. Cut off the Liner flush $\left(+0,-1 / 4^{\prime \prime}\right)$ with the pin end of the Breakoff Sub. 
7. Slip the Liner Support Sleeve through the Retainer Ring and install it into the Liner.

8. Install either of the following to complete the assembly:

a) Soft Formation Assembly: The older Cutting Shoes (OP4458-5) already have an Isolation Sleeve brazed to the inside. If using the newer Shoe (OP4458-6), first install a Bushing into the bottom of the Shoe. Then install two 2-042 O-rings onto the Isolation Sleeve, and install the Sleeve into the Shoe so that the O-rings seal on the seal bore just below the box threads. Insert any combination of standard Core Catchers and Core Catcher Spacers into the Cutting Shoe. The stack should be no higher than the top of the Isolation Sleeve. Finally, make up the Cutting Shoe to the Breakoff Sub.

b) Hard Formation Assembly: Choose either the Acker Diamond Bit or the Acker Amalgamated Bit and make it up to the Cutting Shoe Adapter.

Install an O-ring \#2-335 onto the upper end of the Core Lifter Adapter, then make it up to either a Modified Core Catcher or an Acker Slip-type Core Catcher (consisting of Lifter Case, Lifter, and Stop Ring).

Insert the Core Lifter Adapter into the Cutting Shoe assembly. The upper part should shoulder on the Cutting Shoe Adapter before the lower part contacts the bevel inside the Acker Bit. The gap allows circulation flow to the cutters.

Make up the Cutting Shoe Adapter to the Breakoff Sub. Check to see if the Core Lifter Adapter can rotate within the assembly (with only O-ring drag). If it is pinched, you may have to remove some material from the top of the Retainer Ring.

9. Attach a handling clamp to the Vent Sub, lift the lower section vertical and hangoff in the drill pipe or a storage shuck. Then pick up the upper assembly and stab it into the lower assembly and make up the Quick Release Nut to complete the assembly. 
C. Sub Assemblies Makeup

1. Quick Release Assembly

Entrap the smaller upset on each of the two Dogs inside the groove in the Quick Release Nut. Then slip the Nut and Dogs over the Male Quick Release, with the Dogs engaging the axial slots. Thread the Nut past the first set of threads, stopping after the nut engages the first few threads of the second thread set.

When the Male Quick Release is stabbed into the Female Quick Release and rotated $90^{\circ}$, the nut is threaded down all the way to lock the assembly.

2. Vent Sub Assembly

Position the Vent Sub through the Liner Hanger so that the bearing races line up. Insert 15 ea 5/16" dia. balls in each race through the threaded access holes in the Liner Hanger. Install 2 ea $1 / 2-13 \times 5 / 16$ flat bottom set screws.

Install a 15/16" dia ball into the lower end of the Vent Sub. Then install the Valve Seat Retainer.

3. Latch Assembly

Drop a Washer into the Latch Body and position it so that its slot is rotated $90^{\circ}$ from the windows in the Body. Insert two Dogs into the windows from the inside of the Body.

Slip the Cap, Spring, and remaining Washer onto the Pulling Neck. Then insert the Pulling Neck into the Latch Body and through the lower Washer so that the slot at the bottom of the Pulling Neck aligns with the hole through the lower end of the Body. Finally install the Pivot Pin assembly through the hole to lock the Pulling Neck.

The Pivot Pin is secured with a snap washer, but it may also be tack welded for added security. 
4. Acker Core Lifter Assembly (Slip Type Core Catcher)

Insert the Lifter inside the Lifter case so that the tapers of each piece match. Then install the Stop Ring into the groove at the base of the threads in the Lifter Case. 


\section{XCB DEPLOYMENT}

When not in use, the XCB may be broken down into two sections and stowed horizontally in racks somewhere off of the rig floor. Assume that two shucks are available on or near the rig floor to allow temporary storage of the XCB lower section. Assume also that piston coring operations have just ended, and that it is desired to continue in the hole with the XCB.

1. Attach a Handling Clamp (OP3615) to the Vent Sub of the lower XCB section, pick it up with a tugger, and hang it off in the drill pipe. Remove the tugger line.

2. Attach a second Handling Clamp to the 10" Double Box Sub (below the Latch on the upper section, pick it up with the tugger, stab it into the lower section, and make up the quick release connection.

3. Pick up the assembled tool to take weight off the lower Clamp, remove the Clamp, and lower the tool in the pipe; hang it off with a Hang Off Plate (OD9502) at the narrow hexagon-shaped section just below the Female Head Hex Drive Sub.

4. Remove the upper Handling Clamp and pull out the Hang Off Plate to godevil the tool down the pipe. Make up the drill pipe connection.

5. Prepare a second lower XCB section, attach a Handling Clamp, pick it up with the tugger, and hang it off in one of the shucks.

6. After the first barrel is landed and the core is cut, it is retrieved with the wireline overshot. When it has returned to the surface, the drill pipe is broken to access the XCB.

7. Hang off the XCB with the Handling Clamp just below the Latch.

8. Disconnect the overshot and hook up the tugger line.

9. Remove the XCB from the drill pipe and hang it off in the second shuck with a second Handling Clamp positioned at the Vent Sub.

10. Disconnect the quick release connection, pick up the upper section and stab it into the redressed lower section (which is hung off in the first shuck).

11. Make up the quick release connection, pick up the tool, remove the lower Handling Clamp, and hang it off in the drill pipe with the Hang Off plate as in Step 3. 
12. Pick up the lower section which contains the core, lay it down, and remove the core. Hose it off, redress it with a new Liner, and return it to the shuck. This completes the operating cycle. 


\section{References}

1. Huff, C.F., and Varnado, S.G., (1980), "Recent Developments in Polycrystalline Diamond Drill Bit Design," Technical Report No. SAND79-1592C, Sondia National Laboratories, Albuquerque, New Mexico and Livermore, California.

2. Pope, L.E., (1981), "Analysis of Failed Stratapax ${ }^{\circledR}$-Steel Stud Cutter Elements," Technical Report No. SAND 80-0410, Sandia National Laboratories, Alburquerque, New Mexico and Livermore, California.

3. Middleton, John N., and Finger, John T., (1983), "Diffusion Bonding of Stratapax $B$ for Drill Bits," Technical Report No. SAND 82-2309, Sandia National Laboratories, Alburquerque, New Mexico and Livermore, California. 
APPENDIX A

RESULTS OF EXTENDED CORE BARREL TEST SALT LAKE CITY, MAY 5-7, 1981 


\section{RESULTS OF EXTENDED CORE BARREL TEST}

SALT LAKE CITY - MAY 5-7, 1981

$\underline{\text { Set Up and Test Procedure }}$

The test facility at Terra Tek Consists of an indoor, mobile drilling rig set on rails over a wide pit. Rotation, load and flow rate are controlled and are recorded against time in both digital and analog form along with the dependent parameters such as penetration rate, torque and back pressure. Four types of material were cored: a Berea sandstone block, two 55-gallon drums containing alternate layers of cement (without the aggregate) and soft clay, four 55-gallon drums containing alternate layers of cement (with the aggregate) and soft clay, and a basalt block.

For each test the block or drum was chained to girders located midway down the pit. The drill string was then positioned over it and lowered until the bit made contact. Then a flow diverter "can", measuring $24 "$ high and 18 " in diameter, was lowered over the bit and also chained to the girders. A large diameter hose, connected to the can, returned the water pumped through the drill string to a water pit. The can also served to stabilize the bit at the surface of the block or drum. The material was usually cored to a depth of 2-3 feet. Then the drill string was raised from the hole and moved to the edge of the pit, where it was chained off. The head sub/top sub connection was then broken, and the Extended Core Barrel (XCB) was pulled from the drill string with an automatic chain hoist. 
Results of Extended Core Barrel Test

Salt Lake City

May 5-7, 1981

$\underline{\text { Equipment }}$

The test drill string consisted of a $107 / 32^{\prime \prime} \times 35 / 8^{\prime \prime} \mathrm{XCB}$ bit, a hydraulic bit release, a head sub (used to adapt from the bit release to the collar section), a $91 / 2$ foot length of drill collar, a top sub, an XCB head sub, and a crossover sub to adapt to the drilling rig. The total length was just over 19 feet.

Two alternate XCB designs were tested. In the Clutch Drive XCB the lower section containing the core is disengaged from the rotation of the drill string when in the extended position, and engaged when in the retracted position. In the Locked Drive $\mathrm{XCB}$ the lower section is coupled to the drill string rotation at all times.

Other component variables, common to both the Clutch and the Locked Drive $\mathrm{XCB}$, were the spring pack configuration, the cutting shoe, and the core catcher bearings. The spring pack consisted of stacks of disk springs which could be modified to change the spring rate and stroke of the tool. Two configurations were tested:

1) 110 spring stacked in series to give a calculated $1200 \mathrm{lb}$ load at maximum deflection with a 7 -inch stroke.

2) 124 springs stacked in series-parallel to give a calculated $2400 \mathrm{lb}$ load at maximum deflection with a 4 " stroke.

Two types of cutting shoes were tested:

1) The Stratapax cutting shoe employed eight stratapax diamond disk cutters. The four inside cutters were positioned to cut a core gauge of $25 / 16 "$.

2) The carbide cutting shoe was of the same design, except that it was equipped with tungsten carbide disk cutters instead of stratapax cutters.

Two types of core catcher bearings were tested:

1) The "custom" bearings were made of Delron and had two rows of 5/16" diameter stainless steel balls.

2) The stock "Kaydon" bearings were made of stainless steel and had one row of $1 / 4^{\prime \prime}$ diameter stainless steel balls. 
Results of Extended Core Barrel Test

Salt Lake City

May 5-7, 1981

The locked drive XCB spaced out to within $1 / 2$ " of the latch sleeve in the 7 " stroke mode. (The gap between the latch and the latch sleeve increases directly as the stroke decreases). The Clutch Drive XCB spaced out to within $17 / 8^{\prime \prime}$ of the latch sleeve in the $7 "$ stroke mode.

\section{Objectives}

While holding the drilling parameters constant, the alternate XCB components were directly compared in successive tests in an attempt to optimize core recovery and to watch for any undue wear or damage. The specific objective of the tests through the 55-gallon drums was to recover the interbedded soft clay layers.

\section{$\underline{\text { Test Summaries }}$}

See the individual test sheets at the end of this report.

\section{Conclusions}

The locked drive version of the XCB was moderately successful in recovering core, but several problems surfaced during the tests. These will be discussed in the context of the components to which they relate.

\section{Clutch Drive VS Locked Drive}

These two alternate designs were directly compared in the first four tests. The Locked Drive XCB achieved excellent recovery of sandstone in Test \#2 but had bad recovery in the aggregate cement of Test \#4. (Later, when the fingers of the core catch-

ers were removed, the recovery in aggregate cement improved). The Clutch Drive XCB failed to recover any appreciable amount during Tests \#1 and 3 in sandstone and non- 
Results of Extended Core Barrel Test

Salt Lake City

May 5-7, 1981

aggregate cement respectively. The tips of the male and female clutch drives were worn, and there were no scratches or other evidence to show that they had ever completely engaged. Coupled with this is the fact that the cutting shoe is capable of coring ahead of the bit in sandstone and basalt (as was observed in the bottomhole profiles of Tests \#2 and \#11): It is likely, then, that the Clutch Drive XCB tends to "flutter" between the engaged and disengaged modes. (i.e., as soon as it is partially engaged it rotates with the bit but, cutting faster than the bit, it extends and disengages again.) This situation, in the extreme, may result in the male and female clutch drives merely spinning from tip to tip rather than fully engaging. The efficiency of the cutting shoe would be greatly reduced against the constant penetration rate of the bit, and eventually a piece of untrimmed core will jam in the throat of the cutting shoe.

\section{Cutting Shoe and Core Catchers}

The relief between the inside cutters of the cutting shoes and the I.D. of the core catchers was the primary reason for the inhibited core recoveries in several of the tests. The cutters have I.D guage of $25 / 16^{\prime \prime}$. The I.D. of the core catcher body is $23 / 8^{\prime \prime}$. But the core catcher fingers do not lay flush with the I.D., thereby reducing the effective I.D. of the core catcher. In addition, thread-like grooves on the outside of the recovered cores show tht the cutters tend to thread their way down the core. The diameter of the sandstone recovered in Test \#2 (where complete core catchers were used) was $21 / 4 "$. The sandstone was soft enough to be trimmed by the core catcher fingers. But the diameter of the basalts recovered in Tests \#10 and \#11 (using core catchers without fingers) were 2.315"-3.230". These pieces could not be pushed through a complete core catcher assembly. A modified core catcher was used for Test \#8; the fingers were 
Results of Extended Core Barrel Test

Salt Lake City

May 5-7, 1981

machine down as much as possible without breaking through the hinge pin hole, but the core still jammed in the core catcher.

One or perhaps all of the following modifications are called for:

1) Increase the effective I.D. of the core catcher to $27 / 16^{\prime \prime}$.

2) Reduce the gauge of the inside cutters to $21 / 4^{\prime \prime}$.

3) Install flat-edged inside cutters on the cutting shoe to reduce the possibility of untrimmed core getting past the cutters due to a high penetration vs rotation ratio.

The stratapax cutters were alternated with the carbide cutters in almost every other test. Both cut well in sandstone, non-aggregate cement, and basalt. The carbide cutters suffered less damage in the aggregate cement than did the stratapax cutters. The scope of the tests were insufficient to determine long term effects of wear on the cutters, but from the short term results it appears that the carbide cutters are just as good as the more expensive stratapax cutters.

\section{Core Catcher Bearings}

Both styles of core catcher bearings froze during every run but the last two which were in basalt. The test did not exactly model the real situation in that the drill string was not submerged, and thus there was not water in the core barrel to be diverted down the annulus between the liner and the core barrel (and through the bearings) as the liner filled with core. But it would not have been a strong flow in any case and probably would have done little to prevent the clogging of the bearings. Sealed roller bearings or teflon slip rings may solve this problem.

\section{$\underline{\text { Spring Rate }}$}

The initial spring pack used in the first seven tests was calculated to have a full stroke load of 1200 lbs. The alternate spring pack configuration used in the last four 
Results of Extended Core Barrel Test

Salt Lake City

May 5-7, 1981

tests had a full stroke load of $2400 \mathrm{lbs}$. To double the full stroke load it was necessary to reduce the stroke by $3 "$ (from $7 "$ to $4 "$ ). It was observed in Test \#2 that the Locked Drive XCB was able to core ahead of the bit with the $1200 \mathrm{lb}$ spring pack. Test No. 11 showed that this same tool was able to core ahead of the bit with the $2400 \mathrm{lb}$ spring pack. Nothing else could be discerned of the relative merits of these two spring packs configurations. It would at first seem that the stiffer spring pack is more desirable since it could more often core ahead of the bit in stiff sediment and rock. But the primary objective of the cutting shoe is to core ahead in soft sediments, and serve only as a trimmer working behind the bit in still sediment. Therefore the stiffer spring pack might produce unnecessary wear in the cutters. Also, the shorter stroke may inhibit the primary objective of coring far enough ahead of the bit to recover undisturbed soft sediments.

$\underline{\text { Drive System }}$

The current $\mathrm{XCB}$ drive mechanism consists of a single-eared latch sleeve in the head sub working against a double-fingered latch at the top of the XCB. During these tests the $\mathrm{XCB}$ never popped its latch as it did during the previous testing session last Thanksgiving when a double-eared latch sleeve was used. However, it is probable that, under high torque, the latch sleeve ear can force itself over the latch finger, and spin until it contacts the other latch finger. This stop-go type of rotation may be detrimental to core recovery. The latch down system should be decoupled from the drive system but this modification is not considered necessary for the short term deployment of the $\mathrm{XCB}$. 


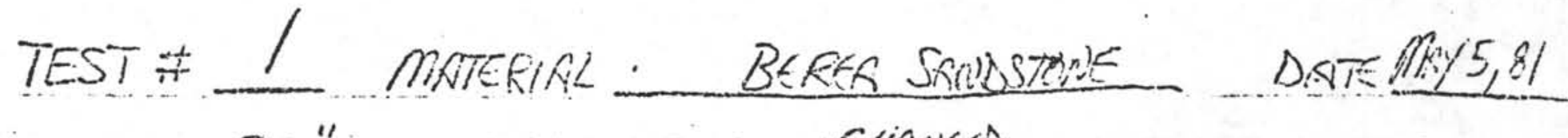

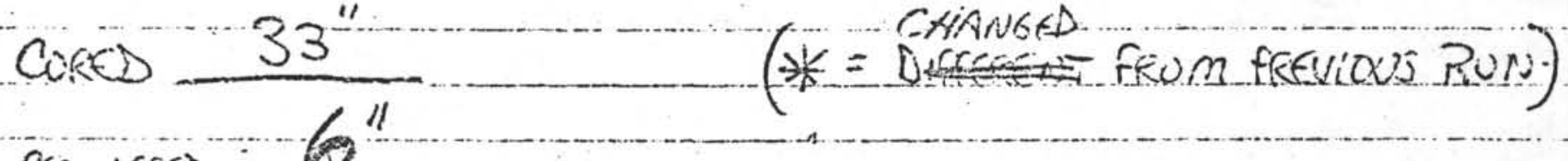

RECOU $\leqslant \in D$ :

$$
\text { ECB VOEISBLS }
$$

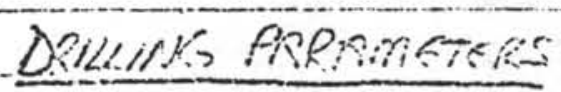

Tyfe

CLUCH DRIS

SFRLE RATE: 1200 frm i so fir

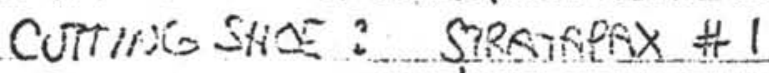
BIT WIGKE: 15000 H CC BESRHE: KAYDEN Frow $: 160.6 \mathrm{~m}$

SUMmRRY

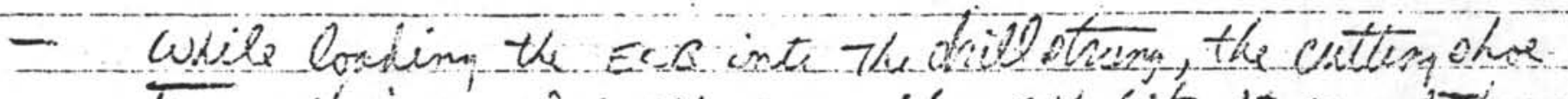

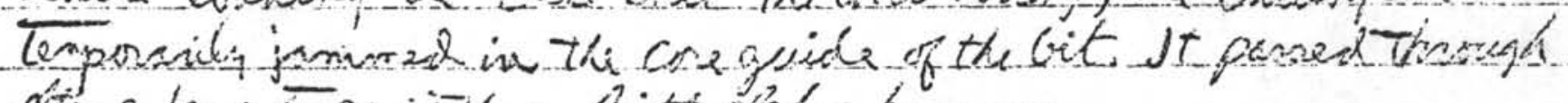

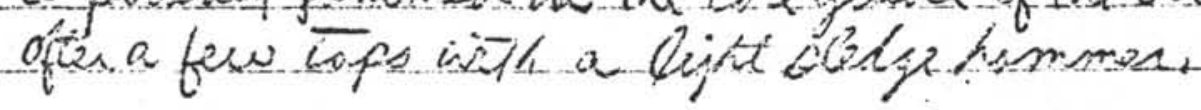

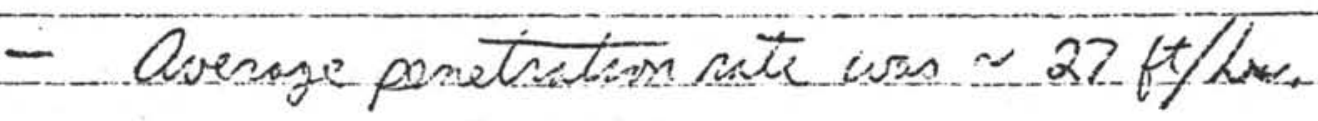

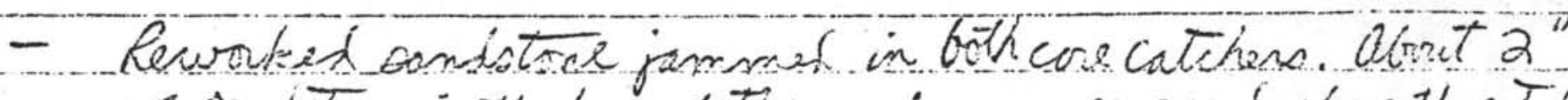

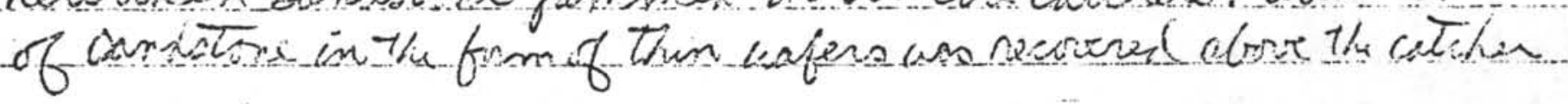

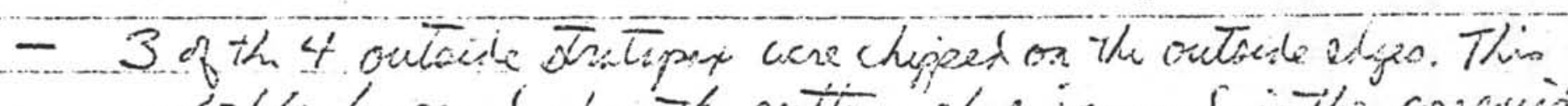

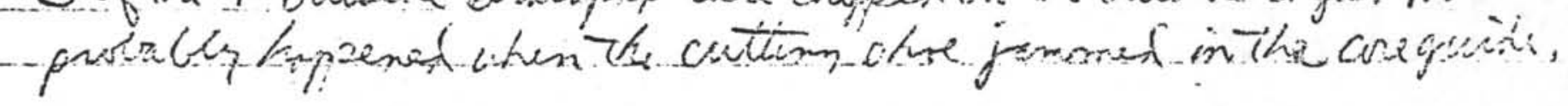

- The Eaydon Gessings arese forgen avith git.

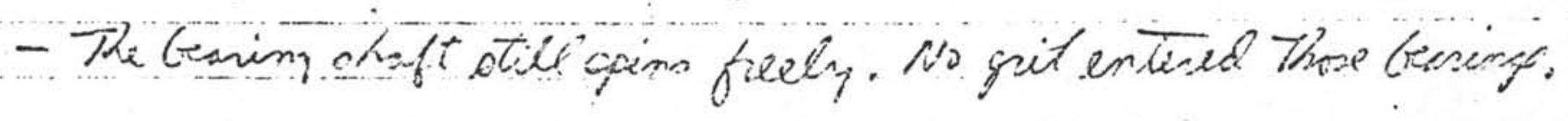

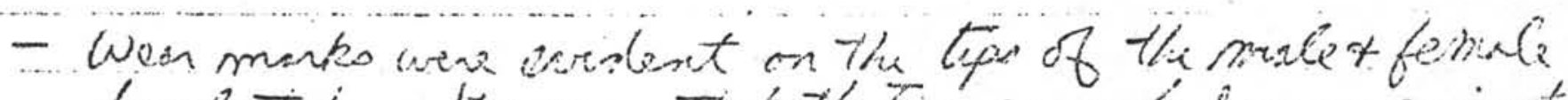

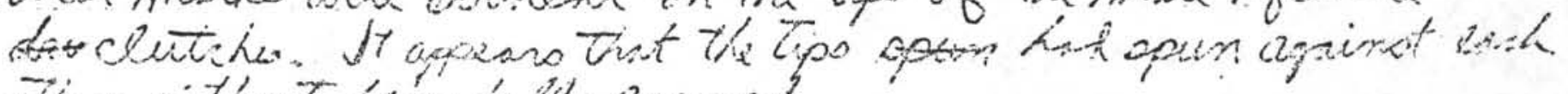

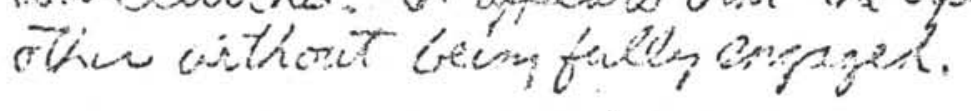

$-55-$ 


$$
\begin{aligned}
& \text { TEST } 2 \text { M MNTERIRL. BEREA SXOASTONE DATE SMAYS } \\
& \cos 134^{\prime \prime} \\
& (X=\text { CHANGEO IRUM PRHYOS RUN } \\
& \text { RECUES: } 29^{\prime \prime} \\
& \text { ECEUKELEIES } \\
& \text { DPILINSE FRRAMETESE } \\
& \text { TYfe } \\
& \text { LO(KE) DRI'E } \\
& \text { Rfm } \\
& 50 \text { RPM } \\
& \text { SEFIL KXTE: } 1200 \% \\
& \text { fri WEllokt: } 15000 \% \\
& \text { CUTHWOSWI: CARRIDE } \\
& \text { FLOW: }: 1606 \mathrm{~mm} \\
& \text { CC STING : Custom * * }
\end{aligned}
$$

Summery

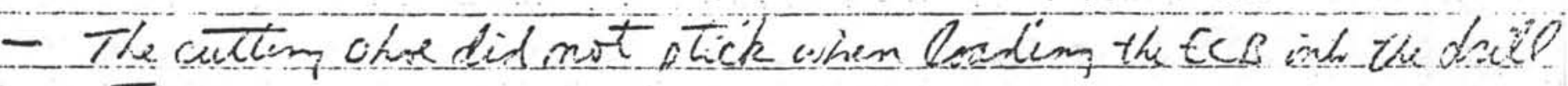
$\therefore$ orsing.

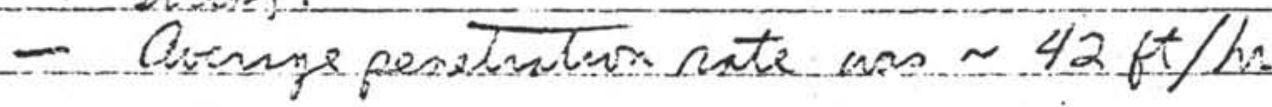

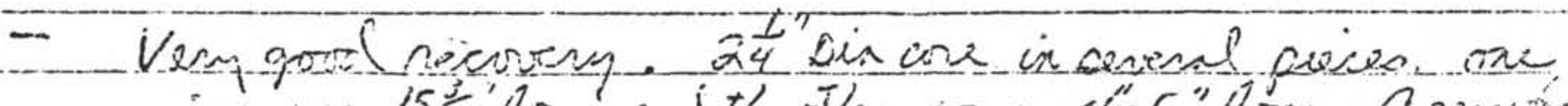

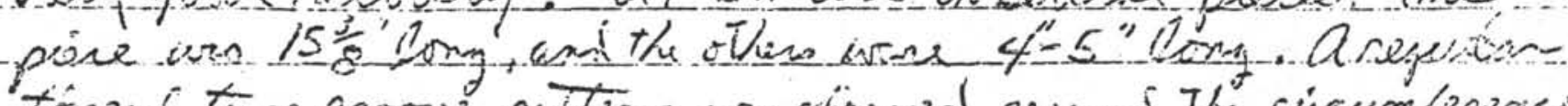

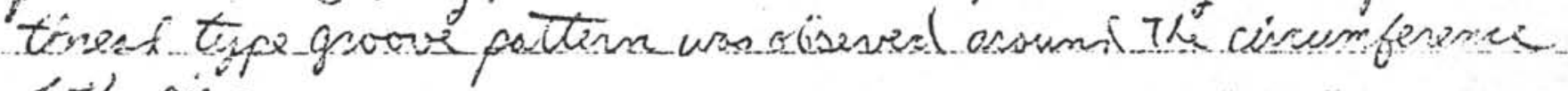
of the fieces.

- Thenbide uncess cose undameger

- The cunton lessing frogs with opit.

- No pit ontene the banim oheft baning.

- The cottro of the hole chowed thet the con barne ait aro abrit l" aind of the bit.

$-56-$ 


\section{** CHECK oUTPUT TO SEE IF if IS OK **}

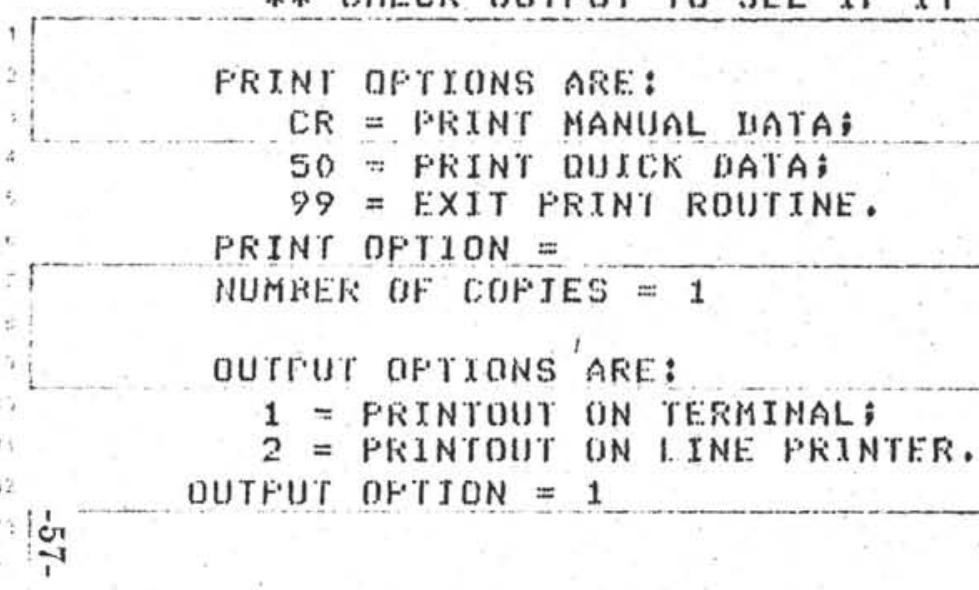
PALE: 1 RLIN $\$ 2$ SANMSTUNE

a/s chamile data tamie

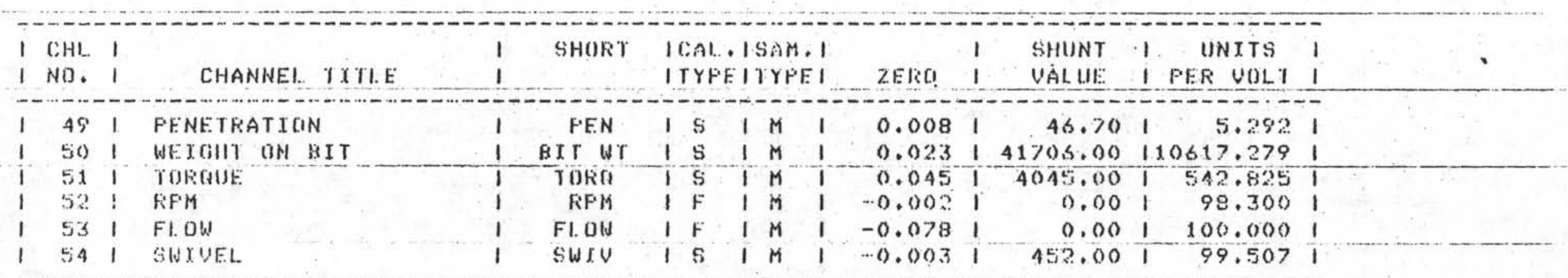




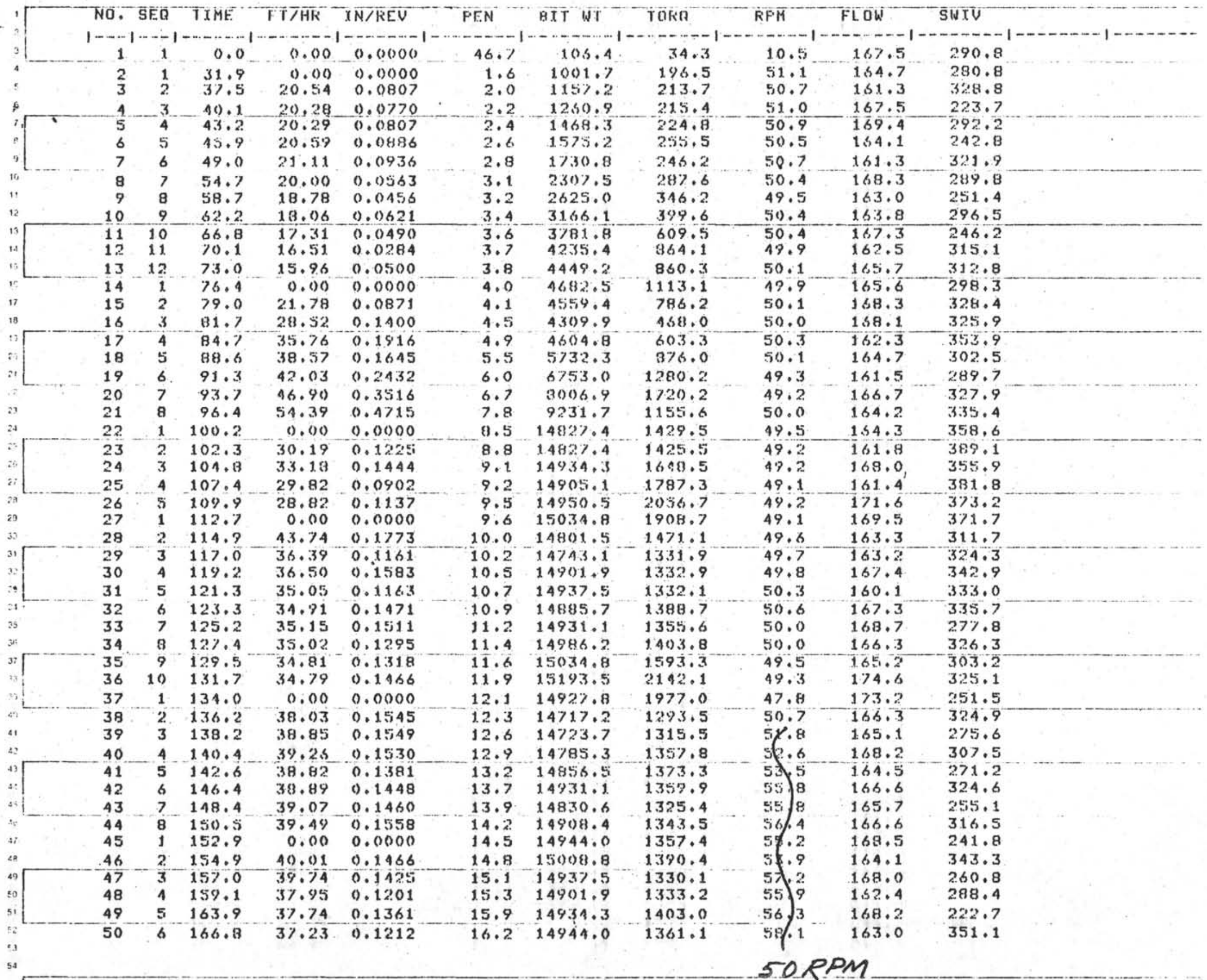




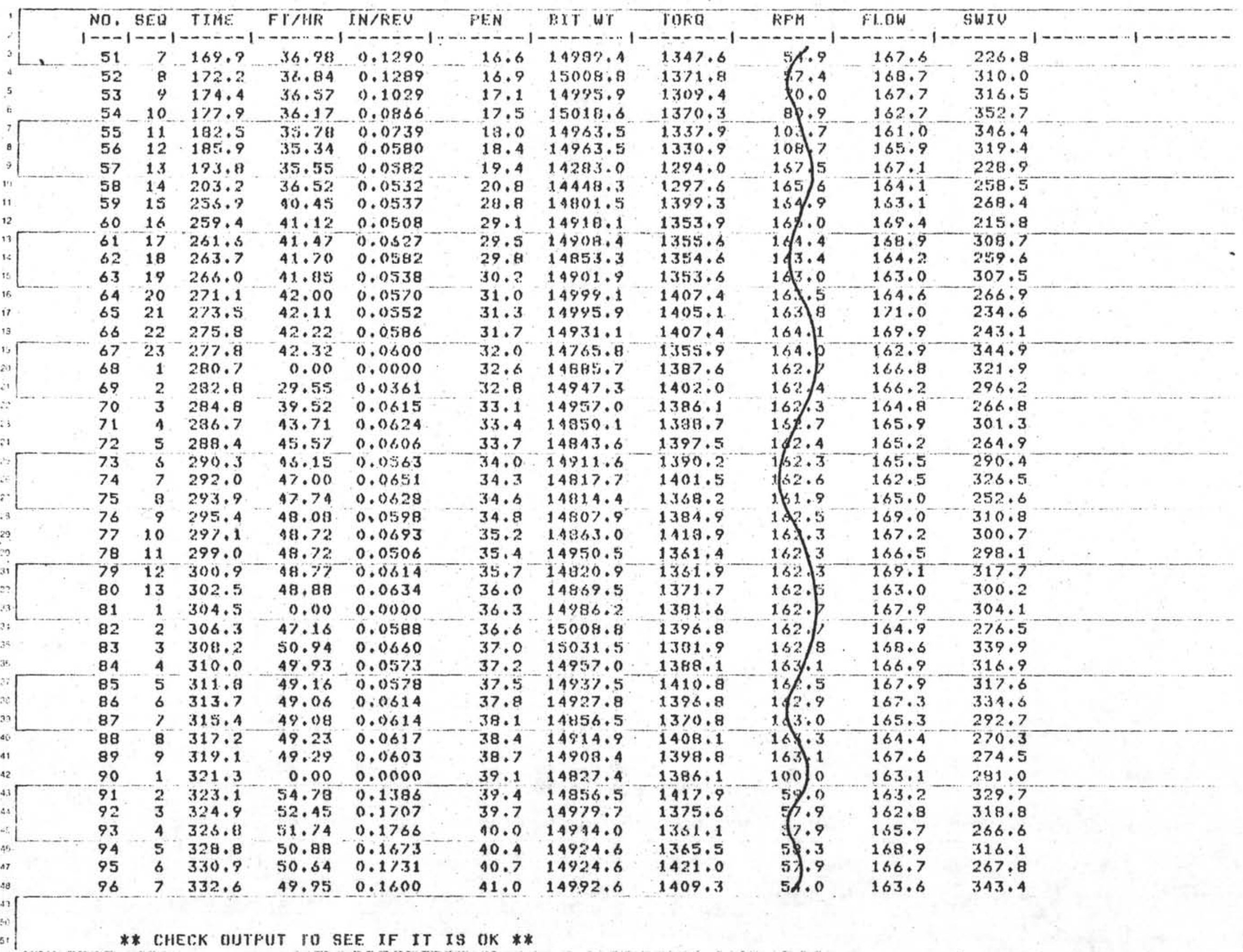


TEST \# 3 MNTERIRL NOW-RGGREGTE CEMENT DRUM DSTESMY8 $\cos 133^{\prime \prime}$

REOU \&ES: CC only

(* CDANGEL from AREVIOUS RUNO)

ESR IERIEEIES

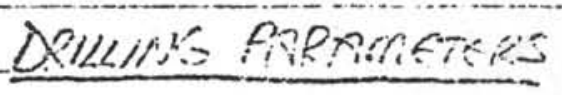

TYFE $:$ CLUTH DRVE $*$

SERING RATE: 1300\#

CUTTWO SNAE: STRATAPAX\#2 *

CC BEERRING : CUSTOM
RAM 50 RPM

BT WETENT: 15 STOH

FLOW:160 GM

Summery

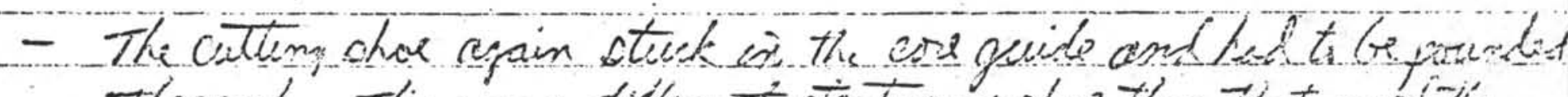

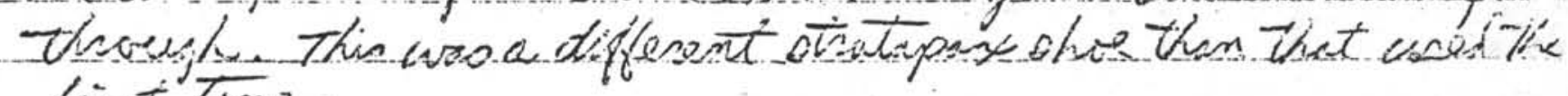
fisit time.

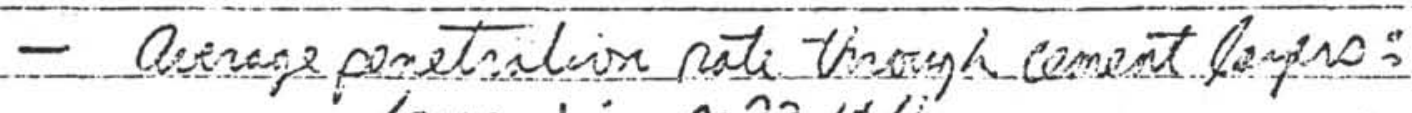

Lagen 1: $223 \mathrm{kt} / \mathrm{in}$

Lamen $=:-4360 / 1$

Layen $3^{\circ}=50 \mathrm{kt} / \mathrm{h}$

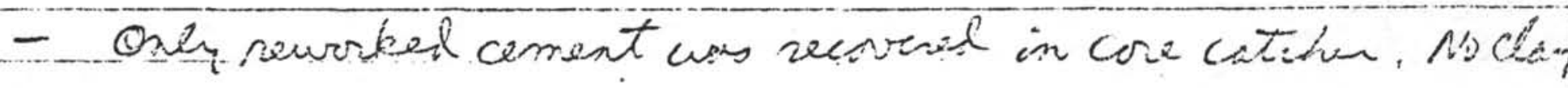

- The ceasimp fwizarain

- The othetiport cutters ure not damszed

$-60-$ 


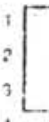

A/D. CHAHMEL DAIA TABLE

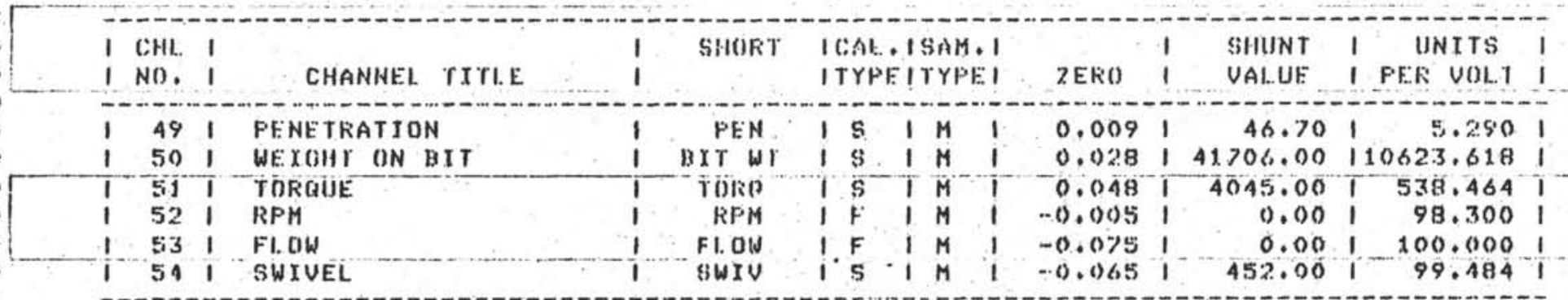

TEST \#3

PAGE: 2. UNXU, OF CALYF, S.D., DRUM \$1, WATER

$5 / 5 / 81 \quad 14: 20: 15$

SY:DRI.. IAAN, DAT ; 1

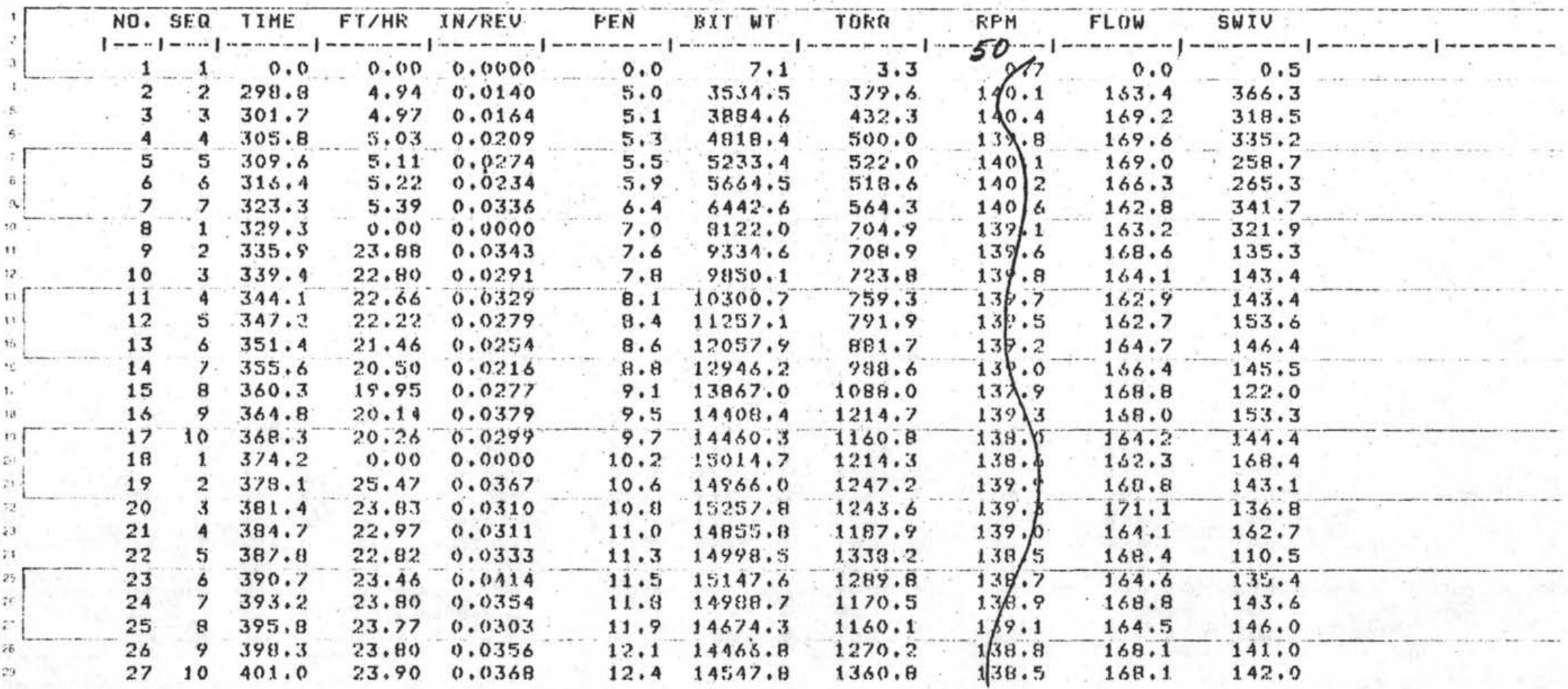




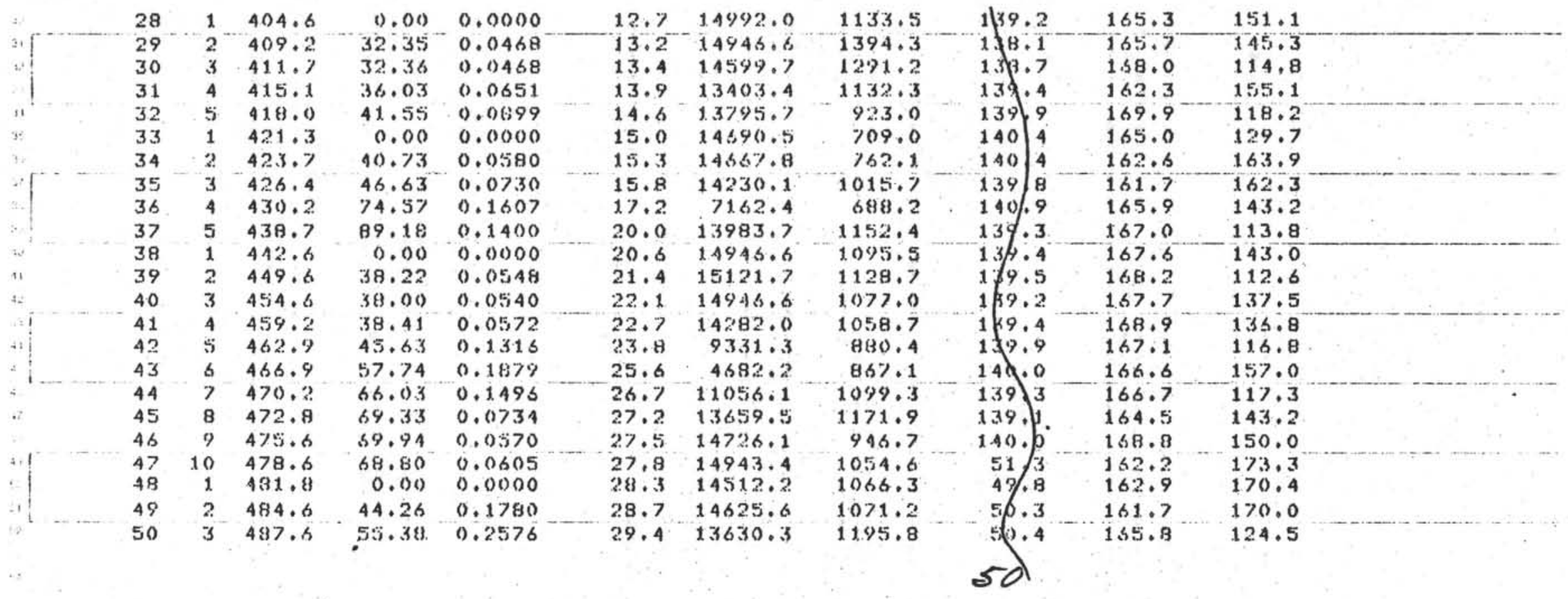

\$ิ宀

PAGE 3 LUIIU, OF CAL.IF.,S.D.,DRIJI \#1, WATER

$5 / 5 / 81 \quad 14: 20: 15$

SY:DRL.MAN. JAT 1

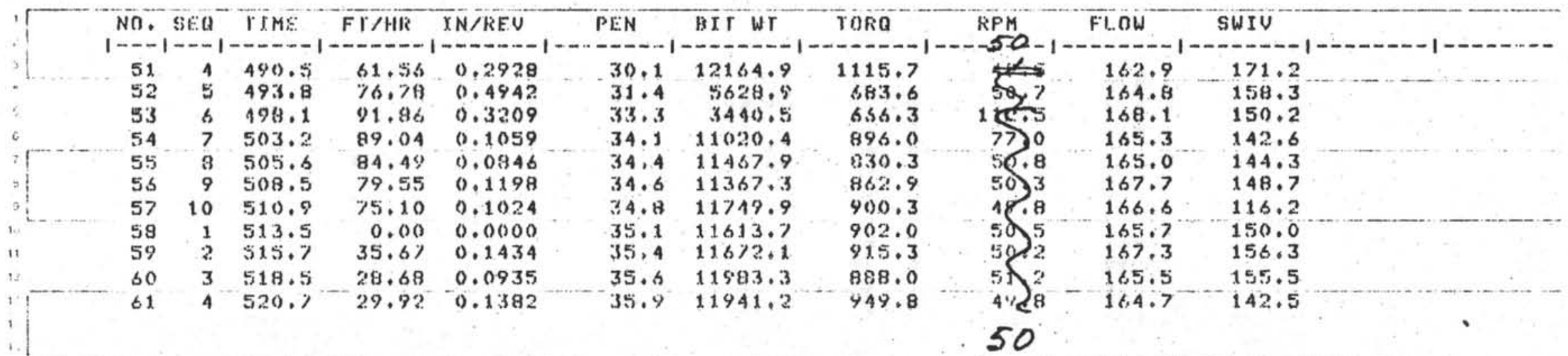

** CIIECK OUTPUT TO SEE IF IT IS OK **

PRINT GPTIONS ARE:

$C R=$ PRXNT MAHUAL. DASTAO

$50=$ PRXMT QUICK DATA;

$99=$ EXIT PRINT ROUTINE.

PRINT OPTION = 


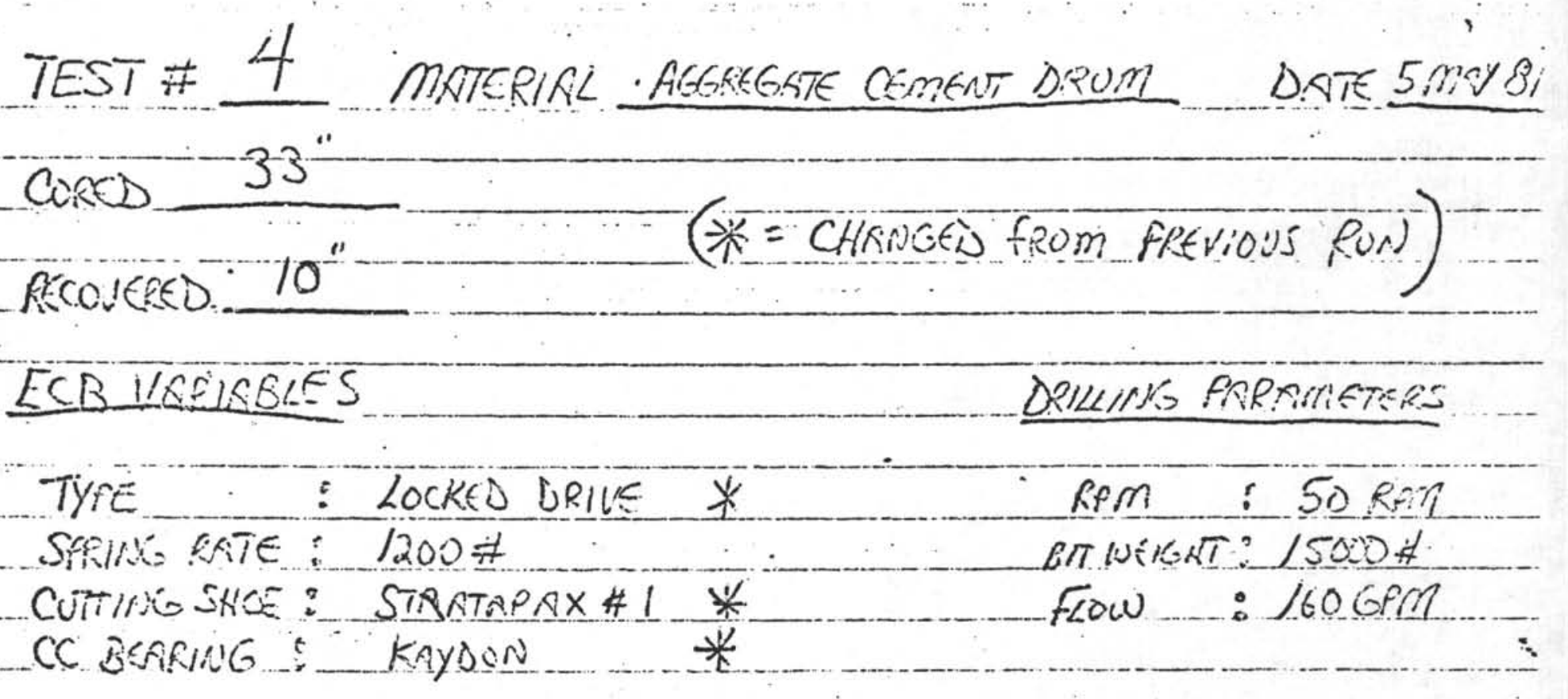

SUmmaky

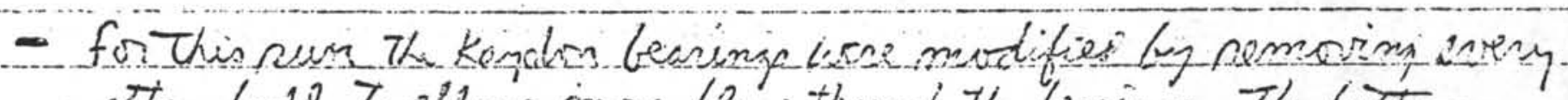

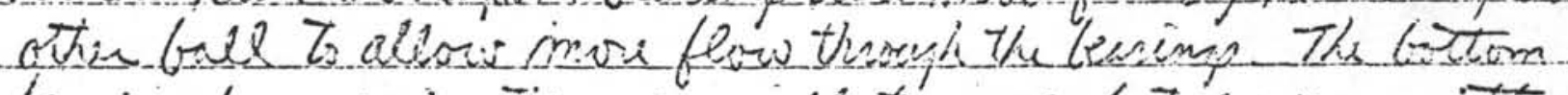

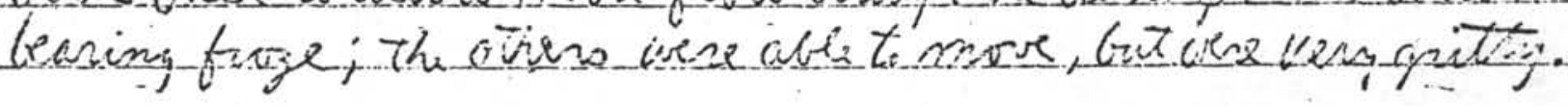

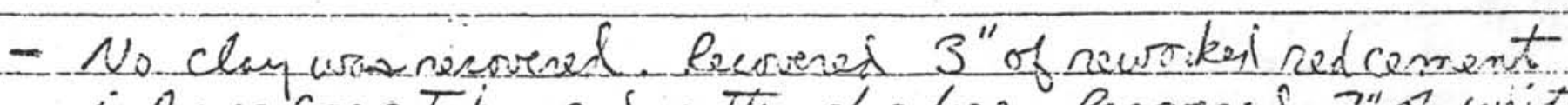

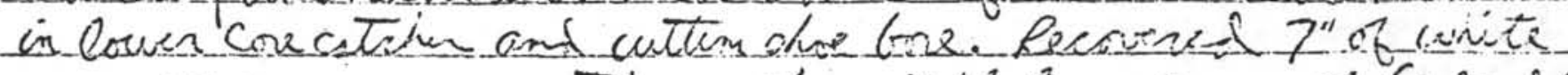

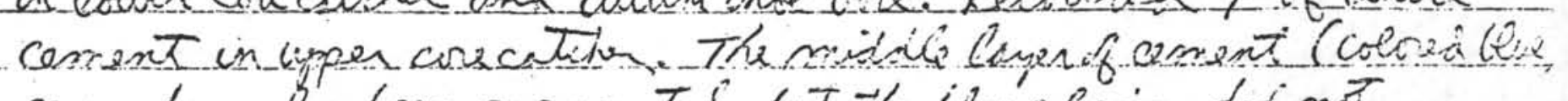

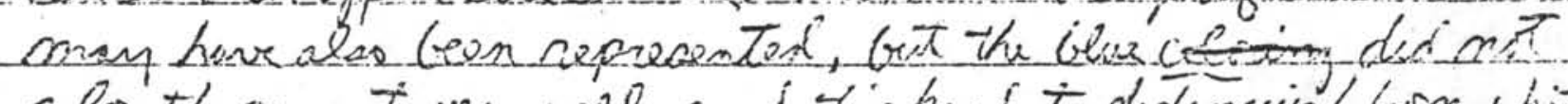

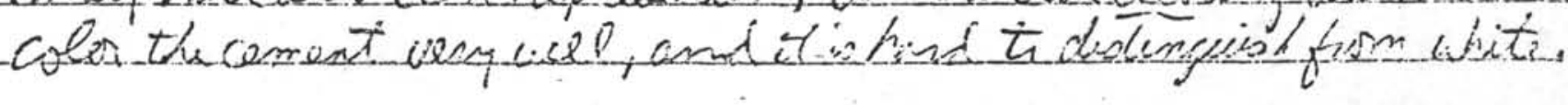

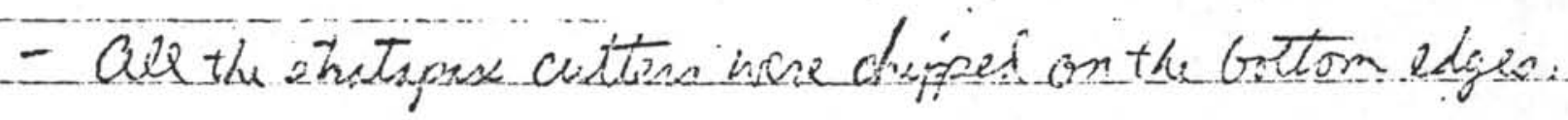

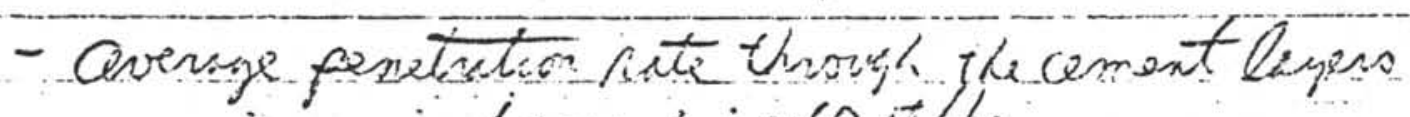
Lamen $i: 60 \mathrm{HJ} / \mathrm{h}$ Linen $2=526 / / h$ Liman $3: 0456 t / 4$

$-63-$ 


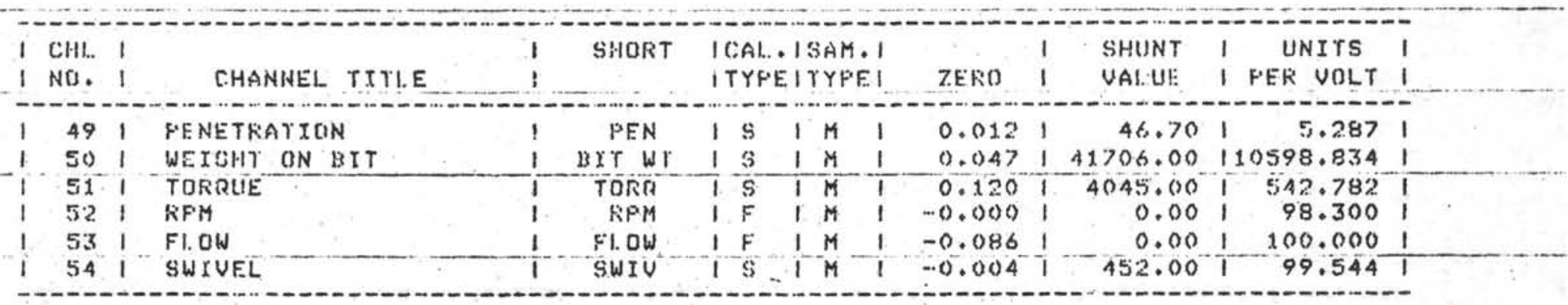

PAGE. 2 UNIV. OF CALIF. S.D., DRUH \$2.WATER

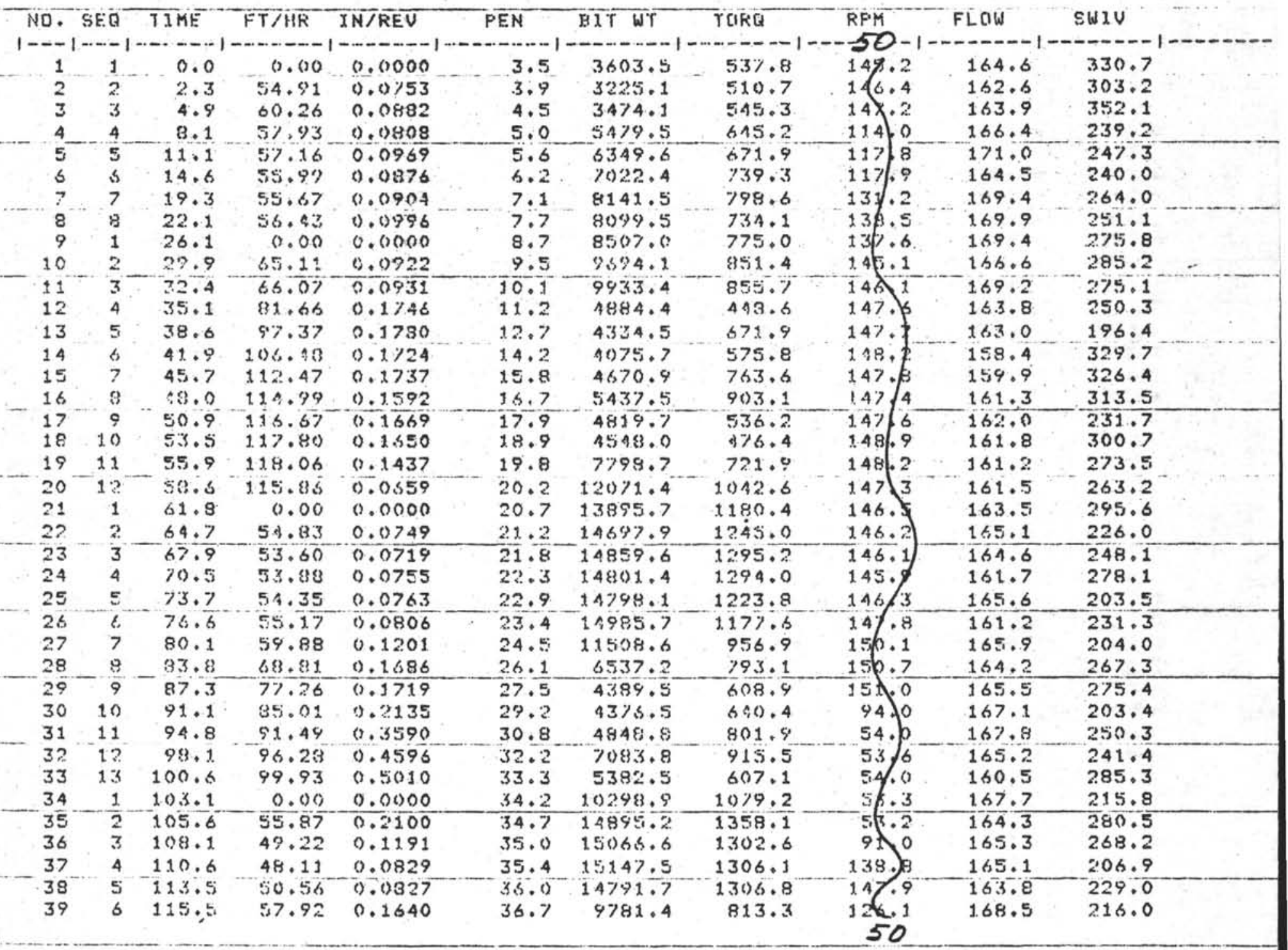


TEST \# 5 MNTERIRL MWNEGREGRTE CEMENT DRUM DATE 6 MRYB

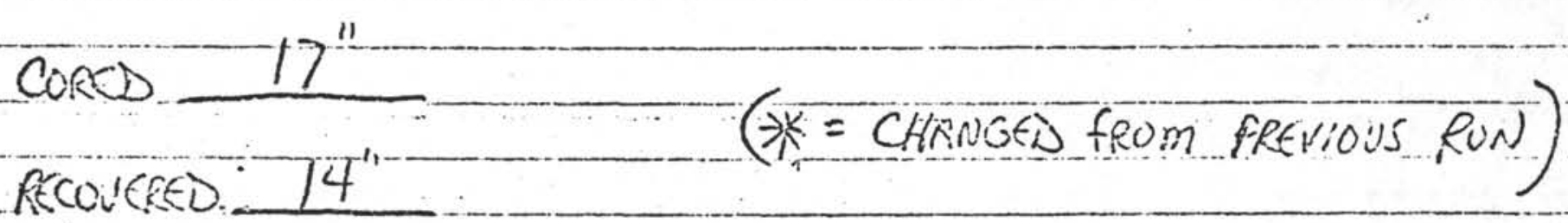

ECB VIAOISBIES

DEMUNG FR RIIAETES:

TYFE $:$ LOCKED DRIVE

Rem $: 50$ Rem

SFRIS KATE: 1200 \#

ERT We'l6 IT: 15000 \#

CUTTIPO SHE: CARGIDE $X$

Frow: $: 1606 \%$

CC BSFRNG: CUSTOM $X$

SUMmREY

- for this tact The fingen of th cre cottlen anes nemoved

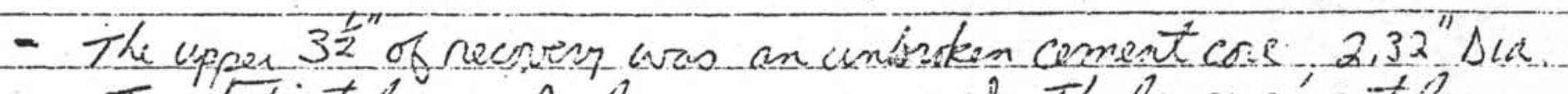

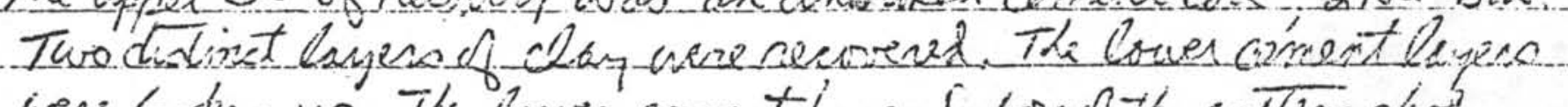

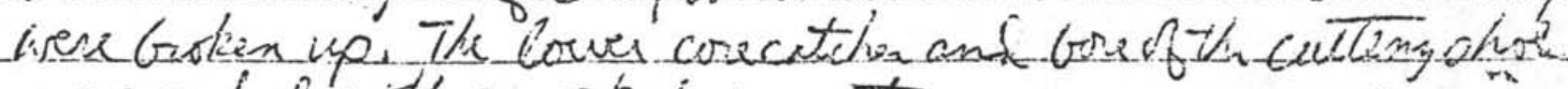
were packer wieth reurikesi cement.

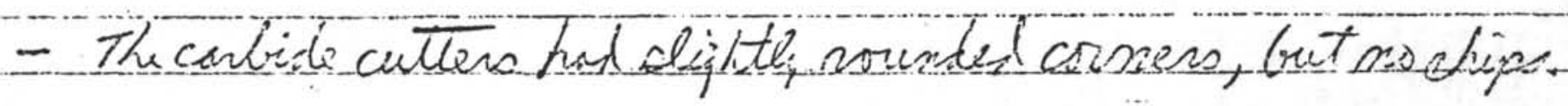

- The custom beavingo forze

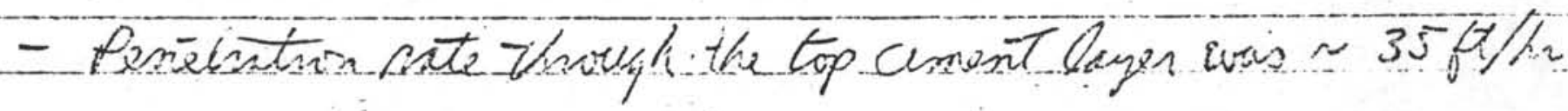

- Tappens that the cuttemg ahoe co not trimming thene.

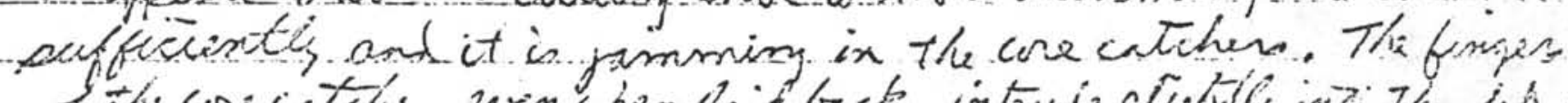

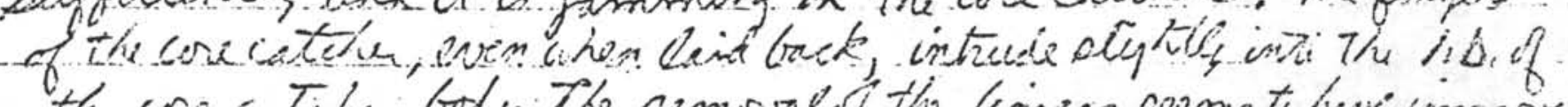

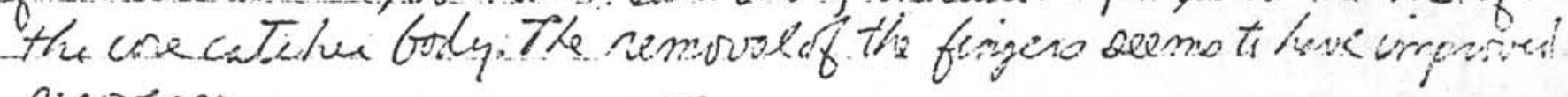
recosens.

$-65-$ 
A/D CMAHHEL. DATA TABLE

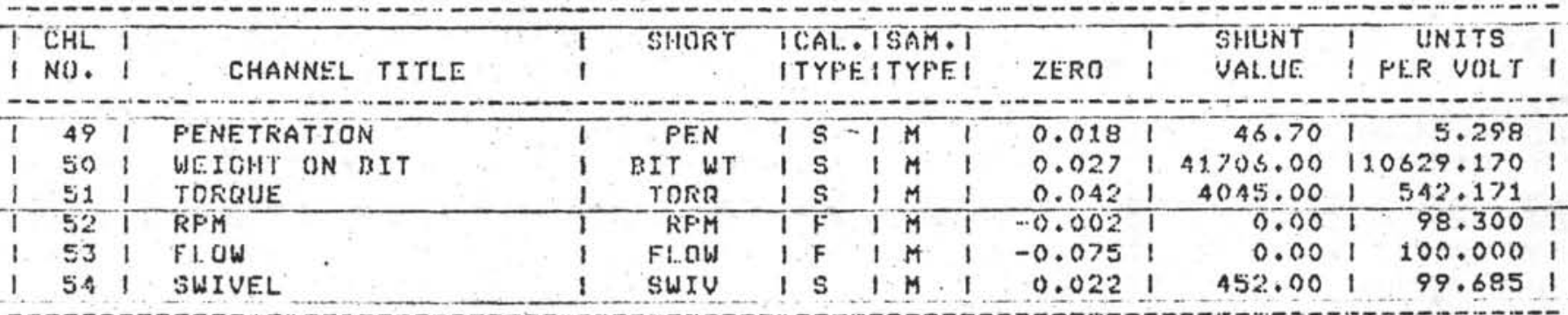

PAGE 2. UNXV. UF CALTF., S. D, DRUM \&3, WATER

$5 / 6 / 8108: 59: 15$

SY:BRL.MAN,DAT

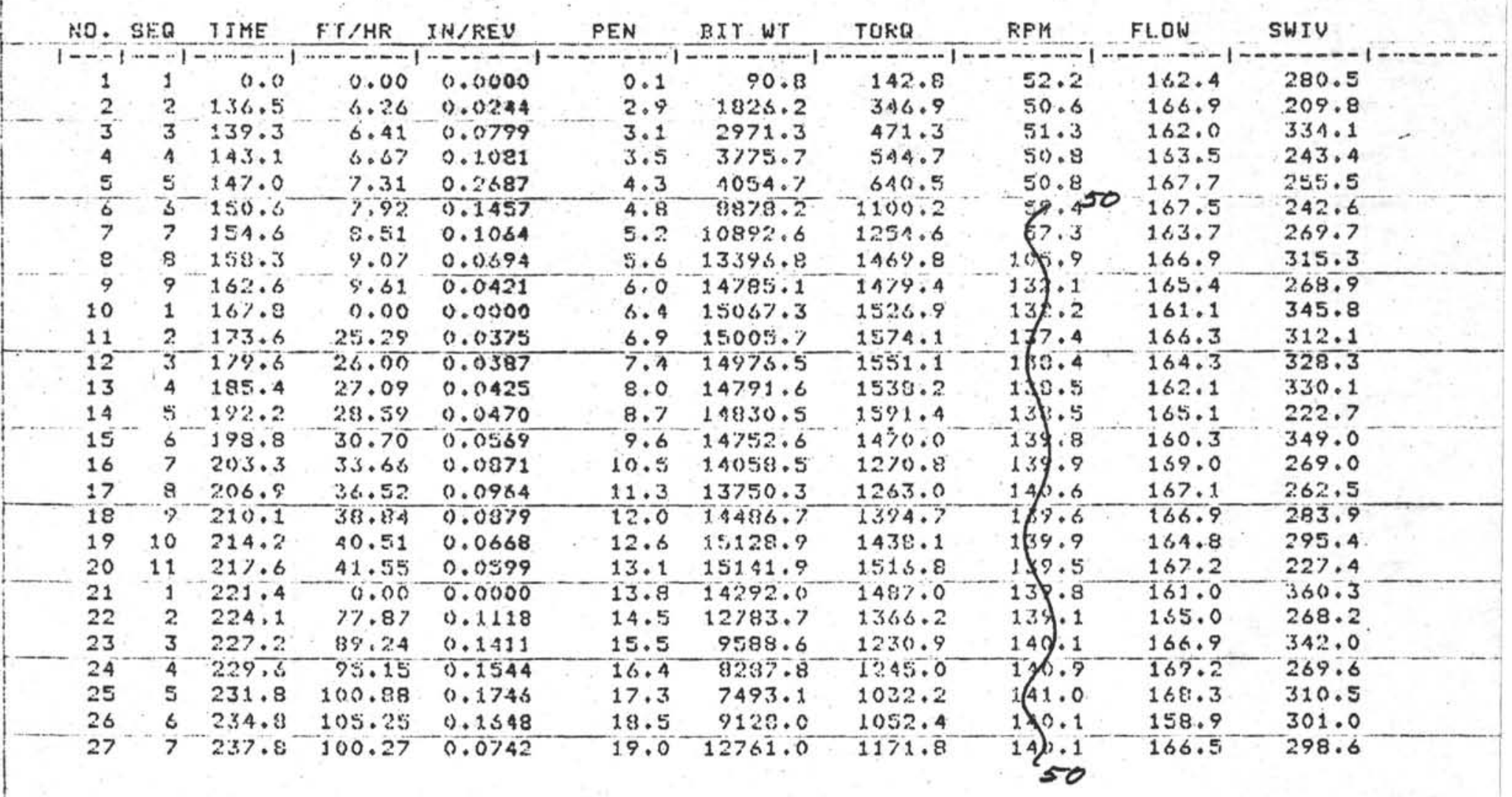

* CHECK OUTPUT TO SEE IF IT IS OK **

FRINT OPTIUNS ARE:

$C R=$ PRINTT MANUAL NATA;

$50=$ PRINT RUICK LATA;

$99=$ FXIT PRINT REUTIME.

PRINT DFTION = 99 


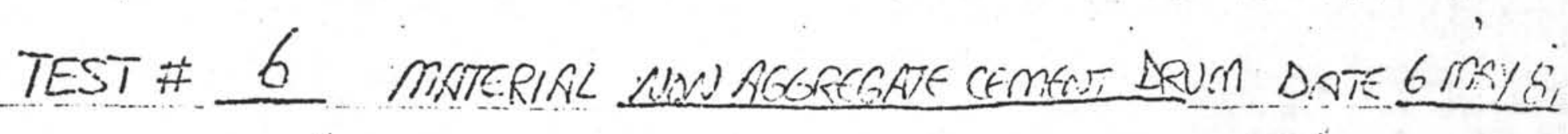

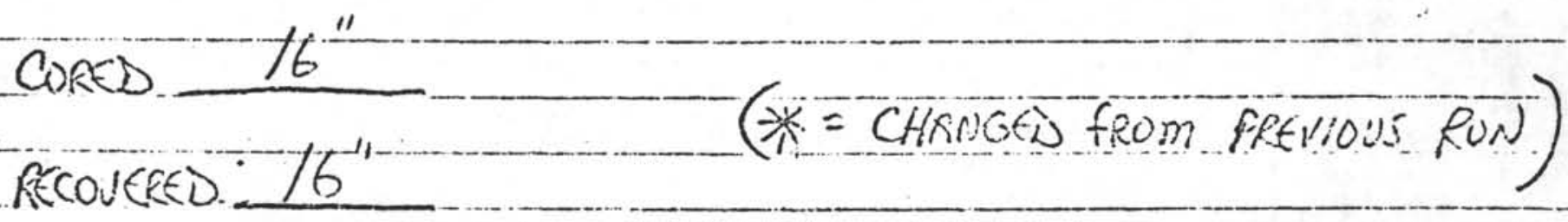

ECR VISEIRBLES

DXMNNG PAPNMETEE

TyfE.

LoCKED DRIVE

Rfm $\div 50 \mathrm{Rm}$

SFEIU, ESTE: 1200\#

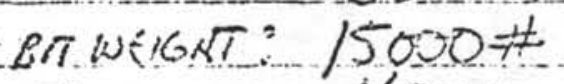

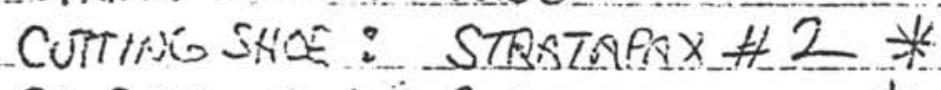

Flow: $: 1606 \mathrm{~m}$

CC B̈ERNG : Custom *

Summery

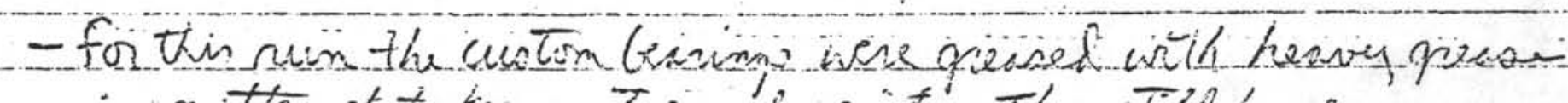

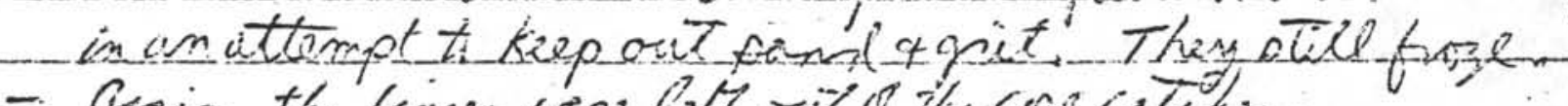

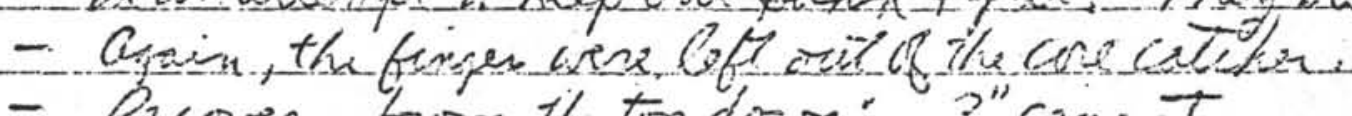

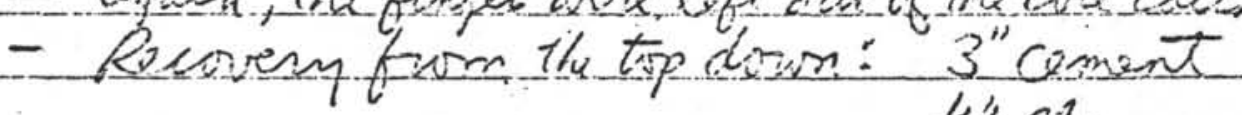

$$
\begin{aligned}
& \text { " "Cley } \\
& \text { 2" cemment } \\
& -\frac{1}{2}{ }^{\prime \prime} \text { cement }
\end{aligned}
$$

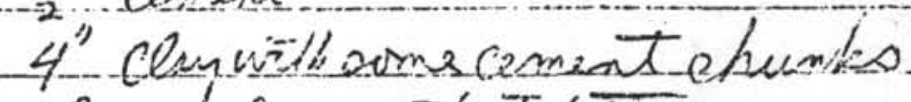
Reurs kess camint at Givirar

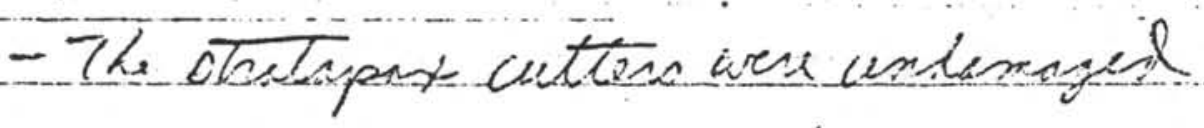

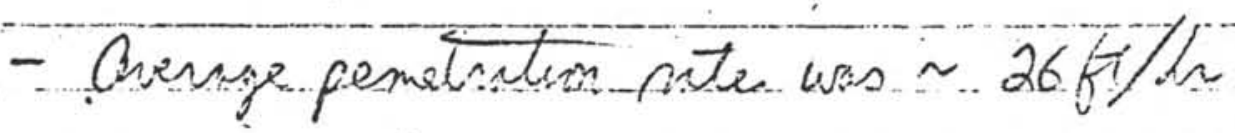

$-67-$ 


\begin{tabular}{|c|c|c|c|c|c|c|c|c|c|c|c|c|}
\hline $\begin{array}{l}\text { CHIL } \\
\text { NO. }\end{array}$ & $\begin{array}{l}1 \\
1\end{array}$ & CHANNEL IYTIE & 1 & SHokT & $\begin{array}{l}\text { TCAL } \\
\text { |TYI }\end{array}$ & $\begin{array}{l}1 \mathrm{~s} \\
\text { it }\end{array}$ & AM & & ZERO & i & $\begin{array}{l}\text { SHUNT } \\
\text { VALUE. }\end{array}$ & $\begin{array}{l}\text { UNITS } \\
\text { I FEK UOLI }\end{array}$ \\
\hline 49 & 1 & PENETRATION & i & FEN & Ts & & M & 1 & 08 & $\mathrm{~T}$ & 46.70 & 5.297 \\
\hline so & 1 & WEICHI ON BIT & 1 & BXT WT & 15 & 1 & M & 1 & 0.050 & 1 & 41705.00 & 111033.961 \\
\hline 51 & 1 & TORQUE. & 1 & TORR & I 5 & 1 & M & i & 0.029 & 1 & 4045.00 & 545.075 \\
\hline 52 & 1 & KPM & $\mathrm{T}$ & KFM & $\mathrm{TF}$ & $T$ & $M$ & 1 & $-0.00 \overline{6}$ & T & 0.00 & 98.300 \\
\hline 53 & 1 & FLOW & 1 & FLOU & I F & 1 & M & 1 & $-0.0 \% 1$ & 1 & 0.00 & 100.000 \\
\hline 54 & 1 & SWIUEL & 1 & SWIV & is & 1 & M & I & 0.033 & I & 452.00 & 100.116 \\
\hline
\end{tabular}

\begin{tabular}{|c|c|c|c|c|c|c|c|c|c|c|}
\hline No. & $E Q$ & IIME & $F T / H R$ & XN/KEV & PEN & BIT WT & TORQ & RPM & FL.OW & sWIV. \\
\hline 1 & 1 & 0.0 & 0.00 & 0.0000 & 0.0 & 3333.1 & 15300 & 50.7 & 163,3 & $286.9^{-1-}$ \\
\hline 2 & 2. & 116.0 & 28.66 & 0.0981 & 11.2 & 612.3 & 272.5 & 66.2 & 168.5 & $\begin{array}{l}280.8 \\
373.0\end{array}$ \\
\hline 3 & 3 & 185.4 & 29.33 & 0.0593 & 18.2 & 2585.5 & 425.0 & 140.8 & 171.4 & 338.1 \\
\hline 4 & 4 & 190.6 & 29.23 & c). 0222 & 18.5 & 3239.3 & 573.7 & 139.9 & 168.7 & 294.5 \\
\hline 5 & 5 & 195.7 & 29.01 & 0.0181 & 18.7 & 4703.6 & 8168.3 & 137.8 & 175.1 & 215.9 \\
\hline$\overline{6}$ & 6 & $20 \% .3$ & 28,93 & 0.0454 & $1 \% .9^{\circ}$ & 10118.5 & 1431.2 & $13 \% .3$ & 170.9 & 306.6 \\
\hline 7 & 1 & 214.5 & 0.00 & 0.0000 & 21.0 & 13633.6 & 1673.9 & +36.8 & 168.4 & 356.8 \\
\hline 8 & 2 & 221.3 & 105.51 & 0.1525 & 23.3 & 5918.2 & 873.3 & 140.1 & 167.8 & 245.1 \\
\hline 9 & 3 & 225.0 & 114.03 & 0.1885 & 25.0 & 4047.0 & 780.0 & 140.9 & 174.7 & 227.0 \\
\hline 10 & 4 & 229.5 & 105.56 & 0.1084 & 26.1 & 15344.2 & 1638.6 & 136.0 & 175.9 & 237.3 \\
\hline 11 & 1 & 232.9 & 0.00 & 0.0000 & 26.6 & 15388.0 & 1654.3 & 137.9 & 175.0 & 328.6 \\
\hline 12 & 2 & 236.4 & 29.74 & 0.0613 & 25.9 & $1533 \% .5$ & 1684.1 & 55.4 & 171.2 & 316.7 \\
\hline 13 & 3 & 240.0 & 29.32 & 0.1093 & 27.2 & 15381.3 & 1960.2 & 49.2 & 172.8 & 313.3 \\
\hline 14 & 4 & 243.4 & 30.41 & 0.1347 & 27.6 & $153 \leqslant 1.1$ & 1839,9 & 49.4 & 171.6 & 375.9 \\
\hline 15 & 5 & $247.1^{-}$ & 31.54 & 0.1404 & 28.1 & 14866.1 & 1898.5 & 49.7 & $1>1.4$ & 279.8 \\
\hline 16 & s & $2 \leqslant 1.2$ & 39.1 A & 0.2981 & 29.1 & 10923.0 & 1591.4 & 50.0 & 175.5 & 273.9 \\
\hline 17 & $?$ & 255.9 & 49.79 & 0.3891 & 30.6 & 8983.4 & 1244.9 & 50.0 & 167.4 & 365.8 \\
\hline 18 & 3 & 260.8 & $5 \% .54$ & 6). 4055 & 32.2 & 11024.0 & 1340.6 & 50.4 & 169.3 & 378.7 \\
\hline 19 & 1 & 265.8 & 0.00 & 0.0000 & 33.2 & 14313.8 & 1293.5 & 49.5 & 169.1 & 284.6 \\
\hline 20 & 2 & $26 \% .8$ & 43.46 & 0.1746 & 33.8 & 14458.6 & 1243.3 & 49.7 & 169.7 & 301.9 \\
\hline 21 & $3^{-}$ & 272.9 & 43.41 & 0.1727 & 34.2 & 14475.5 & 1267.4 & 50.8 & 170.3 & 310.5 \\
\hline 22 & 4 & $2 \% 6.0$ & 44.22 & 0.1340 & 34.7 & 14132.0 & 1211.3 & 50.4 & 172.3 & 3.32 .2 \\
\hline 23 & 5 & 279.1 & 44.94 & 0.1063 & 35.2 & 14297.0 & 1324.4 & 126.6 & 171.9 & 314.7 \\
\hline 24 & 5 & $232 . \%$ & 49.75 & 0.1650 & 36.1 & 9345.4 & 772.5 & 53.8 & 172.4 & $29 \overline{6} .9$ \\
\hline 25 & 7 & 286.1 & 51.53 & 0.1927 & 36.6 & 2858.3 & 381.9 & 51.0 & 169.6 & 301.4 \\
\hline 26 & 3 & 294.2 & 40.54 & -0.0094 & 36.6 & 433.8 & 259.2 & 50.7 & 173.6 & 298.4 \\
\hline
\end{tabular}

* CHECK OUTPUT TO SEE IF XT XS OK **

PRINT OPTIONS ARE:

$C R=$ PRINT MANUIAL MATA;

$50=$ PRINT QUXCK DAIA;

$99=$ FXIT PRINT ROUTINE.

FRINT OPTIOH $=$ 
TEST 2 MATERISL AGGREGATE CEMEAT DRUM DATE GMUE $\cos \theta-33^{\prime \prime}$

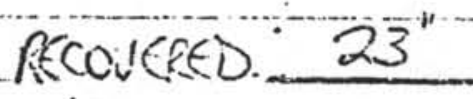

(* = CHFNG fROM fREVIOUS RON )

ECB VKEISBLES

DEUUNRS FNRAMETER

TYPE $\quad$ LOCKAS DRIIK

RfM 60 RPM $x^{\prime}$

SFEIN KATE: 1200 \#

ET WUKt: 8000 \# 掞

CUTHROSHE: CRRBIS *

FLow: $: 16069 m$

CC BSARING: CUSTOM

Summery

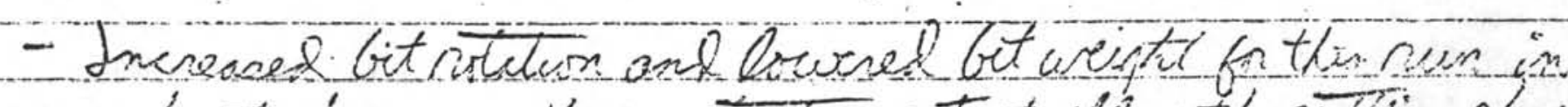

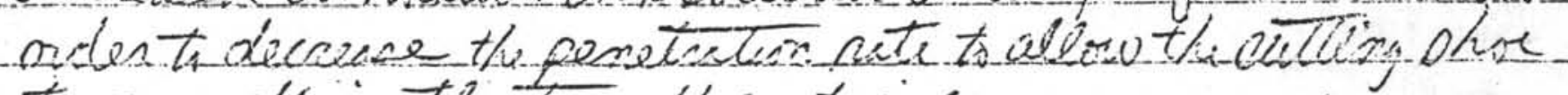

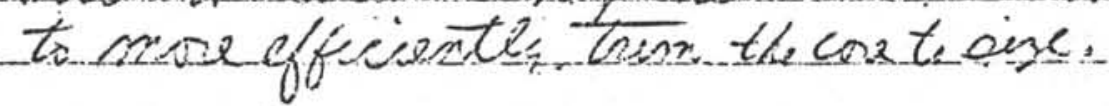

- Ovensge penetratem nate thount the coment laupes

Layes $1 ! \sim 66 \mathrm{ft} / \mathrm{h}$

Lamer $2: \sim 22.6 / \mathrm{h}$

Layes 3: 21 $\mathrm{Et} / \mathrm{M}$

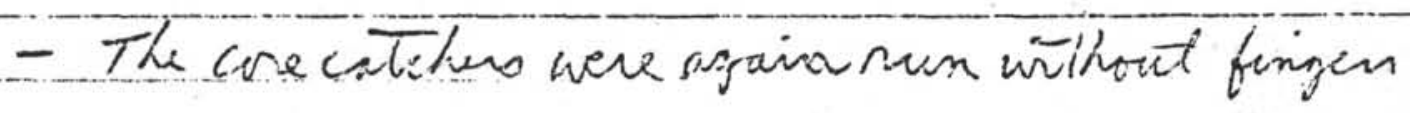

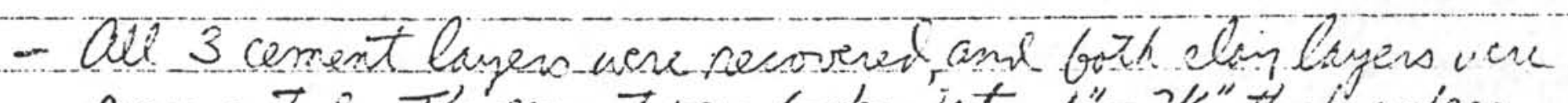

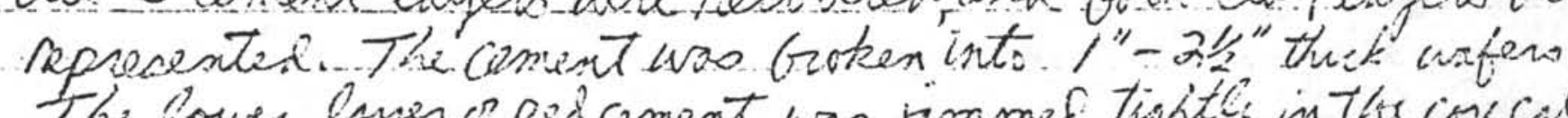

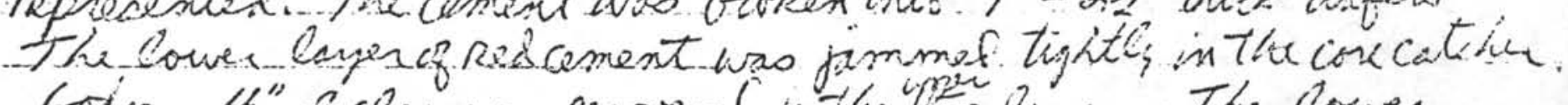

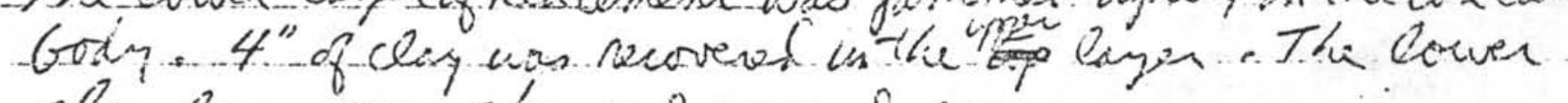

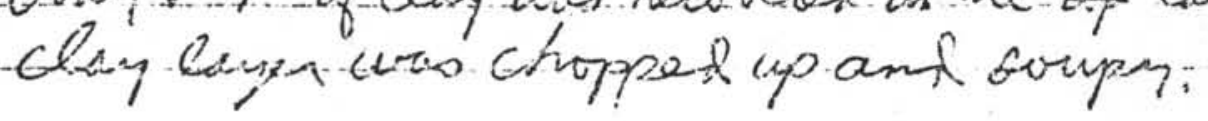

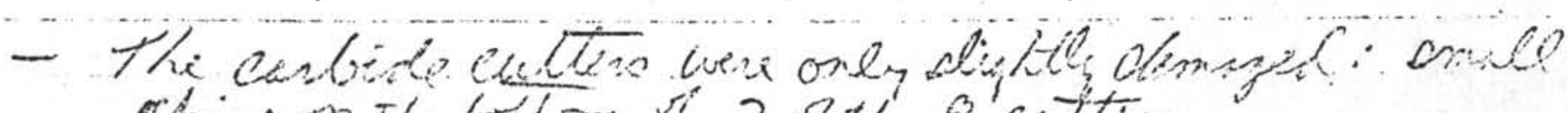
Whipd on the tow of 3 of the 8 cuitto.

$-69-$ 
A/D CHARIREL DATA TABLE

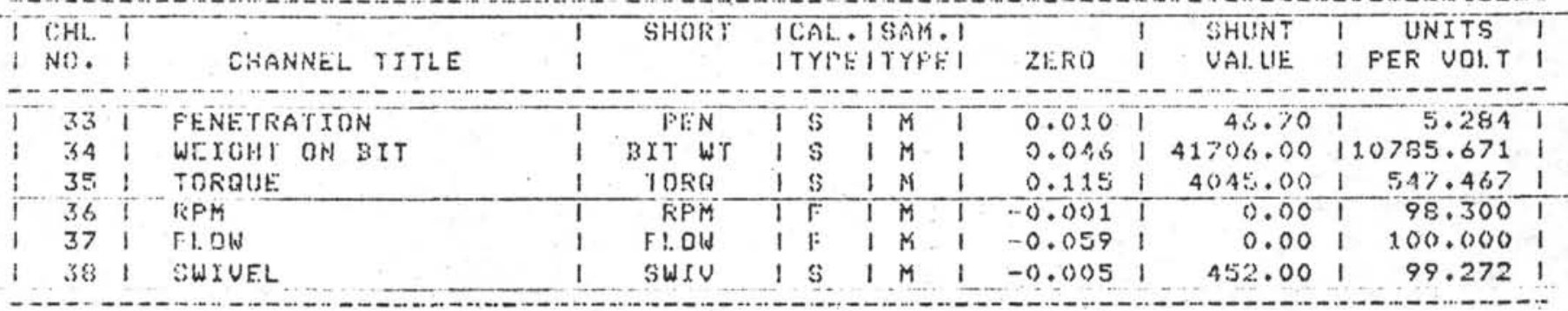

\section{TEST \#7}

PAGE 2 DFLIM $\$ 45 / 6 / 81$

$5 / 5 / 81 \quad 14: 47: 53$

SY: MRLMAN.DF

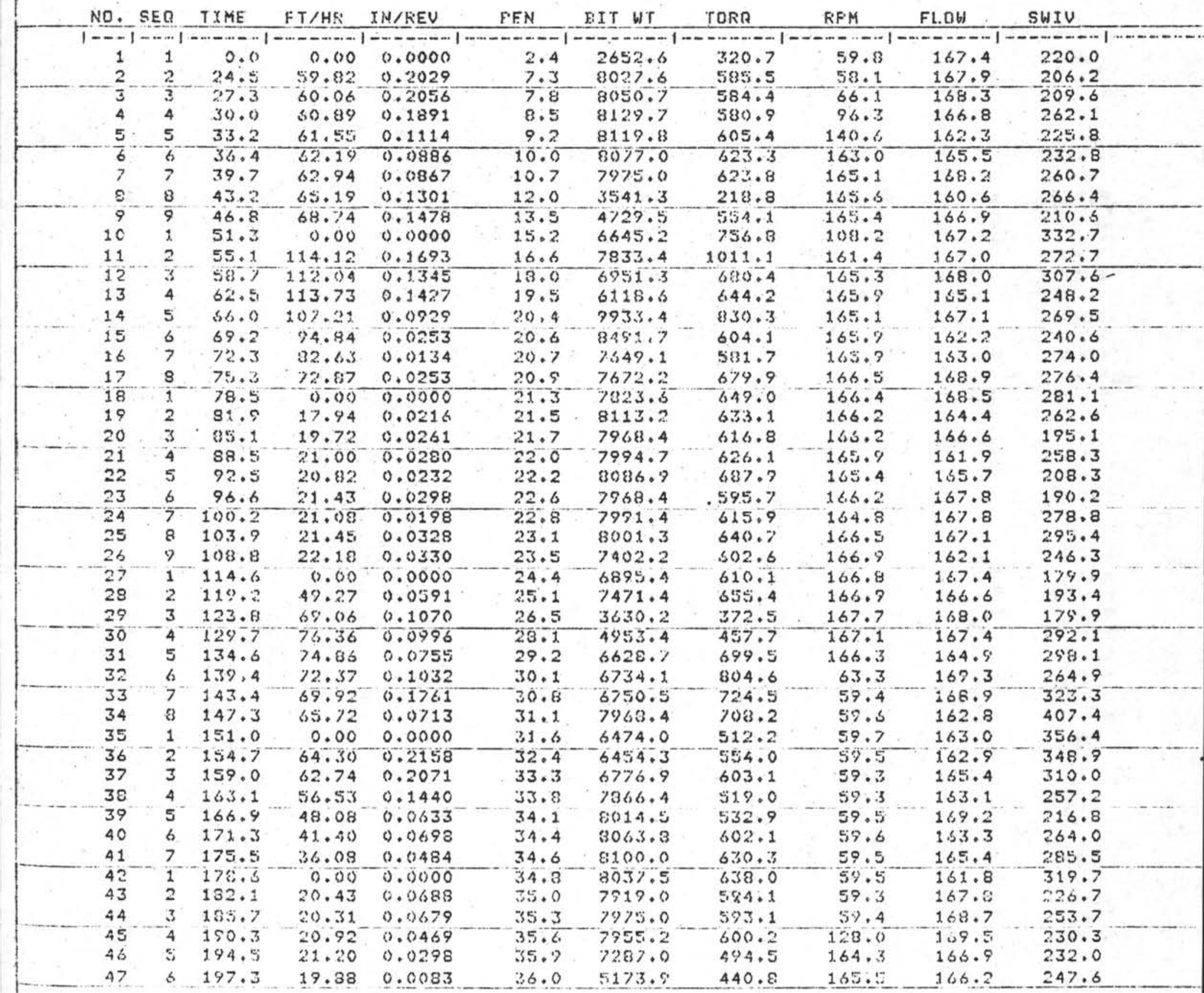




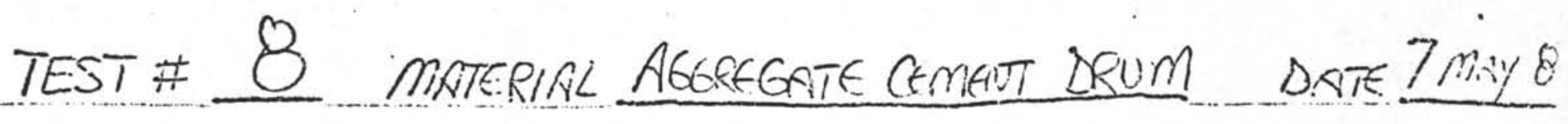

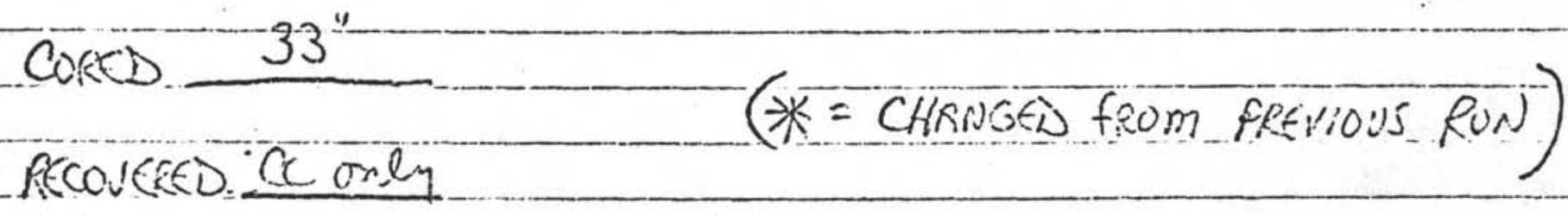

ECB ISEISBLES

DRMING ARPRIETERS

TYre : LoekED QRIVE

RPM $: 60 \mathrm{pPn}$

SFERE, RATE: 2400 \# $*$

ERTWElG LI: 8000 \#

CUTHR日 SHE: STRSARX-42*

Fow: $1606 \mathrm{~m}$

CC BSSRING: CUSTOM

SUMmRRY

- The core cother finses ciers machines down oo that they

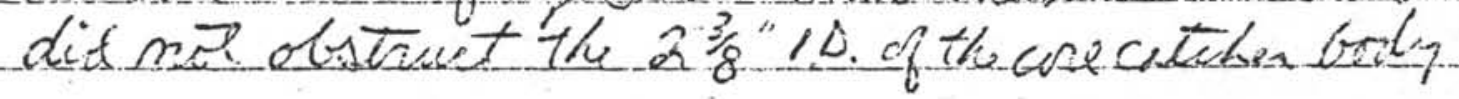

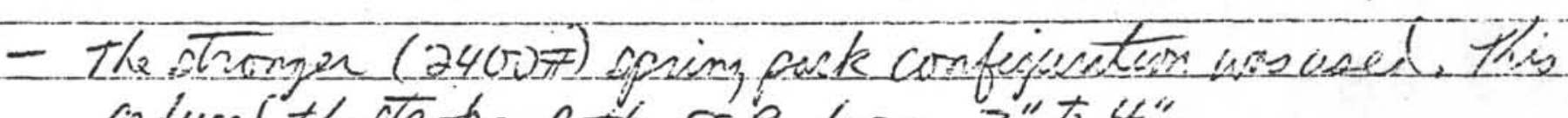
colused the dirate of the EC from 7 "t $\psi^{\prime \prime}$.

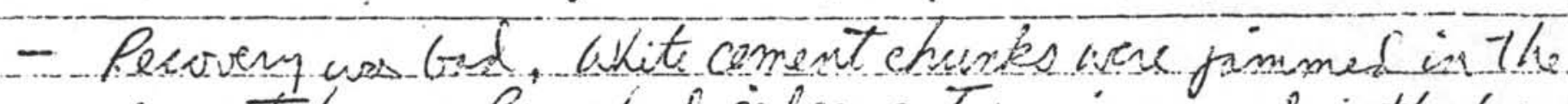

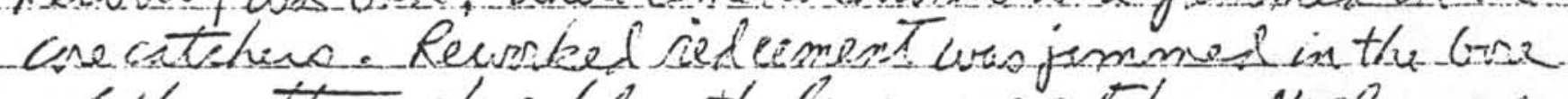

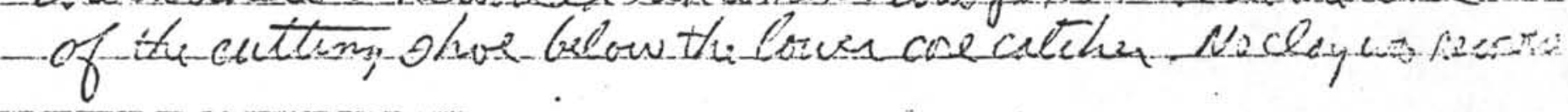

- The custrm bevings froge

- The Endapes cuttro were chiped.

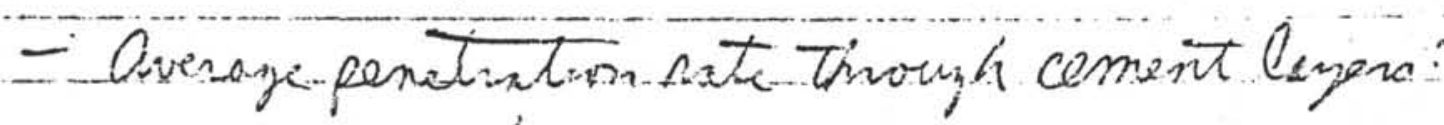

Laven $7=-63 \mathrm{fth}$

Layer 2: $356 \mathrm{GT} / \mathrm{m}$

Lagen $3=\sim 336 \mathrm{t} / \mathrm{h}$

$-71-$ 
$99=$ EXIT FIINT ROUTINE.

PRINT LIFTION =

RUIIEER OF LOPJES $=1$

OUTFUT OFTIONS AIE:

1 - PRTNIOUT ON TERMINAL;

2 = FRTNTOUT ON I. INI FRINTIR.

OUTPUT DIFTIOH $=1$

FALE 1 LRUI $\$ 55 / 7 / 81$

$5 / 7 / 31$ 09:30:05

SY: WILLMAN , MAT ; 1

a/D C:HaNiNEL. Data Table

\begin{tabular}{|c|c|c|c|c|c|c|c|c|c|c|c|c|c|c|}
\hline \multirow{2}{*}{$\begin{array}{l}\text { CHI. } \\
\text { NO. }\end{array}$} & & \multirow{2}{*}{ CHANNEI. IXTIE } & \multirow{2}{*}{$\frac{1}{1}$} & \multirow{2}{*}{ SHOR } & \multicolumn{6}{|c|}{ ICIAL. ISAM. I } & \multirow{2}{*}{1} & \multirow{2}{*}{$\begin{array}{l}\text { SHUNT } \\
\text { UALLEE }\end{array}$} & 1 UNITS & 1 \\
\hline & & & & & & YI: & 1 & $Y 1:$ & & 2EKOI) & & & I FER VUL. T & 1 \\
\hline 33 & 1 & FEINETRAT IOH & 1 & PIIN & 1 & ; & 1 & $M$ & 1 & 0.004 & I & 46.70 & $5.27 \%$ & 1 \\
\hline 34 & 1 & WCXGST UN BIT & 1 & BIT WI & $\mathrm{i}$ & 8 & 1 & $M$ & 1 & 0.004 & i & 41706.00 & 110774.515 & I \\
\hline 35 & 1 & TORQUUË & 1 & TORE & 1 & $\mathrm{~s}$ & 1 & M & 1 & 0.109 & I & 4045.00 & 541.569 & 1 \\
\hline 36 & $i$ & $\mathrm{RF} \cdot \mathrm{H}$ & 1 & $R F M$ & 1 & $F$ & 1 & $M$ & 1 & $\cdots 0.005$ & I & 0.00 & 98.300 & i \\
\hline 37 & ; & F.OW & $i$ & F. C.1J & 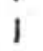 & $1:$ & 1 & $M$ & 1 & -0.083 .3 & 1 & 0.00 & 100.000 & i \\
\hline 30 & $!$ & SWIVEL & 1 & Singe & 1 & $s$ & 1 & M & 1 & -10.102 & 1 & 452.00 & 99.614 & 1 \\
\hline
\end{tabular}




\section{TEST \# B}

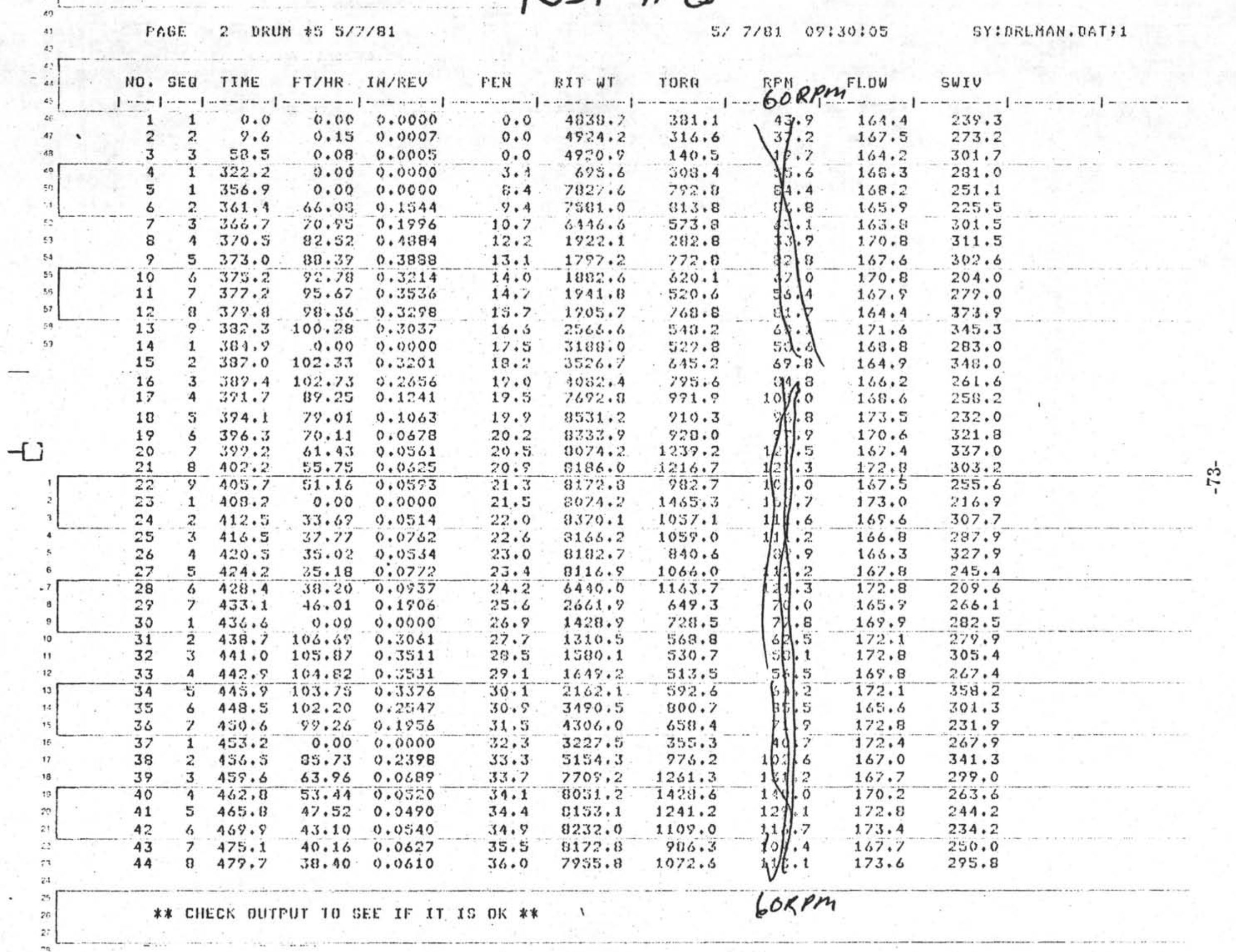


TEST \# 9 MNTERIAL AGGREGATE CEMENT BRUM DATE 7 MYYOI CORED $33^{4}$

$R$ CON $\in E \in D$. $15^{\prime \prime}$

$$
\text { (*) CHFofis from fRerious fors) }
$$

ECB VXEISEIES

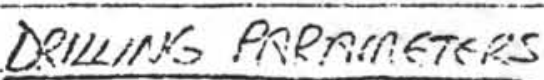

TYFE LOCKED DRIVE

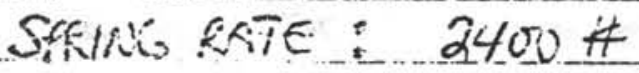

RPM : GO RPM

CUTHISONAE: CARRLA *

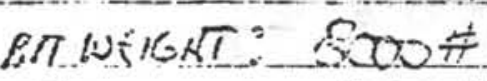

CC BSARIAG

Flow: $16060 \mathrm{M}$

SUMmRRY

- For this ruin, nocre catchers arese west at ald.

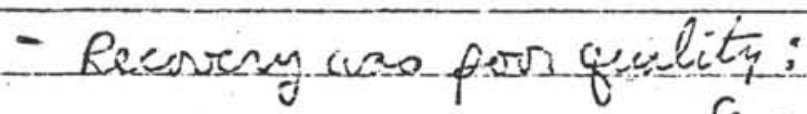

Seusnal / thuck anfens cioment at tion.

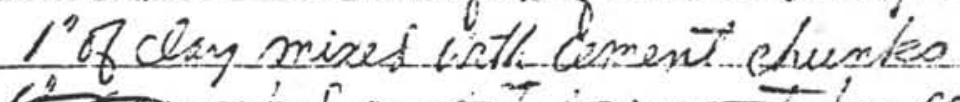

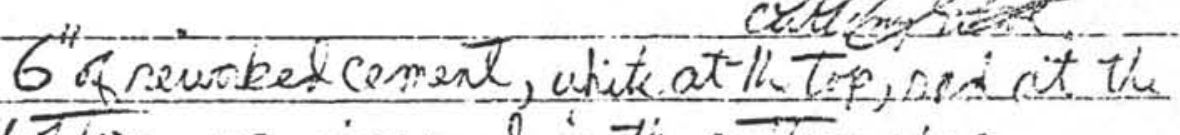

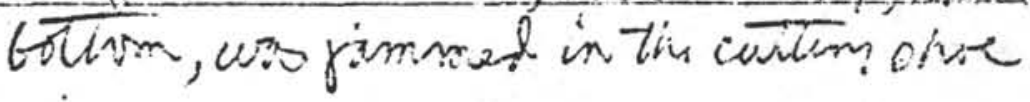

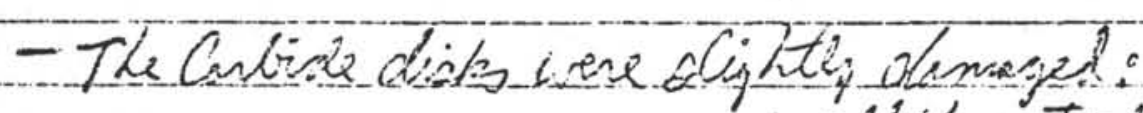

- alt the cuteire cutter cuese chipped slighter

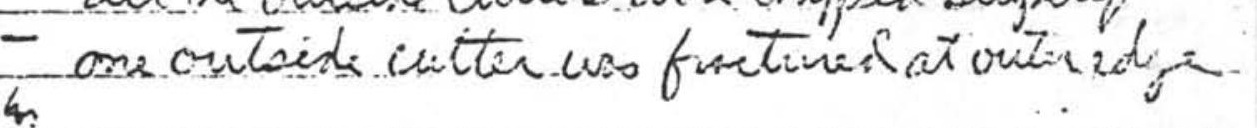

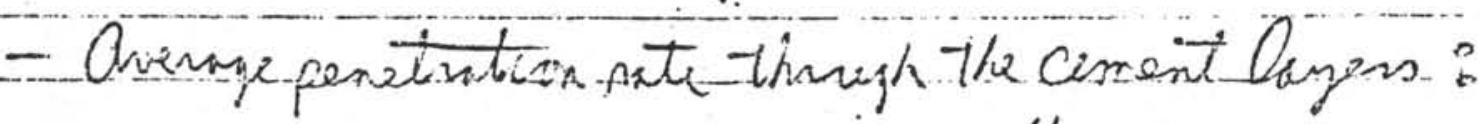

Layen $1,576 t / 2$

Layges $2 \sim 38 \mathrm{ft} / \mathrm{h}$

Lagen $3 \sim 45 \mathrm{kt} / \mathrm{h}$ 
AJD CHARINEL. DATA TABLE

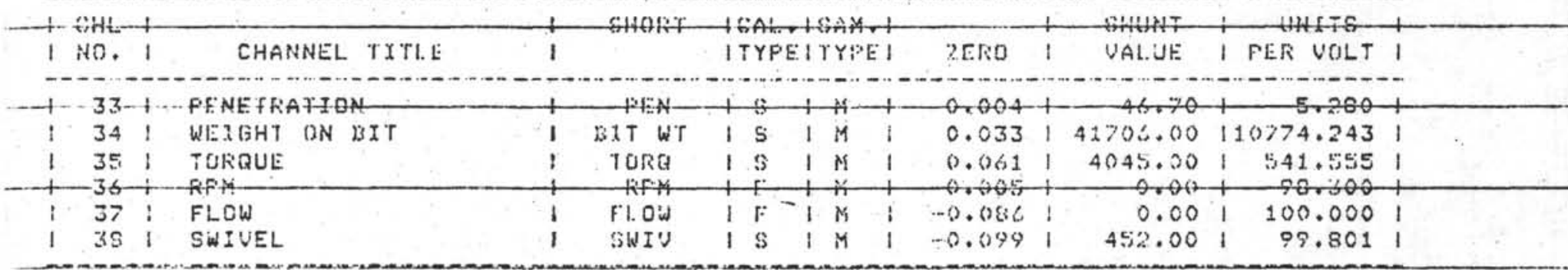

\section{TEST \# 9}

PAGE 2 DRUM $+65 / \% / 81$

5/ 7/31 11:16:46

SY: IIPLMAN . IIAT GORPM

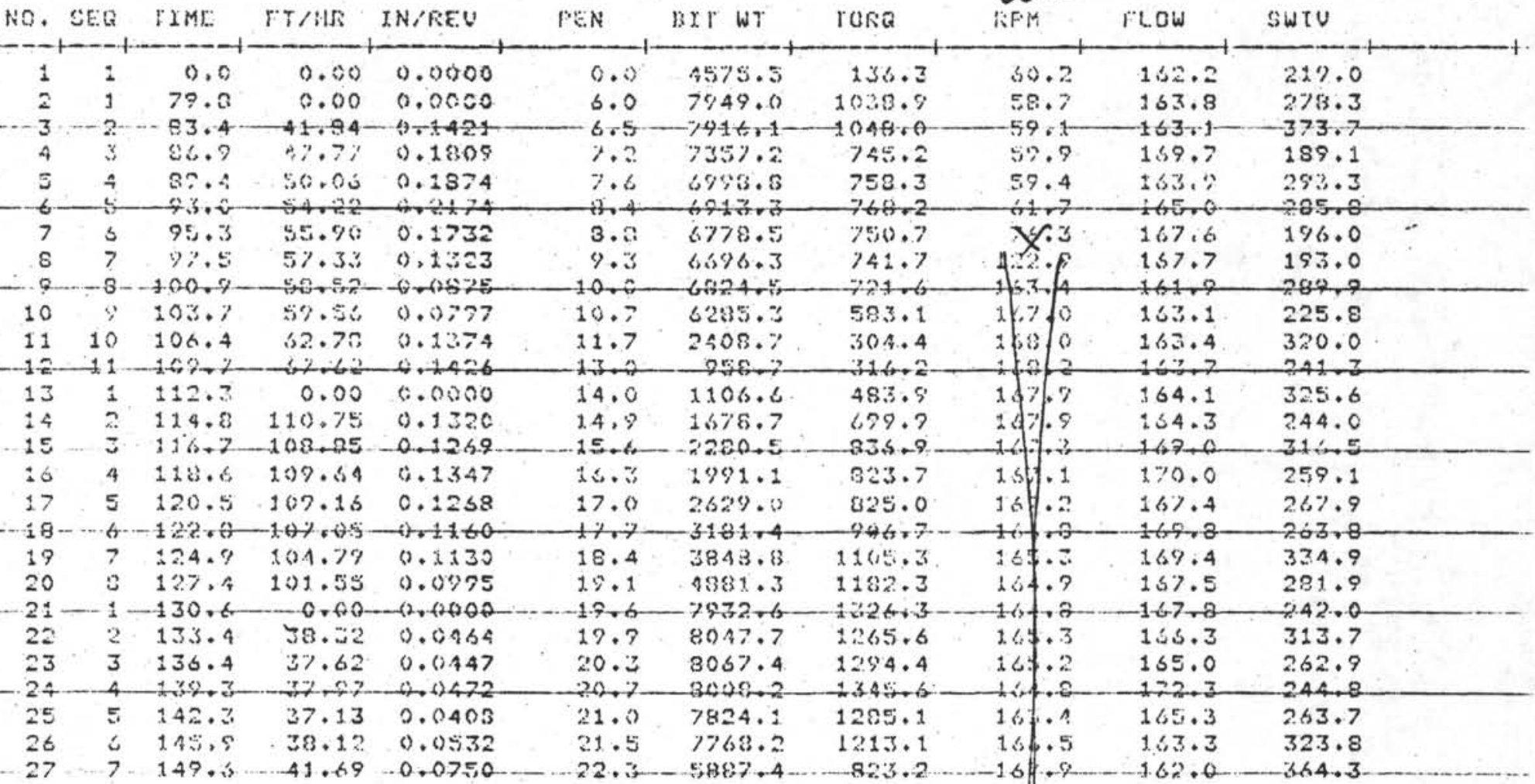




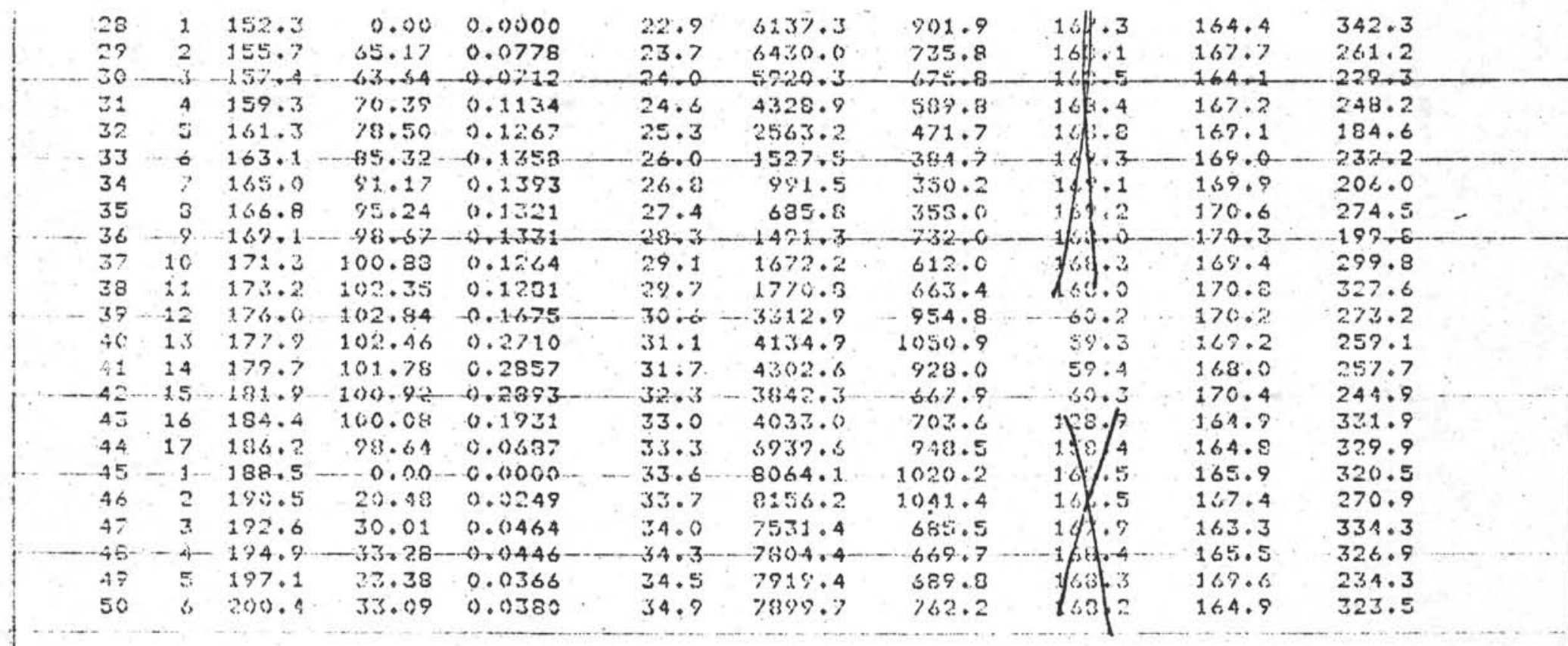

PAGE 3 DKLIM $\neq 6 \quad 5 / 7 / 31$

$5 / 7 / 81 \quad 11: 16: 46$

SY:DRLMAN,DAT

\begin{tabular}{|c|c|c|c|c|c|c|c|c|c|c|}
\hline NO. & $3[Q$ & IXME & rrits & IN/REV & PEN & BrT Wr & rORe & $R F M$ & FLOW & sWIV \\
\hline $5:$ & 7 & 203.2 & 34.19 & 0.0545 & 35.3 & 7252.0 & $727 \cdot 5$ & $\begin{array}{l}5.2 \\
602 p m .\end{array}$ & 165.4 & 305.8 \\
\hline
\end{tabular}

** CHECK DUTPUT TO SLEE Af IT IS CK **

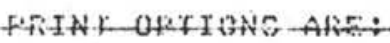

$E R=$ FRINT MANUSAL DATA;

$5 O=$ PIXNT GUICK DATA;

$\nabla Q=E X I T-P H I N T$ FIUHF-TAE.

IRIIT OFTION $=99$ 
TEST \# 10 MATERIRL. EASTILT

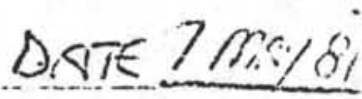

CoKED $22^{11-1}$

$R\left(C O U<\& \in D .22^{-4-}\right.$

( $*$ = CHNOGES from fREVIOUS RON)

ECBDERIABLS

DeMUNG PRPMARTERS

TYYE : LCCKED DRIE

SFRIN RATE: 2400 \#

CUTTWOSHOE: CARBLE

CC BERRG : CUSTOM $*$
RfM $: 40$ Rem

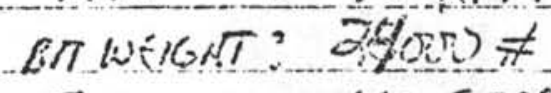

Flow: $16060 \%$

SUMmAKY

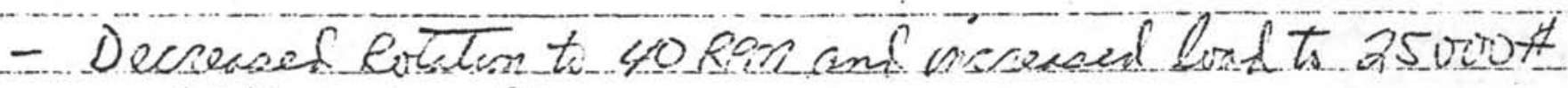
Todill the Goalt.

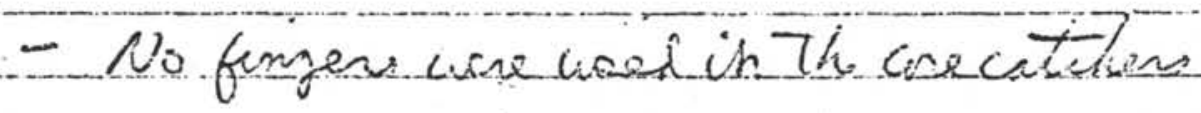

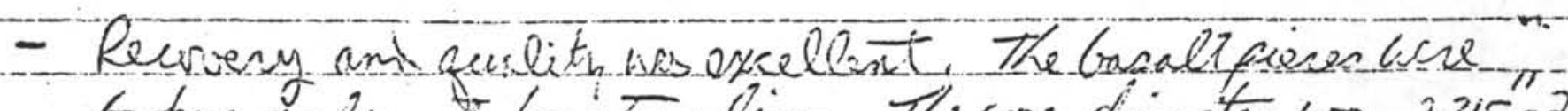

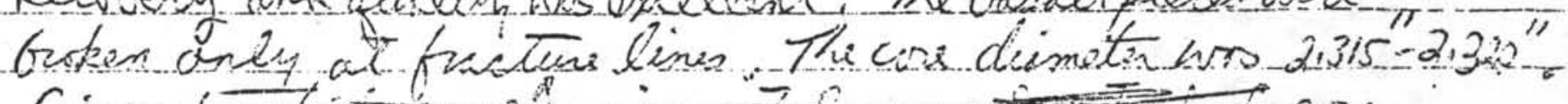
Thom

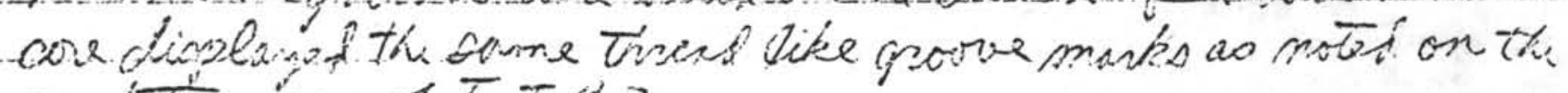

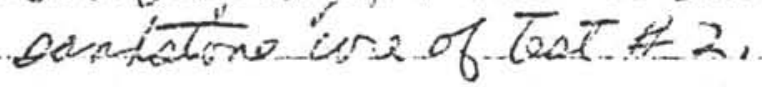

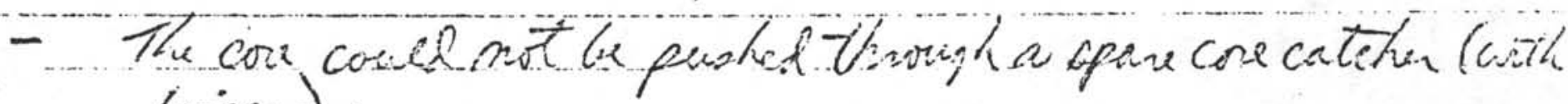
(finjes)

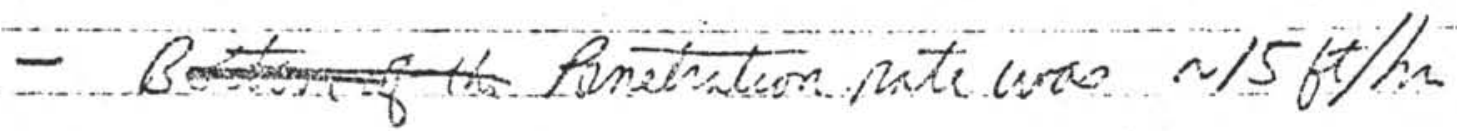

- No vicible wen on antide cutters

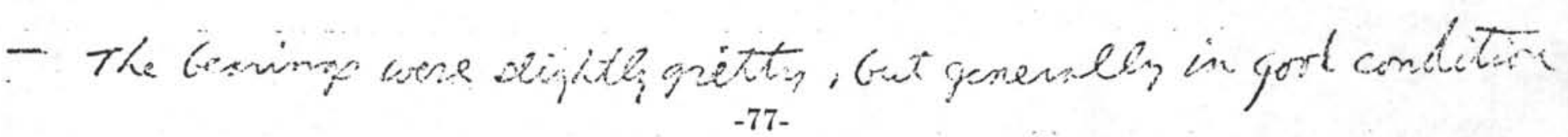


A/I CHANHEL. DATA TABLE

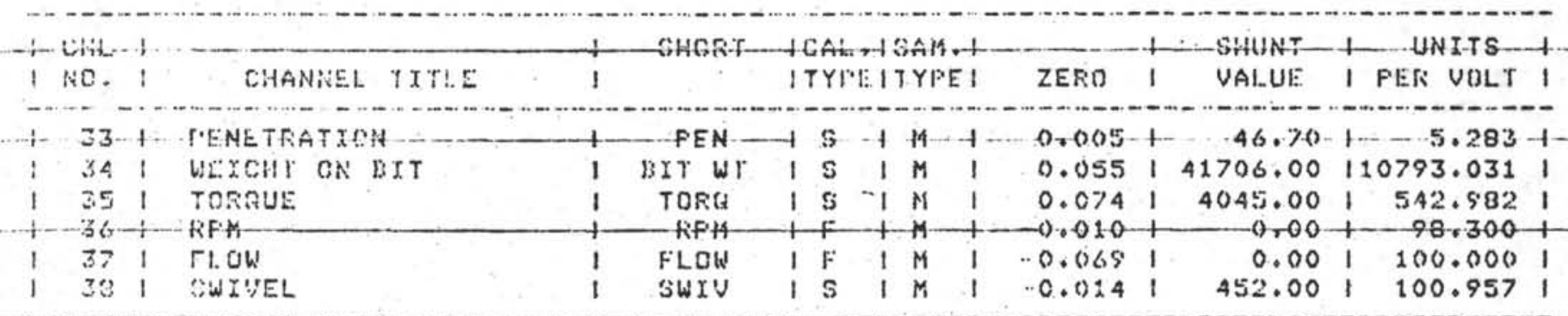

FAOE: 2 DASALT

TES का

SY: BRLMAN.DAT:

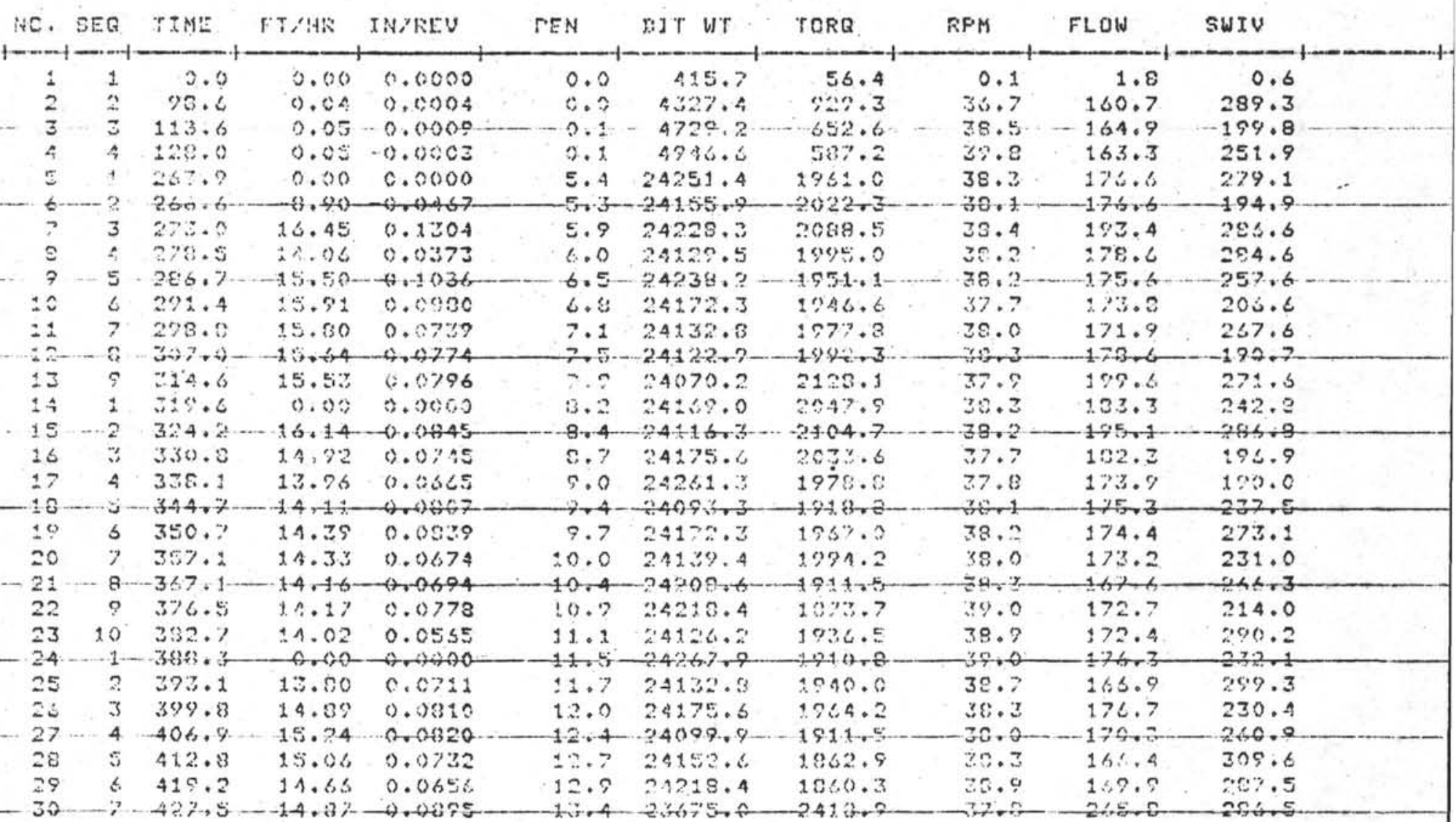




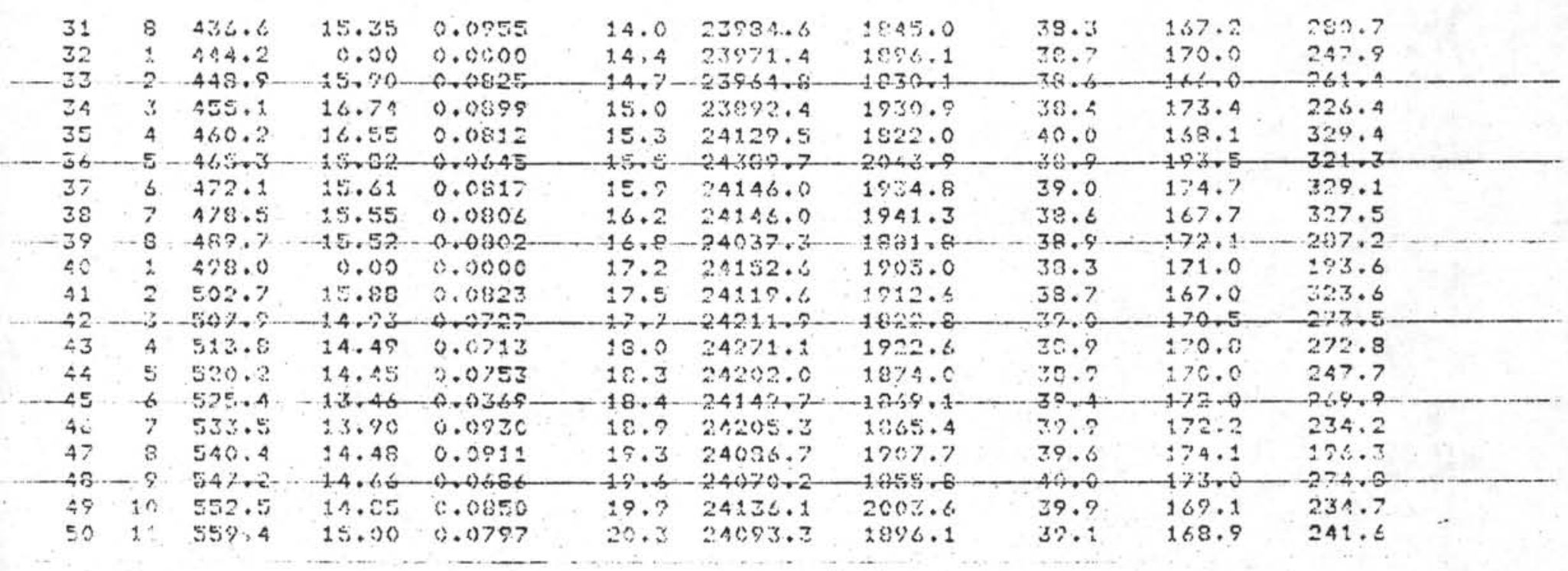

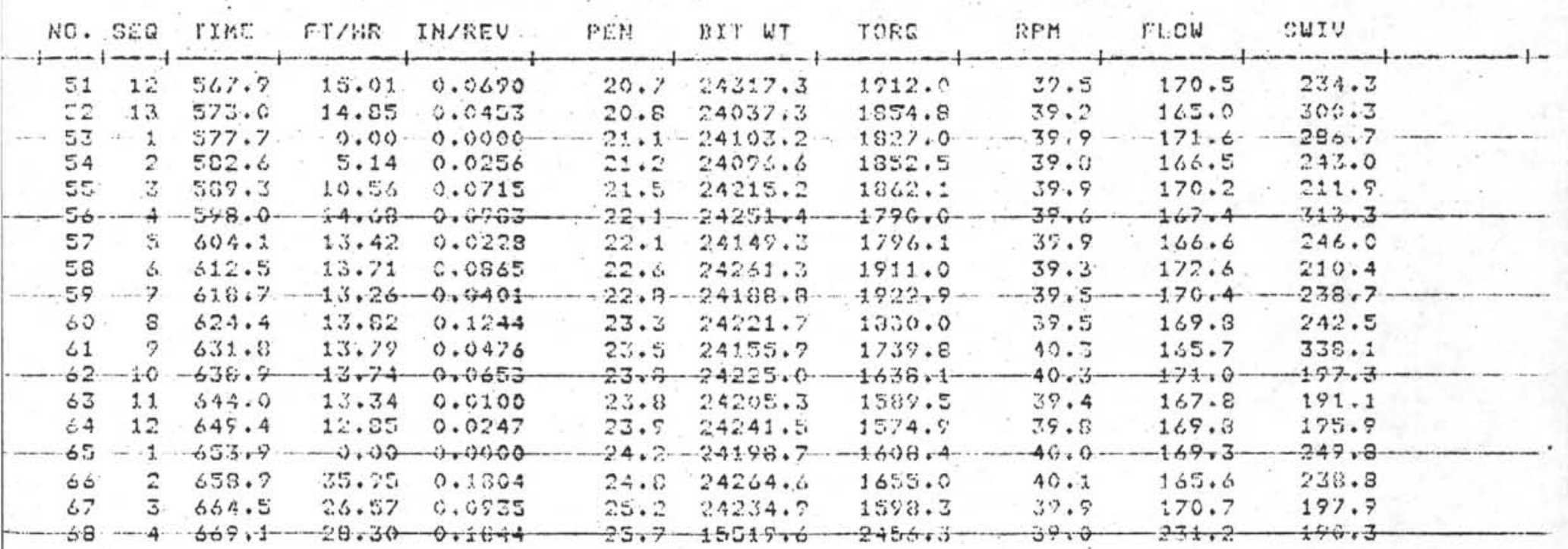

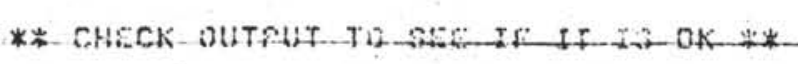

FRINT OFTIONS ARE:

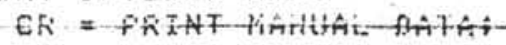

$50=$ FRINT GUICK LATA;

SO = EXIT FriziNT ROUTINE.

-FRINT DFFION $=-99$. 
TEST \# Il MATERIRL. BASATT

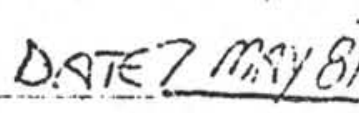

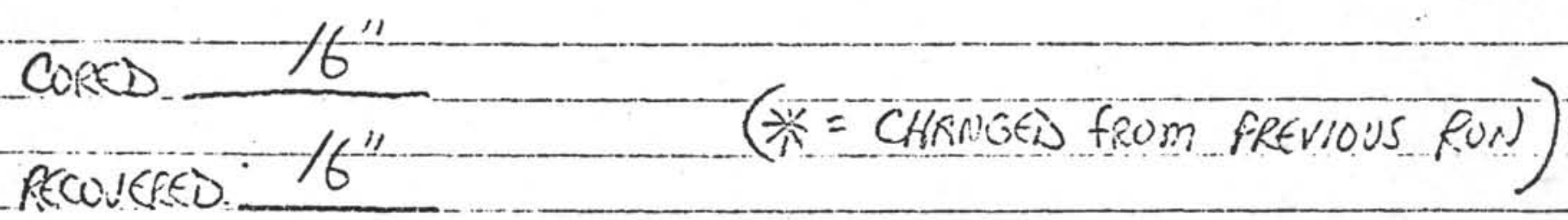

ECBVISELSBLES

DEMUNS PRRXIRETES

TYFE $\angle O C K O$ DRUS RFM : 40 ROM

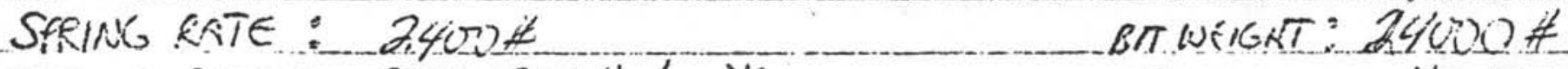

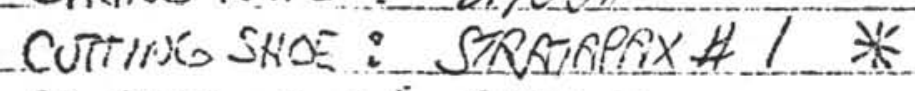

Flow: $16062 ?$

CC BSTING : CUSTOM

SUmmary

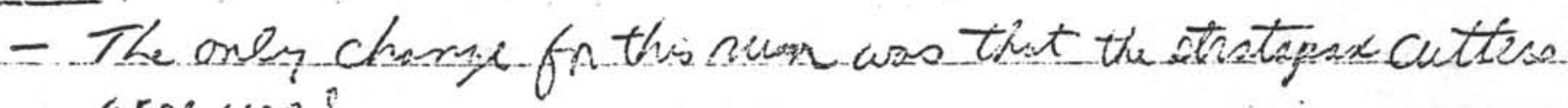
axse-vines.

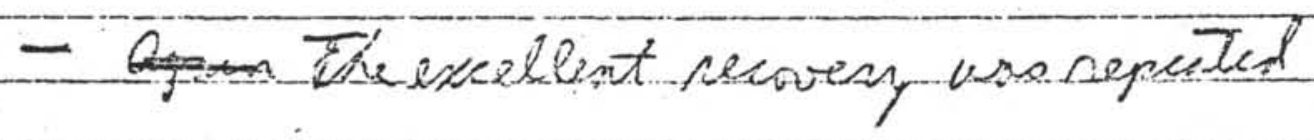

- The leasimga aspin disl mil fuege.

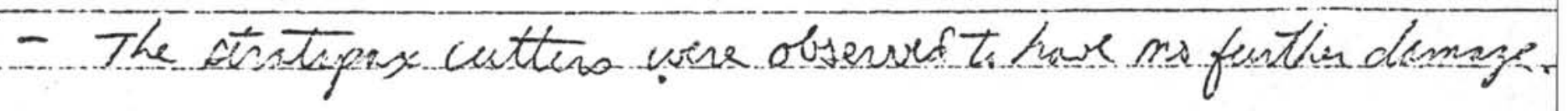

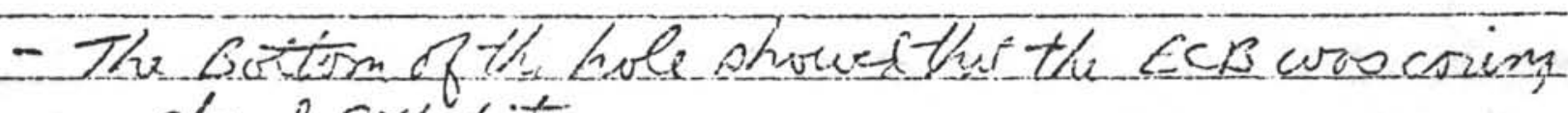
ahesed of wit.

$-80-$ 
ÁQ CHARELL DAYA TABLE

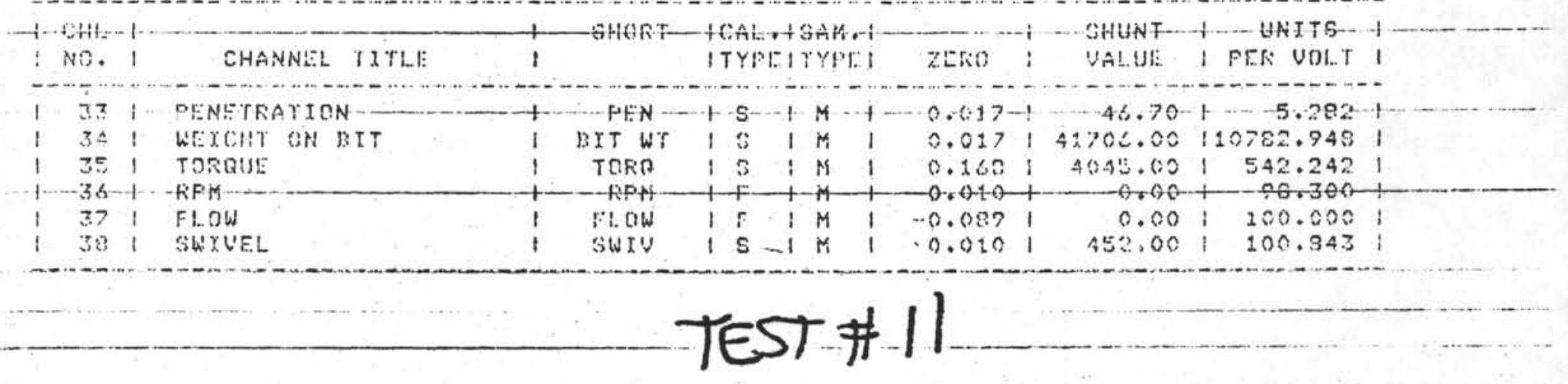

FAGE 2 BASALY $\$ 25 / \% / 81$

5/ $7 / 81 \quad 1 \%: 11: 15$

EY:MRLMAN, DAT:

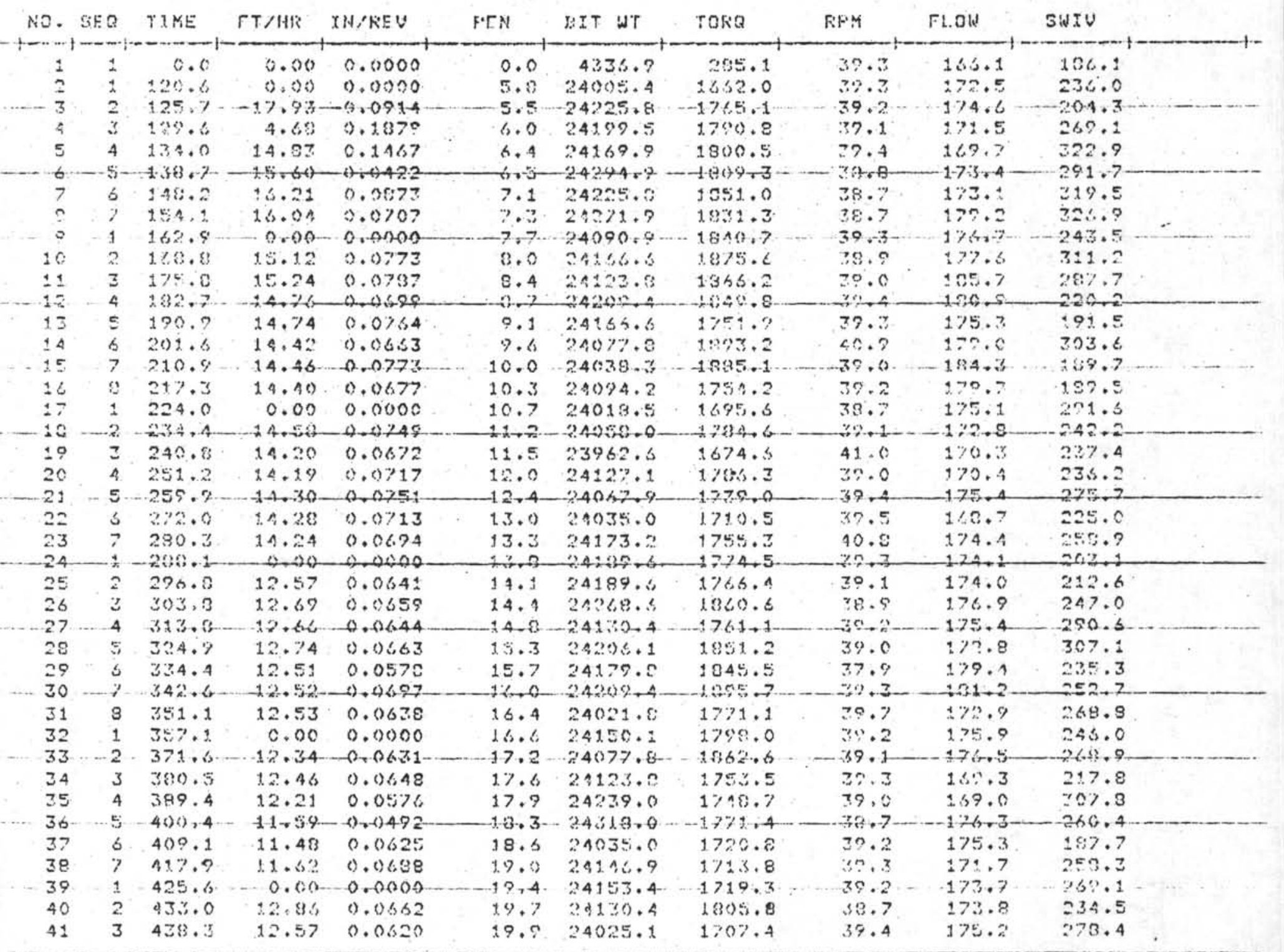


APPENDIX B

SHIPBOARD TEST REPORTS

LEGS 84, 90, 94 


\section{ABSTRACT}

The Extended Core Barrel (XCB) was run nine times on Site 566 during Leg 84. It was run in the same bottom hole assembly as the Variable Length Hydraulic Piston Corer(VLHPC) after the sediment became too stiff for the latter to function effectively. There were no spacing or other dimentional problems, and the spring pack functioned properly. However, core recovery was low due to repeated liner collapse, fractured cutter elements and, ultimately, a faulty latch-drive system. Solutions were devised for all of these problems after Site 566, but there was no opportunity to further test the tool.

\section{INTRODUCIION}

The XCB was designed to allow piston coring and rotary coring through the same bottom hole assembly. The core barrel is rotated with the drill string, but the liner and core catcher are set on bearings which decouple them from barrel. rotation. The cutting shoe (fitted with either tungsten carbide or Stratapax diamond cutting discs) extencs six inches below the bit to core soft sediments before they can be washed away by the bit jets. When hard sediments or rock are encountered the extended section is compressed into the drill bit against a naximum 2400 1bs. spring force. Small holes in the lower section of the core barrel allow circulation water to enter, travel down tirough the annulus between the cutting shoe and core catcher, and exit through jet holes at the bottom of the cutting shoe, thus libricating the cutters and cleaning the extended, pilot hole. 
The XCB measured $38.56^{\prime}$ from the landing shoulder to the latch fingers. The bottom hole assembly included an XCB bit, a mechanical bit release, a $28.97^{\prime}$ long drill collar, a $2.95^{\prime}$ ' long collar spacer, a $3.38^{\prime}$ long stabalizer, a top sub, a head sub with a standard latch sleeve, a 29.72' long drill collar, and another top sub and head sub with a VLFPC seal sleeve. In order to make the XCB compatable with the VLHPC the seal sleeve bore was increased to 3.80 " and the bore through the support bearing was reduced to $3.54 "$. This allowed the XCB to entirely pass through the seal sleeve and still land on the support bearing. Installed in the float valve was a polyurathane-backed flapper to protect the $\mathrm{XCB}$ cutting elements from damage when the tool is landed.

TEST RESULTS

The general plan for Site 566 was to piston core with the $9.5 \mathrm{~m}$ system until refusal and then continue to basement with the $\mathrm{XCB}$. The site was located on a slope and there was an initial problem of establishing the correct water depth. The first two piston cores did not tag bottom. The third did not stroke out fully, recovering 3.7 meters of fairly hard green mud smelling strongly of $\mathrm{H}_{2} \mathrm{~S}$. The top of the liner was collapsed and fractured. The next piston core recovered 6 meters of the same material. It was then decided to switch to XCB coring.

XCBN1 included a diamond cutting shoe with PVC protector buttons, soft formation core catchers, a Kaydon thrust bearing, and a bronze wiper bearing. (The bronze wiper was used on every core barrel except XCB\#8), 2.3 meters of core was cut with a circulation rate of 5 SPM and no rotation. One small lump of mud was recovered in the core catcher. The liner was split along its length and was 
was collapsed near the upper end. The annulus outside the stainless steel connector, the Kaydon bearing and the cutting shoe jet ports were clogged with mud. The ball separater had beed pushed out of the bearing by the intruding mud. The diamond cutters were undamaged.

$\underline{\mathrm{XCB}} \mathbf{2} 2$ was made up exactly the same as $\mathrm{XCB} 1$ 1; it was on 1 ts way down before XCB非 was opened. 9.6 meters of core was cut at 5-7 SPM and 60 RPM. 4 4.6 meters of core was recovered. The liner was collapsed just above the recovered core section. It was also fractured with several pieces broken loose. The Kaydon bearing, circulation annulus and jet ports were clogged with cuttings and the core catcher was jammed with packed mud. The diamond cutters were again undamaged.

XCB作 3 . For this and the succeeding runs the check ball at the top of the core liner was taken out, and the Kaydon bearing was replaced with a bronze thrust bearing (OP4429). 9.5 meters were cored at 10-20 SPM and 5-60 RPM. There was some torquing and the penetration rate was appreciably slower. 4.0 meters of stiff green mud with pyrite and serpentine pebbles was recovered. The lower onemeter section of core liner had been split and twisted completely free of the rest of the liner. The middle section of the liner was undamaged, but the top section was collapsed. Again, mud had infiltrated all of the lower orfices and the core catcher was packed solid. The diamond cutters were undamaged.

XCB非. The core liner for this run was selected from a different batch, and no PVC protector buttons were glued to the cutters. Otherwise the components were the same as for XCB\#3. Out of 9.7 meters cut only 1.3 meters were recovered. The material was notably harder-- Serpentinite rocks cemented in a mudstone matrix. The general texture was "pebbly". This type of structure has been anticipated to be the worst type of material for the relatively brittle diamond cutters. One cutter had popped off but the remaining five were not chipped and showed only slight signs of wear. The liner was collapsed near the upper end. The core catcher 
and fet ports were fammed with mud. A rounded nub of core protruding from the cutting shoe suggested that the $\mathrm{XCB}$ had rotated for a while without penetration.

XCB\#5. For this and the succeeding cores the use of the PVC protector buttons was discontinued. Also, hard formation core catchers were used. 9.7 meters of core was cut while clrculating at 35 SPM. 0.6 meters of rock, gravel, and mudstone were recovered. The stainless steel connector was jammed.up into the core liner causing it to split. The upper section of liner exhibited a sinusoldal fracture along its length. The core was hard packed in the core catcher but two of the jet ports were clean, and the others were only loosely packed with mud. Two of the diamond cutters were missing and two of the remaining six were chipped. The welds had broken on all of the inside cutters, and they had been shifted radially outward.

XCB非. The circulation rate was increased to 40 SPM to.cut this core. The barrel was retrieved after penetrating only 2.0 meters in $1 \mathrm{hr} 40 \mathrm{~min}$. Torque resistance intermittently rose to $4000 \mathrm{ft} 1 \mathrm{bs}$. 0.6 meters were recovered. The Iiner was split and shattered. The jet ports were plugged and the core catcher was jammed. All but one of the diamond cutters were either broken or missing. XCB师7. A slight deformation of the stainless steel connector (probably caused by rough handling when extruding the previous:core) has made it hard to slip on the bronze thrust bushing. Therefore barrels 7 - 9 were fitted with a phenolic thrust bushing. Circulating at 45 SPM, the penetration rate was faster and the torque less than the previous cores. 3.0 meters were cut and 0.70 meters were recovered. The liner was fractured but the core catcher was not jammed and the jet ports were only partially plugged with mud.

XCBAf8. The ship was offset $3000^{\prime}$ to spud a new hole (566A). XCB非 incorporated a previously damaged cutting shoe which was modified by brazing tungsten 
carbide grit on the cutting surface (which also plugged the jet ports). The heat of the brazing torch had warped the seat for the wiper bearing, so a more flexible UHMWPE bearing was used in place of the bronze. Of 7.0 meters cored only 0.12 meters of 1"-2" pebbles were recovered. The upper 4' of 1iner had collapsed. The stainless steel connector was again shoved up into the liner. The cutting shoe showed some signs of wear, but was otherwise undamaged.

XCB\#9. The ship was offset again (566B) and an XCB with a carbide disc cutting shoe was washed down 50 meters before retrieving. There was no recovery. The IIner was totally shattered. The jet ports were clogged but the carbide cutters were undamaged. The fingers of the double fingered latch were both rounded on the driven side and also on the top (latch-down) end. This suggested that the ears of the latch sleeve had ridden over the latch fingers instead of rotating the XCB with the bit (see photo).

XCB非10. Drilling operations ended with the retrieval of XCB非. But since $\mathrm{XCB} 10$ had already been dropped, it was pumped down to latch at 30 SPM as the others were, and was retrleved at the end of the pipe trip. The upper $4^{\prime}$ section of core liner was collapsed even though no cutting was attempted.

The drill bit and polyurathane-backed flapper were in good shape. The ears of the latch sleeve were rounded corresponding to the deformation of the latch fingers. Also the latch down shoulder of the latch sleeve was dented in several places; the width of the dents match the width of the latch fingers (see photo). It appears that, upon landing, the $\mathrm{XCB}$. acts as a large spring which compresses then bounces back to impact against the latch sleeve. The hardness of the latch sleeve may not be to specification. It will be sent back for tests. 
CONCLUSION

No problems were encountered with the routine handling and operation of the $\mathrm{XCB}$. A wheeled nosecap was fabricated to protect the cutting discs as the tool was raised from horizontal to the vertical stab-in position. No maintenance was required in between trips so that the turn around time was the same as "that for a standard core barrel. The polyurathane-padded flapper was sufficient to protect the diamond cutters from impact damage when the tool landed; the PVC protector buttons were unnecessary.

The Stratapax diamond cutters began to chip and pop off as the sediment became rocky. It was unfortunate that this type of sediment was encountered during these first tests, as it had been anticipated that the diamond cutters would fracture in rubble-type drilling. Clearly, several types of cutting shoes are needed for various types of sediment and rock. One damaged shoe was modified by brazing tungsten carbide grit onto the cutting surface. After cutting 7.0 meters in two hours it was relatively unscathed, although the core recovery was low.

The main problems to be resolved are: 1) repeated liner collapse, 2) lack of circulation to the cutter elements and lack of free floating core catchers due to mud clogging the jet ports and annulus between the core catcher and cutting shoe, and 3) an undependable latch/drive mechanism.

Since XCB佀10 suffered a collapsed liner even though it wss only pumped down and retrieved without taking a core, it appears that the liner collapsed due to either impact or circulation pressure--not due to coring or pull-out suction. One theory is that, since the larger I.D. of the XCB does not force the core liner into a circular shape, a slightly oval liner, having less hoop strength, may collapse upon impact as the slug of water inside the moves to create a pressure differential. 
Therefore the grease nipple was removed from the adapter sub, and a 3 " long by $21 / 2$ " diameter aluminum floating piston was fabricated to ride inside the core 1iner. There is enough flow area around the piston to ensure that it will remain stopped against the core catcher during descent. When the barrel lands the piston should prevent any appreciable water movement through the barrel.

The chronic splitting of the lower end of the core liner probably" occurred during coring where core friction separated the stainless steel connector from the upper core catcher adapter and jammed it into the liner. The broken seal may also have accounted for the mud-jammed circulation annulus and jet ports of the cutting shoe. To prevent this from recurring the stainless steel connector and the upper core catcher adapter were Baker-Locked together after installing a bronze thrust bearing.

Finally, it is evident that the XCB may pop its latch and/or slip instead of being driven by the latch sleeve during high torquing conditions. The latch should be redesigned to eliminate the pivoting dogs, since they will always be suceptible to being "worked" closed. As a temporary shipboard solution the I.D. of a new latch sleeve was built up to $3.80^{\prime \prime}$ between the ears and one inch into the body. (the same I.D. as the VLHPC seal sleeve). The tighter clearance should prevent the ears from working over the fingers of the latch.

Unfortunately the above solutions went untested. The scientific schedule for the remainder of the cruise precluded any further use of the XCB.

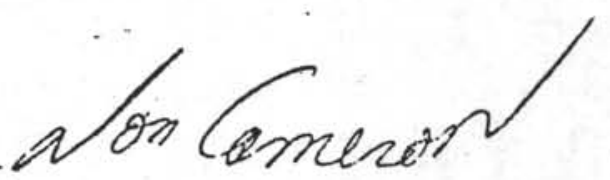

Don Cameron 
DEVELOPMENT ENGINEERING REPORT

EXIENDED CORE BARREL (XCB)

L.EG 90

The Extended Core Barrel through-the-bit soring tool was again tested during Leg 90, after brief and generally unsatisfactory testing during Leg 84 . Based on the lessons learned on Leg 84 , several design changes and improvements had been wade to the XCB for Leg 90 . These were:

1. All-new Cutting Shoes (two different types for soft or hard formations).

2. An improved cutter jet circulation system coupled vith choke type Core Bits.

3. An improved Core Catcher package designed for independent free rotation.

4. A new Core Liner support syscem designed for independent free rotation and isolation of the liner from punp pressure.

5. An all-new latch to transfer drive torgue without precature releasa.

6. A new spacing syster. using inner barrel spacers and a modiffed VLHPC Quick Release to allow the XCE and VLHPC to be interchangeable in a common bottom hole assembly (BHA) while landing at the sute landing sleeve.

Of these changes, the most significant were the new Cuting Shoes, nei tatch and rearranged BHA. A single part was used as Latch and Drive Sleeve for the XCE, Seal Sleeve for the VLFPC, and Landing Sleeve for both tools. This improvement enabled a simplification of the BHA components so that a sing?e restrictive insice diameter at 3.80 inches existed then using a 4.00 inci landirg shoulder on both tools. This also sioplified spacing and allowed more room for greacer design flexibilicy within the XCB tool.

\section{Injtial Assembly and Snace Out Check}

Following the princed instructions and the latest assembiy drawing, two xCE tocls were assembled withnut difficulty. Both included ali oi the working pieces of the $\lambda C B$ below the Quick helease issembly. A single upper section was made tp wict consisted of the Quick Release Shoulder Sub (rale), 27 feet of bling inter barrel and the latch. The same upper section was $15 \mathrm{~s}$. each core with alternate lower sections in the same manner that the rific is ilandied. 
The lower sections were assembled with the Soft Formation Cutting Shoes.' As it turned out, the Hard Formation Shoes were never used during Leg 90 . Al.1 eight cutter jet circulation inlet parts were left open on the Cutting Shoes at first. The non-rotating ball bearings on the two shafts were not grease. packed.

The only alterations made during initial assembly were to widen the grooves on the Liner Adapters ( $P / N 30$ ) to accept cup point set screws (the dog point screws sent with the $\mathrm{XCB}$ equipment were misplaced until later in the cruise).

Since the number of coring tools in use during the voyage exceeded the storage capacity of the vertical scabbards, the XCB sections were laid out on the core walk when not in use.

The dual purpose BHA was spaced out by juggling drill collars to find the optimum combination which would allow the XCB cutting shoe to extend exactly $9 \frac{1}{4}$ " beyond the bit face when hanging on the landing shoulder. Lack of a bit breaker mated to the new $\mathrm{XCB} / \mathrm{VLHPC}$ bits was the only difficulty related to the new BHA configuration.

A retraction test was done by latching the $\mathrm{XCB}$ into the lower portion of the BHA and lowering it down on a wooden $4 \times 4$ on deck. The cutting shoe retracted exactly as intended and approximately 2000 pounds weight was taken off the Martin-Decker indicator ( \pm 300 Ibs.) at the point where the cutting shoe was flush with the bit face.

A VLHPC tool was dressed with new 3-3/4" V-packings and a new Top Sub Cap which had a 4.00 inch landing shoulder. It was landed in the BHA and checked for spacing.

Site-By-Site Synopses of XCE Deployments

Hole 587

Piston coring ended abruptly when the sediment lithology changed from stiff

calcareous ooze to brittle coral/gravel which was partially cemented. The VLHPC simply could not get any penetration and/or the core catchers could not retain the cored material.

The XCB was deployed four times. Maximum recovery was one handful of fragments. No indications of tool malfunction were evident. Six of the eight Cut.ting Shoe circulation inlet ports were eventually plugged and a plastic sock core catcher was tried but no improvement resulted. Paint indicators on the latch and male hex showed that these functioned properly.

Hole 588A

Piston coring reached refusal at $315.6 \mathrm{~m}$ in $\mathrm{firm}$ calcareous ooze. The XCB was deployed three tines. 
Core \#16 - One of eight inlet ports was plugged. The tool seemed to work fine. Recovery was about 3 inches of core packed firmly in the core catcher. The cuttẹr jets came back slightly plugged.

Core 117 - Recovery was 2.35 meters of firm ooze badly broken up. Cutter jets came back plugged completely.

Core \#18 - The lower zerk fitting in the Adaptor Sub was removed to provide a positive vent, realizing that this risked a liner collapse. Recovery was 2.89 meters of good, solid core up to the point of total collapse of the liner, proving a vent was essential.

Hole 588B

Piston coring ended at $238.6 \mathrm{~m} \mathrm{BSF}$ again in firm calcareous ooze. The XCB was deployed three times with modifications made to the vent system since 588A. Two 0-ring grooves were cut in the Bearing Shaft to seal against the I.D. of the core barrel; the existing vent holes in the Bearing Shaft were plugged and new vent holes were drilled above the new 0-ring grooves. Two holes were also drilled through the inner barrel in the Seal Sub. The zerk fitting was reinstalled in the Adapter Sub. The required 0 -rings to fit the new grooves were made from Caterpillar stock parts by cutting and rebonding slightly oversize 0-rings.

Core 非29-Recovered 6.95 meters of good looking core up to point of liner collapse. Cutter jets plugged with ooze. Core firm and tight in core catcher.

Core $\$ 30$ - Total recovery 3.79 meters. Liner was partially collapsed at the bottom but had core above collapse point. Liner was also split badly oves top three feet.

Core $\$ 31$ - Total recovery 5.73 meters. Liner split at bottom, collapsed at top.

Hole 590B

XCB deployment began at $250.7 \mathrm{~m} \mathrm{BSF}$. The vent mods had been redone. The surface of the Bearing Shaft containing the new 0-ring grooves had teen built up with weld overlay and then remachined to provide the proper seall clearance.

This was the first hole where the XCB was completely successful. The tool worked very well for 26 cores. The hole was terminated when the scientific objectives were reached. Initially, the liners suffered partial collapse-always in the top i-2 feet. This effect was eliminated by drilling a $\frac{1}{4}$ " hole in the liners $6-\delta$ inches from the top in all subsequent $X C B$ runs. The source of the higher djfferential pressure on the outside of the liners was not determined, but the $\frac{1}{4} "$ hole apparently allowed it to equalize nonetheless. 
The inner barrel components were rearranged so that the two $25-7 / 8$ " spacers were at the ends of the two 15-foot inner barrel sections. This was a very useful change and the tools were a'ssembled in that configuration from then on; It allowed the new vent seals (0-rings) to seal on the controlled I.D. of the short spacers rather than the out-of-round I.D. of the 15-foot inner barrels. It also placed a short sub just above the Cutting Shoe which is critical for liner removal.

The "floating" core catcher package was finally abandoned near the end of this hole. It was simply too difficult to clean and reinstall. Standard core catchers fit in the Cutting Shoes and so were substituted.

\section{Hole 591A}

Began XCB after VLHPC refusal at 246.5 meters. Nothing but problems at this site. The tool was deployed six times. (Only four cores were officially recorded since the last two had zero recovery.) All six tools came back with liners shattered into strips over their total lengths. This phenomenon was later theorized to be caused by explosion of trapped air inside the liners when the tool impacted the water line inside the pipe far below the rig floor.

Also, at this site, three of the six barrels stuck in the pipe or BHA before reaching the bit. Later it was determined that the XCB latch was causing this problem.

XCB Disassembly and Inspection Between Hole 591A \& 592

Both lower sections were disassembled, cleaned, inspected, and reassembled between sites. The Belleville washers, under the nuts on the bearing shafts, were removed to help alleviate the liner shatter problem. The major problem, revealed by the inspection, was the presence of silt collected in and around the spring stack. The detritus material probably contributed to the fact that 6-8 washers were broken in each spring stack. All the broken ones were the exotic alloy type. The stainless washers looked good.

In one of the two XCB's the non-rotatirg ball bearings in the sub on top of the spring section were completely disintegrated:

\section{Hole 592}

This was an alternate site planned to be done as quickly as possible. Success of the dual compatibility BHA enabled the site to be completed within the allowed time frame and nicely demonstrated the vaiue of the new VLUPC/XCB systens. Deployed the XCB sixteen times. 
Solved liner shatter problems of the previous site by having the driller fill the pipe with water just before breaking the lest connection prior to inserting the XCB. This seemed to prevent, the long free fall through air to the water line inside the pipe.

Latch problems began in earnest at this site. The first tool go-deviled to the bit without difficulty. The second stuck near the top of the BHA so firmly that two overshots were broken trying to jar up to loosen the barrel. It was finally banged loose by go-deviling a deplugger barrel on top of it. This apparently jarred the latch rod back down and allowed the barrel to fall to its proper place. The remainder of the XCB deployments at this site were accomplished by running the tools in on the wireline and drilling with the line in place packed off by the line wiper. No problems with that technique up to pump pressures of 450-500 psi. One tool did stick temporarily in the pipe in spite of being on the wireline, probably due to being run a bit too fast allowing the sinker bars to slightly overrun the XCB. At that point, the latch behaved exactly as if the wireline wasn't there at all.

\section{Hole 593}

XCB deployment began at 225.9 meters BSF and continued for 345.6 meters of which 270.44 meters $(78 \%)$ was recovered including about 15 meters of very hard volcanogenic turbidites in two of the cores.

To improve the latch-jam problems and allow go-deviling the XCE, a couple of modifications to the new latches were made. The first was to cut the latch dogs down so that their assembled O.D. was reduced by about 0.130 inches. This only made the latch more susceptible to jamming. The modified dogs were set aside (and painted red to identify them.) The second mod was to cut the tops of the dog windows in the latch body about $3 / 4$ inch longer to eliminate one surface which may have been contributing to the jamring phenomenon. This worked and the XCB's were run for the next 24 cores without incident.

At Cores No. 49, 51, and 53, the liners came back shattered even though the practice of filling the pipe just before dropping the tool was being routinely practiced. In addition, Core No. 51 stuck in the top of the BHA (again). Starting at Core No. 55, the last six cores were taken by running the XCB on the wireline. This procedure solves both the latch-jam and liner-shatter problems, but is tedious.

The hard volcanic rock layer was cored nicely with the Soft Formation Cutting Shoes, resulting in good core recovery and only slight wear on the shoes. The hard facing weld beads, on the face of the saw teeth, proved quite valuable.

$\underline{\text { Hole } 593 \mathrm{~A}}$

The XCB was deployed five times to recore the intervals poorly recovered from the adjacent hole. Also, the XCB barrel was used as the wash barrel for 


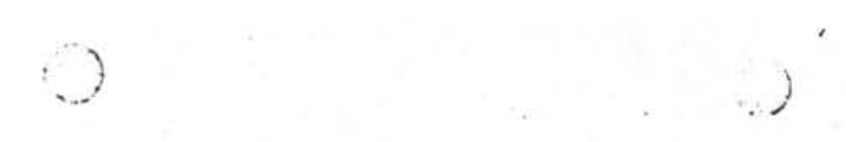

239.5 meters of wash after VLHPC refusal. The five cores were taken by running the tool on the wireline with no difficulties.

\section{Hole 594}

This hole provided the first hemipelagic sediment with some clay to try out the XCB after endless calcareous ooze and chalk at the previous sites. VLHPC refusal occurred earlier than in the calcareous ooze sediments--at 130.7 meters. The ХСВ was then deployed 39 times over 374.4 meters, recovering 204.84 meters $(54.7 \%)$. The hole was prematurely terminated by bad weather.

The tools were go-deviled for the first 19 cores. Of these, the latch caused the tool to stick somewhere in the pipe or BHA five times and one liner split. The final 20 cores were taken while running the $\mathrm{XCB}$ in on the wireline to avoid headaches.

\section{Hole 594A}

This hole was another example of how much versatility is possible with the dual purpose BHA. The repeat piston core sequence was done, then the XCB was used as a wash barrel to wash between desired zones to repeat nil recovery cores of the adjacent hole. A long wash then followed to the termination point of the 594 hole.

Fifteen XCB cores were taken, all run in on the wireline. The sediment here had a consistency with more clay and thus tended to block off in the core catchers. This redused recovery rates noticeably. Also, repeated sections of fully lithified turbidites turned up interbedded with chalk and coze. All were cut with the Soft Fortation Cutting Shoes, which finally began to shoe appreciable wear at the pointed ends of the saw tecth.

\section{Flow/Back Pressure Test}

The final thing done with the XCB prior to the end of the final site was a flow test to measure back pressure of the XCB in place in the pipe. The $\mathrm{XCB}$ as made up for this test was assembled with the Soft Formation Cutting Shoe, a 4-inch, fluted landing shoulder, 27 feet. of $3 \frac{1}{2}$ " inner barrel between the latch and the Q.R. All cutter jet inlet ports were closed.

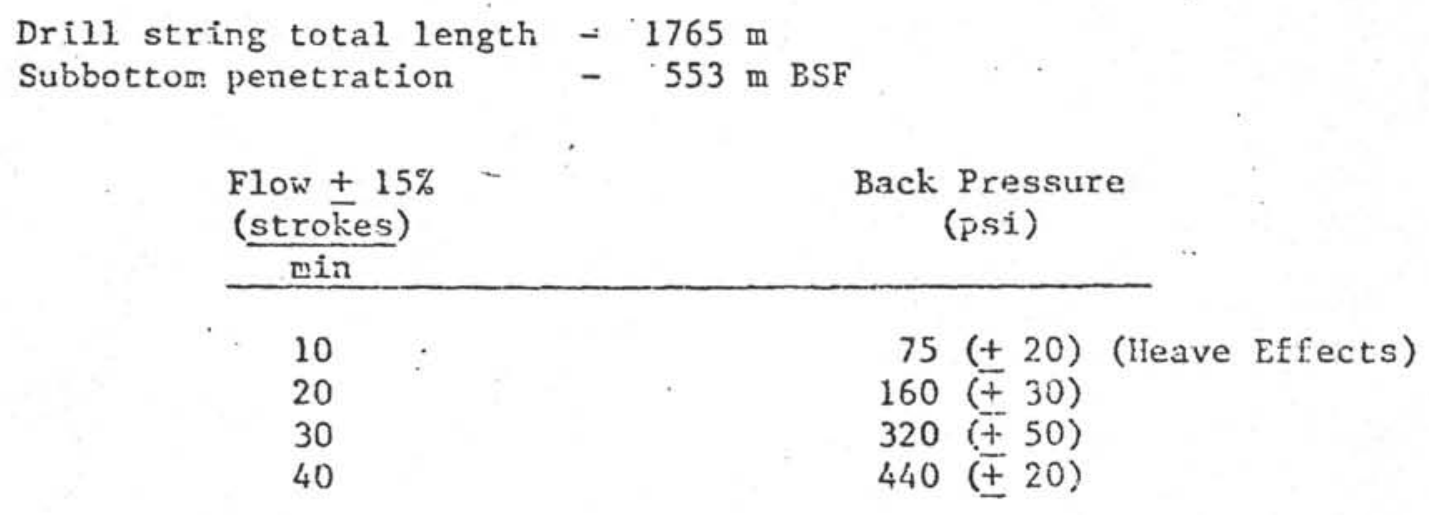


XCB CORING RECORD - LEG 90

\begin{tabular}{|c|c|c|c|c|}
\hline $\begin{array}{l}\text { Hole } \\
\text { No. }\end{array}$ & $\begin{array}{c}\text { Cored } \\
\text { (Meters) }\end{array}$ & $\begin{array}{l}\text { Recovered } \\
\text { (Meters) }\end{array}$ & $\begin{array}{c}\begin{array}{c}\text { Washed } \\
\text { (Meters) }\end{array} \\
\end{array}$ & Comments \\
\hline 587 & 38.4 & Traces & -- & No vent. Bad formation. \\
\hline $588 \mathrm{~A}$ & 28.8 & 5.40 & -- & No vent. \\
\hline $588 B$ & 28.8 & $: 16.47$ & - & First vent mods. Some liner collapses \\
\hline 590B & 248.4 & 230.99 & -- & Improved vent mods. Excellent cores. \\
\hline $591 \mathrm{~A}$ & 38.1 & 11.44 & -- & Shat tered liners. \\
\hline 592 & 153.6 & 114.30 & $\therefore$ & $\begin{array}{l}\text { Filled pipe before dropping tool. } \\
\text { First stuck barrel. }\end{array}$ \\
\hline 593 & 345.6 & 270.44 & -- & $\begin{array}{l}\text { Two latch mods. Many stuck barrels. - } \\
\text { Hard turbidites cored. }\end{array}$ \\
\hline $593 \mathrm{~A}$ & 48.0 & 34.60 & 239.5 & Spot cores below VLHPC refusal. \\
\hline 594 & 374.4 & 204.84 & & $\begin{array}{l}\text { Sporadic latch jams--run on } \\
\text { wireline at end. }\end{array}$ \\
\hline $594 \mathrm{~A}$ & 163.2 & 80.69 & 288.0 & $\begin{array}{l}\text { Ooze, chalk and turbidites. All } \\
\text { runs on wireline. }\end{array}$ \\
\hline TOTALS & 1467.3 & 969.17 & 527.5 & \\
\hline
\end{tabular}


COMENTS, NOTES, RECOMMENDATIONS, ETC.

\section{Cutting Shoes}

1. The Hard Formation Shoes were not used on Leg 90 .

2. Wear: Prior to coring the turbidite sequences near the end of the leg, the most wear on the Soft Shoes was due to handling on deck. Overall, the saw-tooth design with hard-facing in the prime wear locations appeared to be very satisfactory.

3. Cutter Jet Circulation: There were two problems with the cutting Shoe circulation system. In spite of the new side-discharge principal for the jets, clogging still routinely occurred. They were also more difficult to clean out on deck because of the right angle bend. The eight inlet ports were plugged or.left open in different combinations but no differences could be detected in core quality, clogging tendencies, or any other coring parameter. The second problem associated with the circulation system was the appearance of inward bulges of the inner wall of both Cutting Shoes. As unlikely as it seems, these could only have been caused by internal pressure blocked off by clogged cutter jets.

\section{Core Catchers}

The special, free-floating core catcher package turned freely by hand inside the Cutting Shoes after the first assembly of the tools and then never again. After each core the package was thoroughly clogged and presented a difficult cleanout problem. The thin.sleeves were too vulnerable to withstand the cleanout procedures and had to be replaced much too often. It is doubtful that the core catchers ever truly "floated" as designed. This may always be the case in mud, clay or ooze type sediments. In limestone, firm chalk or rock the "float" principle may still be viable.

\section{Floating Liner System}

A key element in providing for a free-floating liner is using over-size core barrels which allow clearance on the outside of the liners. This, however, removes a source of mechanical support to the liners making them tore prone to failure by a number of assorted failure modes. As a result, the XCB liners did fail quite often by any and all of the following mechanisms: implosion (collapse), explosion (shattering, splitting), axial overload (crumpling, crushing), torsion overload (twist off) or combinations of the above. Whether or not the liner actually "floated" with the core was definitely determined.

\section{Vent Modifications}

The early failure to get good core at Holes 587 and $598 \mathrm{~A}$, demonstrated that a positive vent through a check valve is essential. At the same tine, the 
vent system must prevent pump pressure from reaching the outside of the liners. The field modifications to the XCB vent accomplished this but a more straightforward, "clean" design should be devised. The current field mods showed no signs of deterioration with usage, however, and should be reliable until the general redesign of the $\mathrm{XCB}$ is done.

\section{Retraction System}

All indications were that the spring-loaded retraction system functioned as designed. Operationally it proved very popular. The drillers noticed that it made it easier to get undisturbed core in bad heave conditions because it helped to compensate for bit motion automatically.

The Belleville washers tended to collect silt and this probably contributed to the demise of many of the washers. The spring stack should be sealed to prevent ingress of detritus but must allow for displacement during retraction.

\section{Latch}

Modifications made to the latch did not completely resolve the propensity for the dogs to pop out in wide spots in the drill string and then $j$ am when re-entering 4-1/8" diameters bores. The latch is basically a very sound design which holds great promise as a successor to the hinged latches now in use. The latch is maintenance-free and cannot be assembled wrong. No problems of any kind were detected involving its normal functions: latching in and holding upward force, transferring torque, unlatching on command. Only the janming problem remains to be solved before this latch will be a candidate for all coring tool latch requirements. Running the tool on the wireline prevented the latch from causing difficulties. This is not a recomended practice, however, for several reasons. First, it is inherently dangerous since rotation with the wireline in the pipe always risks snarling the line. It takes longer to get the tool down on the line than by free-fall. Pump pressure beyond 500 psi is impractical since the wireline wiper begins to leak badly above that pressure. Also, drilling with the tool attached to the line requires good coordination between the driller and sandline which operator. If the driller lowers the pipe faster than the winch operator lets out the line, the tool will unlatch during coring. If the winch operator lets out the line faster than the driller is aaking the hole, the-line will sag and snarl.

\section{BHA Components}

Since spacing the XCB in the BHA is so critical, it was recessary to change outer core barrels several times during the first space out. This solution is not adequate--an adjustable latch sleeve is called for. The current latch sleeve/landing sleeve/VLHPC seal sleeve worked very nicely and seems to be the way to go for future dual purpose BHA's.

Float valve flappers padded with urethane were used when the $\mathrm{XCB}$ was run to prevent damage to the cutting shos. This is a helpful precaution except. 
that the first one lost its urethane pad on the first hole. After that an unpadded flapper was used for scveral sites with no distinct wear on either the Cutting Shoes or the flapper itself.

\section{VLHPC Compatibility}

Running the VLHPC in the dual purpose BHA required that 3-3/4" V-pack seals be used in place of the standard, smaller seals. The larger seals stacked higher (with metal spacer rings) than the ones they replaced, so to make them fit one of the three V-packings was deleted. Also, a 15-3/4" inner barrel spacer was required between the Top Sub and Bypass Sub. These changes were made to both the $9.5 \mathrm{~m}$ and $5 \mathrm{~m}$ VLHPC's and no problems werc encountered using them throughout the cruise.

XCB Handling On Deck

With the Quick Release and 27 feet of spacer on top of the working (lower) section of the XCB, the tool was handled exactly like the VLHPC. Only the lower section was laid down for core liner removal and redressing. The breaking and reassembly of the Q.R. was done in the blue HPC working stands. The only drawback to this operation was the lack of a hang-off plate below the latch to allow easy release for go-deviling. A standard clamp was used to hang the tool in the pipe and also to release it. This worked but is awkward.

The heave compensator is not compatible with XCB operations for the same reason that it is not compatible with the VLHPC. The HC hoses occupy the heidroom over the rig floor where the upper section of the tool must swing (suspended on a tagger line) prior to lowering into the pipe.

\section{Conclusions}

The $\mathrm{XCB}$ has finally earned its wings. Its usage during leg 90 was not only successful for the tool design but also contributed, in a big way, to the success of the operations during the leg--both in saving time by eliminating pipe trips and in the quality of cores. Several of the holes where conditions were right, saw core recovery percentage and core quality which was excellent. The scientific staff was enthusiastic about the $\mathrm{XCB}$ core quality. Using a drag bit action to cut soft cores ahead of the roller bit naturally leads to less core disturbance. This principle seems now to be proven.

The XCB in combination with the VLHPC in a dual purpose BHA, make for a level of operational versatility which is highly desirable. This is especially true when tine is limited and downhole scientific objectives are determined as cores are recovered. The VLUPC was never used after the XCB in a hole or. leg 90 but the potential existed and vill prove valuable in the future.

The Soft Formation Cutting Shoes were very effective in mud, clay, ooze and chalk. The fact that they efficiently cored 20-25 meters of very hard volcanogenic rock was an uncxpected bonus. 
The fine results of the XCB usage is further highlighted by the fact that' the "floating" core catchers and liners were probably not effective. Even without those features results were good. With further design improvements to these and other aspects of the design, the $\mathrm{XCB}$ will soon obsolete the conventional rotary coring system. 
EXTENDED CORE BARREL

LEG 94

\section{Product Improvements}

The newest version of the Extended Core Barrel (XCB) encompasses several design modifications which are listed below.

1. New Latch: The main differences between the new latch and the old one are that the latch dogs are longer (4" vs $2^{\prime \prime}$ ) and lock out farther (5" O.D. vs $4 \frac{1}{2} "$ O.D.), which prevent them from locking out any place except under the latch sleeve. In addition, the dogs are flat-bottomed and work over flats on the pulling neck rather than on a cylindrical surface. The problem with the old latch was that it frequently stuck in various parts of the drill string--usually in the bottom hole assembly (BHA). It was surmised that it jammed when the dogs locked out in either a Drilco Bore-Back or a bumper sub. The Bore-Backs, which may occur in several BHA connections, present a $6 "$ I.D. for a length of $3 \frac{1}{2} "$. An open bumper sub exposes a 4-3/4" I.D. for a length of 5 feet. Even if the latch dogs lock out they should still be free to disengage against a downward force, but friction and/or corrosion debris from the drill pipe may inhibit this action.

2. Vent Sub/Liner Hanger: This assembly replaces the field-modified Bearing Shaft/Bearing Sub/Seal Sub Assembly of the old-style XCB. Its dual purpose is to provide a one-way exhaust valve for the displaced water in the core barrel, and to provide a friction-free support for the top of the core liner.

3. Double Box Core Barrels (3" I.D. $x$ 31" O.D.): The old-style core barrels measured 3-1/8" I.D. $\times 3-5 / 8^{\prime \prime}$ O.D. with 3-3/4" O.D. upsets at the connections. The upsets cause a critical circulation flow restriction inside the 3.8" I.D. Seal Bore Drill Collar employed in the BHA for the new Advanced Piston Corer (APC). In order for the XCB to be compatible with the APC, the XCB core barrel O.D. was slimmed down to $3 \frac{1}{2} "$. But at least a $3^{\prime \prime}$ I.D. was needed to allow the core liner enough clearance to remain non-rotating inside the core barrel. A standard box/pin core barrel cannot have a $3 "$ I.D. because the DSDP pin thread connection requires a $2-7 / 8^{\prime \prime}$ I.D. In the new XCB assembly two $15^{\prime}$ long double box inner core barrels are linked with a 1 " double pin connector. Thus the $30^{\prime}$ core liner rubs the core barrel only at the $2-7 / 8^{\prime \prime}$ I.D. double pin connector. A comparison of flow rate vs pressure (read at the rig floor) was made for both the old-style and new-style barrels. The results are shown in Table 1. 
4. DSDP Soft Formation Cutting Shoe: Two minor modifications were made to improve circulation efficiency. The exterior water channels were shortened so that the core guide choke will not be bypassed as the shoe retracts into the bit; the eight jet slots at the bottom of the shoe were lengthened by $1 / 8$ " to $3 / 8^{\prime \prime}$. The slots are now $1 / 8^{\prime \prime} \mathrm{W} \times 3 / 8^{\prime \prime} \mathrm{L}$.

5. Acker Hard Formation Cutting Shoes (Fig. 1): Acker Drill Company produces a line of natural and synthetic diamond cutting shoes which cut a $2 \frac{1}{2} "$ diameter core and are slim enough to pass through a 3.8". I.D. core bit. DSDP has purchased several of these shoes, and has fabricated adaptors to allow them to be run in lieu of the DSDP soft formation shoes on the XCB system. The natural diamond shoes will be used for solidbasalt drilling. The synthetic diamond shoes fall into two categories: The "Geoset" shoe has a stepped pyramid profile studded with synthetic diamonds, and has been claimed to have produced very high penetration rates in limestone and in soft to medium-hard rock. The "Amalgamated" shoe has a flat profile composed of natural and synthetic diamond chips set in a hard metal matrix. It should be useful for coring broken basalt. Several Acker core catchers were also purchased and adapted for XCB use. Each consists of a split friction ring in a tapered case which allows upward core entry, but squeezes against the core to prevent any downward movement. It was recognized that the split ring core catchers might not effectively retain anything softer than basalt, so two standard DSDP core catchers were modified to be used with the Acker shoes.

\section{Field Modifications}

1. Lower Latch Washer OP4474: During the initial assembly, it was discovered that the XCB latch dogs would not fully retract flush with the latch body when the pulling neck was lifted. The problem was traced to the lower latch washer. When the latch dogs shouldered against the washer, they were not yet clear of the ramp on the pulling neck. The washer was ground down to $1{ }^{\prime} /{ }^{\prime \prime}$ from its original $1 \frac{1}{2} "$ thickness to provide more axial movement for the dogs to clear the ramp and fully retract.

2. Soft Formation Cutting Shoe OP4458: During Site 609 the inlet holes on two of the three shoes were widened from $\frac{1}{4} "$ to $3 / 8^{\prime \prime}$ diameter to increase circulation flow.

3. Modified Core Catcher OP4483: After Site 608 both of the modified core catchers were damaged. Each was rebuilt by replacing the standard core catcher body OR7020 with a 2-5/8" I.D. sleeveless core catcher body 0R7024. The larger I.D. was intended to provide more clearance over the $2 \frac{1}{2} "$ diameter core cut by the Acker shoes.

4. Alternate Liner Support Sleeve OP4458: This optional piece (2.6" I.D.) was used subsequent to Site 608 to replace the regular 2.5" I.D. 1iner support sleeve in order to increase core clearance. The larger radial dimensions of the alternate sleeve required that the bottom of the core liner be reamed for a length of $2 \frac{1}{2} "$. A drill powered reaming tool (previously used for shipboard liner splicing) was adapted for the purpose, but it could only penetrate one inch. One and one half inches were trimmed off of the alternate sleeve to maintain correct spacing. 


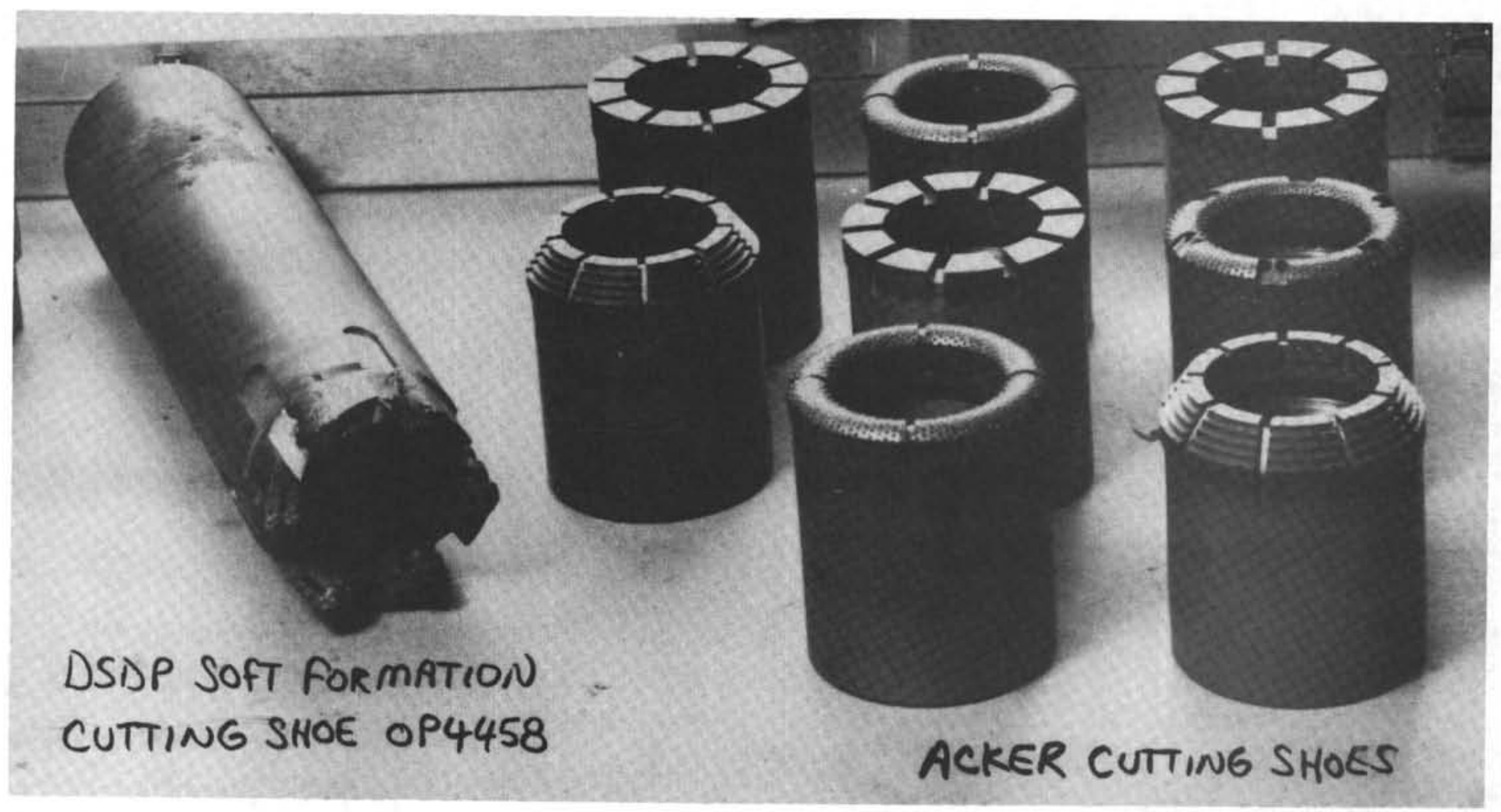

FIGURE 1 


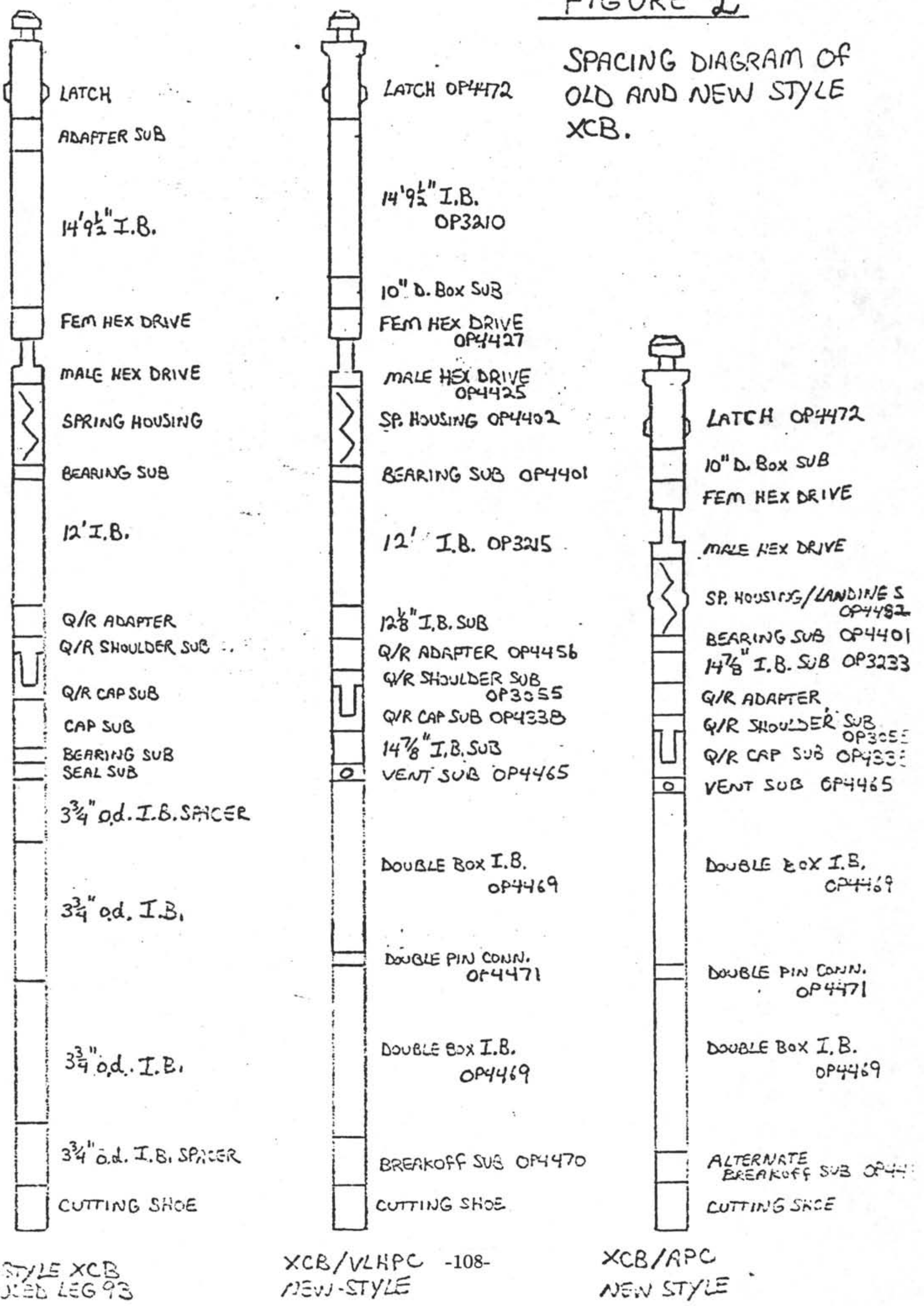


Assembly and Spacing

The XCB was assembled into several configurations during Leg 94 . The ones selected as most practical are depicted in Figs. 2 and 3 . The assembly steps are clearly delineated in the XCB manual.

The shortest version of the XCB, configured to be compatible with the Advanced Piston Corer (APC) was used only once before it was lost in Hole 606A. Thereafter the XCB was configured to match the length of the VLHPC. The loss of one of the two newly modified $X C B$ 's made it necessary to alternate the remaining new-style lower section with an old-style lower section used on previous legs (Fig. 2).

A third configuration, also shown in Fig. 2, incorporated the Core Barrel Pressure Tool (CBPT). This was accomplished by removing one 15' double box core barrel from the lower section, and adding the CBPT and spacers to maintain the original overall length. The core capacity of this assembly was limited to five meters. The CBPT could have been added to the lower section without removing the core barrel (and the overall length maintained by removing spares from the upper section above the quick release). But it was decided that the extra-long lower section would be too awkward and dangerous to routinely handle, especially with the adverse weather conditions expected in the North Atlantic.

Bottom Hole Assembly (BHA)

The lower BHA components used with the XCB/APC were as follows:

Extended Core Barrel/Hydraulic Piston Corer Bit

Bit Sub (including float valve, Guide Ring OL1020, and a support bearing outer race.)

Bit Sub Spacer OG1021

Seal Bore Drill Collar OL1043

Landing/Saver Sub OG0620

3' Spacer

Top Sub

Head Sub (including Latch Sleeve OL1013)

Monel Drili Collar

These components were lost when the BHA parted on Site 606A. For the remainder of the cruise, the lower BHA was spaced to accept the XCB/VLHPC as follows:

Extended Core Barrel/Hydraulic Piston Corer Bit

Bit Sub (including float valve, guide ring, and support bearing outer race) Outer Core Barrel ( $9.06 \mathrm{~m})$

3' Spacer $(.92 \mathrm{~m})$

3' Spacer $(.91 \mathrm{~m})$

Drill Collar $(9.18 \mathrm{~m})$

Top Sub

Head Sub (including Latch/Seal Sleeve OL1014)

The spacing of the XCB was checked by lowering the BHA (with the XCB installed) onto the rig floor. The $\mathrm{XCB}$ was slightly rotated several times within the BHA before the latch dogs engaged the slots between the drive ears of the latch sleeve and allowed the tool to retract fully into the bit. 


\section{Operational Results}

The $\mathrm{XCB}$ was run in 11 holes and recovered 1398.9 meters of core at an overall recovery rate of $75 \%$. The core quality was generally good to excellent. The operation and handling of the tool went smoothly throughout the cruise. In most of the holes the HPC penetrated only about 120 meters before high pull-out forces or collapsing core liners necessitated a switch to XCB coring. The XCB cores immediately below the HPC refusal point were usually indistinguishable from the previous HPC cores.

A few chalky formations were encountered which proved difficult to recover; the core was either janmed or washed away as the circulation flow rate was continually adjusted to achieve optimum core recovery. Glacial erratics, pebbles of up to $6 \mathrm{~cm}$ in diameter, were continually recovered either in situ or after having dropped down hole; these may have inhibited core recovery in many cases.

There were a few occasions in which ths XCB may have encountered alternating hard/ soft sediment interbeds but did not recover the soft layers in an undisturbed state; it was difficult to determine whether the soft material was in situ or drilling slurry. In other instances, the cores definitely consisted of discrete biscuits in a matrix of drilling slurry. In these cases the XCB cores were no better (but not worse) than standard rotary cores in similar formations.

The new latch and vent sub/liner hanger assembly functioned flawlessly. The Belleville disc springs did not fare as well; as few as six and as many as 54 of the 200 springs in the tool were cracked or broken after each site. The expensive chrome-molybdenum alloy steel springs appear to be more brittle than the cheaper zinc plated steel springs, but the latter also suffered many casualties. The failures appear to be due mainly to fatigue, perhaps aided by corrosion; they were characterized by radial cracks initiating around the inside, higher stressed edges of the springs.

The DSDP built soft formation cutting shoes were used almost exclusively in the predominately nanno ooze formations encountered throughout the voyage. It was discovered that the tungsten carbide grit was layed too thick around the cutting edges of the three soft formation shoes; the I.D. gage was $5.5 \mathrm{~cm}$ instead of $6.2 \mathrm{~cm}$. The softer sediments were recovered at full gage, as the core expanded after it was cut. The core diameter reduced to $5 \mathrm{~cm}-5.5 \mathrm{~cm}$ in some of the harder formations. The DSDP shoe recovered $70 \mathrm{~cm}$ of fairly fresh vesticular basalt near the bottom of Hole 608 while sustaining little extra wear or damage.

The circulation jets at the bottom of the DSDP shoe usually returned plugged with mud. It is apparent from the normally excellent core recovery obtained with this shoe that either the circulation ports remained at least partially open during coring (and clogged only after most of the core had been cut), or the ports clogged almost immediately, and the resulting inefficiency of the unlubricated shoe caused it to retract until it was in the range of the main bit jets. On Site $609 \mathrm{~B}$, the $3 / 4$ diameter circulation inlet holes were widened to $3 / 8^{\prime \prime}$ diameter on one of the three DSDP shoes. This shoe was alternated with an unmodified shoe to compare core recoveries. At first it appeared that the larger holes distinctly increased core recovery; recovery was excellent for both shoes, but the modified shoe consistently recovered more core than the other one. Then it was discovered that the new-style core barrel--which had the modified shoe--was $14 \mathrm{~cm}$ longer than the old-style core barrel. Still, the average recovery difference was greater than $20 \mathrm{~cm}$, so a second DSDP shoe was modified, and these were used throughout the rest of the voyage. 
The Acker Geoset Cutting Shoe was used only a few times in each of Holes 607 , 608 , and 609 (Table 2). Its rather poor recovery rate of $42.7 \%$ can be attributed mostly to core jams due to the lack of clearance between the $2 \frac{1}{2}$ " gage of the shoe and the core catcher and liner support sleeve. For Site 609, the core catcher and liner support sleeve were widened to present a minimum 2.6" I.D. between the cutting shoe and the core liner resulting in increased recovery for subsequent cores, but it was always less than the recovery of neighboring cores taken with the DSDP cutting shoe. The Acker split ring core catcher was tried once in a hard chalk formation, but the core slipped out.

The Acker natural diamond cutting shoe with bottom discharge ports was tried for two cores in basalt at Site 608. Both attempts achieved low core recovery due to basalt jams in either the core catcher or the liner support sleeve. The shoe was badly damaged during the second coring attempt; radial cracks had initiated at each bottom discharge port, and several sections of the cutting face had broken off (Fig. 4). The remaining surface was splayed out of gage. The basalt cores were cut with $15,000-20,000$ lbs bit weight at 30-45 rpm.

About $50 \%$ of the XCB runs were wirelined because the liners of ten shattered when the barrels were go-deviled down the pipe. At Site 607, three drop tests were conducted in an unsuccessful attempt to determine whether the go-deviled 1 iners shattered upon impact with the water or upon landing in the BHA. In the first test the barrel was dropped through the drill pipe, which had been previously topped off with water, and retrieved before landing at the bottom. The conditions were the same for the second test except that the pipe was not topped off with water. For the third test, the barrel was go-deviled, landed and retireved without coring. In neither case could the liner be made to shatter, attesting to the apparent randomness of the phenomenum

\section{Conclusions and Recommendations}

Much of the planning for Leg 94 hinged upon the successful operation of the XCB. Every site had both upper sediment objectives requiring HPC coring, and deeper objectives requiring XCB rotary coring. If the drill pipe had to be round tripped after HPC refusal at each hole, the extra time required would have severely hampered the achievement of the rather ambitious goals of Leg 94 . The compatibility feature alone, which allowed both HPC and XCB coring in the same BHA, made the $\mathrm{XCB}$ indispensible for Leg 94. In addition, the tool suffered no lost time breakdowns and maintained a consistently high core recovery percentage.

The DSDP soft formation cutting shoe was effective over the whole range of formation hardness encountered on Leg 94. Based on these results and on results from Legs 90-93, the soft formation shoe can core the entire sedimentary hardness range and even can tag basaltic basement. It has not yet been tested in limestone, sandstone or chert. It is not effective in broken basalt.

The chief problem with the Acker hard rock shoes is the $2 \frac{1}{2} "$ core gage. Acker has been consulted, and for a 10\% surcharge, they can customize their standard shoes to provide a smaller cutting gage. More tests in basalt are needed to determine whether or not the Acker shoes can be effectively adapted to XCB coring. 


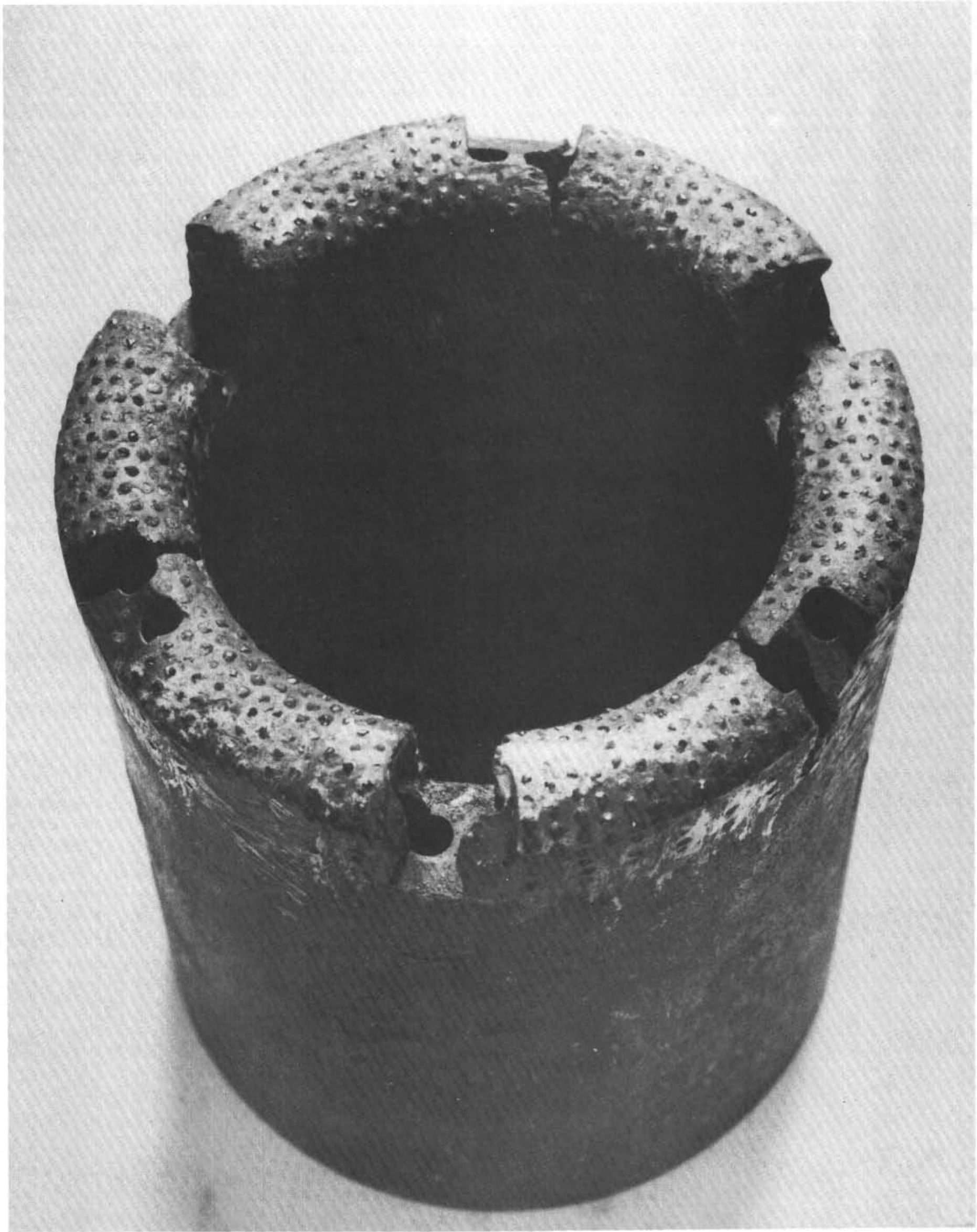

FIGURE 4 
The current method to provide circulation to the cutting shoes is partially effective, but the passive system can never achieve the fine degree of control metering which may be necessary for optimal core recovery in changing sediment formations. This area should receive top priority in future design improvements.

The disc springs, the core of the extension/retraction capability of the XCB, are acceptable for the time being but have two disadvantages:

1. They frequently crack, requiring the maintenance of a large replacement stock.

2. The present system cannot accommodate a longer stroke unless the tool is lengthened appreciably. The current disc spring stack is $25^{\prime \prime}$ long to produce a $7^{\prime \prime}$ stroke. If the stroke were lengthened to $36^{\prime \prime}$, the stack would have to be over 10 feet long.

Future design improvements should consider the employment of a compression spring, perhaps in combination with disc springs. The compression spring might be external to the $\mathrm{XCB}$, and operate in the area of the latch sleeve in the BHA.

The random shattered liners occurred only when the XCB was go-deviled down the drill pipe. They have been attributed to either a trapped-air explosion when the barrel impacts the water, or to impact-induced brittle failure when the barrel lands in the BHA. Similar erratic failures have occurred in HPC liners, which support the theory that the core liners are being subjected to forces which marginally exceed their strength limit. The strength limit might vary widely from liner to liner due to the fabrication process or weathering, but this has not been proved. The aggravating factor contributing to the XCB liner failures is the clearance between the liner and the core barrel. The clearance is needed to allow non-rotation of the liner during coring, but the lack of wall support reduces the overall strength of the liner.

In summary the XCB, in its present stage of development, is a fully operational tool which has greatly expanded shipboard coring capabilities. Future improvements, listed in order of priority, should include:

1. A truly controlled circulation system for the cutting shoes.

2. Stronger core liners, either through better quality control, a material change or a dimensional change.

3. Continued development of hard rock cutting shoes.

4. A helical compression spring stroking system, possibly external to the XCB.

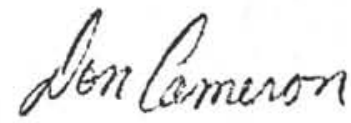




\section{TABLE I}

FLOW RATE VS PRESSURE DROP THROUGH DRILL STRING WITH XCB IN PLACE

(DATA TAKEN AT SITE 607)

\begin{tabular}{|c|c|c|c|c}
\hline $\begin{array}{c}\text { Pipe Length } \\
\text { (M) }\end{array}$ & $\begin{array}{c}\text { Pump Strokes } \\
\text { (SPM) }\end{array}$ & $\begin{array}{c}\text { F1ow Rate } \\
\text { (GPM) }\end{array}$ & \multicolumn{2}{|c}{ Pressure (PSI) } \\
\cline { 4 - 5 } 3660 & 10 & 81 & 50 & O1d-Style XCB \\
& 20 & 163 & 150 & 50 \\
& 30 & 244 & 350 & 350 \\
& 40 & 325 & 600 & 550 \\
& 50 & 406 & 900 & 825 \\
\hline \multirow{3}{*}{3572} & 20 & 163 & & 150 \\
& 30 & 244 & & 350 \\
& 40 & 325 & & 600 \\
& 50 & 406 & & 925 \\
& & & & \\
\end{tabular}

NOTES: 1. The XCB lands inside a 4-1/8" I.D. Outer Core Barrel

2. The 01d-Style XCB Barrel is 3-5/8" 0.D. with 3-3/4" Upsets

3. The New-Style XCB Barrel is $31 / 2^{\prime \prime}$ O.D. 
TABLE 2

ACKER CUTTING SHOE PERFORMANCE

\begin{tabular}{|c|c|c|c|c|c|}
\hline Type & Core Catcher & Hole/Core & Cored & Recovered & Comments \\
\hline Geoset & 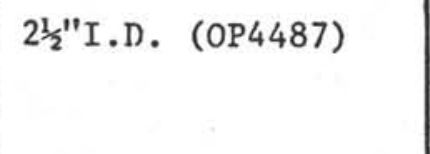 & $607 / 17$ & 9.6 & 2.56 & $\begin{array}{l}\text { Firm nanno ooze. Totally } \\
\text { shattered liner impeded } \\
\text { recovery. }\end{array}$ \\
\hline Geoset & 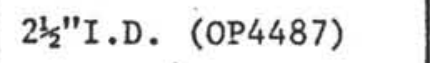 & $607 / 29$ & 9.6 & 4.27 & Firm nanno ooze. \\
\hline Geoset & 21/2"I.D. (OP4487) & $608 / 33$ & 9.6 & 3.66 & $\begin{array}{l}\text { Hard chalk. Core jammed i } \\
\mathrm{cc} \text { and liner support sleev }\end{array}$ \\
\hline Geoset & Acker Split Ring & $608 / 47$ & 9.6 & 0 & Core slipped out of $\mathrm{cc}$. \\
\hline Geoset & 2-5/8"I.D. modified & $609 / 27$ & 9.6 & 5.82 & Hard chalk. \\
\hline Geoset & $2-5 / 8 " I . D$, modified & $609 / 29$ & 9.6 & 8.8 & Hard chalk. \\
\hline Geoset & 2-5/8"I.D. modified & $609 / 31$ & 9.6 & 2.21 & Hard chalk. CC jammed. \\
\hline Geoset & 2-5/8"I.D. modified & $609 B / 33$ & 9.6 & 5.54 & Firm nanno ooze. \\
\hline $\begin{array}{l}\text { Natural } \\
\text { Diamond }\end{array}$ & 21/2"I.D. (OP4487) & $608 / 58$ & 6.6 & 0.67 & Basalt. Core catcher jamm \\
\hline $\begin{array}{l}\text { Natural } \\
\text { Diamond }\end{array}$ & Acker Split Ring & $608 / 59$ & 9.0 & 0.84 & $\begin{array}{l}\text { Basalt. Jammed in liner } \\
\text { support sleeve. Shoe } \\
\text { cracked and out of gage. }\end{array}$ \\
\hline
\end{tabular}


APPENDIX C

EXTENDED CORE BARREL

FLOW TESTS 


\section{ABSTRACT}

Previous static pressure tests have shown that the core liner can only withstand $\approx 33 \mathrm{psi}$ external pressure. The design of the XCB cutting shoe circulation system subjects the core liner to varying amounts of external pressure depending on the drill string circulation pressure. Flow tests were conducted on the interacting systems to determine flow vs pressure curves. The "safe" range of flows was determined to be too narrow to ensure the integrity for the core liner under normal drilling operations. Even at pressures under $30 \mathrm{psi}$ the liner was found to elastically deform to allow unwanted water flow through its connections and into the core space. Based on test data it was determined that the system should be redesigned to totally isolate the core liner from pressure due to circulation flow. 


\section{INTRODUCTION AND OBJECTIVES}

Of the several problems encountered with the XCB during testing on Leg 84, the most troublesome was that the core liner collapsed during every test. Subsequent static pressure tests conducted on the core liner have shown that it can only withstand $28-38$ psi external pressure, depending on the water temperature. It was suspected that the cutting shoe circulation system allowed too much back pressure inside the core barrel and caused the liner to collapse.

The object of these flow test was to determine pressure vs. flow curves for the XCB circulation system, the maximum circulation flow the liner can withstand, and to judge whether the imposed limitations would be acceptable for normal drilling operations. 


\section{PROCEDURE}

\section{A. Determination of Flow Curves}

\section{Introduction}

Several interacting variables needed to be determined as a function of the circulation immediately above the bit:

a) Flow rate through the annulus between the $\mathrm{XCB}$ and the core guide of the bit.

b) Flow rate through the four bit jets

c) Flow rate through the cutting shoe jets

d) Pressure drop across the XCB inlet holes.

The drill bit used in the test had a larger core guide I.D. (3 5/8") that the one used on Leg 84 (3.54" I.D.), so the flow rate through the annulus could not be isolated and measured. However the annulus area $\left(0.221 \mathrm{in}^{2}\right)$ is approximately equal to the area of one bit jet $\left(0.196\right.$ in $\left.^{2}\right)$, so the total flow was approximated by multiplying the flow through one bit jet by a factor of 5 :

$$
\begin{aligned}
\text { TOTAL FLOW } & =\text { FLOW THROUGH } 4 \text { BIT JETS + FLOW THROUGH ANNULUS } \\
& \approx \text { FLOW THROUGH } 1 \text { BIT JET } x 5
\end{aligned}
$$

calibration curves for the remaining variables were determined by isolating each variable in the following tests. The flow rate through a bit seal was also measured, although a bit seal was not used during the XCB sea trials on Leg 84 . 
2. Circulation pressure vs. flow rate through one bit jet.

The test assembly was set up as shown in Fig. 1. Note that three of the four bit jets were plugged, and that an O-ring was inserted in the throat of the bit to plug annular flow, so that the only flow was that through the single bit jet.

Water was pumped through the assembly at various controlled pressures. The flow rate at each pressure was determined by measuring the length of time required to capture 15-60 liters of flow in a container. The accuracy of the method decreased with increasing pressure because the higher velocity flows caused increased splashout. The results are shown in Table 1. The last column in table 1 is an extrapolation to the total flow ( 5 times the flow through one jet). The extrapolated flow is graphed in Fig. 2.

3. Flow Rate vs. Circulation pressure through the XCB cutting shoe and pressure drop across the inlet holes.

The assembly was set up as shown in Fig. 3. All four bit jets were plugged as was the annulus through the core guide, so that the only flow path was through the 2-7 open inlet holes in the $\mathrm{XCB}$ (and out the cutting shoe jets.). Inside the $\mathrm{XCB}$ a stainless steel sleeve was inserted in place of the core liner. A pressure hose, plumbed through the sleeve as shown, led to a gage which measured the annular pressure between the sleeve and the core barrel. An upset section of the sleeve served as a snubber ring which made a tight sliding fit inside the core barrel. The purpose of the snubber ring was to restrict flow while still allowing relative rotation between the sleeve and the core barrel. This design was not used on Leg 84 , but 
was incorporated in these tests as a possible solution to protecting the liner from pressure spikes. The pressure above the snubber ring was not measured in this test.

The flow through the cutting shoe jets was measured at various pressures with 2-7 inlet holes open. Two of the inlet holes, which were always open, measured $1 / 8^{\prime \prime}$ Dia. The other 5 holes measured 5/18" Dia. The results are shown in Table 2 . The measured flow rate as a function of the annulus pressure (pressure inside the $\mathrm{XCB}$ ) is plotted in Fig. 4. The pressure drop across the inlet holes is plotted in Fig. 5.

4. Flow rate vs. circulation pressure through a bit seal.

The test assembly was set up as shown in Fig. 6 . All 4 bit jets were plugged, as were the $\mathrm{XCB}$ inlet holes, so that the only flow was through the bit seal (and out the annulus between the $\mathrm{XCB}$ and the core guide). It was hard to capture all the flow in a container for accurate flow rate measurements since some of it deflected off the bit cones. Several tests were run over a period of days with widely varied results. It appeared that, in addition to the relative inaccuracy of the measuring technique, the bit seal flow characteristics would change with each test. (Perhaps it was sealing differently each time). The results are shown in table 3 and graphed in Fig. 7. 
B. Flow tests with the core liner.

1. Flow test on the XCB system as used on Leg 84 .

The assembly was set up as shown in Fig. 8 . With 3 inlet holes left open, the circulation pressure was adjusted to $100 \mathrm{psi}$, then increased to $190 \mathrm{psi}$. The liner did not collapse, although it elastically deformed to allow a major water flow through its upper and lower connections. The annular pressure actually decreased as the circulation pressure increased because the liner deformed to allow more flow bypass.

A second test was run with six of the inlet holes left open. This time the liner collapsed at $42 \mathrm{psi}$ circulation pressure ( $33 \mathrm{psi}$ annular pressure). The results are shown in Table 4.

2. Flow test with core liner and snubbering ring.

Test objective was to determine if a steel sleeve with a snubber ring inserted between the core liner and the inlet holes would help to protect the liner from excess pressure. A pressure tight O-ring type seal could not be used because the sleeve (and core liner) have to rotate freely inside the core barrel. The assembly was a combination of Fig. 3 and Fig. 8. A core liner section was slipped onto the stainless steel sleeve above the snubber ring shown in Fig. 3; the core barrel was lengthened accordingly. The upper end of the core liner was sealed as shown in Fig. 8. Six of the inlet holes were left open. As the circulation pressure was increased, the pressure in the annulus below the 
snubber ring was recorded against the pressure above the ring. The snubber ring was able to maintain a $60 \%$ pressure differential up to the pressure which caused the liner to collapse. The results are shown in table 5 . 


\section{IV. $\underline{\text { CONCLUSION }}$}

The normal range of circulation flow rates during coring is $150-300 \mathrm{Gpm}$ with surges of up to $500 \mathrm{Gpm}$ (when checking for core barrel latch-in). According to Fig. 2 this corresponds to a normal circulation pressure range of 32-154 psi with spikes of up to 500 psi. On Leg 84 the XCB was always run with 7 open inlet holes. From Table 2 it can be seen that 7 open inlet holes drop the pressure by $15 \%$, so that the pressure acting on the core liner was normally $27-131 \mathrm{psi}$, and sometimes as high as $425 \mathrm{psi}$. Thus the liner was usually subjected to more than the critical 33 psi collapse pressure.

If only 2 inlet holes are opened, Table 2 shows that the circulation pressure is dropped by $93 \%$. This would protect the liner against the high pressure spikes, but would reduce the normal range of annulus pressure to only 2-11 psi - too low to maintain the desired minimum of 20 GPM flow rate out the cutting shoe jets.

The use of a snubber ring between the inlet holes and the core liner would allow high enough back pressure to maintain an acceptable flow rate out the cutting shoe jets while dropping the pressure to the liner to a safe level. But since the snubber ring is a flow restrictor instead of a pressure seal, a continuous flow is necessary to maintain a pressure differential; that flow exits through the upper and lower liner connections and into the core space as the liner elastically deforms under the less than-critical pressure.

In conclusion, the liner collapse problem has been determined to be caused by excess circulation pressure entering the annulus between the core barrel and the core liner. Some pressure is needed to maintain an acceptable flow rate out the cutting shoe jets. The pressure seen by the liner can be limited to a safe level by a proper combination of open inlet holes and a flow restrictor between the liner and the inlet holes. It was also found 
that, even when exposed to less than critical pressure, the liner elastically deformed to dump unwanted flow into the core space. (Indeed, that is the only reason the flow restrictor worked). If the liner connections were to be sealed by O-rings, then the flow into the core space would be stopped, but the pressure would equalize across the restrictor and the liner would collapse.

The present circulation system design necessarily subjects the liner to over pressurization. As a result of these tests it was decided to redesign the circulation system to totally isolate the liner from circulation pressure. 
TABLE 1

FLOW RATE VS. PRESSURE THROUGH ONE BIT JET AND EXTRAPOLATED TOTAL FLOW

$\begin{array}{cccc}\begin{array}{c}\text { Circulation } \\ \text { Pressure (Psi) }\end{array} & \begin{array}{c}\text { Measured Flow Through } \\ \text { One Jet (Liters/Sec) }\end{array} & \begin{array}{c}\text { Flow Rate } \\ \text { Gpm }\end{array} & \begin{array}{c}\text { Total Flow Rate } \\ (\mathrm{Gpm})\end{array} \\ 10.8 & 60 / 53 & 17.9 & 89.5 \\ 34 & 41 / 21.9 & 29.7 & 148.5 \\ 34 & 48 / 24.3 & 31.3 & 156.5 \\ 51 & 55 / 23.5 & 37.1 & 185.5 \\ 55 & 50 / 19 & 41.7 & 208.5 \\ 55 & 55 / 21 & 41.5 & 207.5 \\ 55 & 40 / 16 & 39.6 & 198 \\ 55 & 40 / 16.5 & 38.4 & 192 \\ 76 & 38 / 13.9 & 43.3 & 217.5 \\ 76 & 42 / 15.6 & 42.7 & 213.5 \\ 76 & 42 / 16 & 41.6 & 208 \\ 76 & 40 / 14.2 & 44.6 & 223 \\ 92 & 40 / 13.9 & 45.6 & 228 \\ 92 & 40 / 14.5 & 43.7 & 218.5 \\ 92 & 35 / 11 & 50.4 & 252 \\ 92 & 45 / 15 & 47.5 & 237.5 \\ 93 & 16 / 20 & 47.5 & 237.5 \\ 130 & 57 / 16.5 & 54.8 & 274 \\ 190 & 55 / 11 & 79.3 & 396.5\end{array}$


TABLE 2

PRESSURE DROP ACROSS INLET HOLES, AND

FLOW RATE VS. PRESSURE THROUGH CUTTING SHOE JETS

\begin{tabular}{|c|c|c|c|c|c|}
\hline $\begin{array}{c}\text { No. of Open } \\
\text { Inlet Holes }\end{array}$ & $\begin{array}{c}\text { Circulation } \\
\text { Pressure (Psi) }\end{array}$ & $\begin{array}{c}\text { Annulus } \\
\text { Pressure (Psi) }\end{array}$ & $\begin{array}{c}\text { \% Pressure } \\
\text { Drop }\end{array}$ & $\begin{array}{c}\text { Flow } \\
\text { (Liters/Sec) }\end{array}$ & $\begin{array}{c}\text { Flow Rate } \\
\text { (Gpm) }\end{array}$ \\
\hline 7 & 46.5 & 15 & 15 & $57 / 32.8$ & 27.5 \\
& 92 & 78 & 15 & $57 / 25.8$ & 35 \\
& 180 & 153 & 15 & $58 / 19$ & 48.4 \\
\hline 4 & 53 & 27 & 49 & $59 / 44$ & 21.25 \\
& 91 & 47 & 48 & $60 / 34.2$ & 27.8 \\
& 190 & 102 & 46 & $53 / 21.2$ & 39.6 \\
& 39 & 13.5 & 65 & $59 / 68$ & 13.75 \\
& 53.5 & 17.8 & 67 & $60 / 60$ & 15.8 \\
& 78 & 26.25 & 66 & $60 / 49$ & 19.4 \\
& 78 & 26.25 & 66 & $58 / 46$ & 20 \\
& 95 & 30.4 & 68 & $60 / 44.5$ & 21.4 \\
& 107 & 35 & 67 & $60 / 41$ & 23.2 \\
& 186 & 59.5 & 68 & $51 / 27.5$ & 29.4 \\
& 186 & 59.5 & 68 & $53 / 29$ & 29 \\
\hline 2 & 53 & 4.75 & 91 & $60 / 162$ & 5.9 \\
& 90 & 6.25 & 93 & $60 / 126$ & 7.5 \\
& 107 & 7 & 93 & $60 / 116$ & 8.2 \\
& 195 & 10.4 & 95 & $60 / 86$ & 11.1 \\
& 245 & 12.7 & 95 & $60 / 87$ & 12.4 \\
\hline
\end{tabular}


TABLE 3

FLOW RATE VS. PRESSURE FOR BIT SEAL

\begin{tabular}{|c|c|c|c|}
\hline Date & $\begin{array}{c}\text { Circulation } \\
\text { Pressure (Psi) }\end{array}$ & $\begin{array}{c}\text { Measured Flow } \\
\text { Liters/Sec }\end{array}$ & $\begin{array}{c}\text { Flow Rate } \\
(\mathrm{Gpm})\end{array}$ \\
\hline Sept 10, 82 & 54 & $63 / 26.5$ & 37.7 \\
& 90 & $60 / 22$ & 43.2 \\
& 188 & $60 / 18$ & 52.8 \\
\hline Sept 17, 82 & 17 & $60 / 32$ & 29.7 \\
& $49-50$ & $60 / 21$ & 45.3 \\
& 90 & $60 / 16$ & 59.4 \\
& 157.5 & $60 / 16$ & 59.4 \\
& & & 20.7 \\
& 5.8 & $60 / 46$ & 35.2 \\
& 25 & $60 / 27$ & 40.5 \\
& 44 & $60 / 23.5$ & 42.3 \\
& 55.56 & $60 / 22.5$ & 55.9 \\
& 92 & $60 / 17$ & 52.8 \\
& 92 & $60 / 18$ & 52.8 \\
& 125 & $60 / 18$ & 59.4 \\
& 149 & $60 / 16$ & 59.4 \\
\hline
\end{tabular}


TABLE 4

CIRCULATION PRESSURE VS. ANNULAR PRESSURE

DURING FLOW TEST THROUGH LEG 84 XCB SYSTEM

\begin{tabular}{|c|c|c|c|}
\hline $\begin{array}{c}\text { No. of Open } \\
\text { Inlet Holes }\end{array}$ & $\begin{array}{c}\text { Ciculation } \\
\text { Pressure (Psi) }\end{array}$ & $\begin{array}{c}\text { Annulus } \\
\text { Pressure (Psi) }\end{array}$ & Comments \\
\hline 3 & $95-100$ & 15 & Major Flow Through Liner Connections \\
& 190 & 11 & Major Flow Through Liner Connections \\
6 & 42 & 33 & Liner Collapsed \\
\hline
\end{tabular}


TABLE 5

PRESSURE DROP ACROSS SNUBBER RING (6 INLET HOLES OPEN)

\begin{tabular}{c|c|c|c|c}
$\begin{array}{c}\text { Circulation } \\
\text { Pressure (Psi) }\end{array}$ & $\begin{array}{c}\text { Annular Pressure } \\
\text { Below Ring (Psi) }\end{array}$ & $\begin{array}{c}\text { Annular Pressure } \\
\text { Above Ring (Psi) }\end{array}$ & $\begin{array}{c}\text { \% Pressurre } \\
\text { Drop }\end{array}$ & Comments \\
\hline 17 & 14.5 & - & - & \\
50 & 40 & 16 & 60 & \\
73 & 55 & 23 & 58 & \\
85 & & 33 & & Liner Collapsed
\end{tabular}


APPENDIX D

ASSEMBLY INSTRUCTIONS FOR XCB AS USED ON LEGS 94-96 


\section{EXTENDED CORE BARREL ASSEMBLY \\ for Legs 94-96}

The Extended Core Barrel can be assemblied into two configurations to make it compatible with either the APC or VLHPC. The shorter version, which has the landing shoulder located on the spring housing/landing sub, is compatible with the APC. The longer version, compatible with the VLHPC, lands on a landing shoulder at the latch. The assembly steps which are not similar to both versions are designated by alternate step numbers.

\section{A. Upper Section Assembly}

1. Install 200 disc springs (OP4419) and six spring spacers (OP4403) onto the spring shaft (OP4426). Stack the springs in a series parallel configuration (2 up, 2 down 2 up, etc.). Divide into five sets, 40 springs per set, each set separated by a spring spacer with a spring spacer at either end of the entire stack.

2. Insert an angular contact bearing (OP4408) into each end of a bearing sub (OP4401) so that the thrust bearing sides are facing outward from the sub.

3. Insert the spring shaft through the bearing sub. Then slip on a spring spacer, 5 disc springs, another spring spacer, a nut (OP4424) and a cotter pin (OP4409). Tighten the nut until it shoulders; this preloads the spring stack.

4. For APC compatibility slip the spring housing/landing sub (OP4482) over the spring shaft and make it up to the bearing sub.

4A For VLHPC compatibility slip the spring housing (OP4402) over the spring shaft and make it up to the bearing sub.

5. Install a bearing (OP4413), a T-seal (TR-025), and a wiper (D1750) onto the male sub-hex drive (OP4425). Then slip this sub over the shaft and make it up to the spring housing.

6. Slip the female head-hex drive (OP4427) over the spring shaft to entage the male sub. Then install an O-ring (\#2-324), a spring shaft washer (OP4407), a nut and cotter pin onto the shaft.

7. Make up the 10" double box sub (OP3236) to the female head-hex drive sub.

8. For APC compatibility, make up the latch (OP4472) directly to the $10^{\prime \prime}$ drive sub.

8A For VLHPC compatibility, make up a 14' $91 / 2^{\prime \prime}$ inner barrel (OP3210) a 14$7 / 8$ " inner barrel sub (OP3233), and the latch (OP4472) to the 10 " double box sub.

9. For APC compatibility, make up a 14-7/8" inner barrel sub (OP3233) to the bearing sub at the lower end of the spring housing/landing sub.

9A For VLHPC compatibility, make up a 12' inner barrel (OP3215) and a 12-1/8" inner barrel sub (OP3231) to the bearing sub at the lower end of the spring housing. 
10. Make up the quick release adapter sub (OP4456) and the quick release shoulder sub (OP3055) to the inner barrel sub. This completes the assembly of the upper section.

B. Lower Section Assembly

1. Connect two double box inner barrels (OP4469) with a double pin connector (OP4471). NOTE: One of the barrels should already have the double pin connector Baker-locked onto it.

2. Install two O-rings \#2-330 onto the liner hanger (OP4464), which is part of the vent sub assembly.

3. Install a check ball and valve (OP3107) into the vent sub (OP4494). Then make up the vent sub to the upper end of the inner barrel assembly.

4. Make up the quick release cap sub to the vent sub.

5. For APC compatibility, make up the alternate breakoff sub (OP4488) to the lower end of the inner barrel assembly.

5A. For VLHPC compatibility, make up the breakoff sub (OP4470) to the lower end of the inner barrel assembly.

6. Install either of the following to complete the assembly:

a) Soft Formation Assembly: Insert any combination of standard core catchers, flapper core catcher, and spacer (OP4481) into a soft formation cutting shoe (OP4458). The stack should be no higher than the top of the isolation sleeve (OP4418) inside the cutting shoe. Then make up the cutting shoe to the breakoff sub.

b) Hard Formation Assembly: Choose a suitable Acker diamond bit and make it up hand tight to the cutting shoe adapter (OP4485).

Install O-ring \#2-335 onto the upper end of the core lifter adapter (OP4484).

Make up either a modified core catcher (OP4487) or an Acker lifter assembly (consisting of lifter case \#101544, lifter \#101546, and stop ring \#101545) to the lower end of the core lifter adapter.

Insert the core lifter adapter into the cutting shoe adapter. The upper part should shoulder on the cutting shoe adapter just before the lower part contacts the bevel inside the Acker Bit. The gap allows circulation flow to the cutters. The gap may be increased by inserting an adjustment shim (OP4486) into the upper end of the cutting shoe adapter before installing the core lifter adapter. 
Makeup the cutting shoe adapter to the breakoff sub. Check to see if the core lifter adapter can rotate within the assembly. If it is pinched, you may have to remove some material from the top of the retainer ring (OP4415).

Finally, torque up the Acker bit to the cutting shoe adapter. 
APPENDIX E

MACHINE DRAWINGS

$-139-$ 
EXTENDED CORE BARREL

PARTS LIST

\begin{tabular}{|c|c|c|}
\hline $\mathrm{P} / \mathrm{N}$ & DESCRIPTION & NO. REQ'D \\
\hline OP4435 & XCB Assembly (F/APC Compatibility)-MOD. II & - \\
\hline *OP4401 & Bearing Sub & 1 \\
\hline *OP4403 & Spring Spacer & 8 \\
\hline OP4407 & Spring Shaft Washer & 1 \\
\hline OP4414 & Nut, For Spring Shaft & 2 \\
\hline OP4415 & Delrin Retaining Ring & 1 \\
\hline OP4416 & Liner Support Sleeve & 1 \\
\hline OP4418 & Isolation Sleeve & 1 \\
\hline *OP4419 & Disc Springs & 205 \\
\hline *OP4424 & Nut, Spring Shaft & 2 \\
\hline *OP4425 & Male Hex Drive & 1 \\
\hline${ }^{*} \mathrm{OP} 4426$ & Spring Shaft & 1 \\
\hline OP 4427 & Female Hex Drive & 1 \\
\hline OP4432 & Compression Spring & 1 \\
\hline OP4445 & Acker "Natural Diamond" Bit & 1 \\
\hline OP4447 & Acker "Amalgamated" Bit & 1 \\
\hline OP4448 & Acker Lifter Case (\#101544) & 1 \\
\hline OP4449 & Acker Lifter (\#101546) & 1 \\
\hline OP4450 & Acker Stop Ring (\#101545) & 1 \\
\hline OP4451 & Extension Measuring Gauge & -- \\
\hline OP4458 & Soft Formation Cutting Shoe & 1 \\
\hline OP4459 & Isolation Sleeve & 1 \\
\hline OP4460 & Bushing & 1 \\
\hline OP4464 & Liner Hanger & 1 \\
\hline OP4469 & 15' Double Box Inner Barrel & 2 \\
\hline OP4470 & Breakoff Sub & 1 \\
\hline OP4471 & Double Pin Inner Barrel Connector & 1 \\
\hline OP4472 & Latch Assembly Complete & 1 \\
\hline OP4473 & Latch Dog - XCB Latch & 2 \\
\hline OP4474 & Washer - XCB Latch & 2 \\
\hline OP4475 & Body - XCB Latch & 1 \\
\hline OP 4477 & Pulling Neck - XCB Latch & 1 \\
\hline OP4478 & Spring - XCB Latch & 1 \\
\hline OP4479 & Landing Shoulder Cap - XCB Latch & 1 \\
\hline OP4480 & Cutting Shoe Gage & 1 \\
\hline OP4481 & Core Catcher Spacer & $1-2$ \\
\hline
\end{tabular}




\begin{tabular}{rlr}
\multicolumn{1}{c}{ P/N } & \multicolumn{1}{c}{ DESCRIPTION } & NO. REQ \\
\hline & & \\
OP4482 & Spring Housing/Landing Sub \\
OP4484 & Core Lifter Adapter \\
OP4485 & Cutting Shoe Adapter \\
OP4487 & Modified Core Catcher \\
OP4489 & Spring Shaft \\
OP4493 & Male Drive Sub \\
OP4494 & Vent Sub \\
OP4495 & Spring Housing \\
OP4496 & Adapter, 3 Lug Quick Release \\
OP4497 & Spring Stop Sub \\
OP4498 & Spring Stop Washer \\
& \\
OP3024 & Pivot Pin - XCB Latch \\
OP3107 & 15/16" Check Ball And Seat \\
OP3108 & Valve Seat Retainer \\
OP3230 & Inner Barrel Sub, 9 3/4" \\
*OP3233 & Inner Barrel Sub, 14 7/8" \\
OP3236 & Double Box Inner Barrel Sub \\
*P3310 & Drilling Sub, 13 5/8" \\
OP3400 & Core Liner, Butyrate, 2.817 x 32' 6" \\
OP4752 & Quick Release Nut \\
OP4753 & Quick Release Dog \\
OP4825 & Male Quick Release \\
OP4827 & Female Quick Release
\end{tabular}

Fasteners, Seals \& Bearings

OD2324

OD2330

OD2335

*OD5100

*OD5200

OD6515

OD6585

OD7160

OD7220

*OD7222

*OD7224
O-Ring \#2-324, Buna-N, 70D

O-Ring \#2-330, Buna-N, 70D

O-Ring \#2-335, Buna-N, 70D

T-Seal, Parker \#TR025

Wiper Ring, Parker \#D1750

Set Screw, Socket, 1/2-13 x 3/4

Set Screw, Socket, 1/2-13 x 5/16

Cotter Pin, $1 / 4 \times 2-1 / 2$

Ball Bearing, 5/16 Dia.

Bearing \#7207 BYG

Bearing \#6009

Core Catcher Alternatives

Acker Slip-Type Core Catcher, Includes:

Lifter Case (\#101544)

Lifter (\#101546) 
OP4450 Stop Ring (\#101545) 1

OP4487 Modified Core Catcher 1

OR7010 Core Catcher, Complete, Dog Type "10" 1-2

OR7020 Core Catcher, Complete, Dog Type "8" 1-2

OR7100 Core Catcher, Complete, Flapper Type 1

$\underline{\text { Outer Barrel Components }}$

OL1010 Head Sub 1

OL1012 Window Latch Sleeve 1

OL1021 Landing/Saver Sub 1

OL1022 Long Top Sub 1

OL1029 Long Bit Sub 1

OL1031 Guide Ring 1

OL1044 Seal Bore Outer Core Barrel 1

OL1504 Padded Flapper (Replaces OL1510) 1

* Used With Disc Spring Version Only 


\begin{tabular}{|c|l|l|l|l|l|}
\hline NO. & \multicolumn{1}{|c|}{ DESCRIPTION } & DATE & BY & CH. & APR. \\
\hline 1 & NEW PART $\$$ DWG NO. & RK & & & \\
\hline 2 & $213 / 16$ WAS 31/8 & $R K$ & 1.9 .9 & & \\
\hline 3 & REDR MWN FOR COMPREHENSION REDIM. & CKK & $7.0_{8}$ & DH & DPH \\
\hline
\end{tabular}

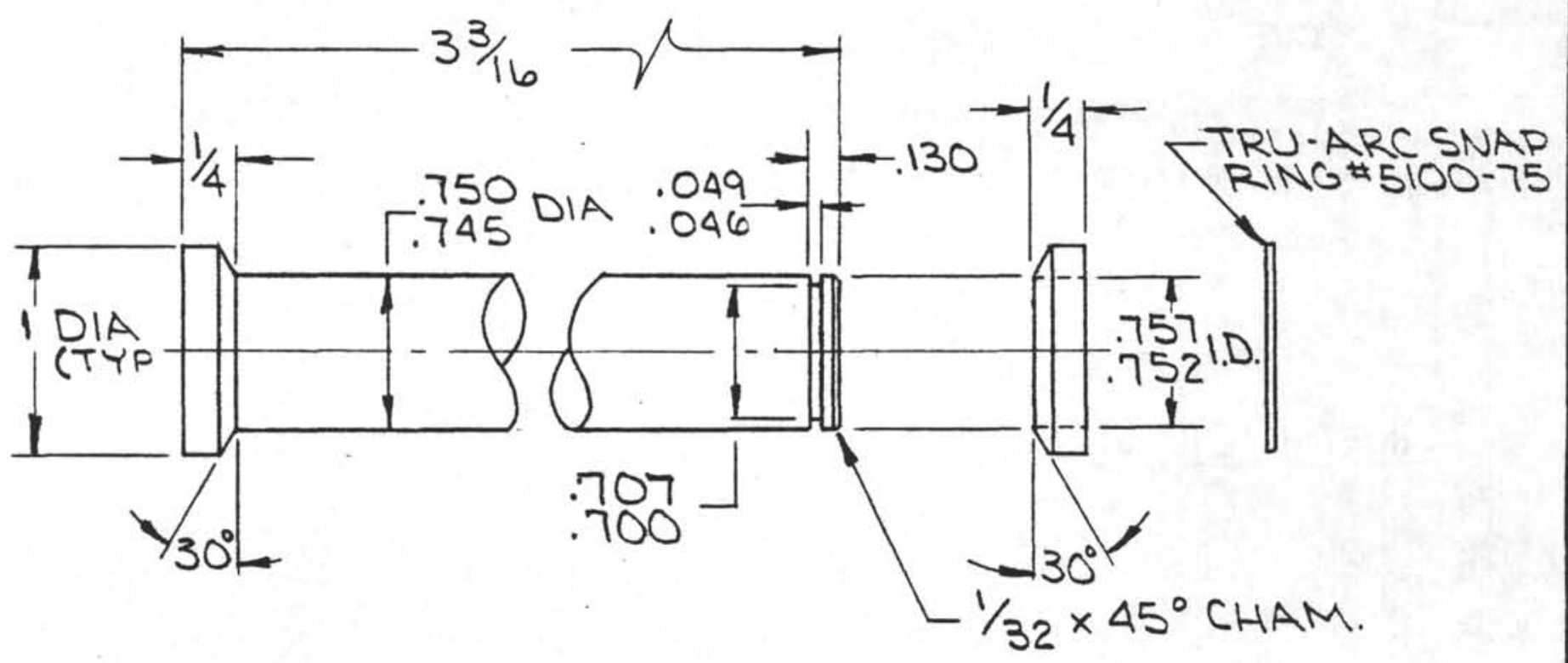

DO NOT SCALE TOLERANCES UNLESS NOTED

FRACTIONS $\pm 1 / 64$ DECIMALS \pm .005 ANGLES $\pm 1 / 2^{\circ}$ CORNERS $1 / 64 \times 45^{\circ}$ or $1 / 64 R$ FINISH 125 SUAFACE TREATMENT PARKOLUBE HEAT TREATMENT $36-40 R$
CONCENTRICITY ALL DIAMETERS: TIR.003

\section{DEEP SEA DRILLING PROJECT}

SCRIPPS INSTITUTION OF OCEANOGRAPHY UNIVERSITY OF CALIFORNIA, SAN DIEGO LA JOLLA, CALIFORNIA 92093

PIVOT PIN 
SPECIFICATION SHEET

\begin{tabular}{|c|c|c|}
\hline PART NUMBER & : & $0 P-3107$ \\
\hline DESCRIPTION & : & \\
\hline ITEM & : & Check Ball \& Seat \\
\hline MANUEACTURER & : & Harbison-Fischer \\
\hline P/N FOR ORDERING & : & 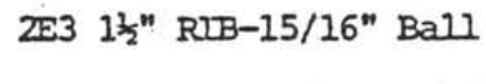 \\
\hline DIMENSIONS & & \\
\hline
\end{tabular}

OTHER INFORMATION :

VENDOR

: Harbison-Fischer Mfg. Co.

P.O. Box 2477

Fort Worth, Texas 76101

(817) $355-4381$

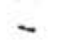

0P-3107 


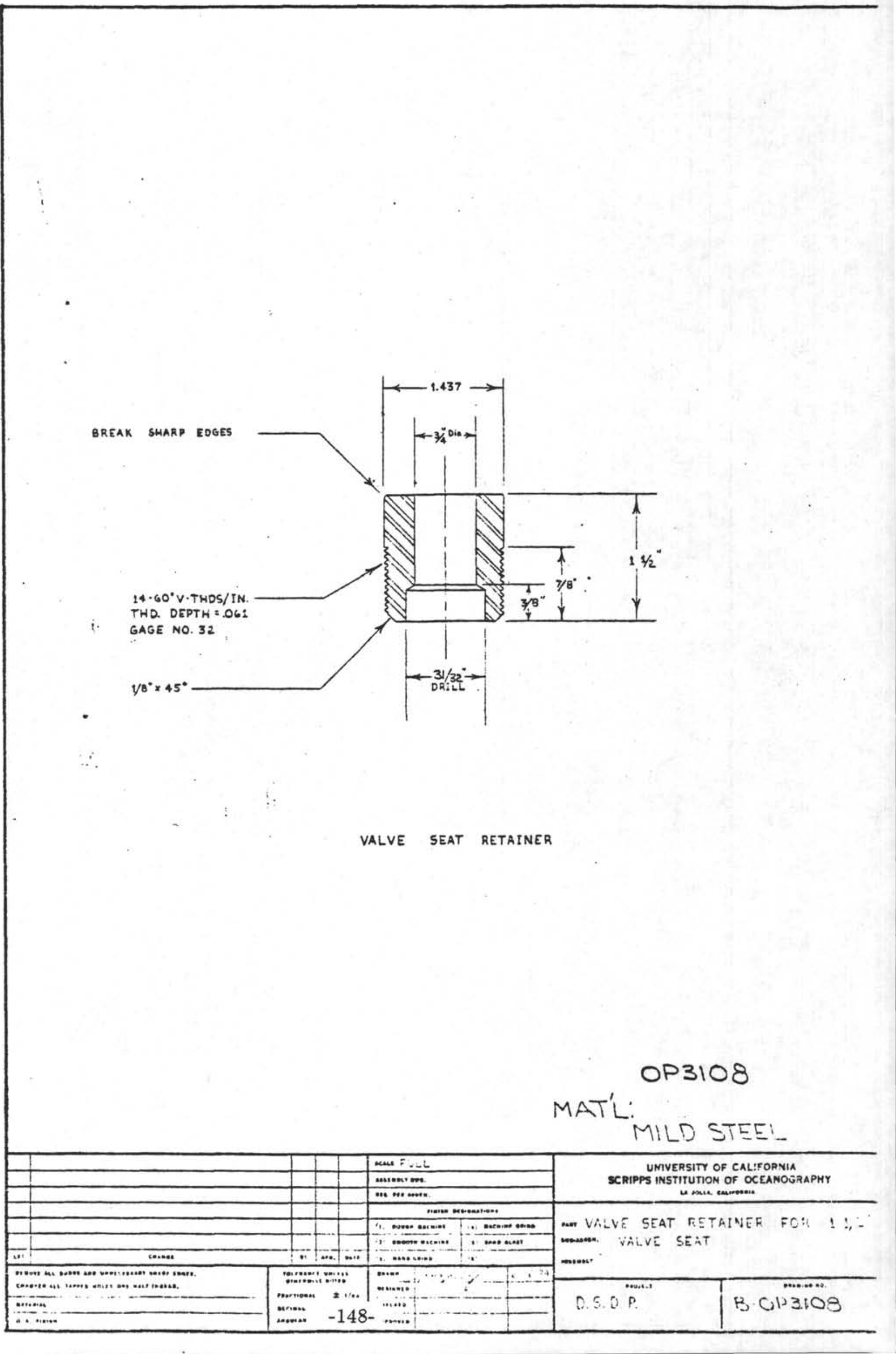




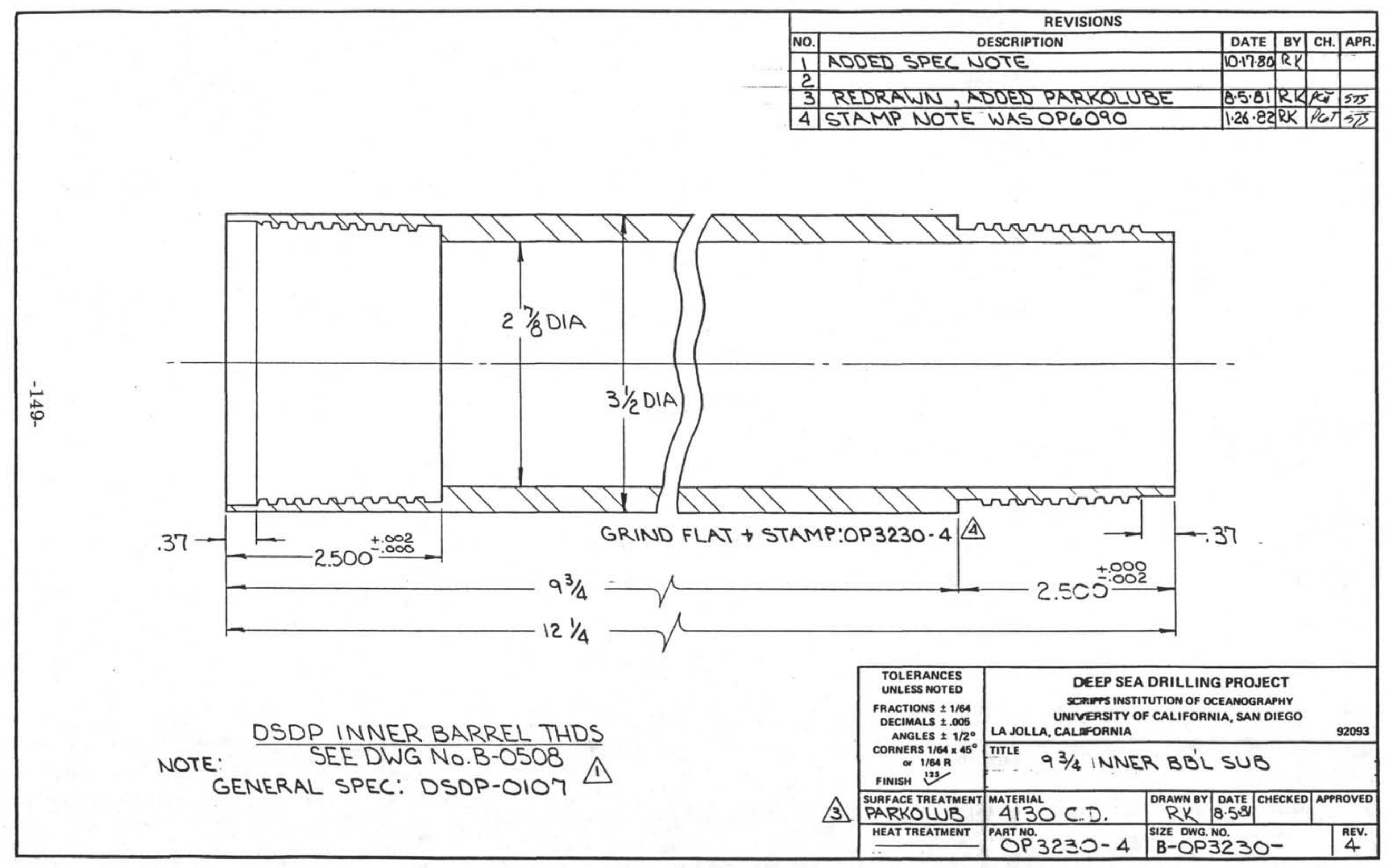




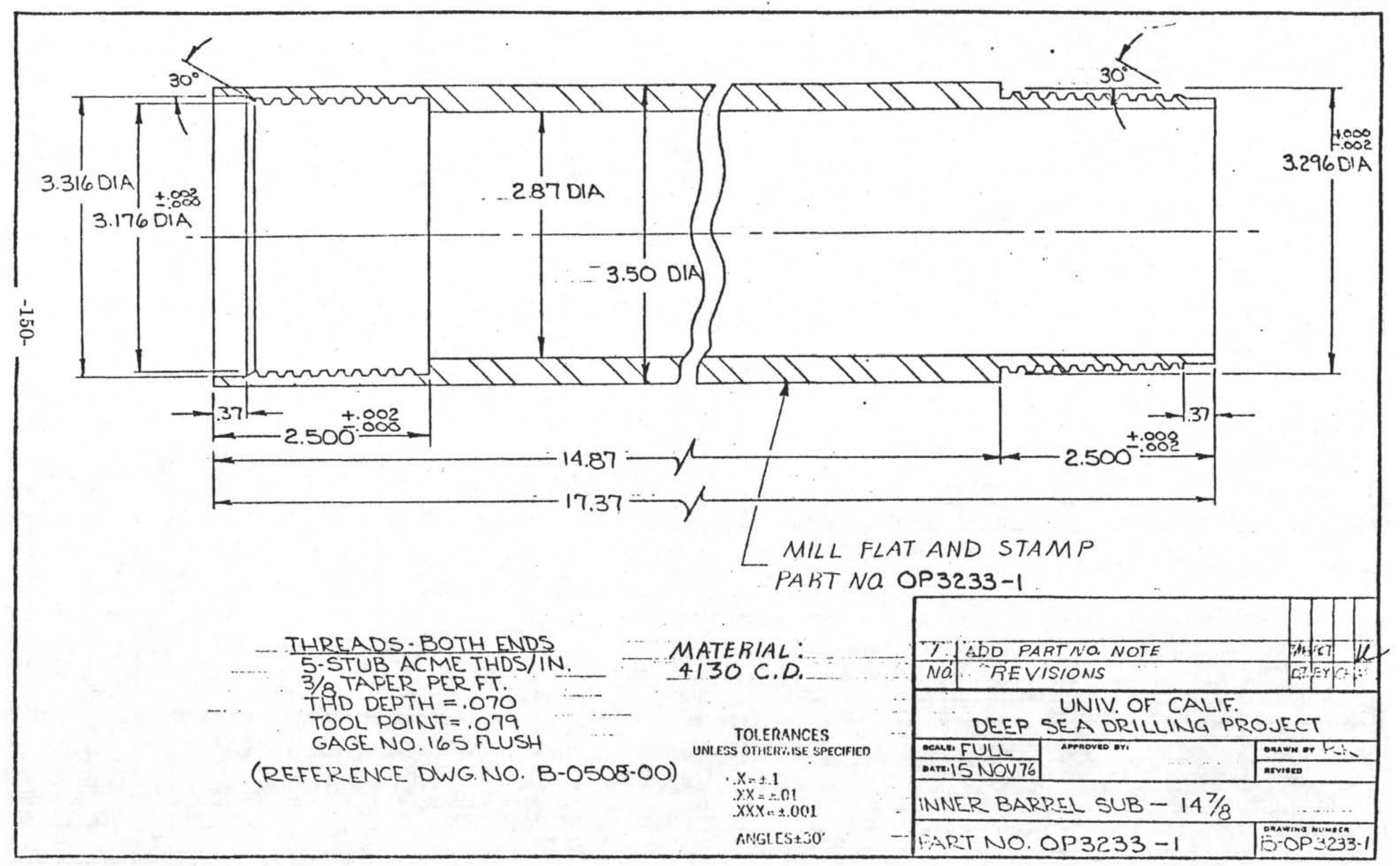




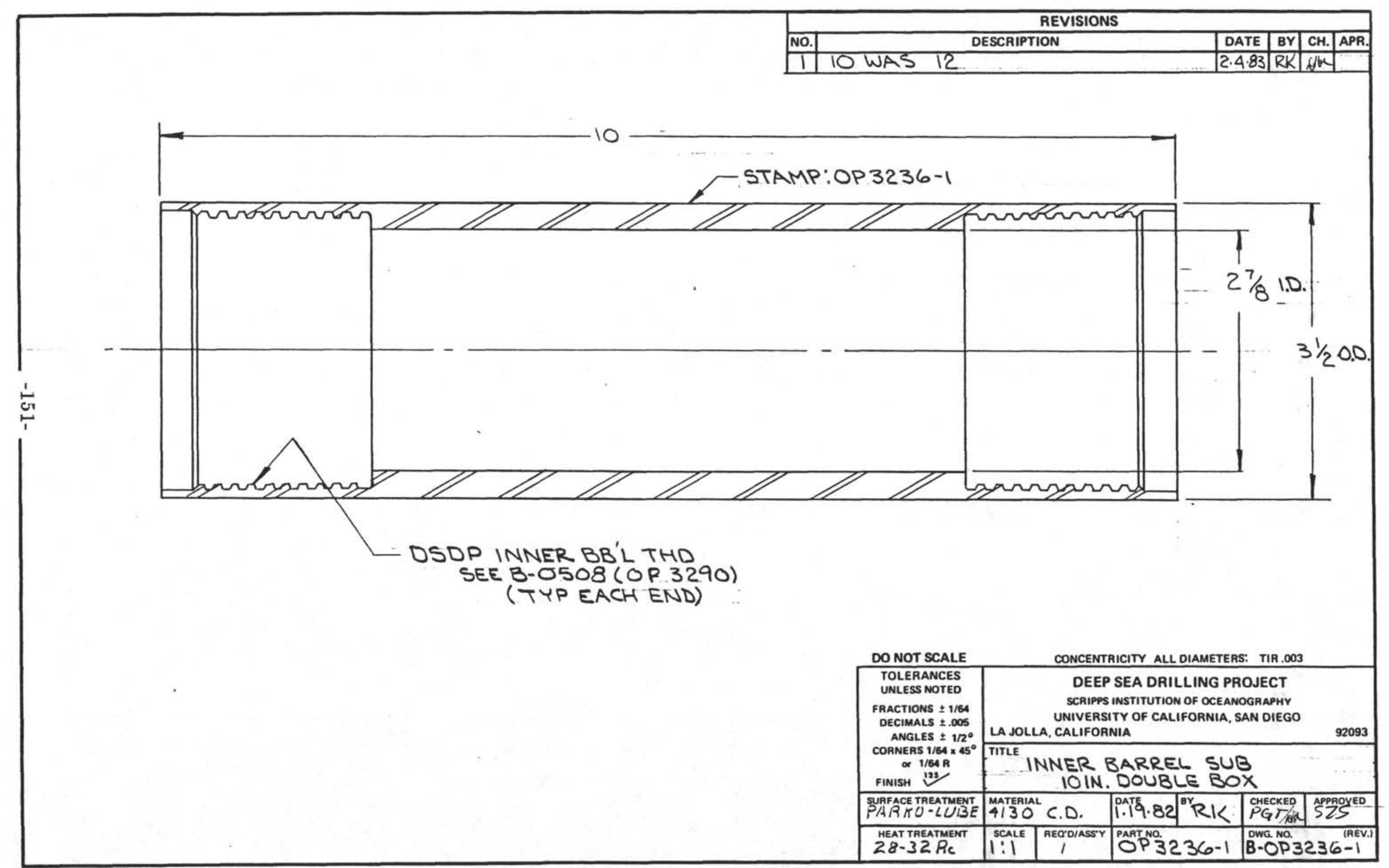




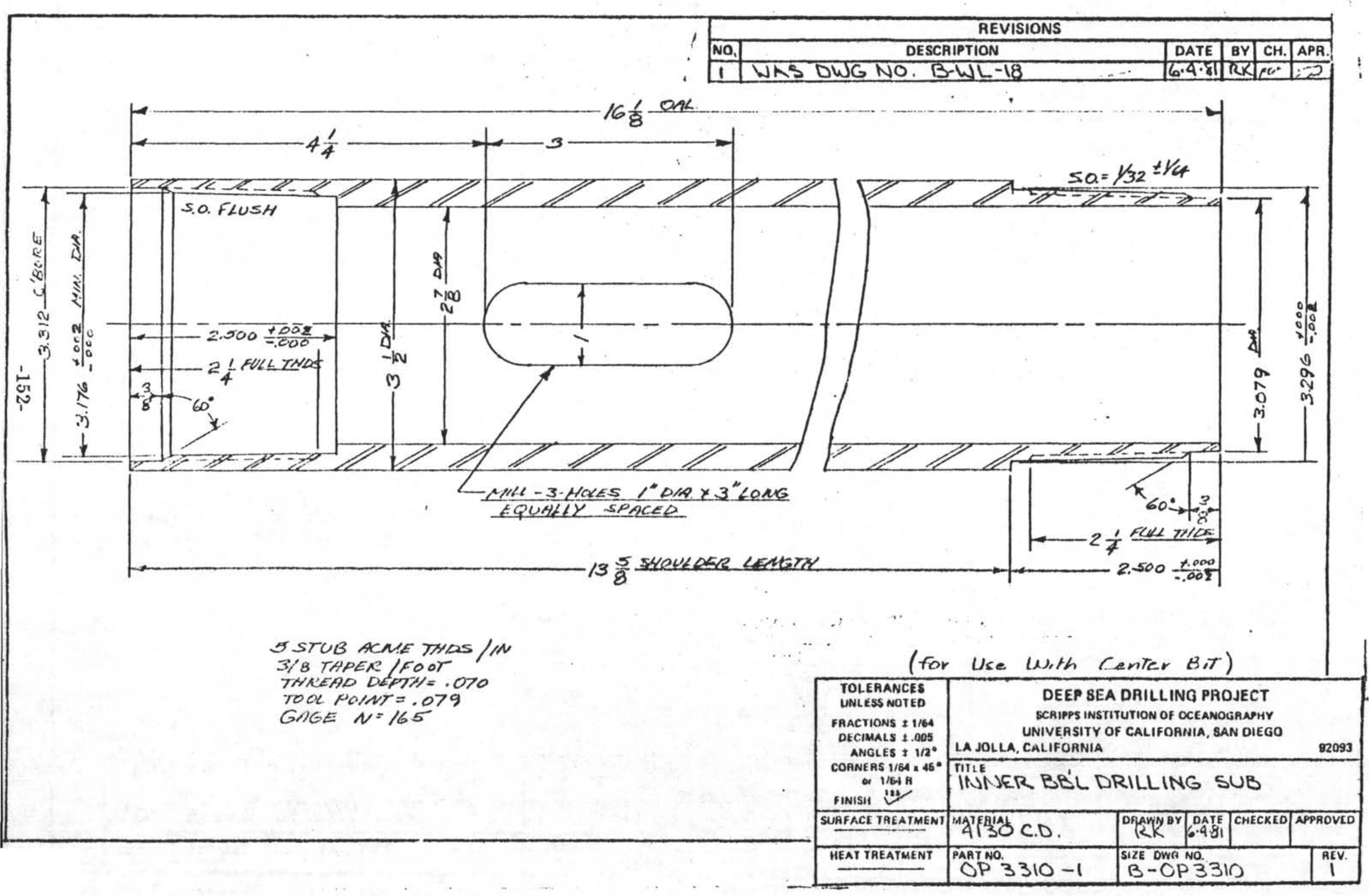




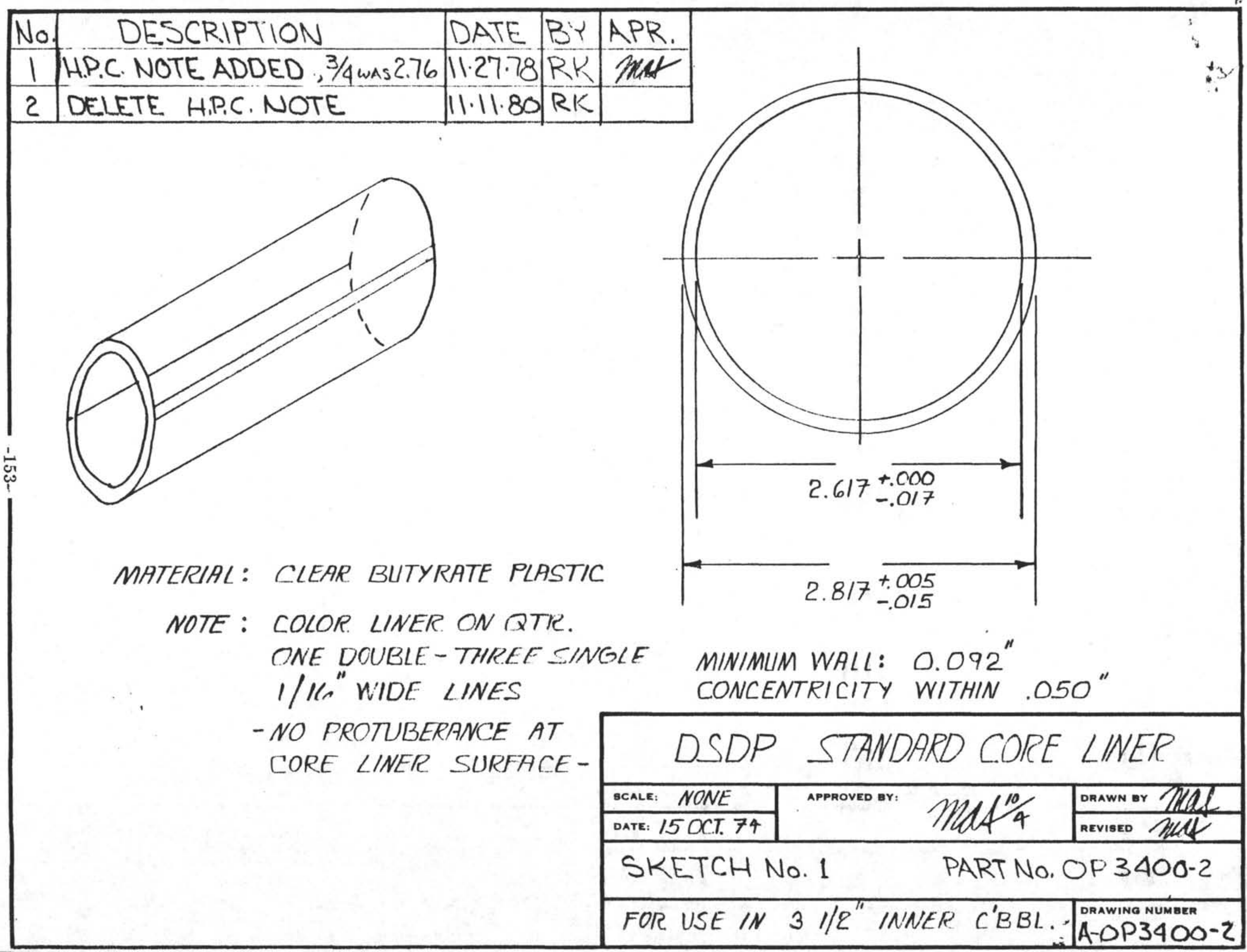




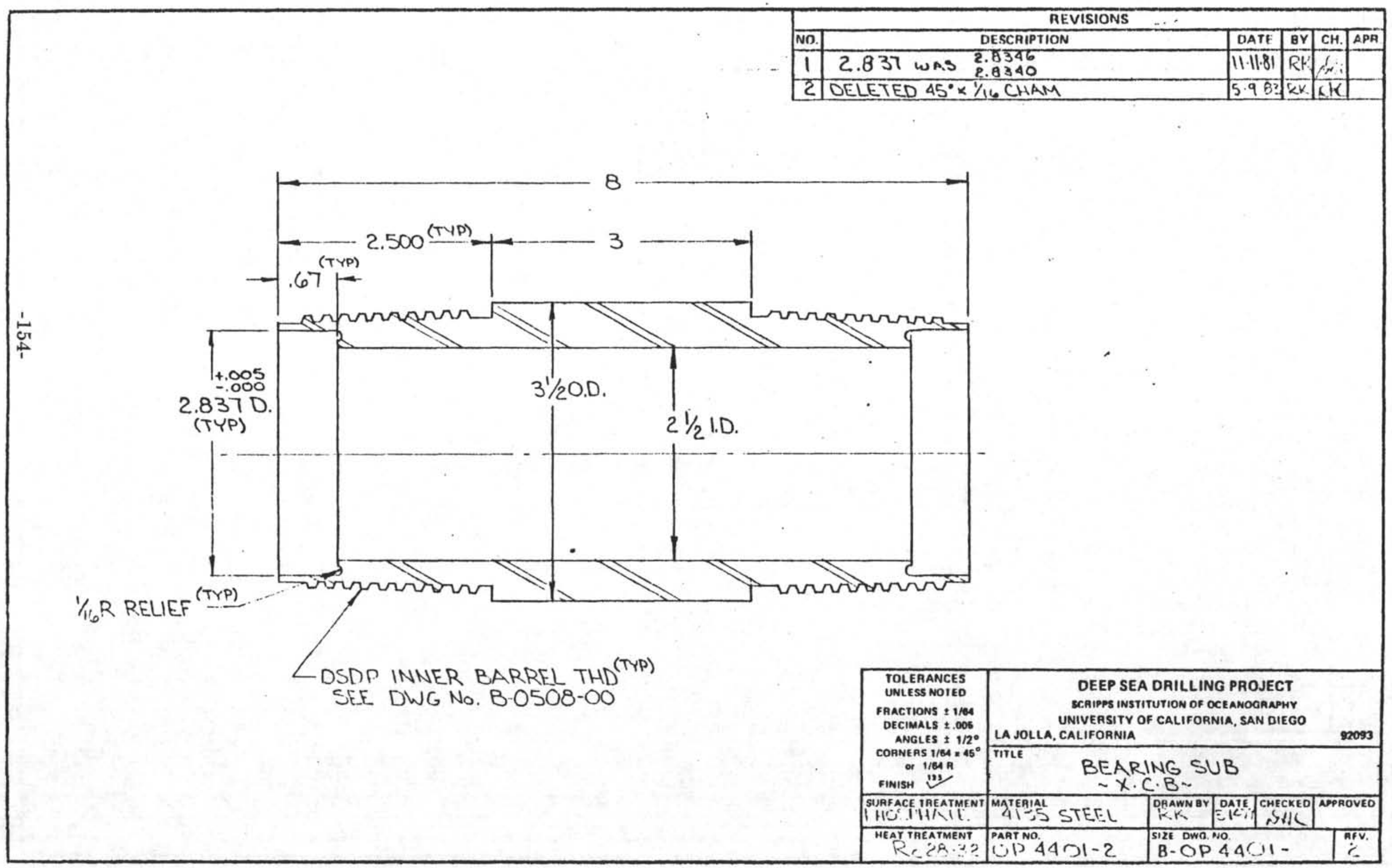




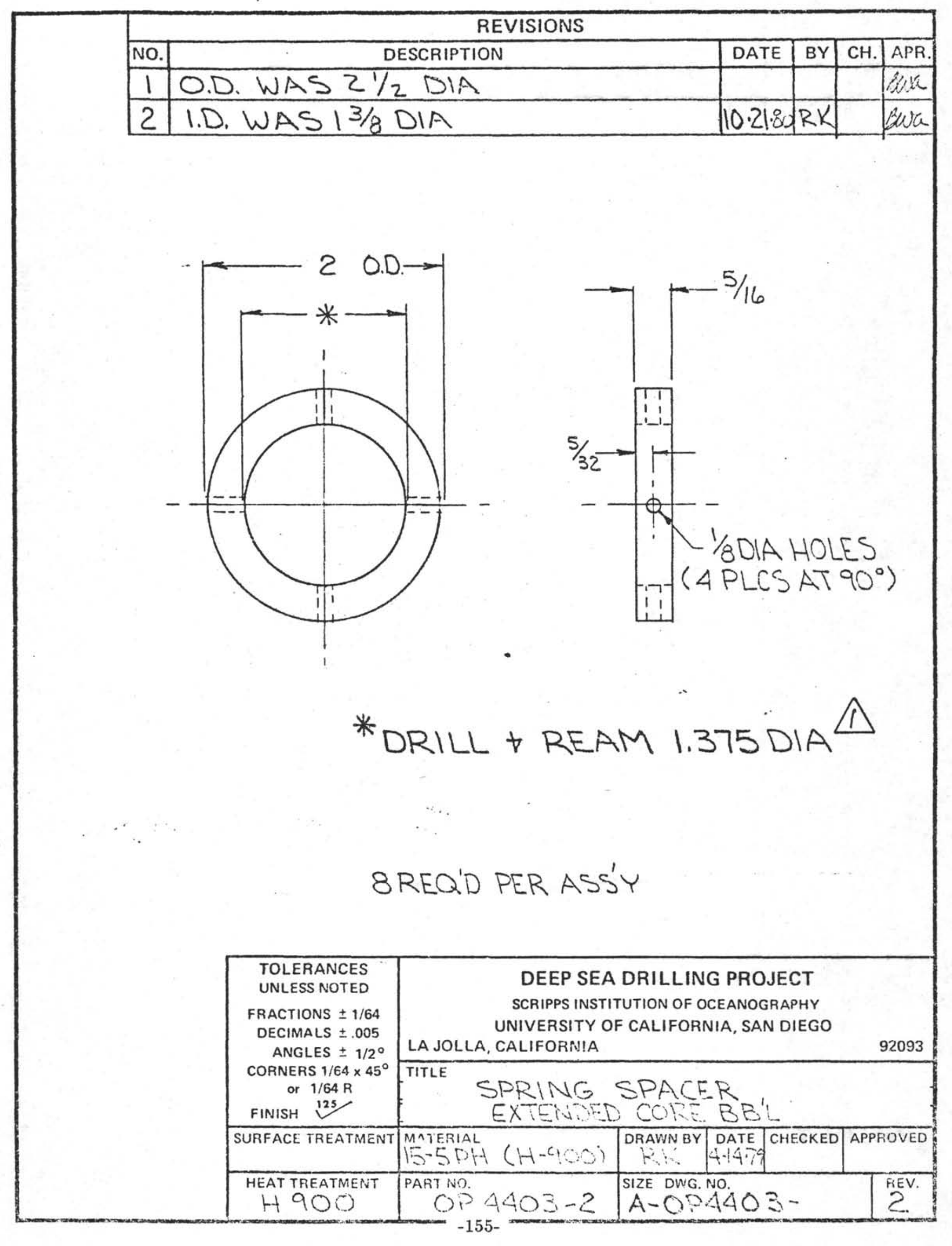




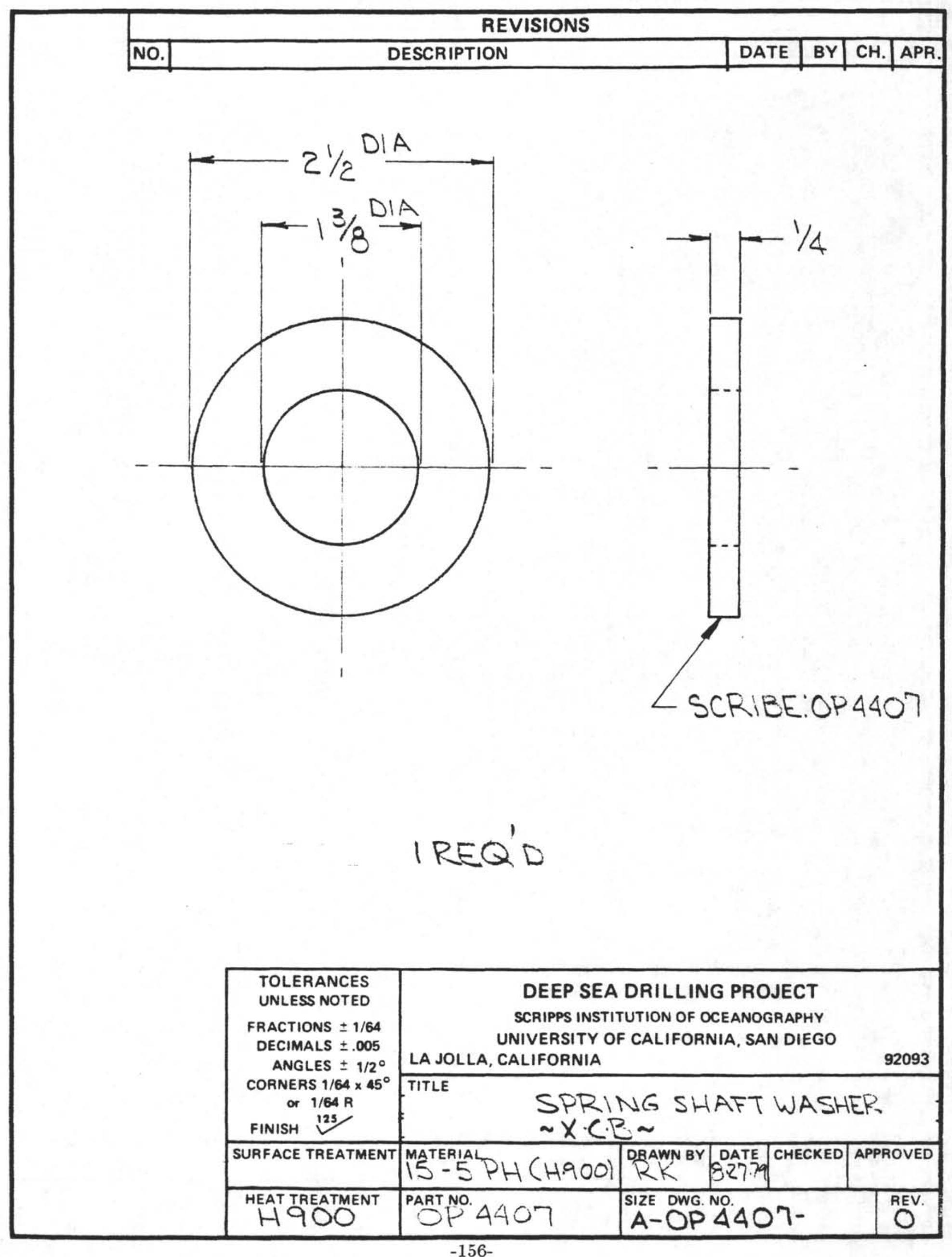




\begin{tabular}{|l|l|l|l|l|l|}
\hline \multicolumn{4}{|c|}{ REVISIONS } \\
\hline NO. & DESCRIPTION & DATE & BY & CH. & APR. \\
\hline
\end{tabular}

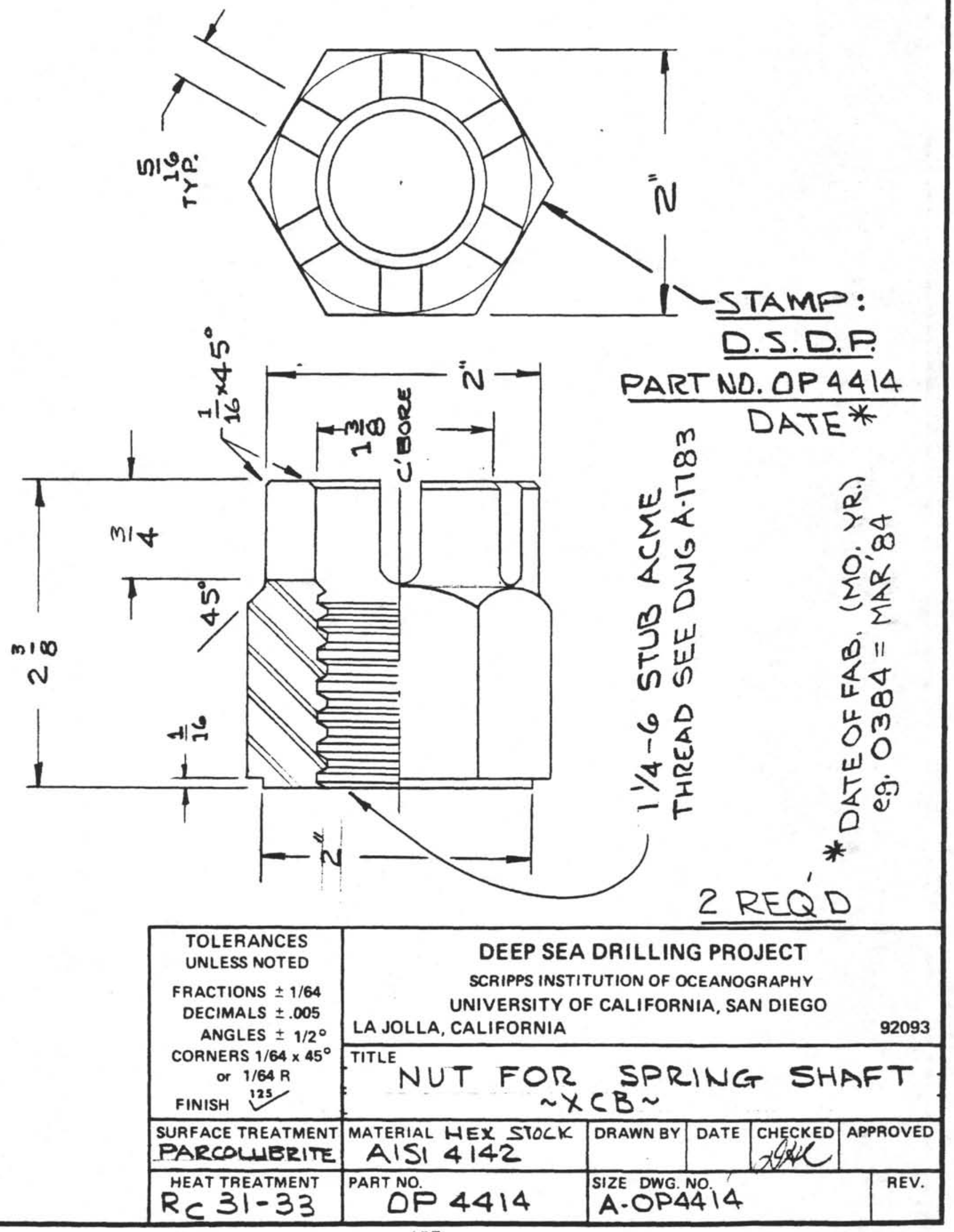




\begin{tabular}{|c|c|c|c|c|c|}
\hline NO. & DESCRIPTION & DATE & $\mathrm{BY}$ & $\mathrm{CH}$. & APR. \\
\hline 1 & $\begin{array}{l}3.122, A D D . \text { CHAM. } \\
\text { CKELL PL, } 2.714 \text { WPS }\end{array}$ & $8 ?$ & RK & $\Delta C$ & \\
\hline
\end{tabular}

$2.619,490$ wAS $.500 \pm .005$, DELETE $1 . D$. CHAM.

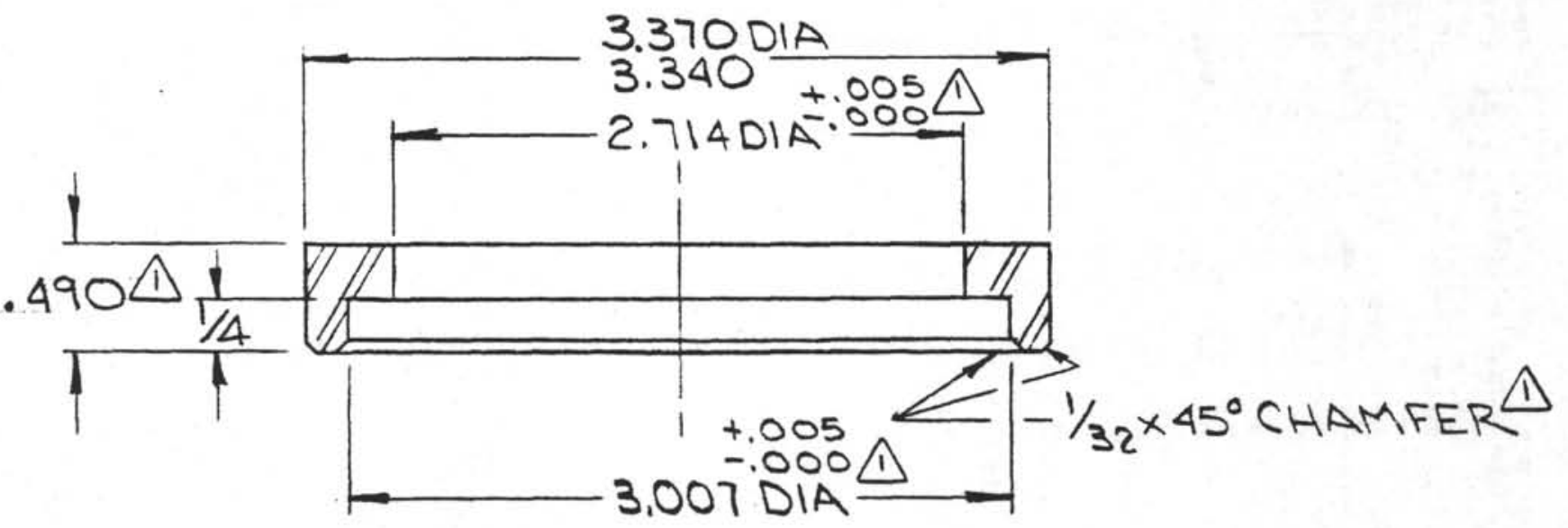

DO NOT SCALE TOLERANCES UNLESS NOTED

FRACTIONS $\pm 1 / 64$ DECIMALS \pm .005 ANGLES $\pm 1 / 2^{\circ}$ CORNERS $1 / 64 \times 45^{\circ}$ or $1 / 64 R$ FINISH 123 SURFACE TREATMENT OHEAT TREATMENT 0
CONCENTRICITY ALL DIAMETERS: TIR.003

\section{DEEP SEA DRILLING PROJECT}

SCRIPPS INSTITUTION OF OCEANOGRAPHY UNIVERSITY OF CALIFORNIA, SAN DIEGO

LA JOLLA, CALIFORNIA

92093

RETAINING RING $\sim X \cdot C \cdot B \sim$

MATERIAL DELRIN AF \begin{tabular}{l|l}
\hline SCALE & REQ'D/ASS'Y
\end{tabular} $\mid$\begin{tabular}{l|l} 
DATE \\
$|-2|-83$ & BY \\
\hline PAK
\end{tabular} PART NO. $0 P 4415-1$ DWG. NO. APPROVED

CHECKED APPROVED
DWG. NO.
$A=O P \triangle \triangle 15-1$




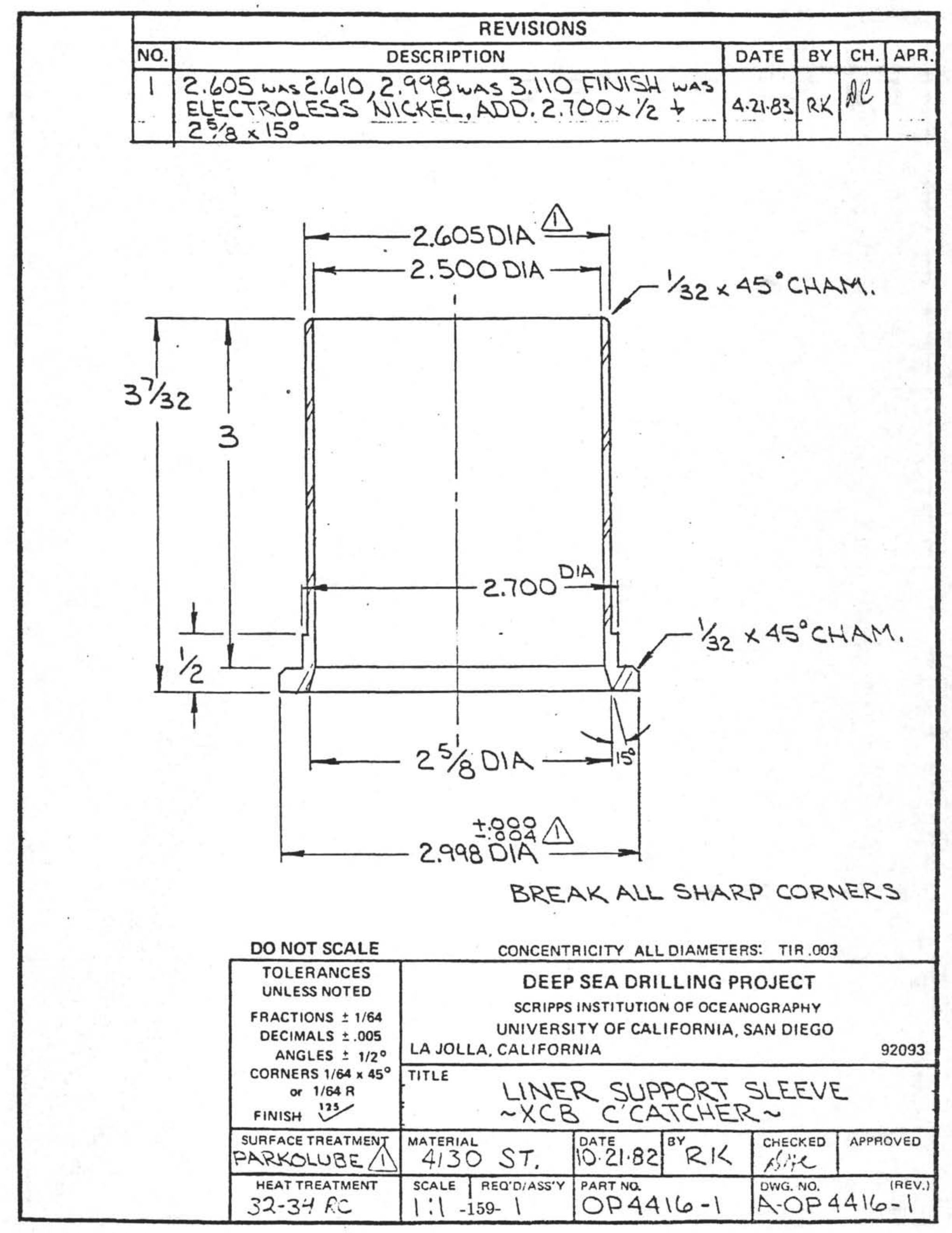




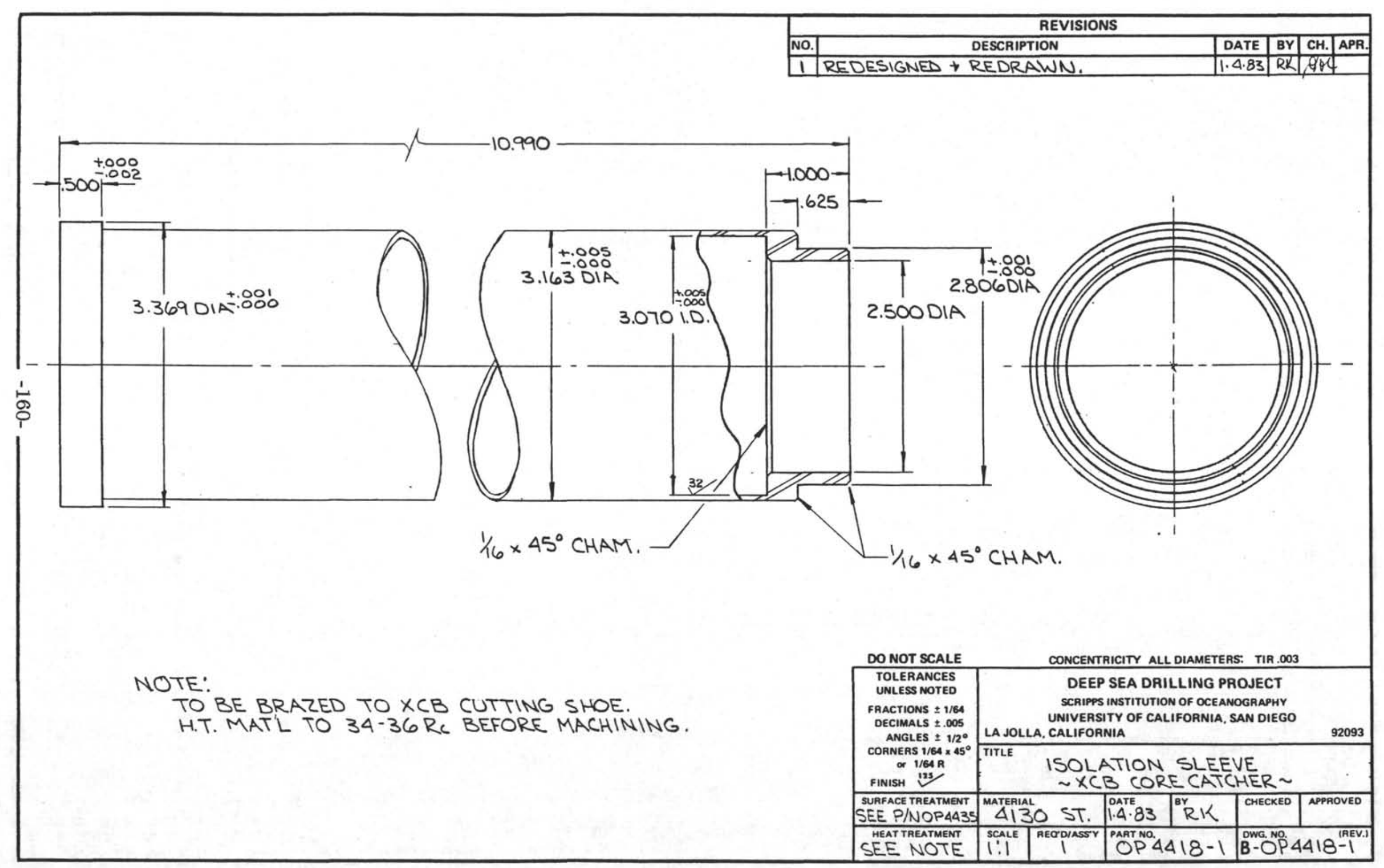




\begin{tabular}{|c|c|c|c|c|c|}
\hline NO. & DESCRIPTION & DATE & BY & CH. & APR. \\
\hline 1 & 2.80 WAS $2.70(2.80$ is STOCK DIA $)$ & 6.6 .83 & RK & ( $)$ & \\
\hline
\end{tabular}

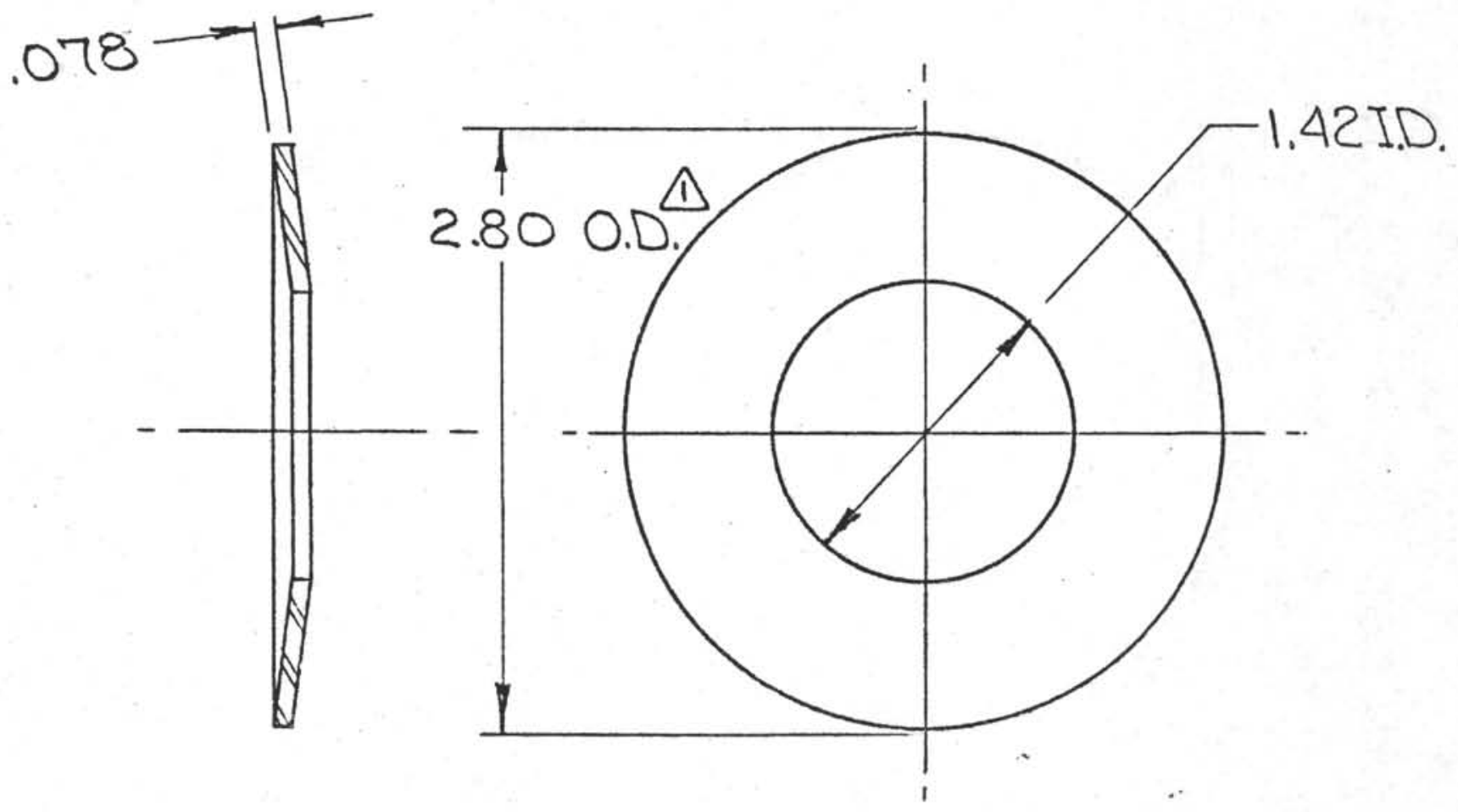

VENDER:

SCHNORR-NEISE DISC SPRING CORP. $71 \times 36 \times 2 \mathrm{~mm}$ REQ'D

\begin{tabular}{|c|c|c|c|c|c|}
\hline \multirow{2}{*}{$\begin{array}{l}\text { TOLERANCES } \\
\text { UNLESS NOTED } \\
\text { FRACTIONS } \pm 1 / 64 \\
\text { DECIMALS } \pm .005 \\
\text { ANGLES } \pm 1 / 2^{\circ} \\
\text { CORNERS } 1 / 64 \times 45^{\circ} \\
\text { or } 1 / 64 \mathrm{R} \\
\text { FINISH } 125\end{array}$} & \multicolumn{4}{|c|}{$\begin{array}{l}\text { DEEP SEA DRILLING PROJECT } \\
\text { SCRIPPS INSTITUTION OF OCEANOGRAPHY } \\
\text { JNIVERSITY OF CALIFORNIA, SAN DIEGO } \\
\text { CALIFORNIA }\end{array}$} & 92093 \\
\hline & $\begin{array}{r}\text { DISK SPE } \\
\sim X \cdot C \cdot B\end{array}$ & 111 & & & \\
\hline SURFACE TREATMENT & MATERIAL VENDDER & DRAWNBY & $\begin{array}{l}\text { DATE } \\
3: 0 \\
\end{array}$ & CHECKED & APPFOVED \\
\hline HEAT TREATMENT & PART NO $A-19-1$ & $\begin{array}{l}\text { SIZE DWG. } \\
A-O F .\end{array}$ & 4419 & & REV. \\
\hline
\end{tabular}




\begin{tabular}{|l|l|l|l|l|l|}
\hline NO. & DESCRIPTION & DATE & BY & CH. & APR. \\
\hline
\end{tabular}

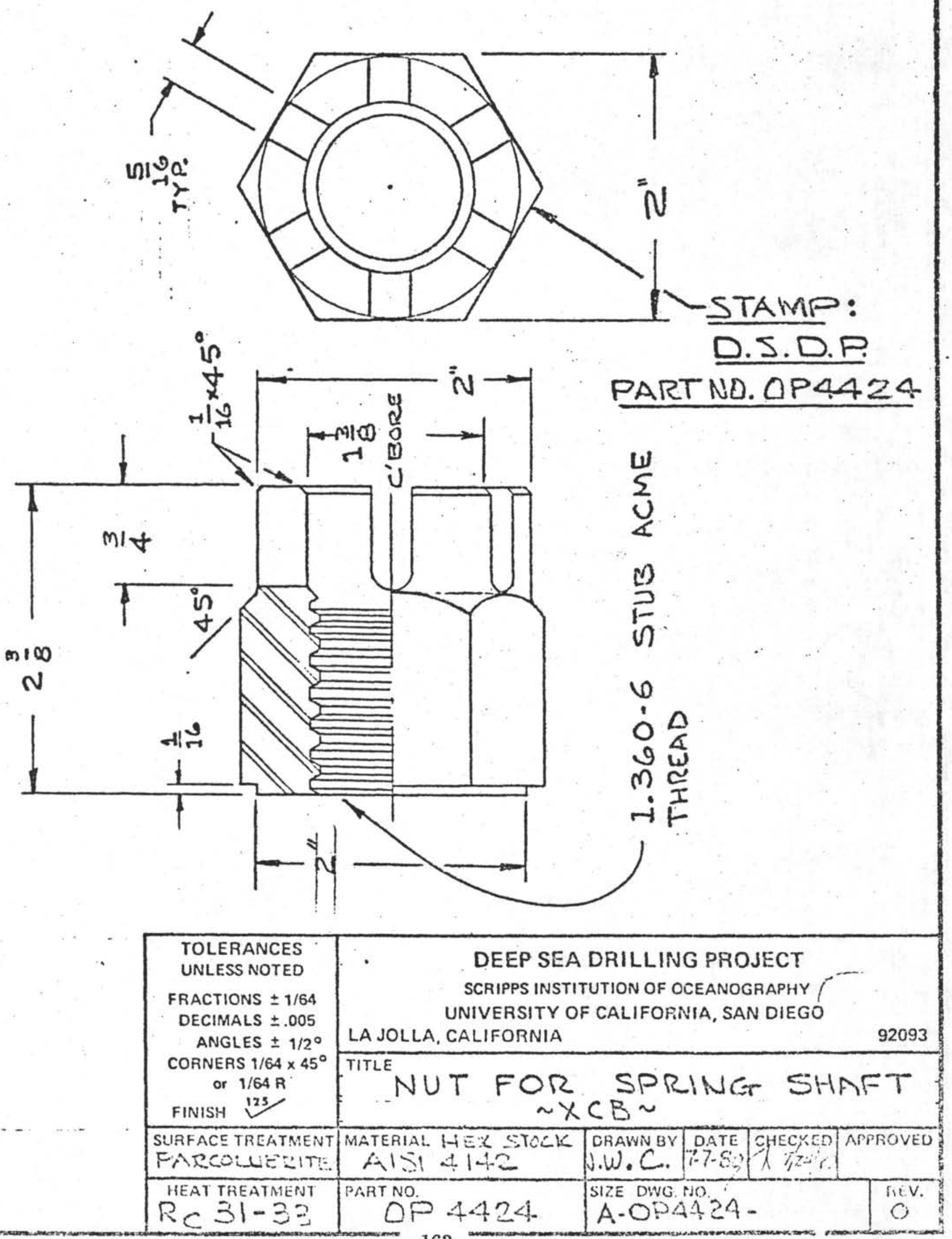




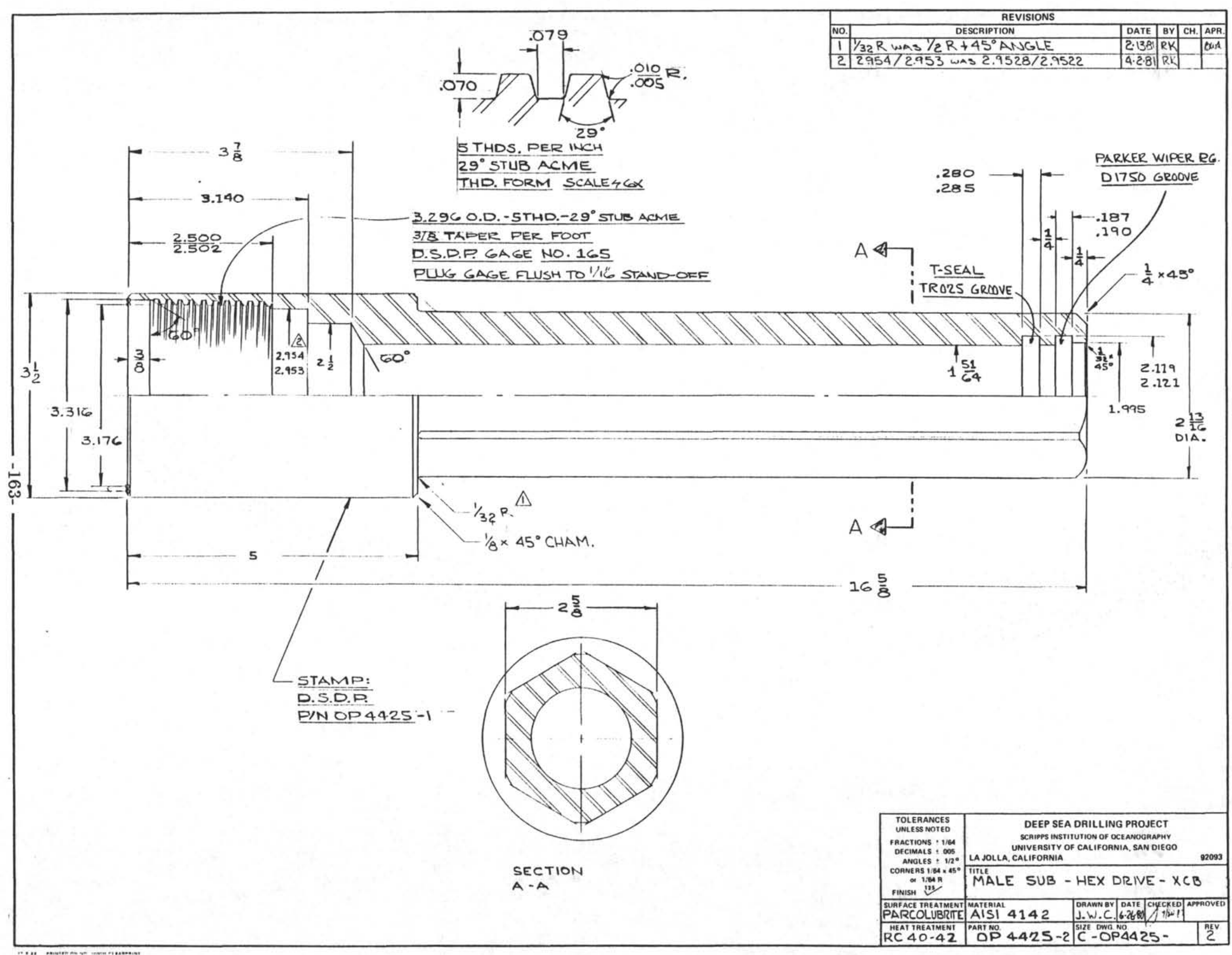




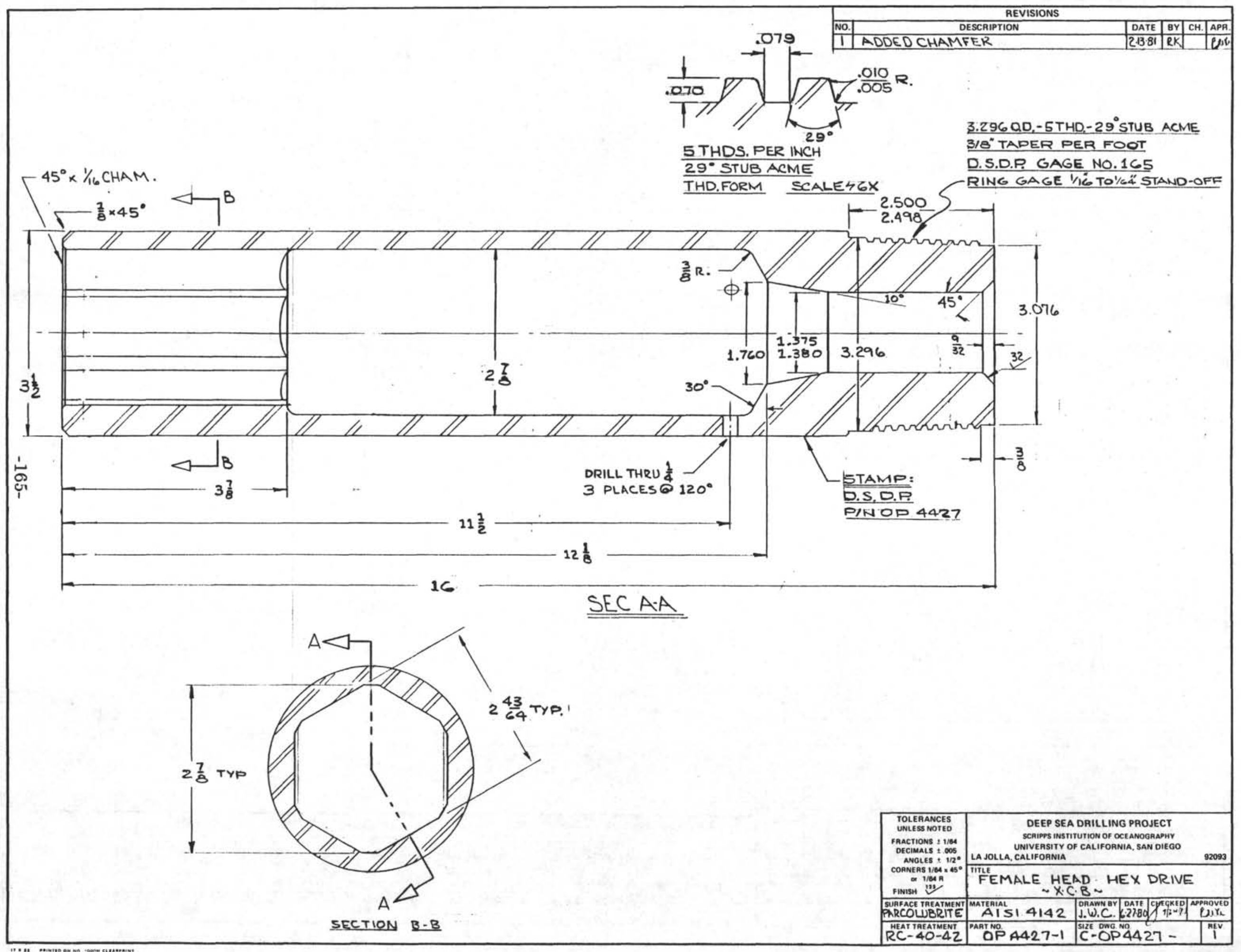




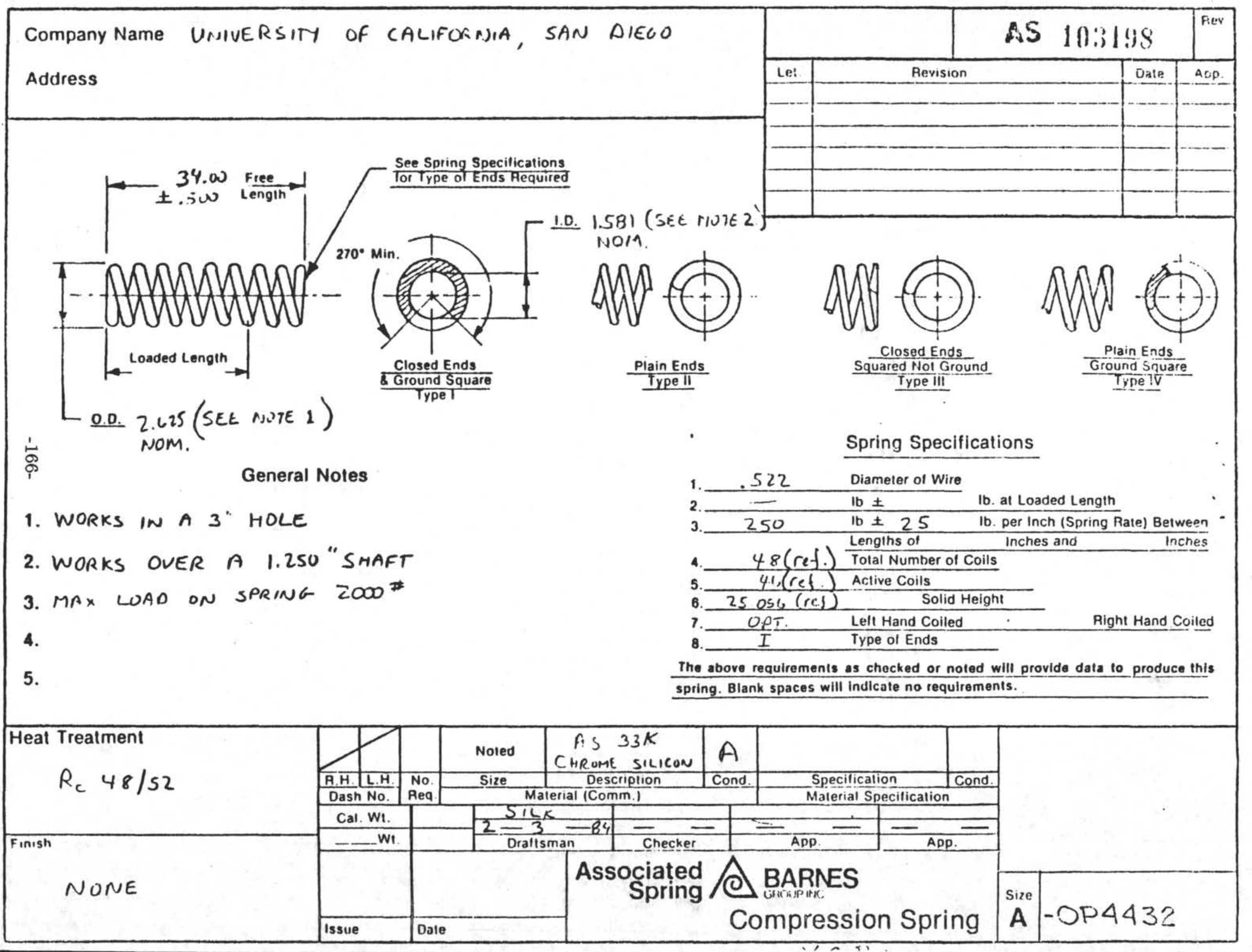




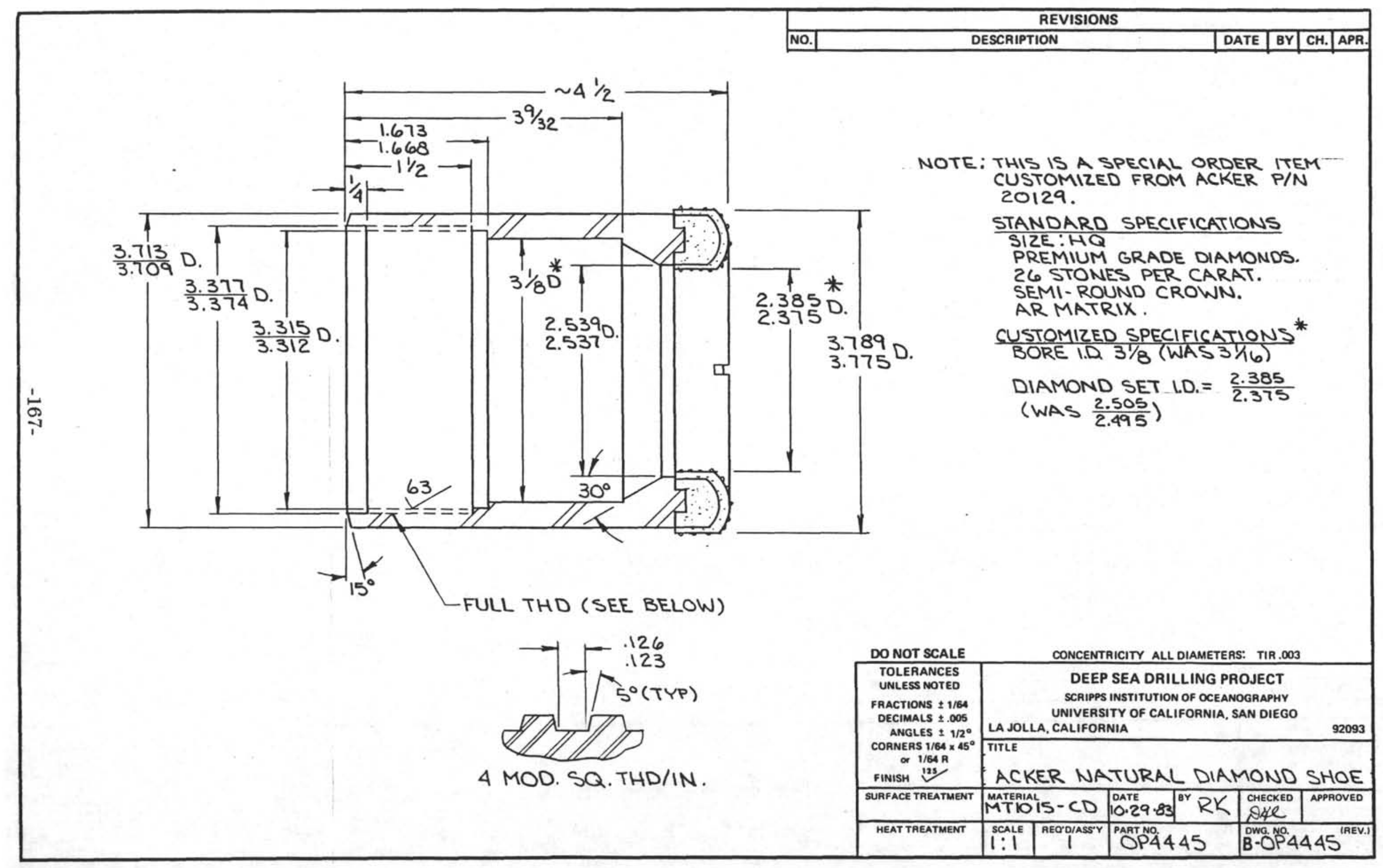




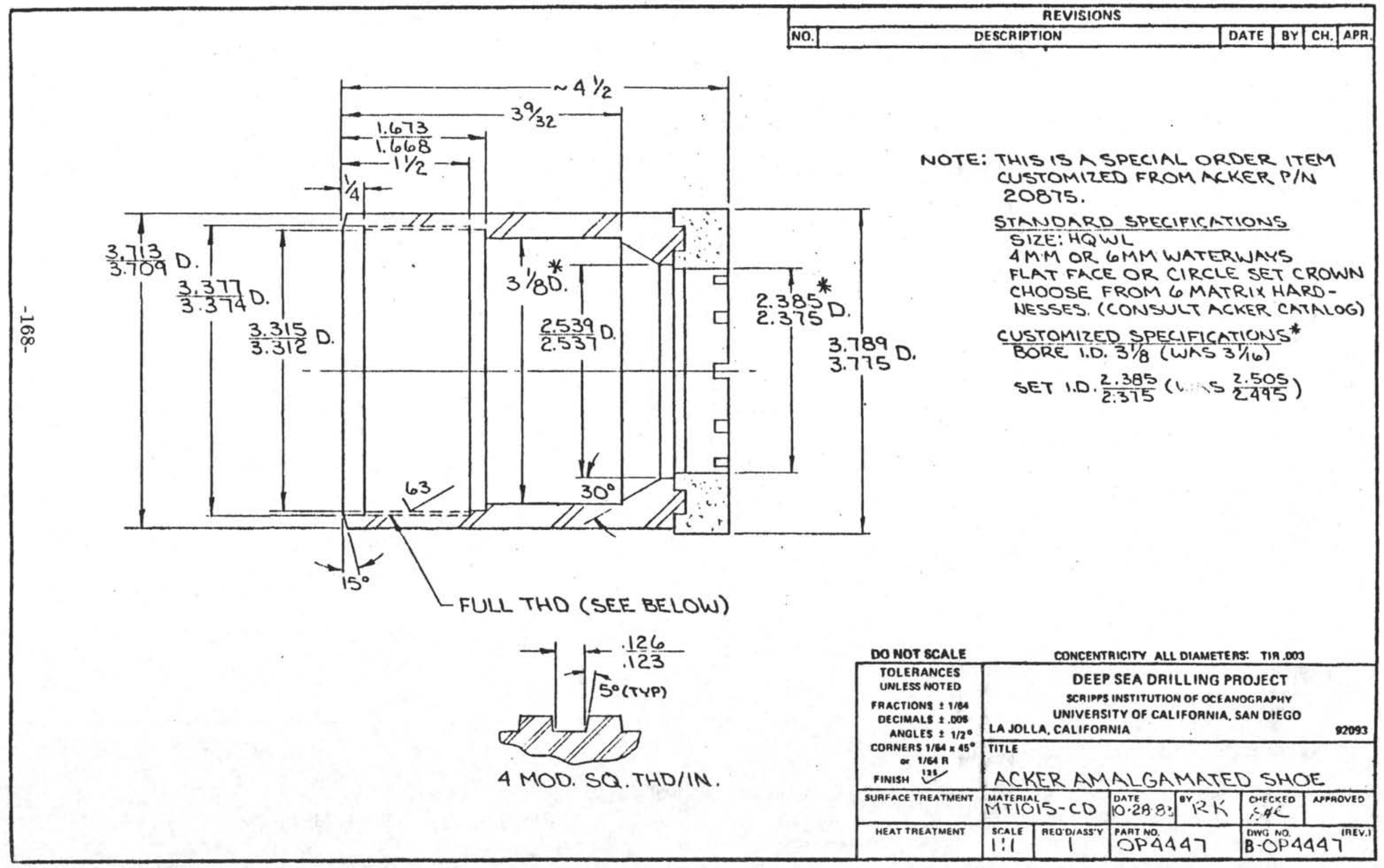




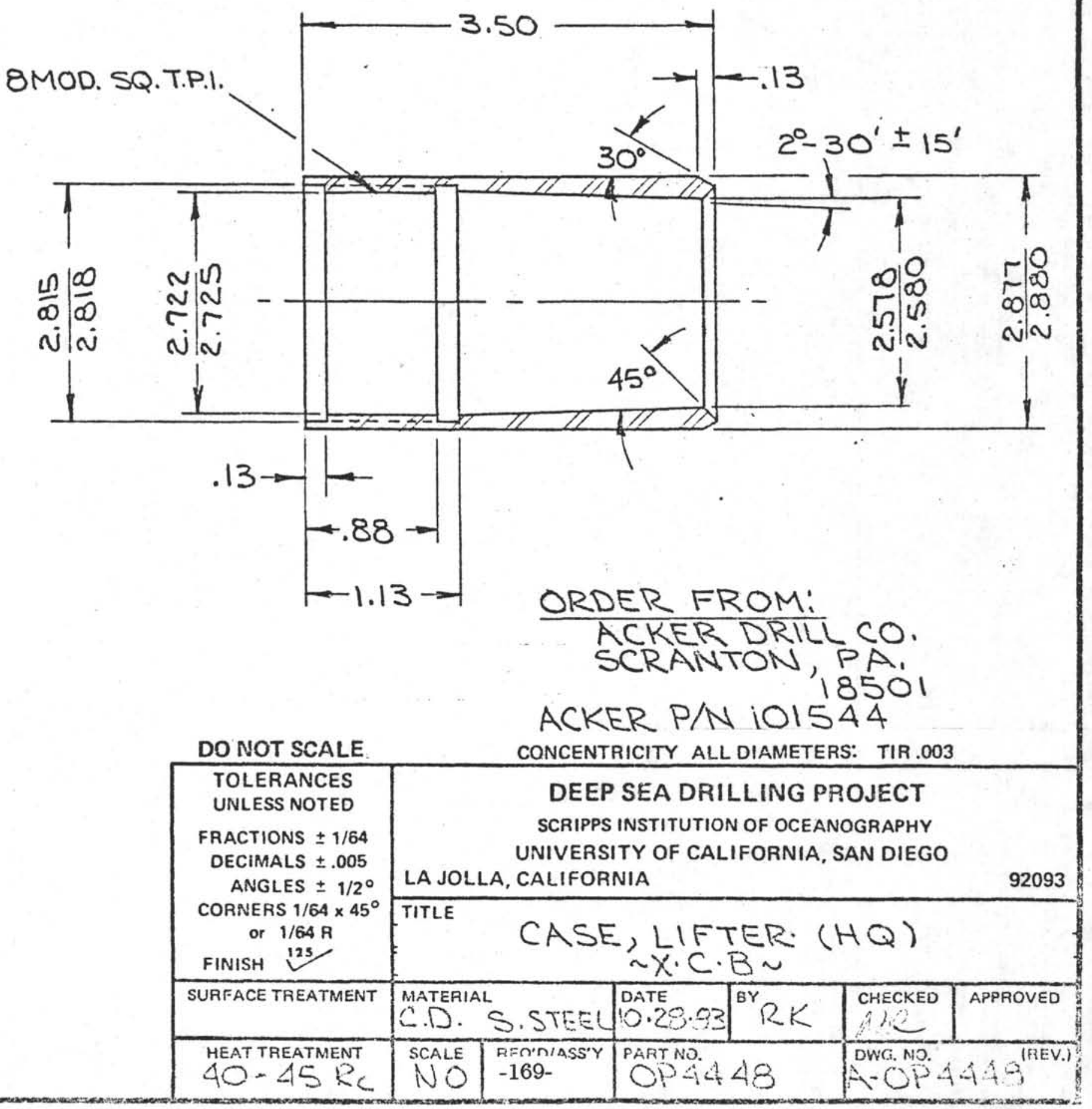




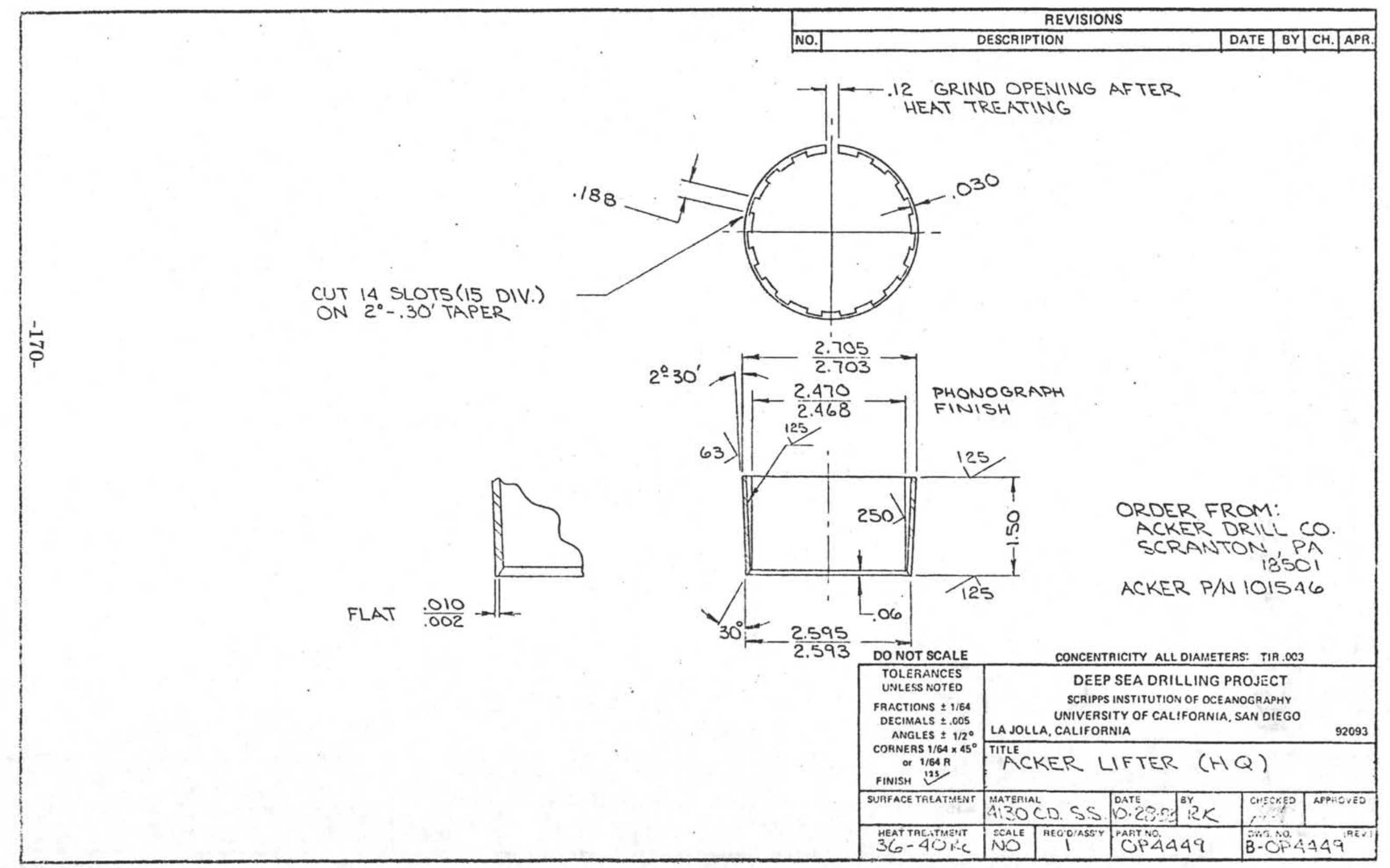


SPECIFICATION SHEET

PART NUMBER

DESCRIPTION

ITEM

MANUFACTURER

P/N FOR ORDERING

DIMENSIONS

\section{OTHER INFORMATION}

: $\quad 0 P-4450$

: Stop Ring

: Acker

: $\quad 101545$

VENDOR

: Acker Drill Company, Inc.

P.0. Box 830

Scranton, PA 18501

(717) 586-2061 


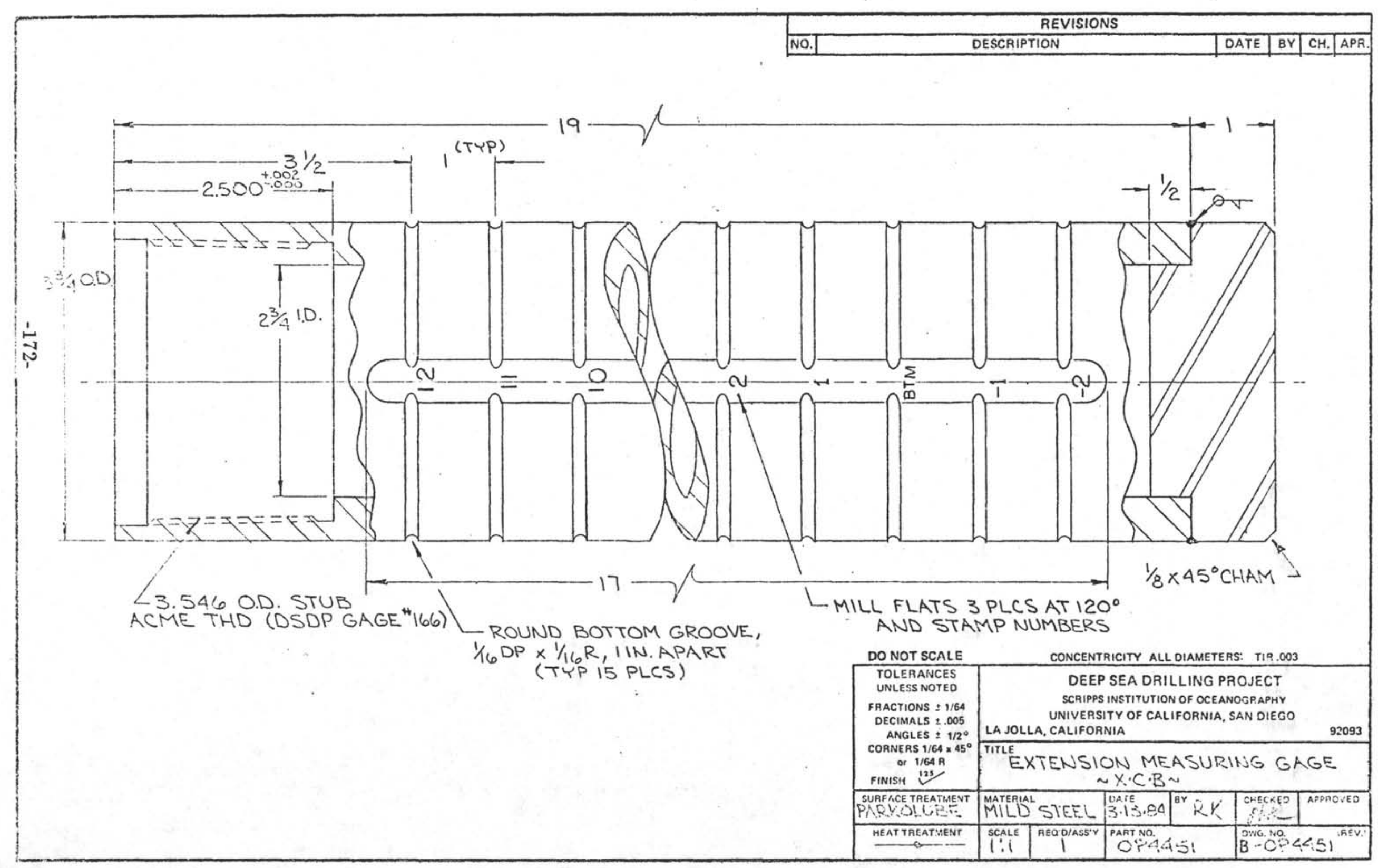




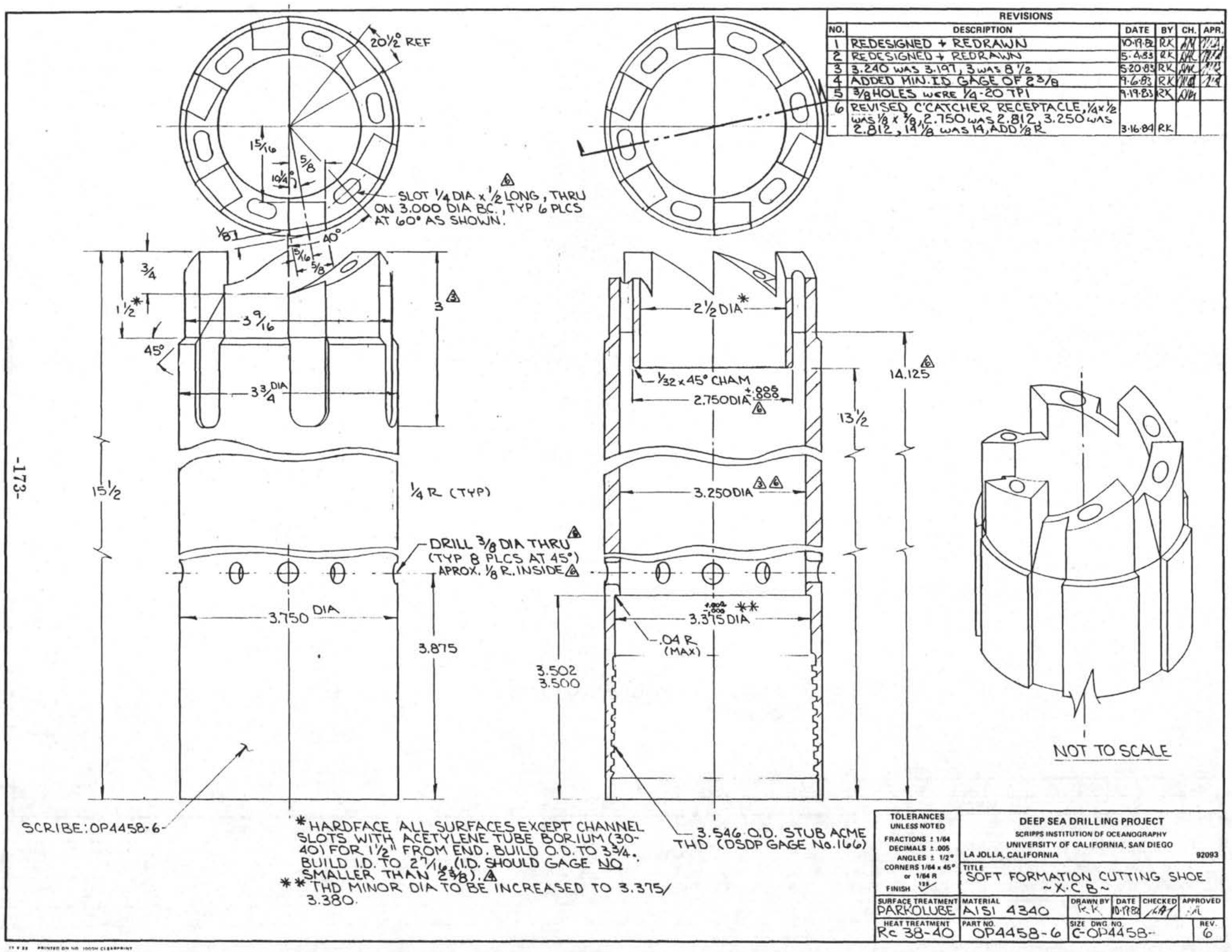




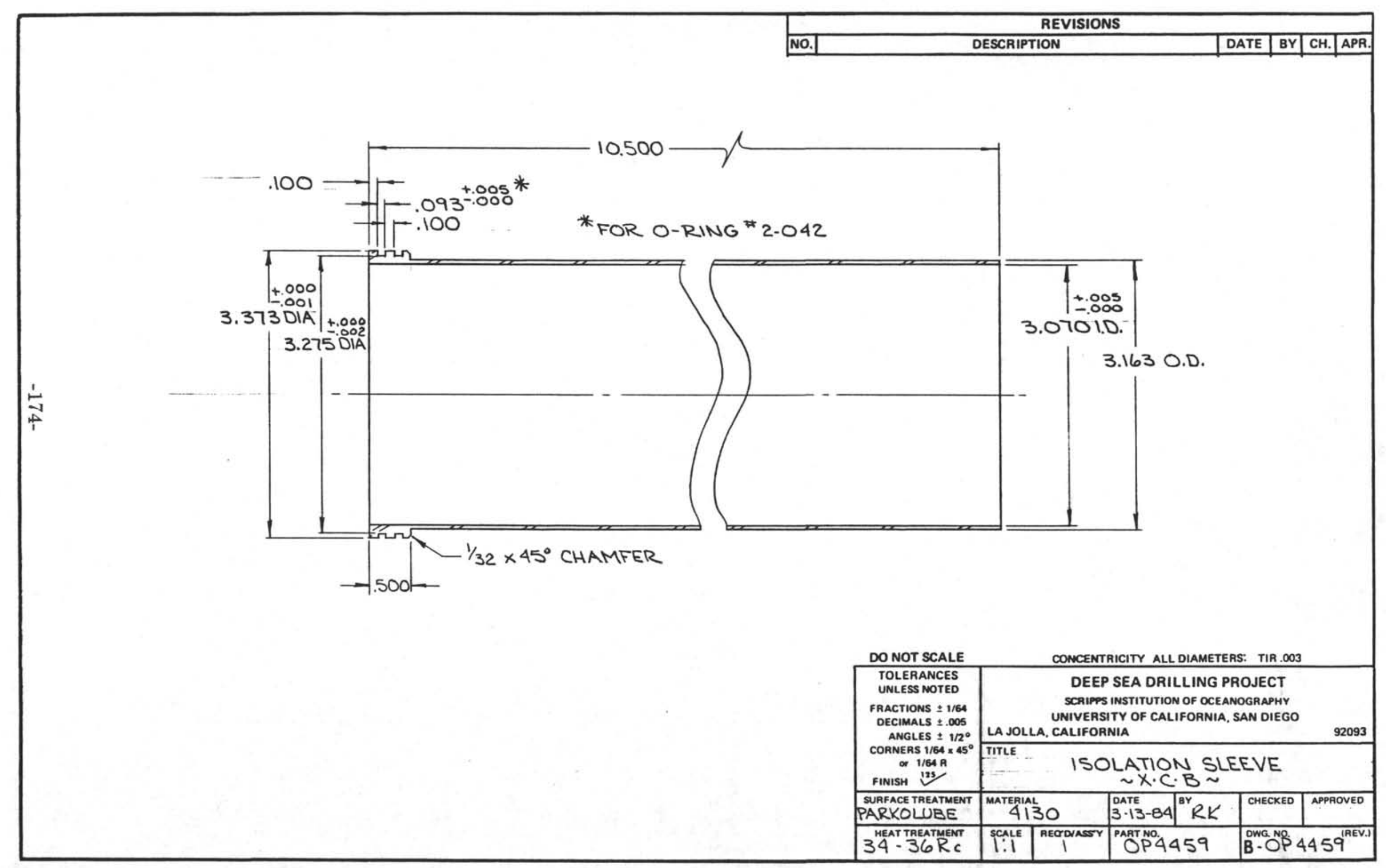




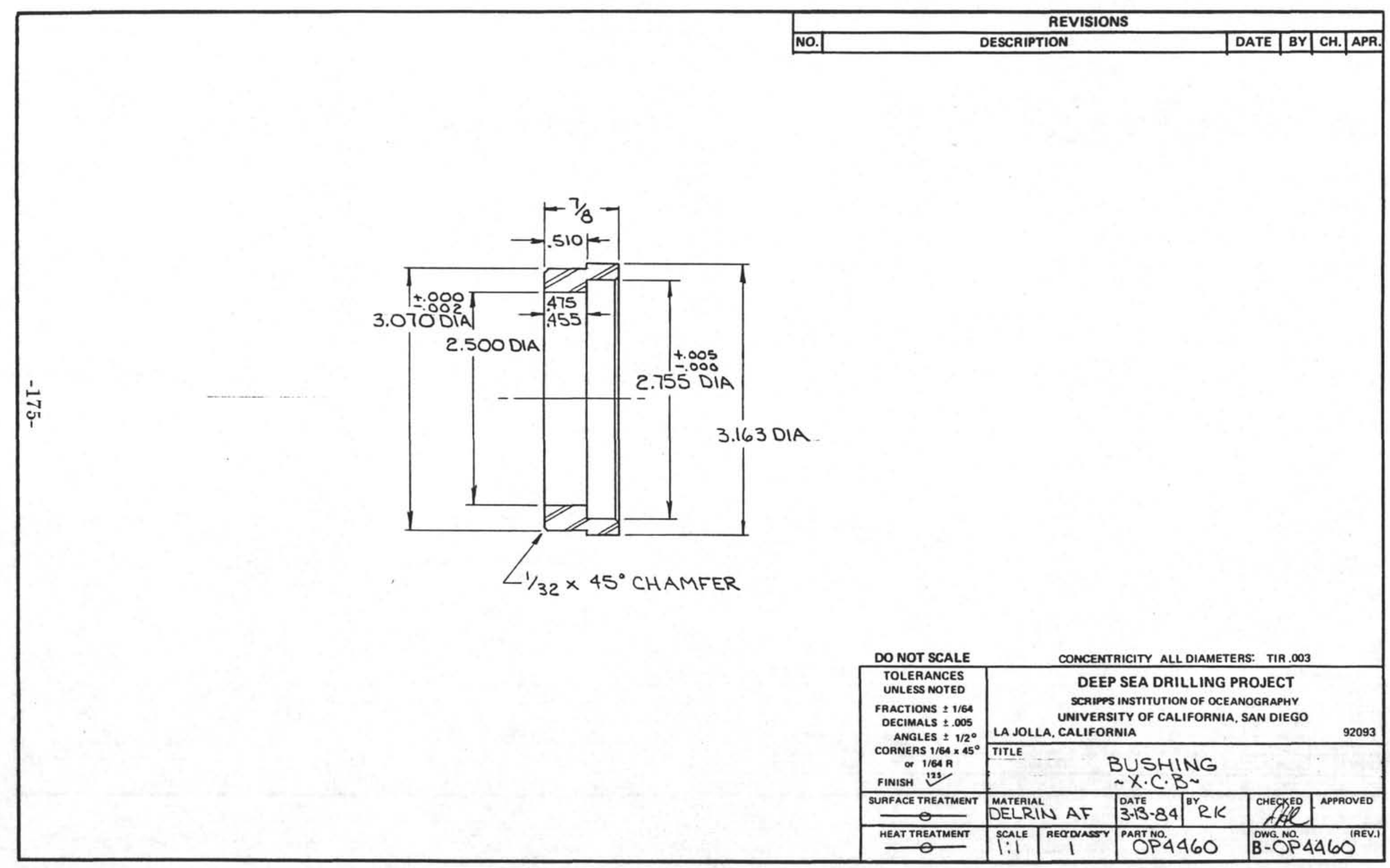




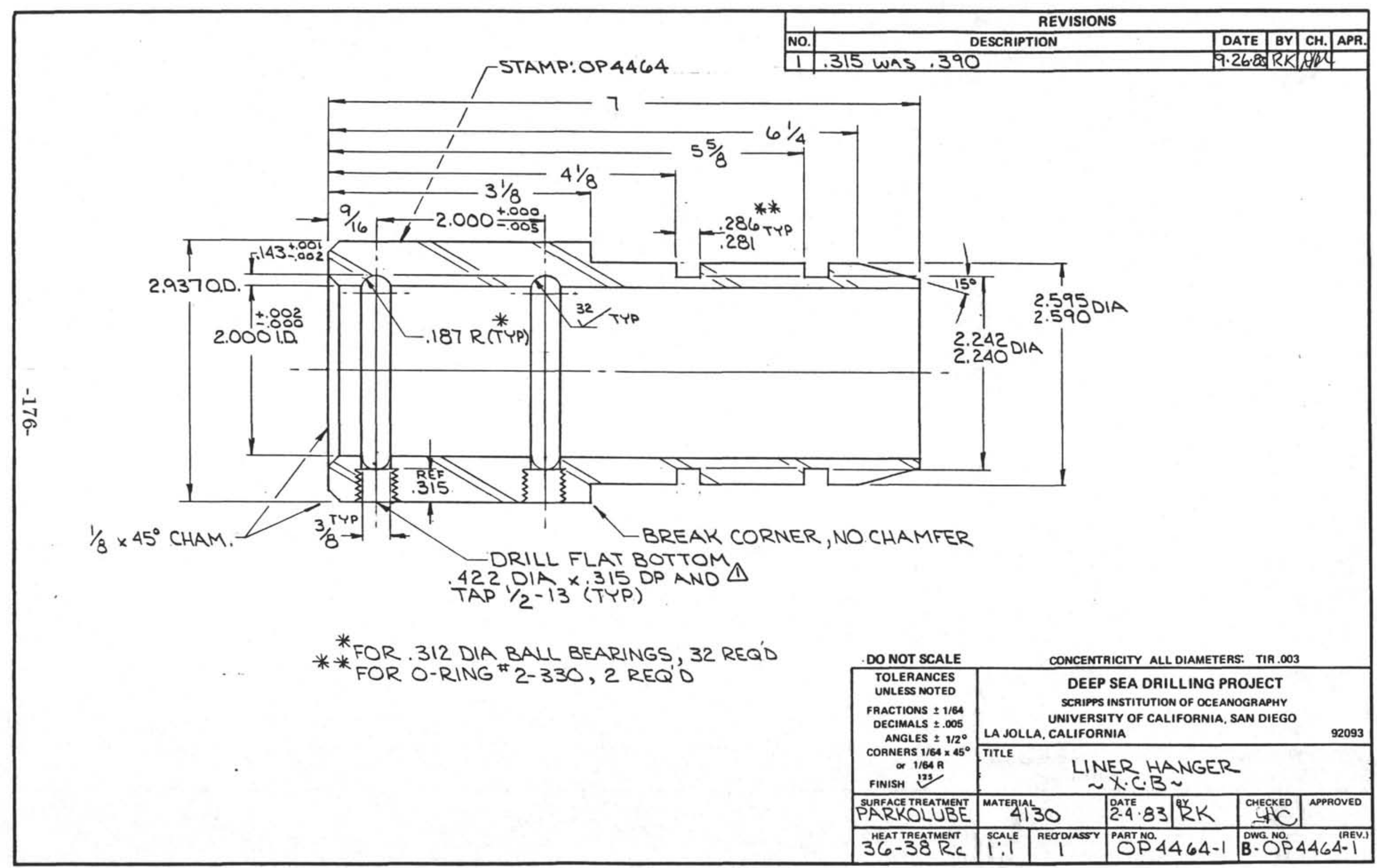




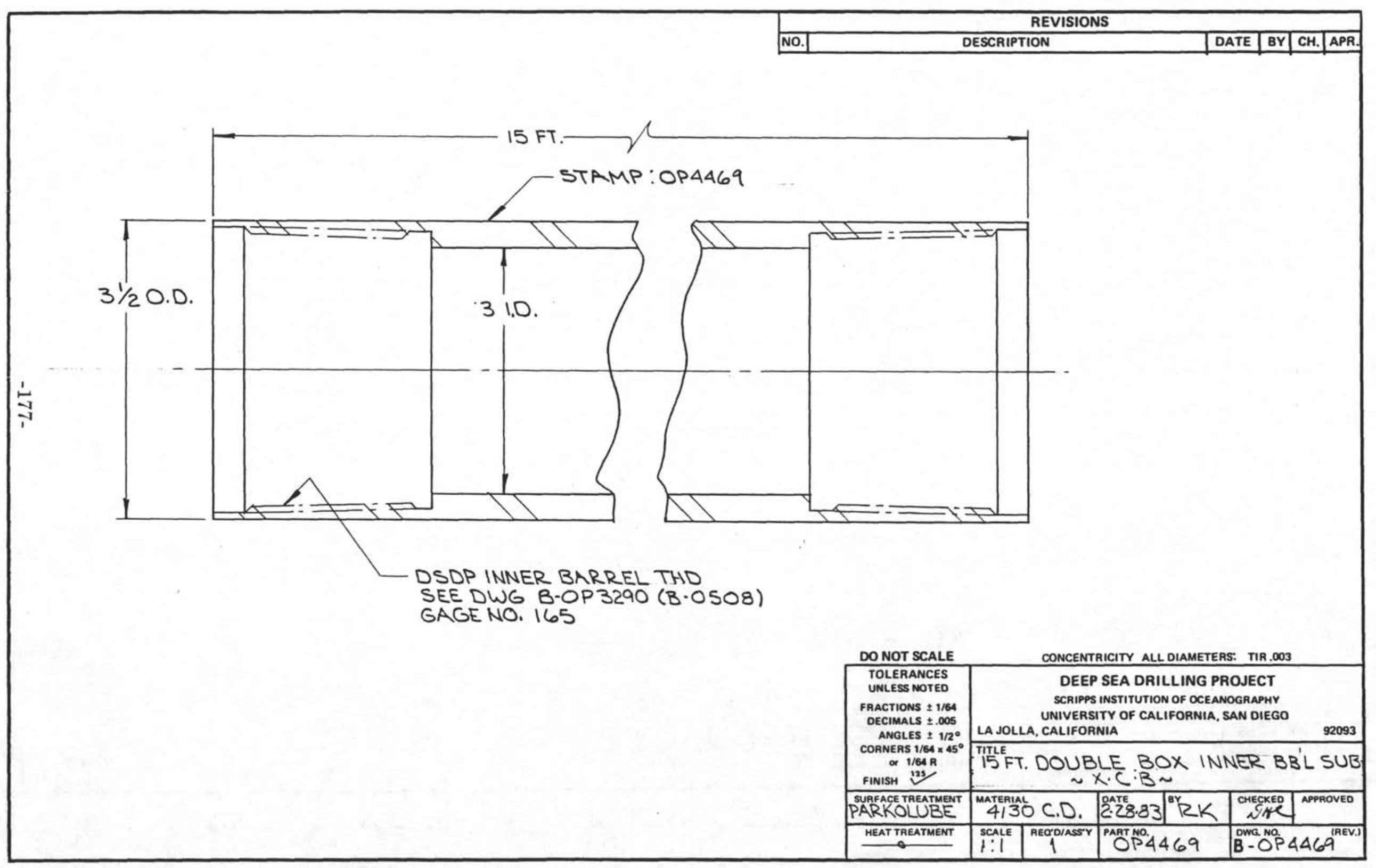




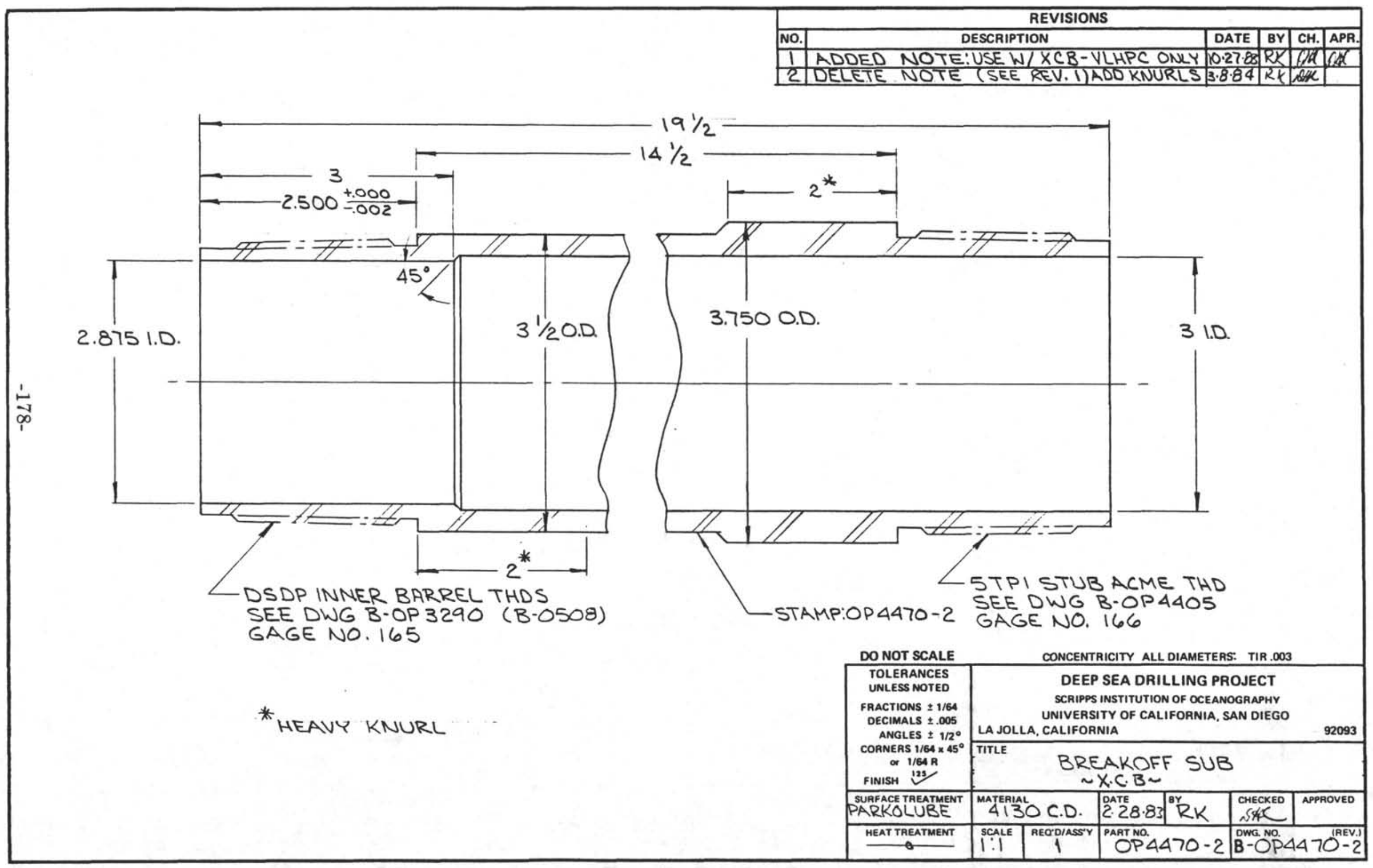




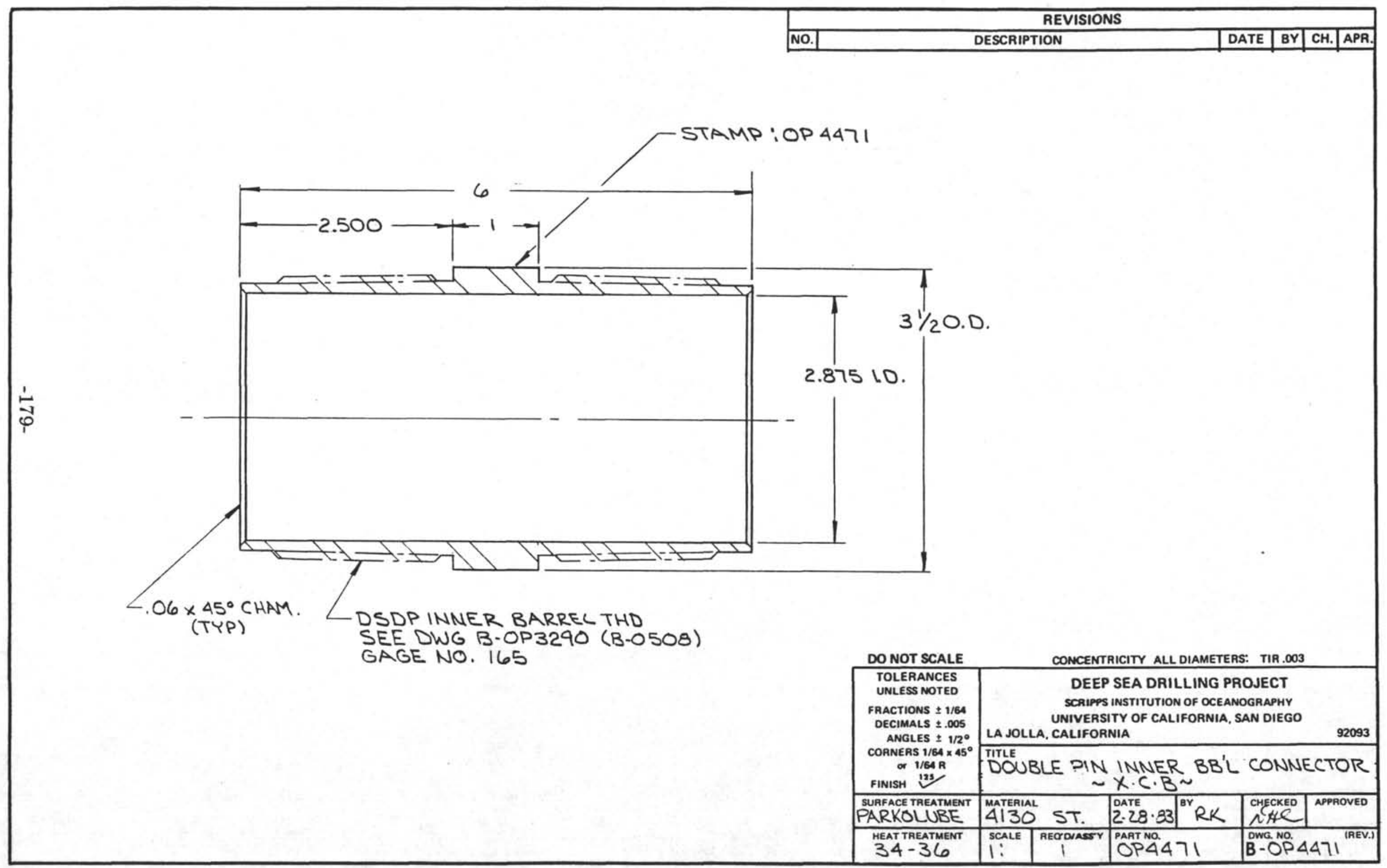




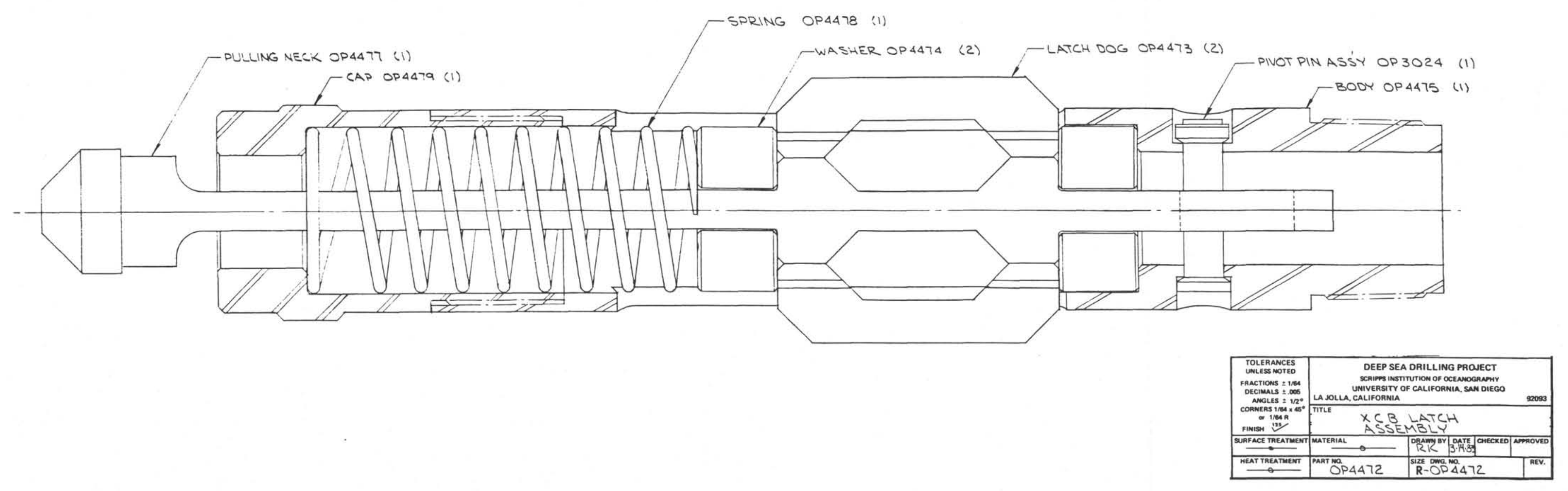




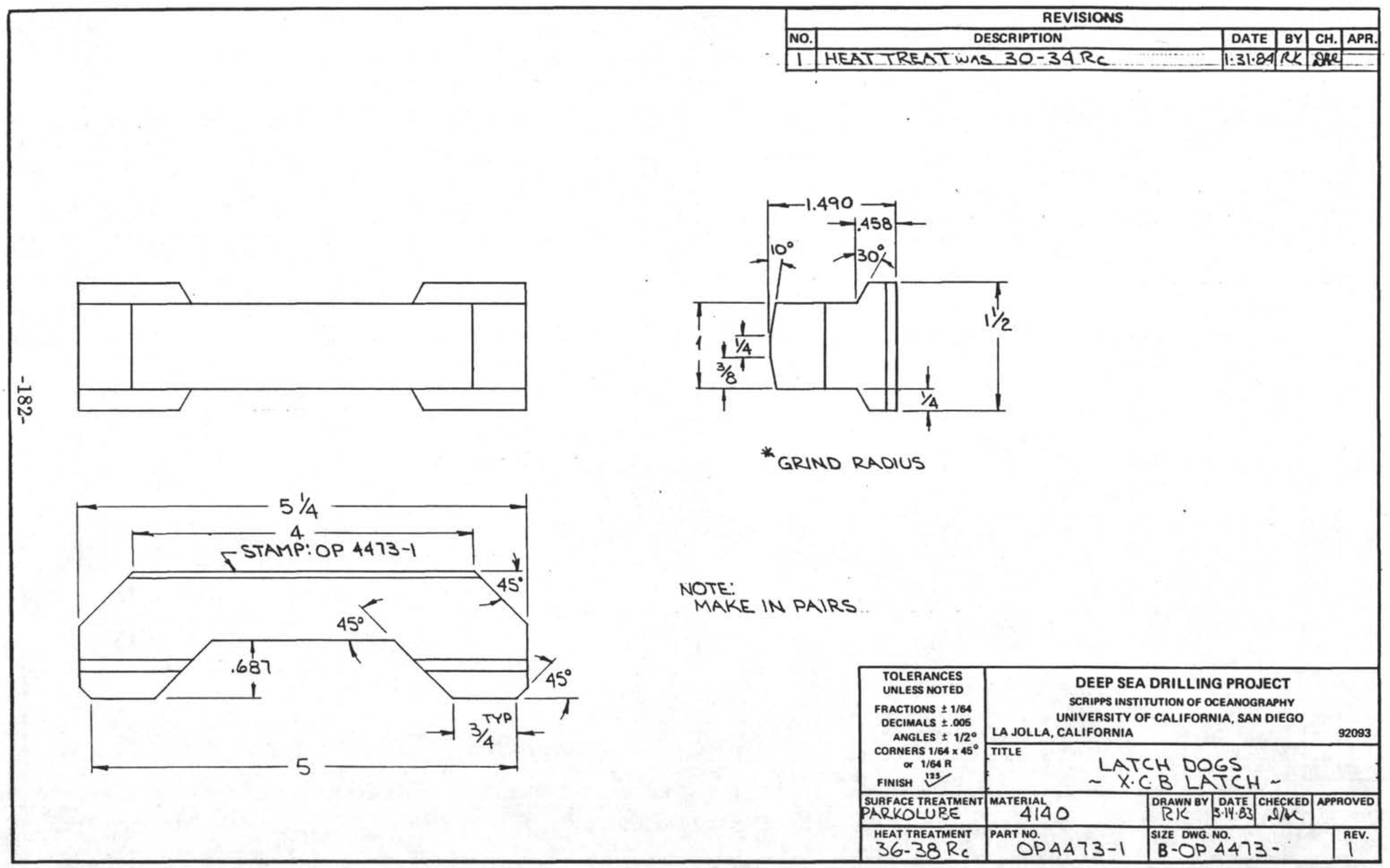


REVISIONS

\begin{tabular}{|c|c|c|c|c|c|}
\hline NO. & DESCRIPTION & DATE & BY & CH. & APR. \\
\hline 1 & $15 / 16$ WAS $11 / 2$ & 9.19 .85 & RK & OHC & \\
\hline
\end{tabular}

$1 / 16 \times 45^{\circ}$ CHAM.
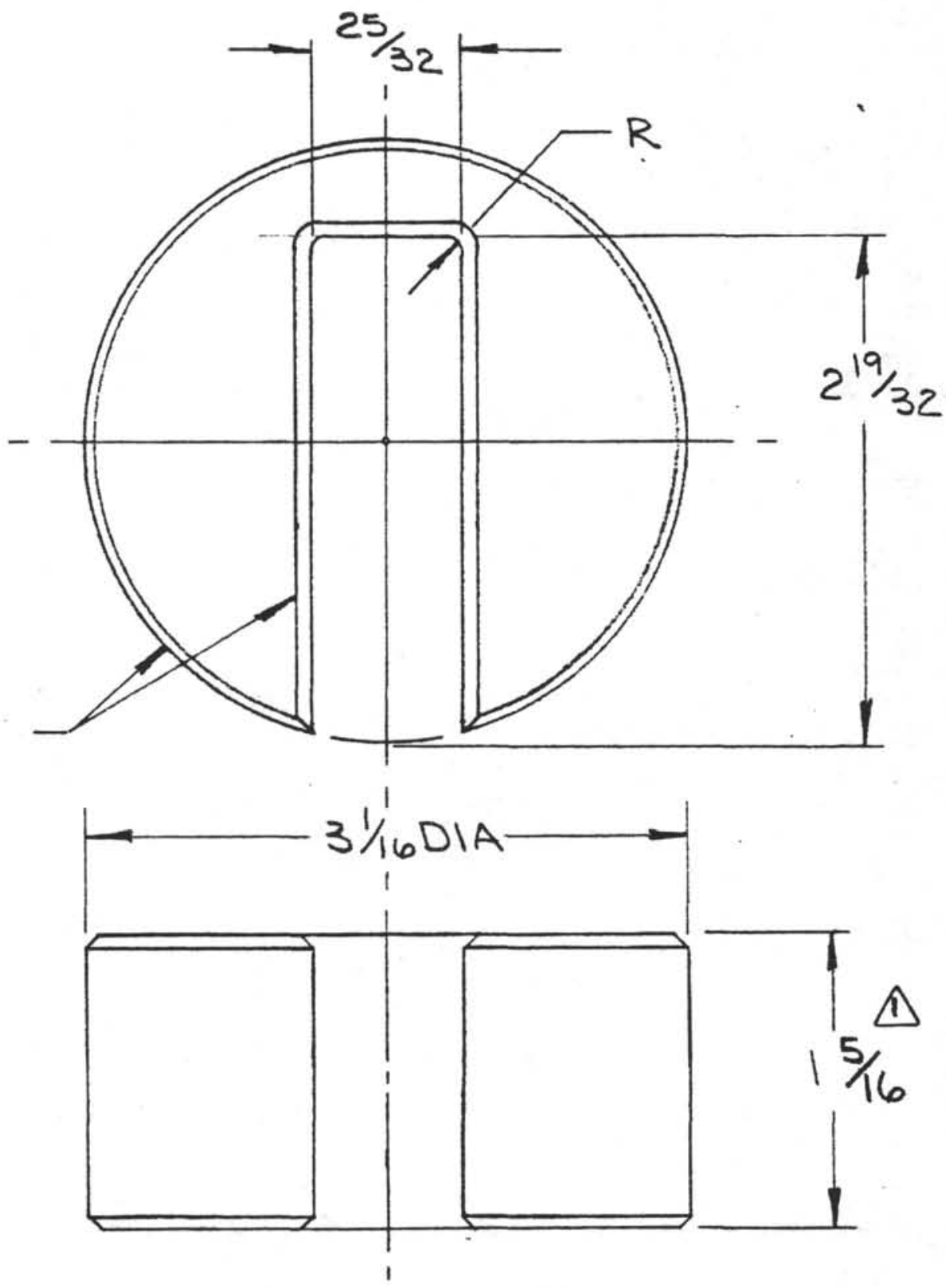

DO NOT SCALE

CONCENTRICITY ALL DIAMETERS: TIR.003

TOLERANCES UNLESS NOTED

FRACTIONS $\pm 1 / 64$ DECIMALS \pm .005

ANGLES $\pm 1 / 2^{\circ}$ CORNERS $1 / 64 \times 45^{\circ}$ or 1/64 R

FINISH 123

WASHER DEEP SEA DRILLING PROJECT

SCRIPPS INSTITUTION OF OCEANOGRAPHY UNIVERSITY OF CALIFORNIA, SAN DIEGO

LA JOLLA, CALIFORNIA

TITLE

$\sim X . C \cdot B$ LATCH

SUPFACE TREATMENT

PARKOLUBE MATERIAL DATE APPROVED 


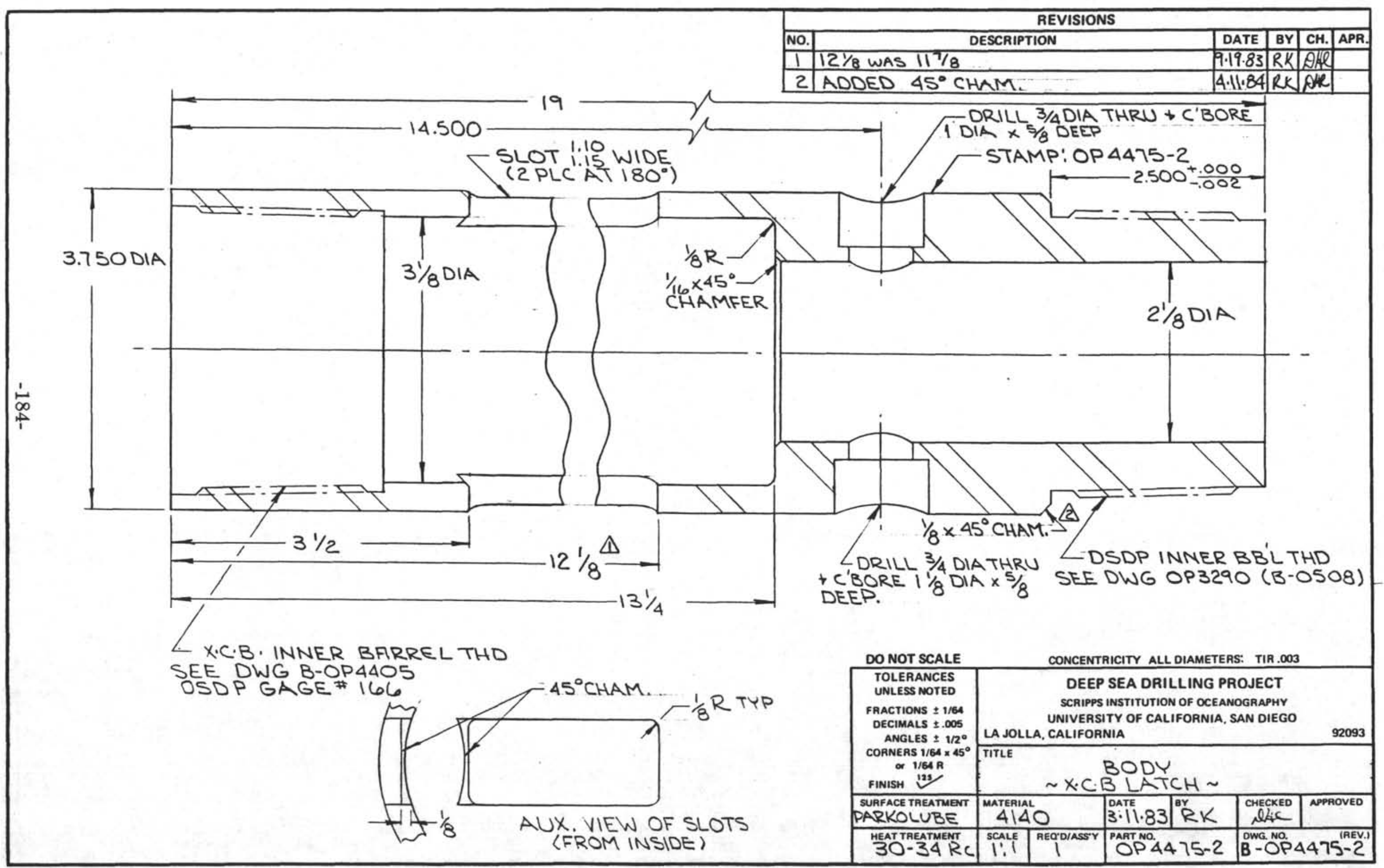




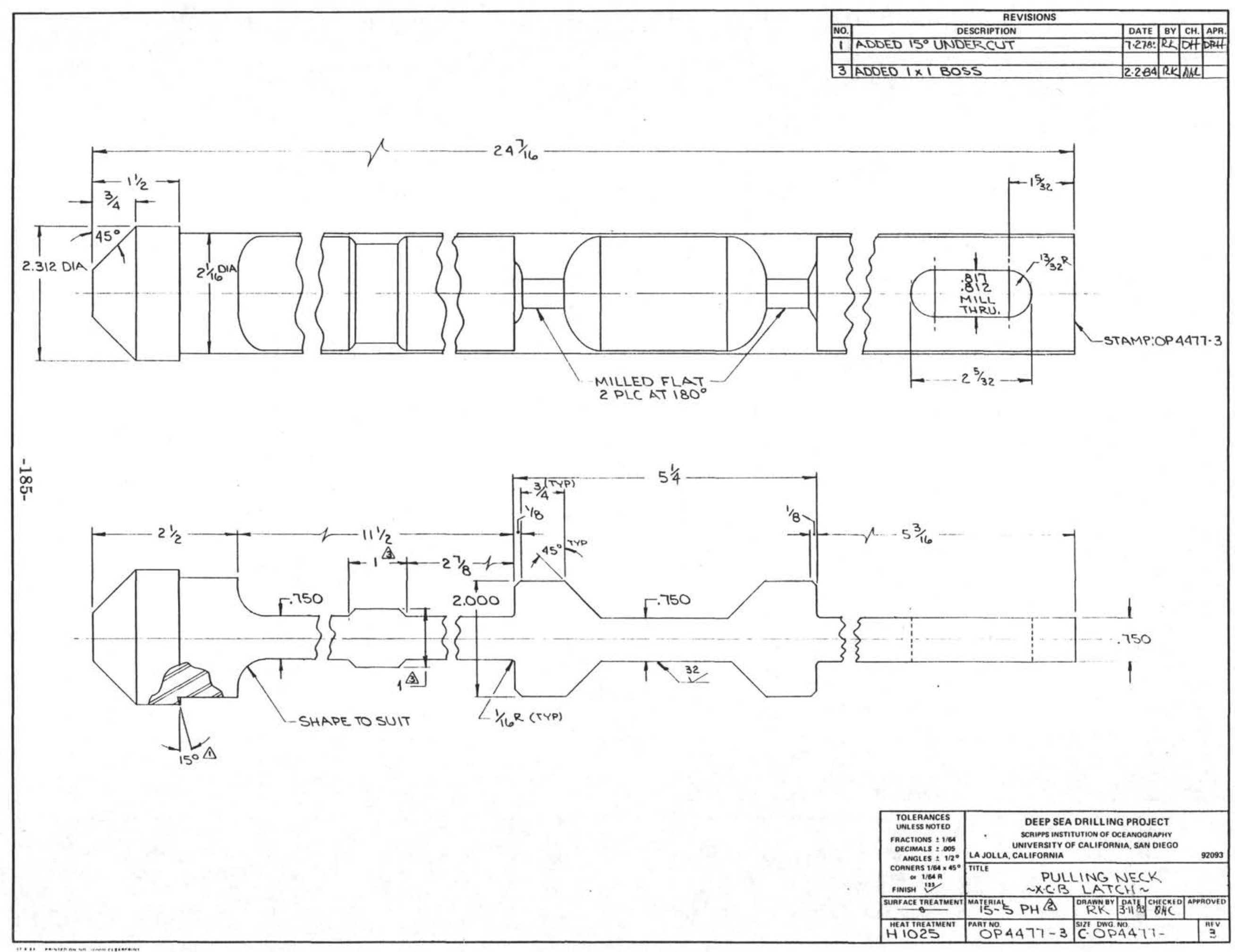




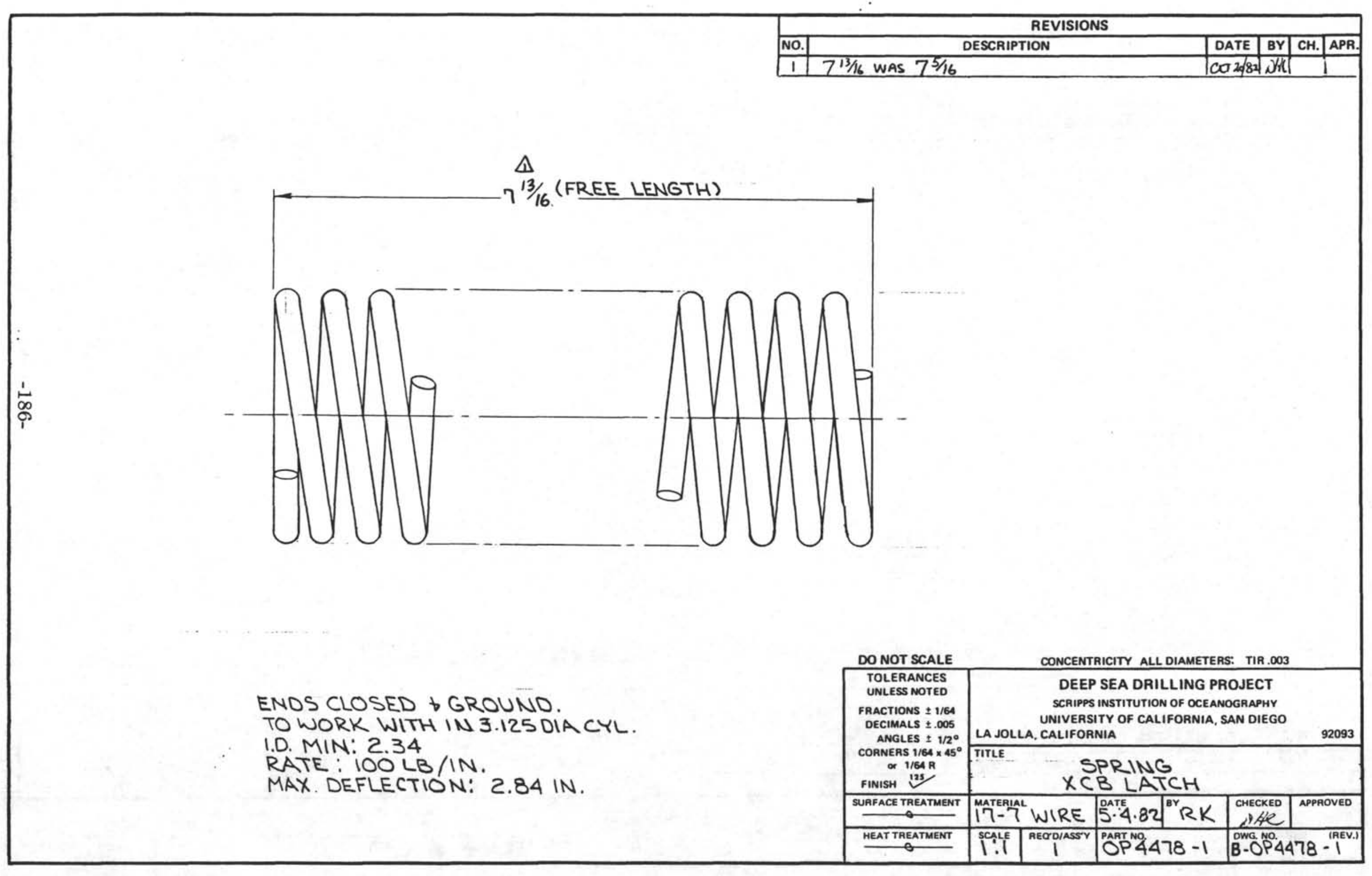




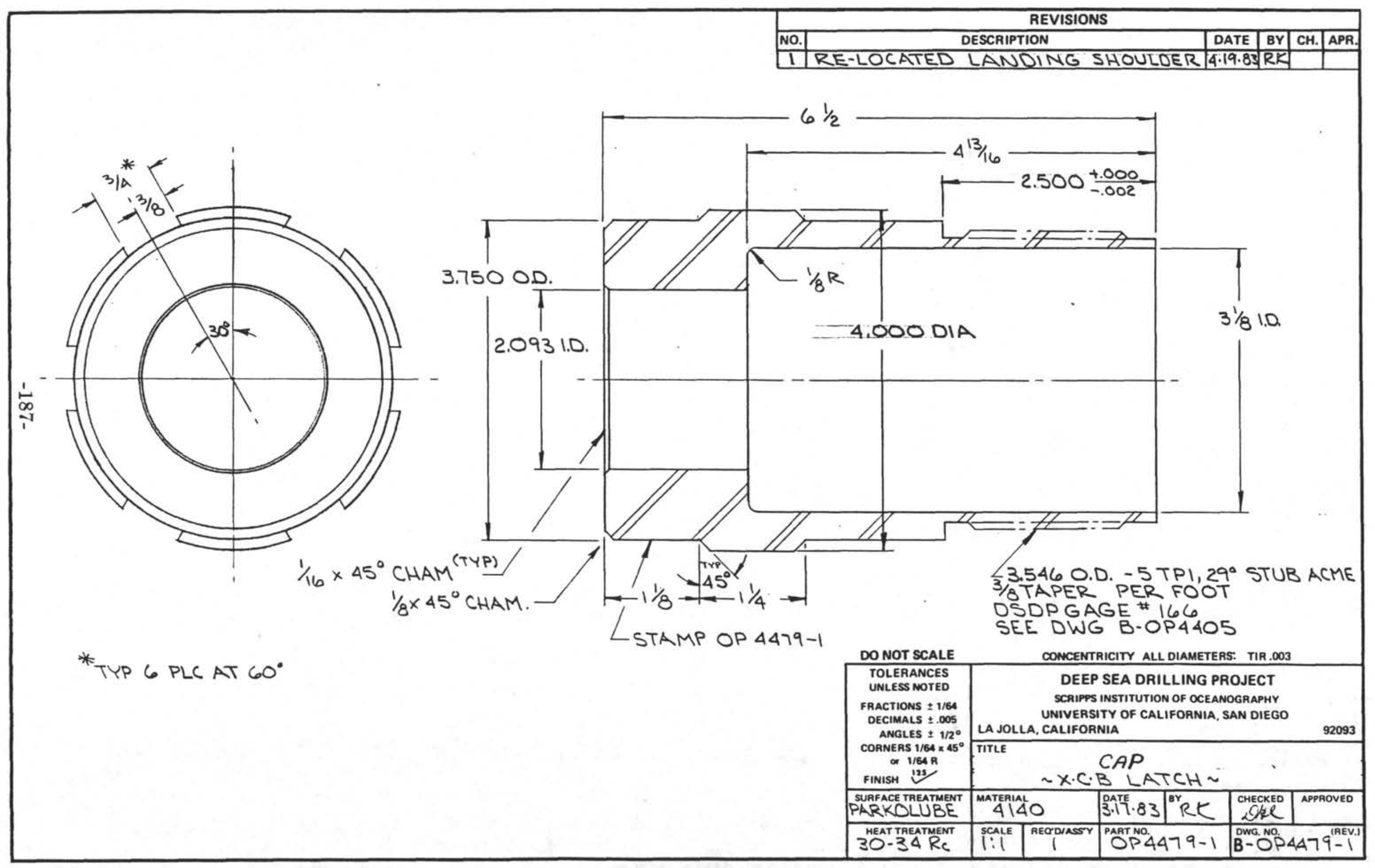




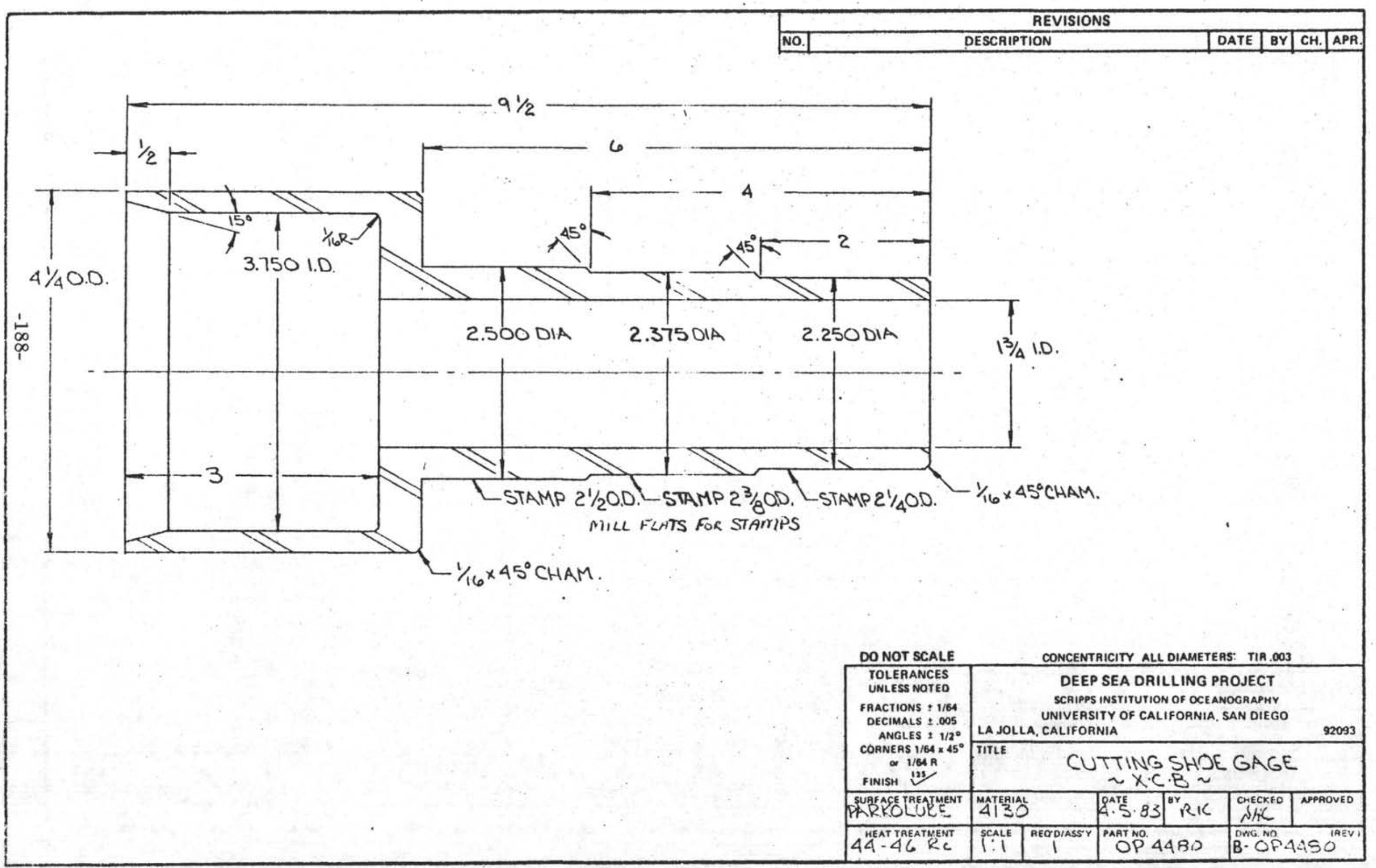




\begin{tabular}{|c|c|c|c|c|c|}
\hline NO. & DESCRIPTION & DATE & BY & CH. & APR. \\
\hline 1 & $21 / 2$ wAS $23 / 4$ DELETED GROOVES & $10.27-53$ & RK & & \\
\hline
\end{tabular}

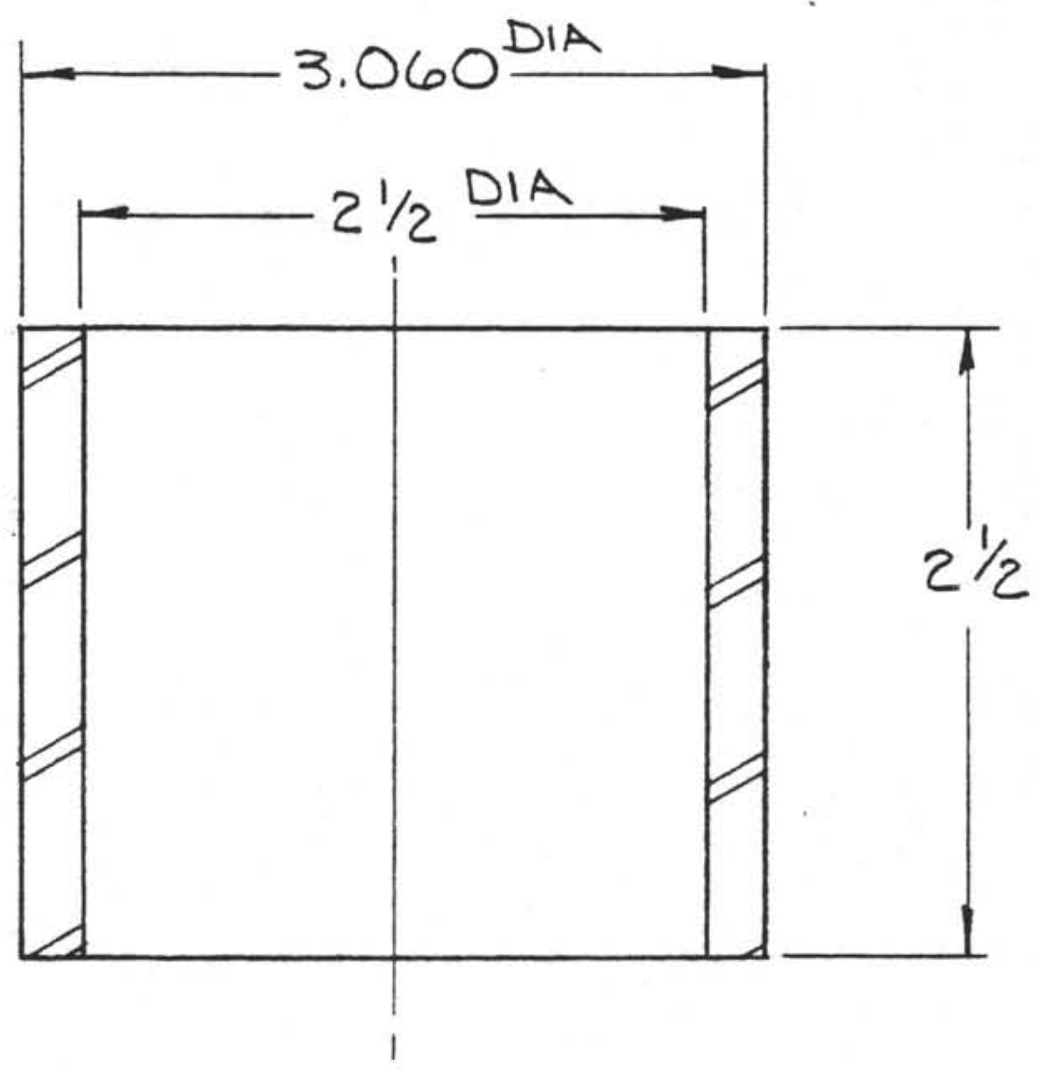

DO NOT SCALE TOLERANCES UNLESS NOTED

FRACTIONS $\pm 1 / 64$

DECIMALS \pm .005

ANGLES $\pm 1 / 2^{\circ}$ CORNERS $1 / 64 \times 45^{\circ}$ or $1 / 64 R$ FINISH 25 SURFACE TREATMENT
LA JOLLA, CALIFORNIA

CONCENTRICITY ALL DIAMETERS: TIR.003

\section{DEEP SEA DRILLING PROJECT}

SCRIPPS INSTITUTION OF OCEANOGRAPHY UNIVERSITY OF CALIFORNIA, SAN DIEGO

TITLE

CORE CATCHER SPACER $\sim X \cdot C \cdot B \sim$

\begin{tabular}{|c|c|c|c|c|}
\hline $\begin{array}{l}\text { MATERIAL } \\
\text { BRASS }\end{array}$ & 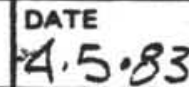 & RK & CMECKED & APPAOVED \\
\hline \begin{tabular}{l|l} 
SCALEE & REO'D/ \\
$1: 1$ & $\mid$
\end{tabular} & $\begin{array}{l}\text { PART NO. } \\
\text { OPA } 4\end{array}$ & 8 & $A=O P$ & \\
\hline
\end{tabular}




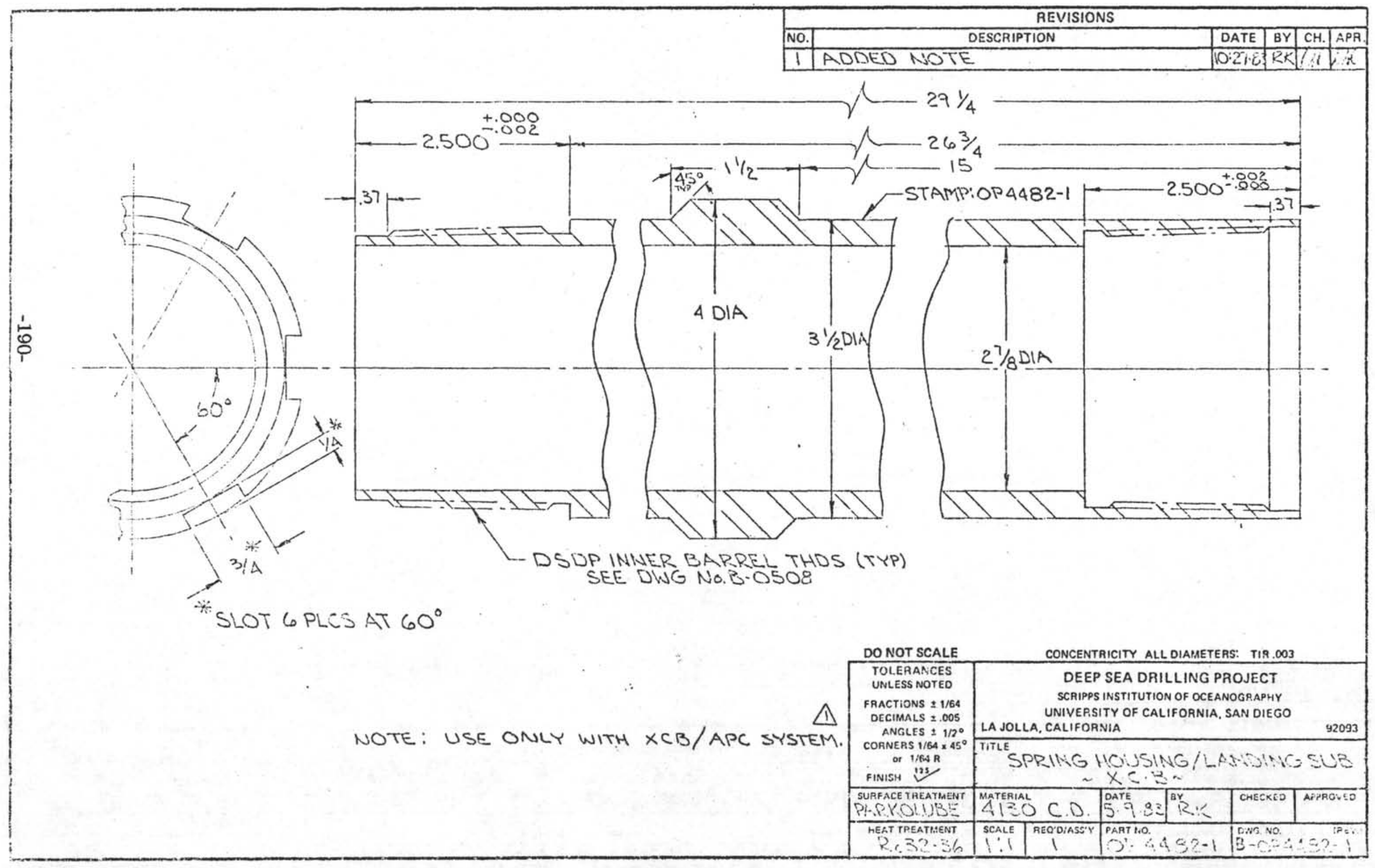




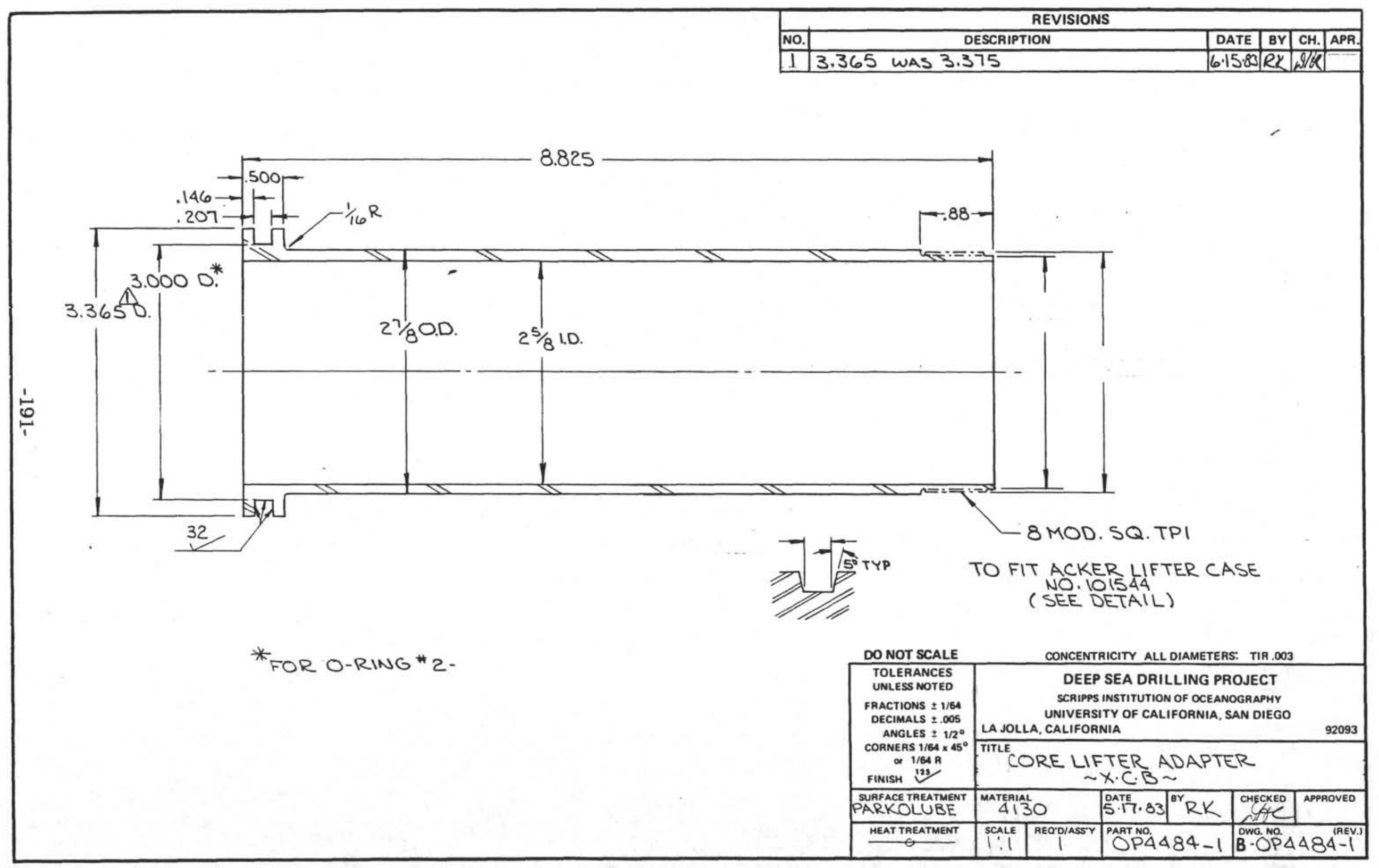




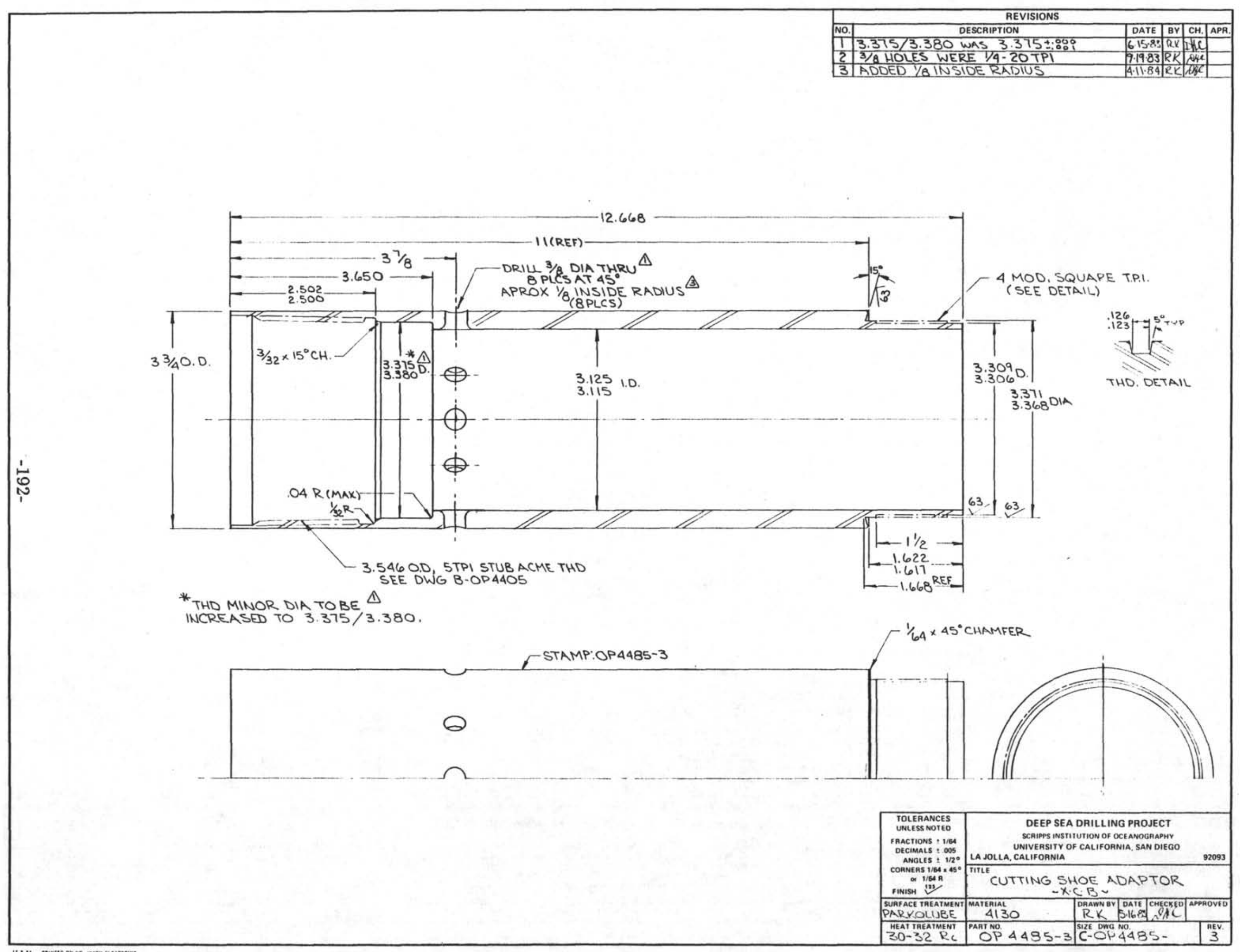




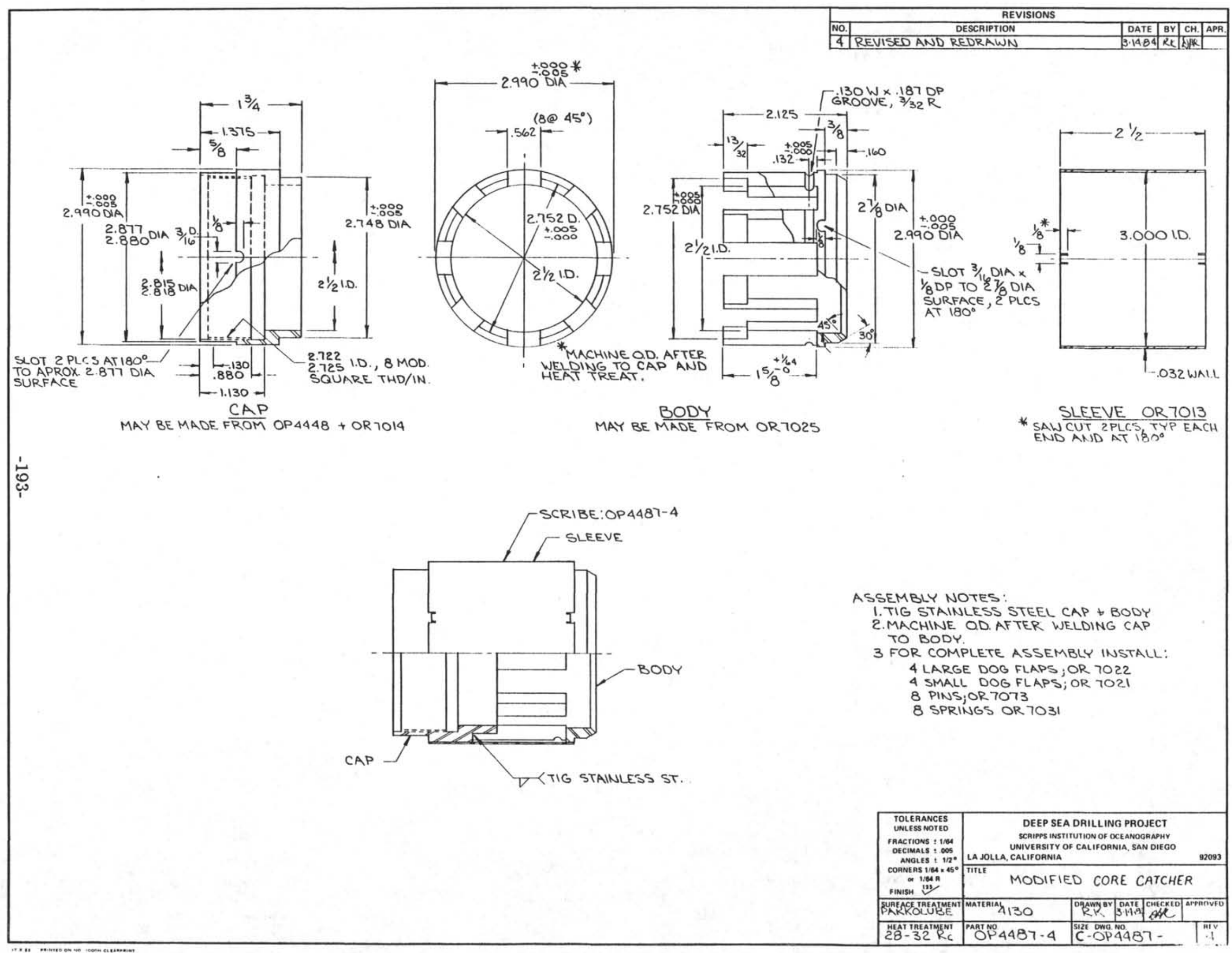




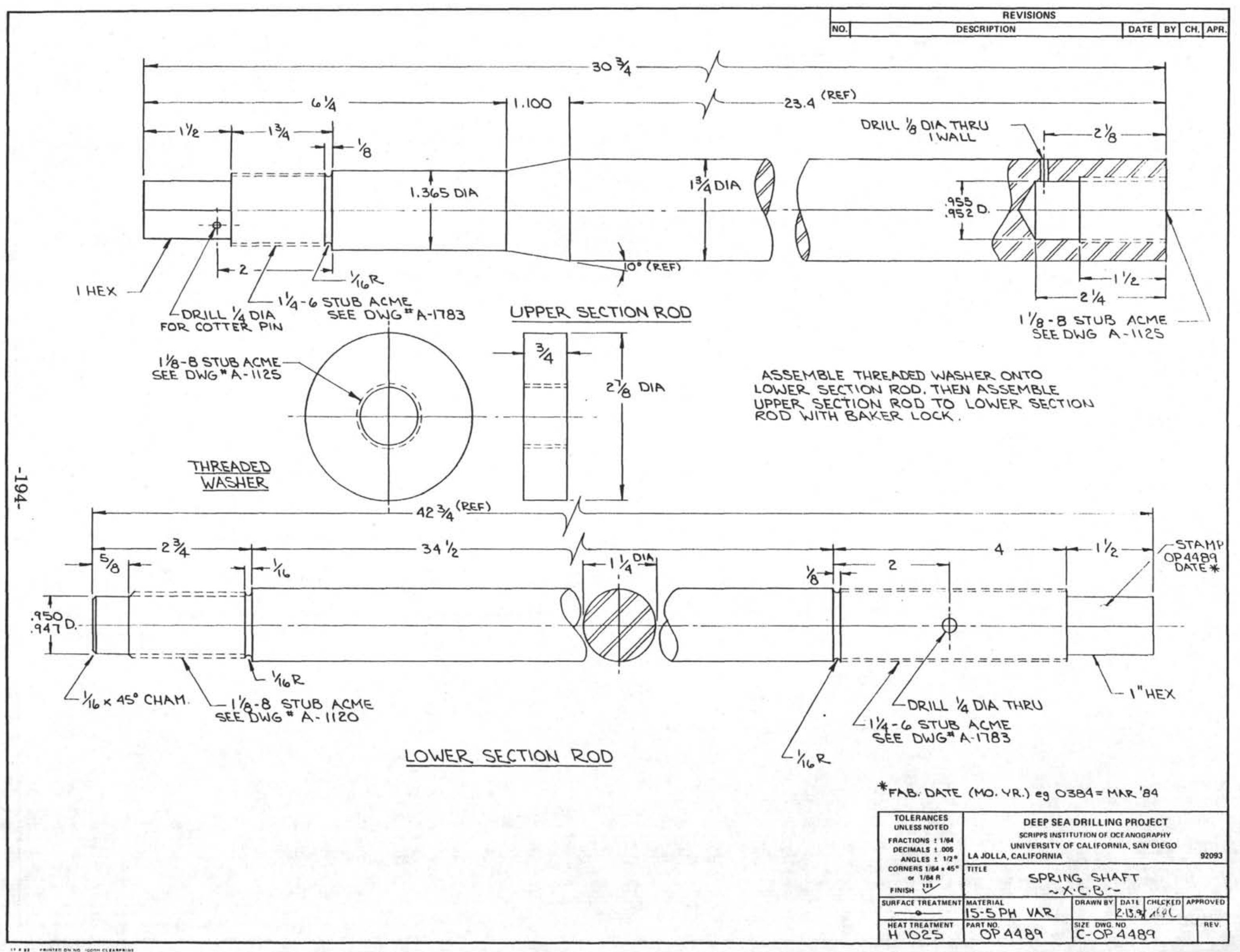




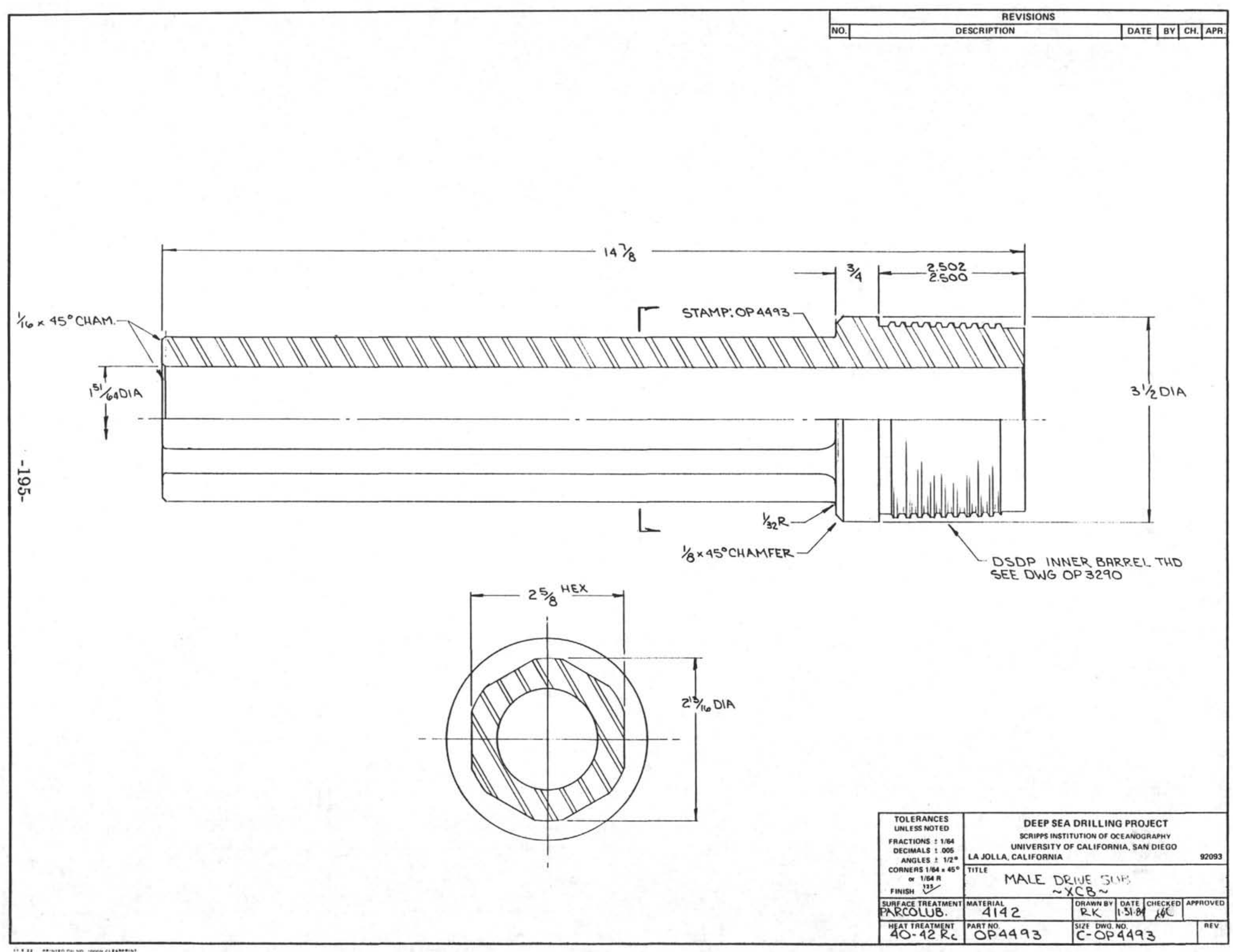




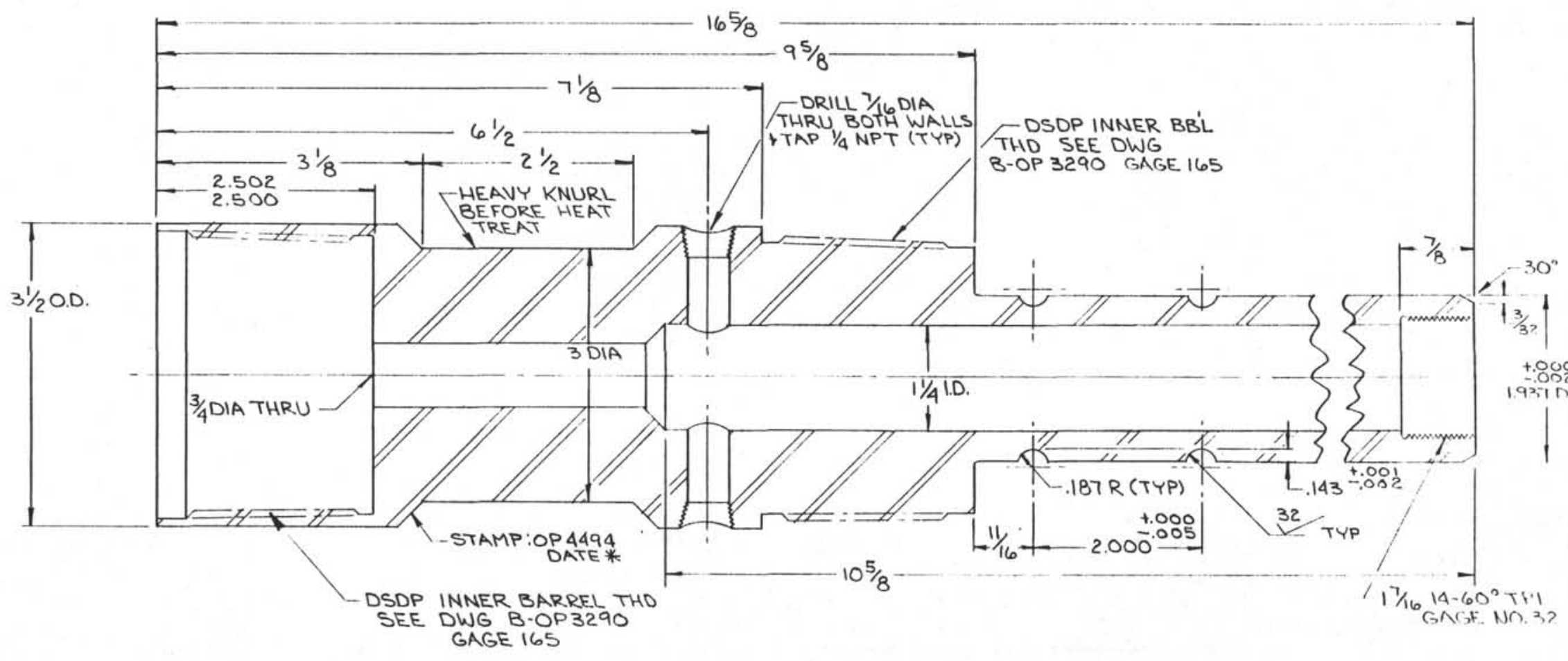

* fab. date (Mo. yr.) e.g. 0384 = Mar '84

\begin{tabular}{|c|c|c|c|}
\hline \multirow{2}{*}{ 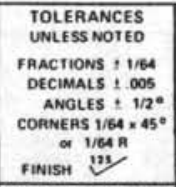 } & \multicolumn{3}{|c|}{ 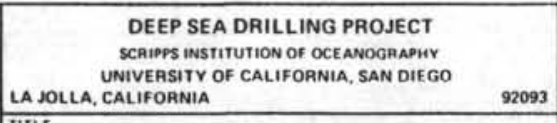 } \\
\hline & \multicolumn{3}{|c|}{$\begin{array}{l}\text { VENT SUB } \\
\sim X \cdot C \cdot B \sim \sim\end{array}$} \\
\hline $\begin{array}{l}\text { MAFACE IAEATMENT } \\
\text { ARIOLUUE }\end{array}$ & 4130 & 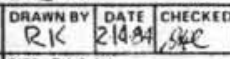 & \\
\hline $36-38$ & & 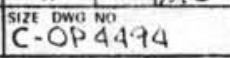 & \\
\hline
\end{tabular}




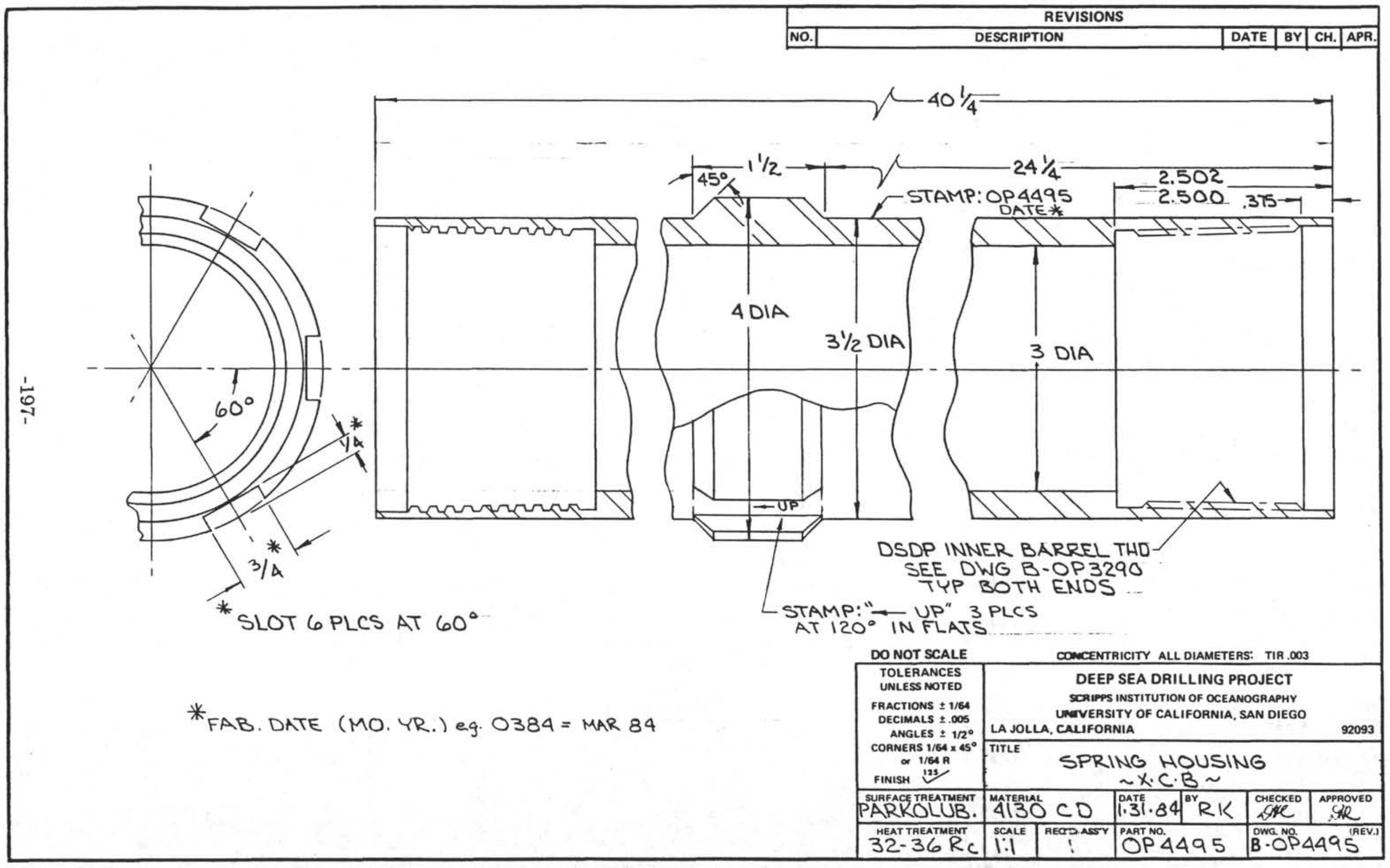




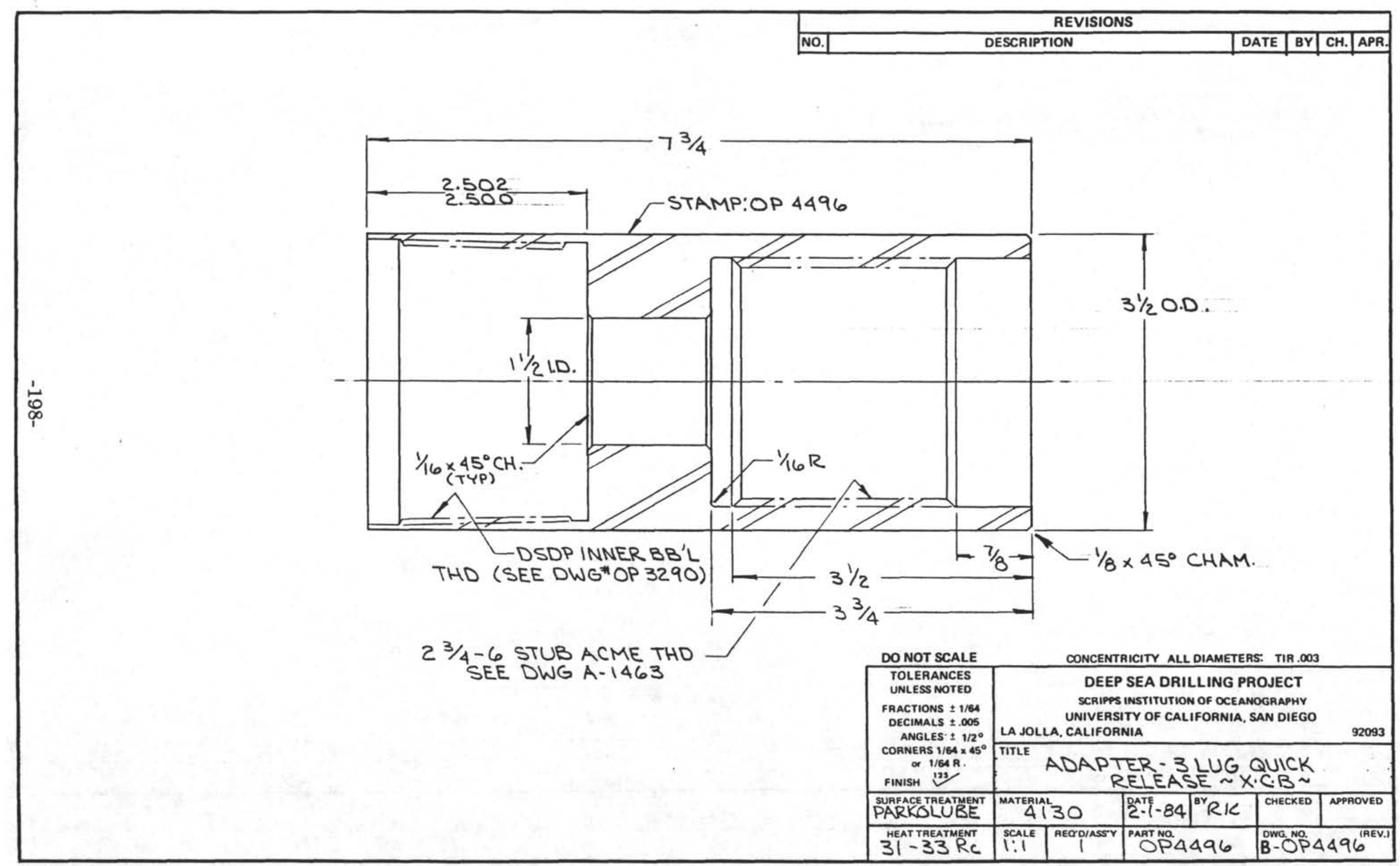




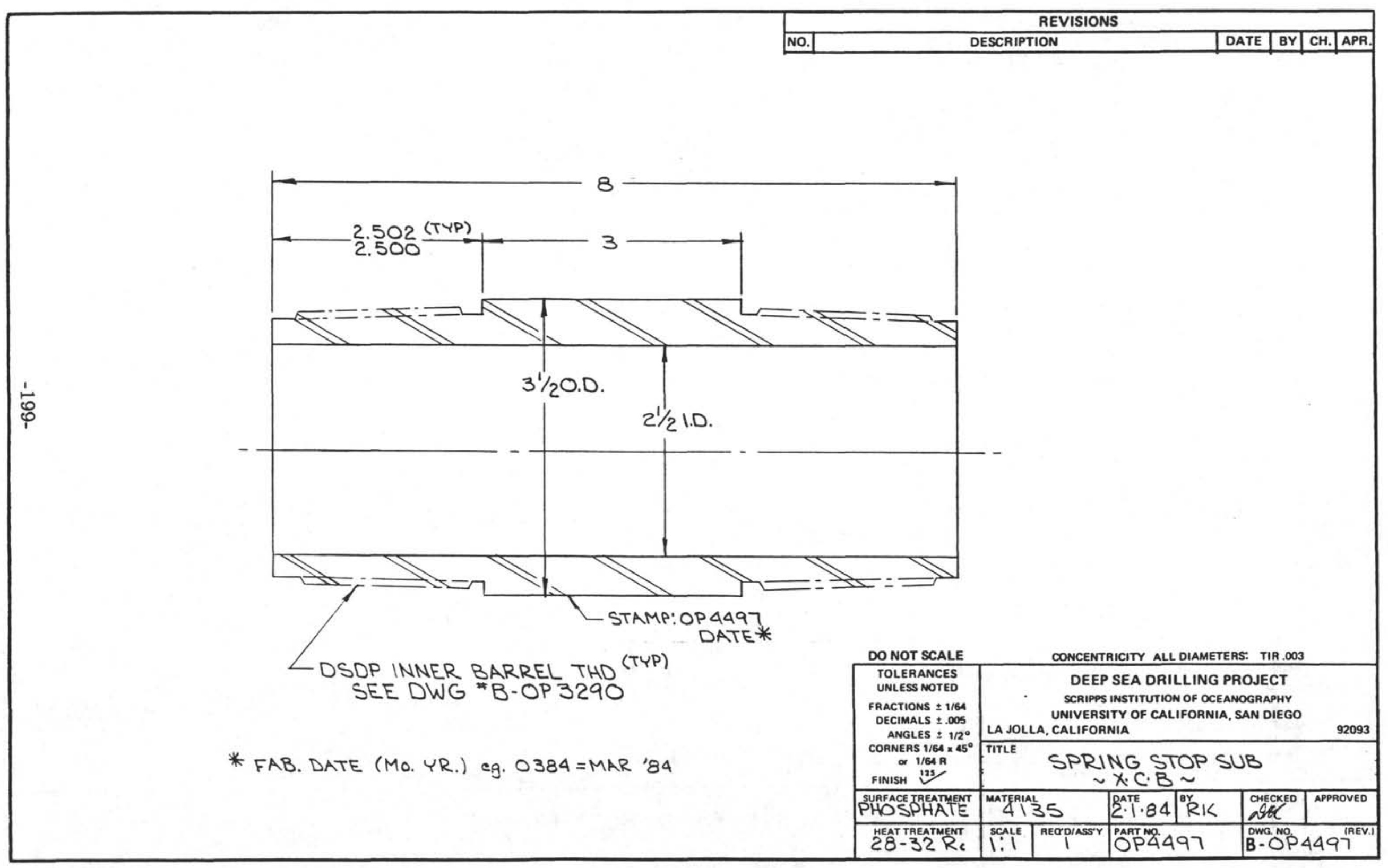




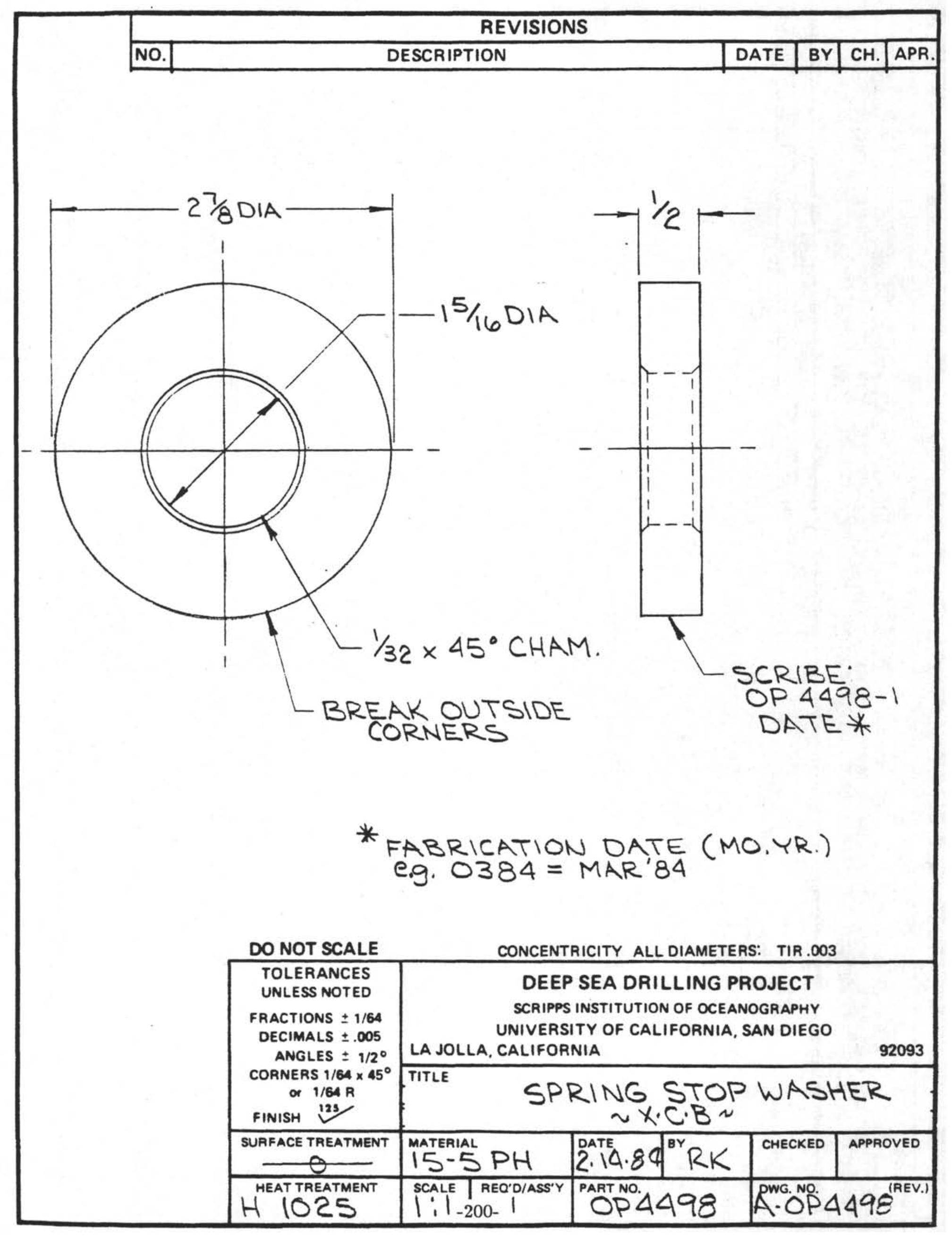




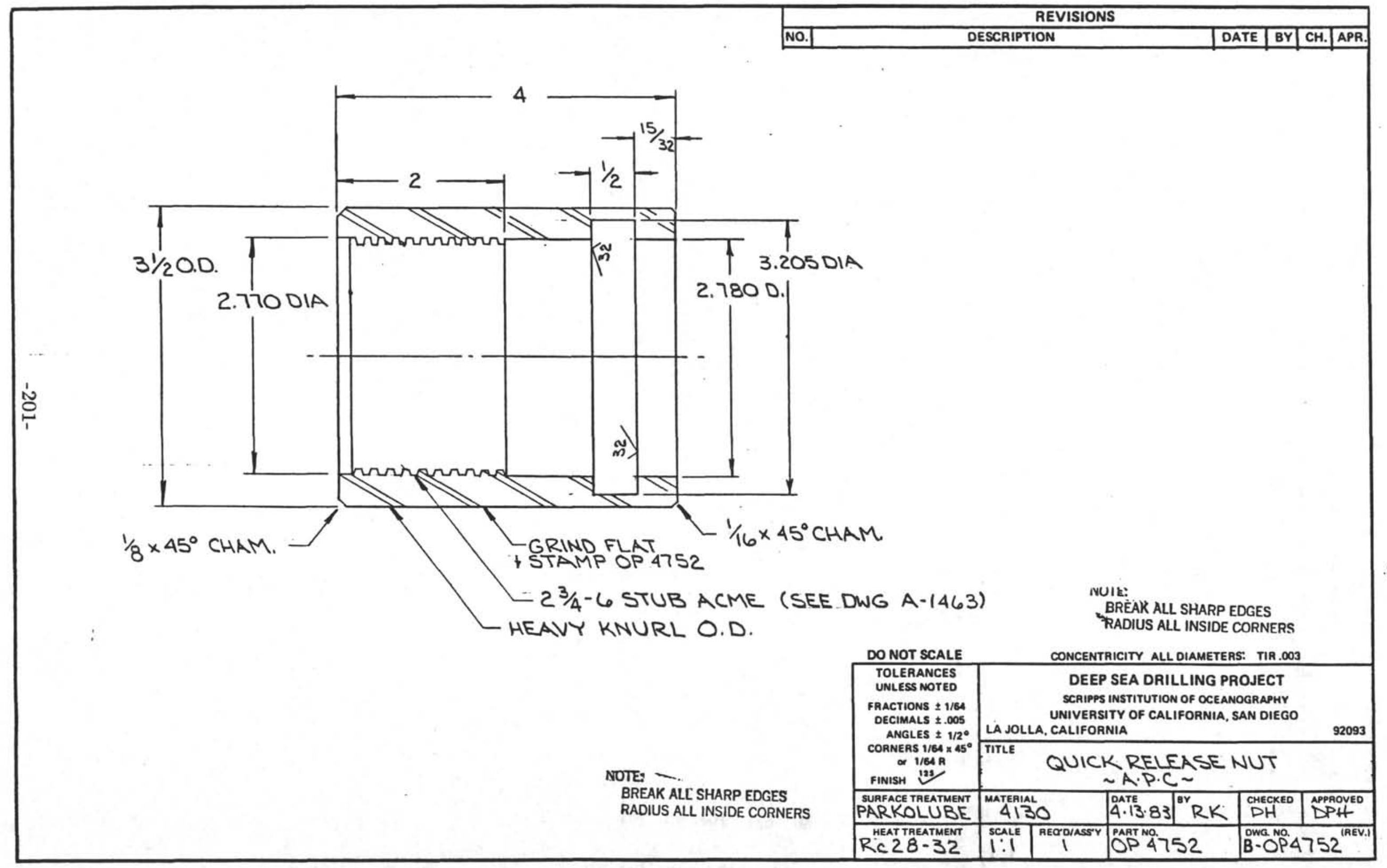




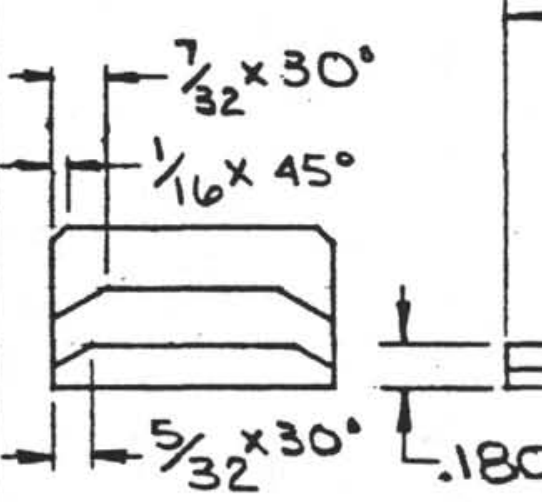

$3 \frac{3}{4}$

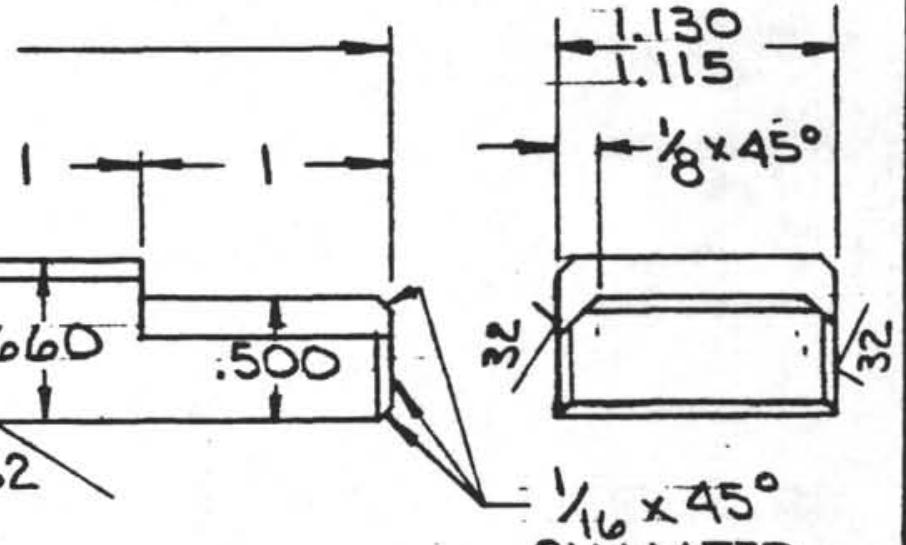

STAMP: OP 4753

CHAMFER

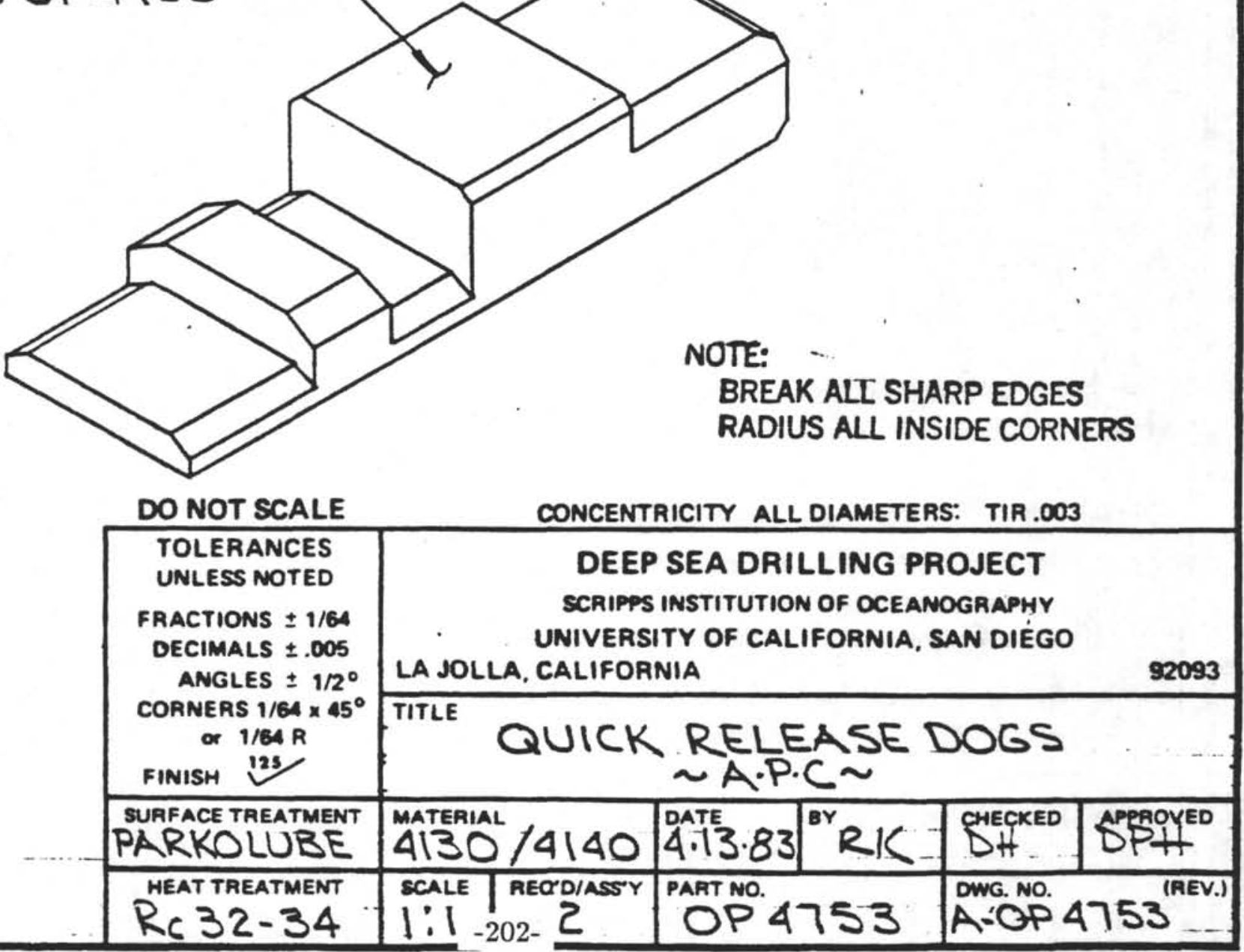




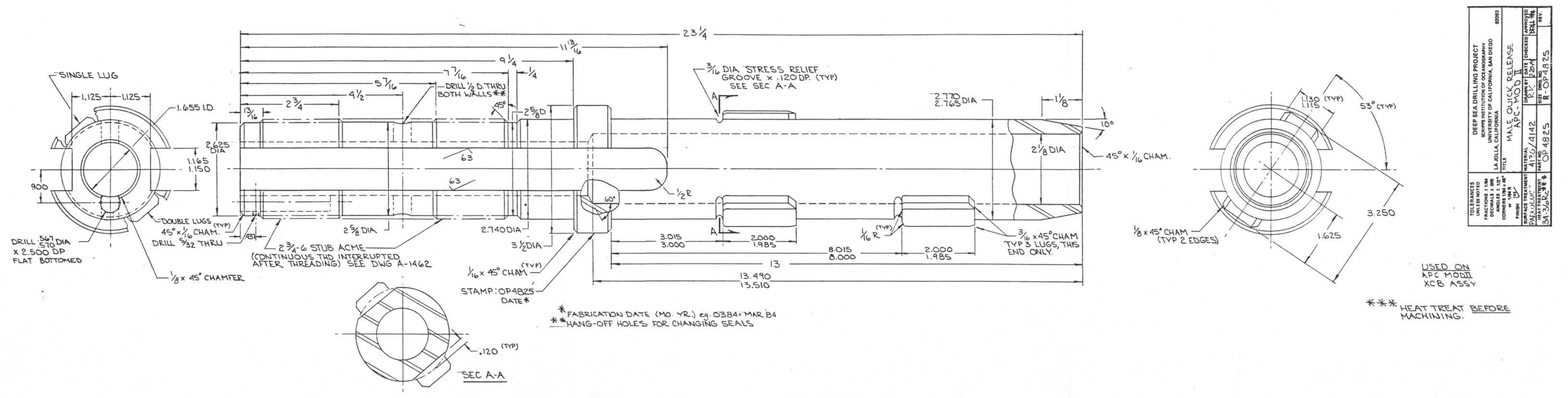




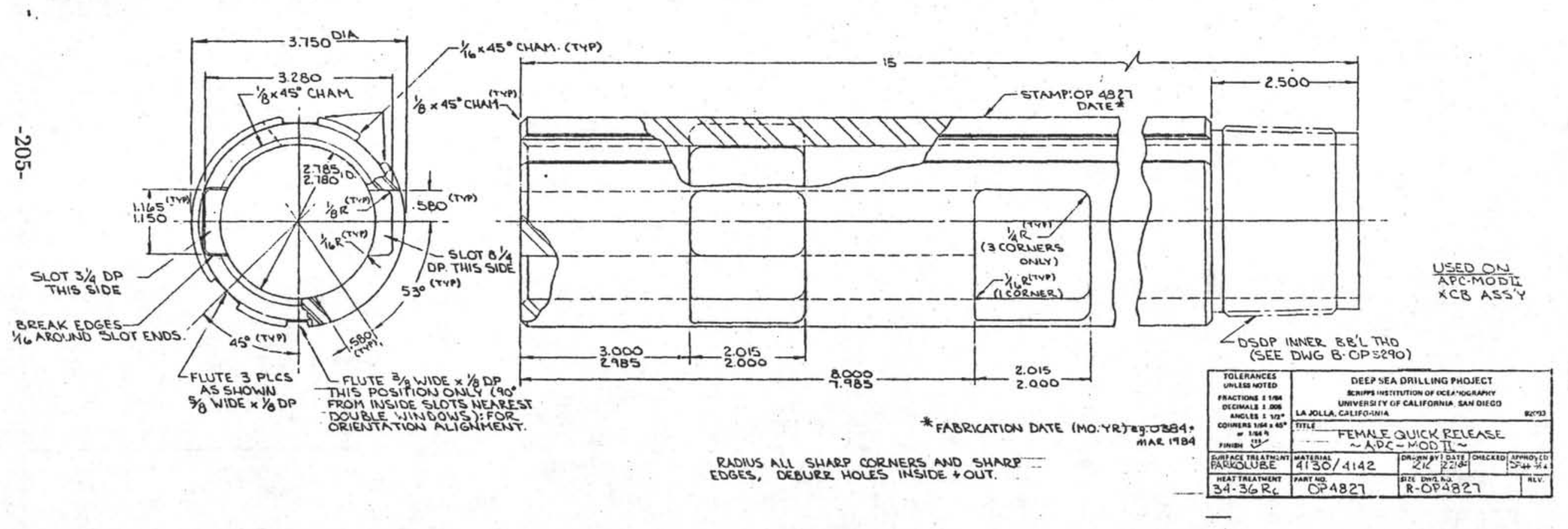




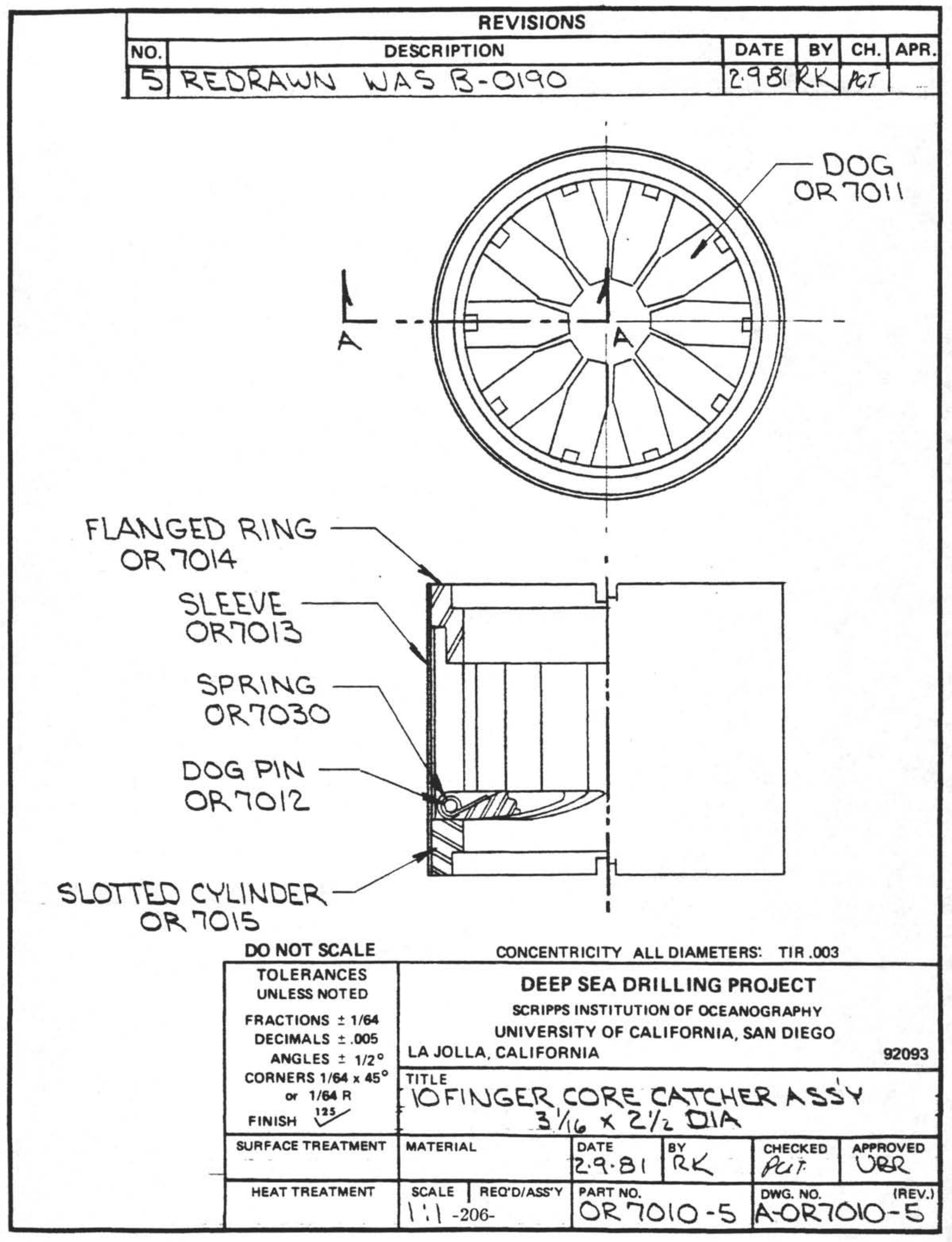




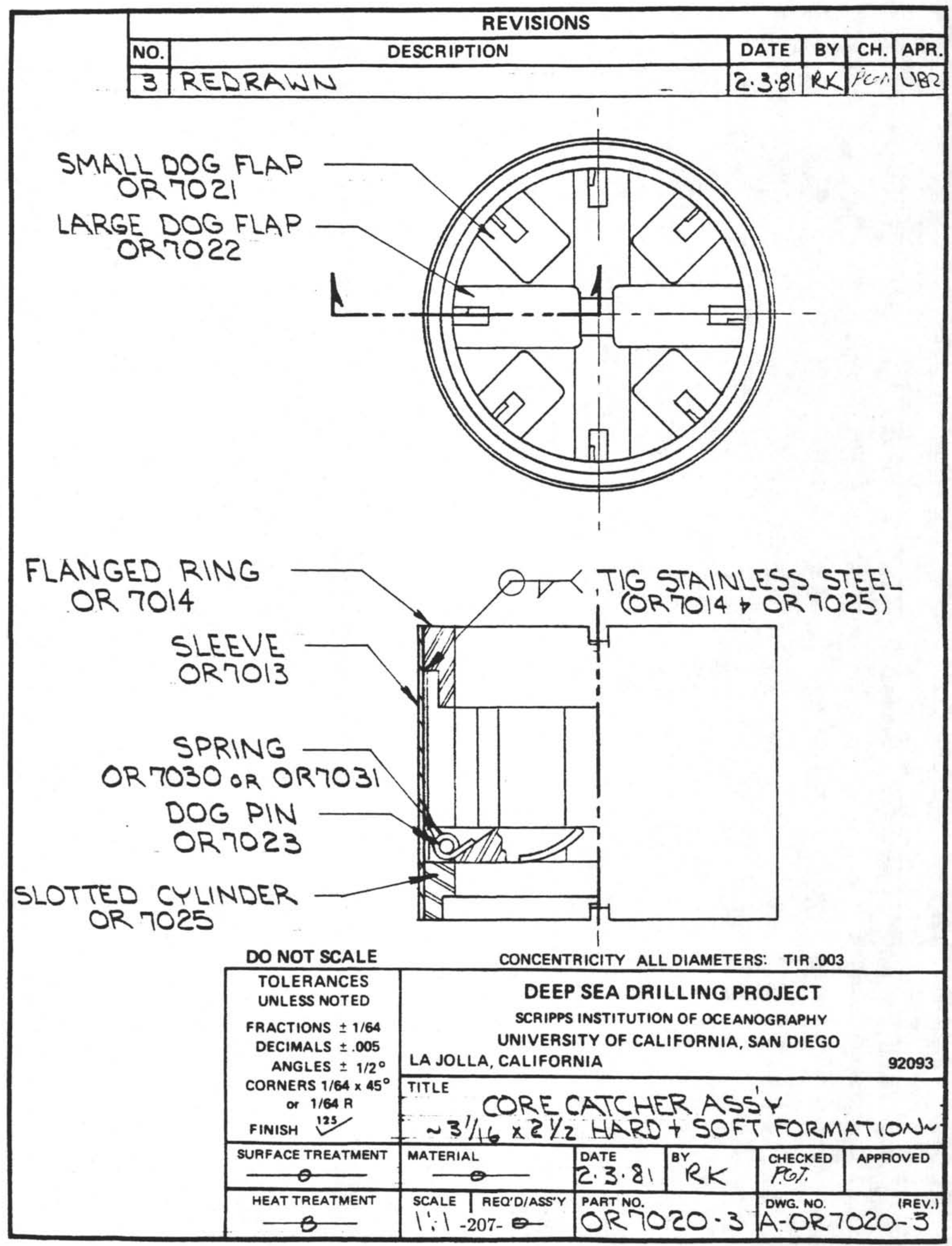




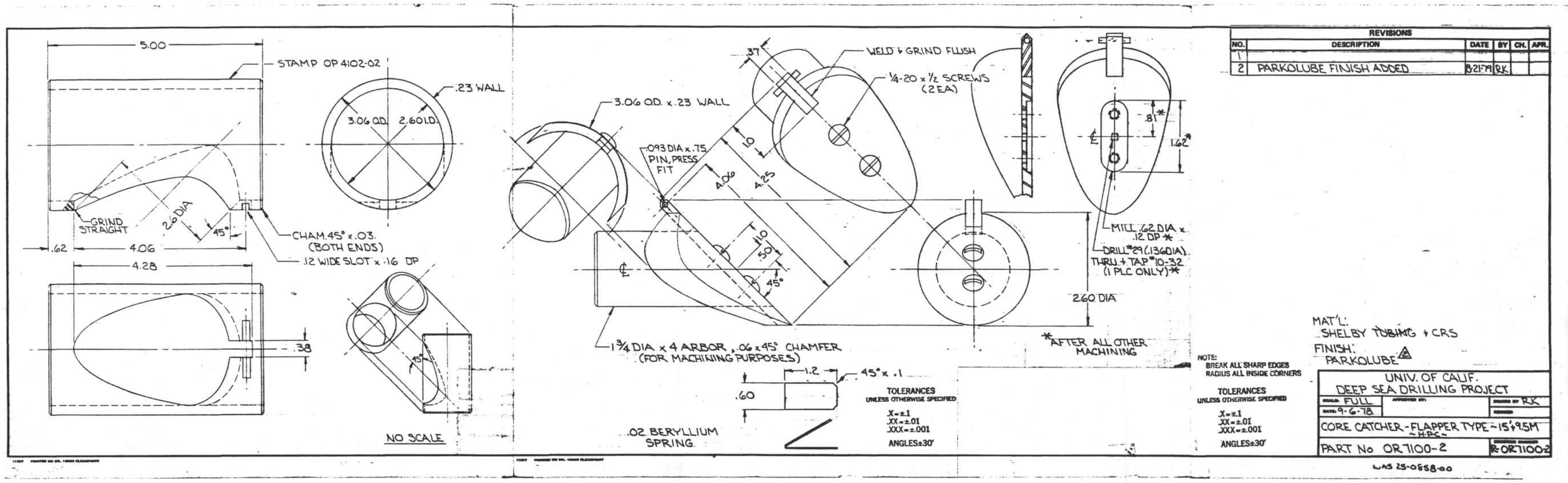




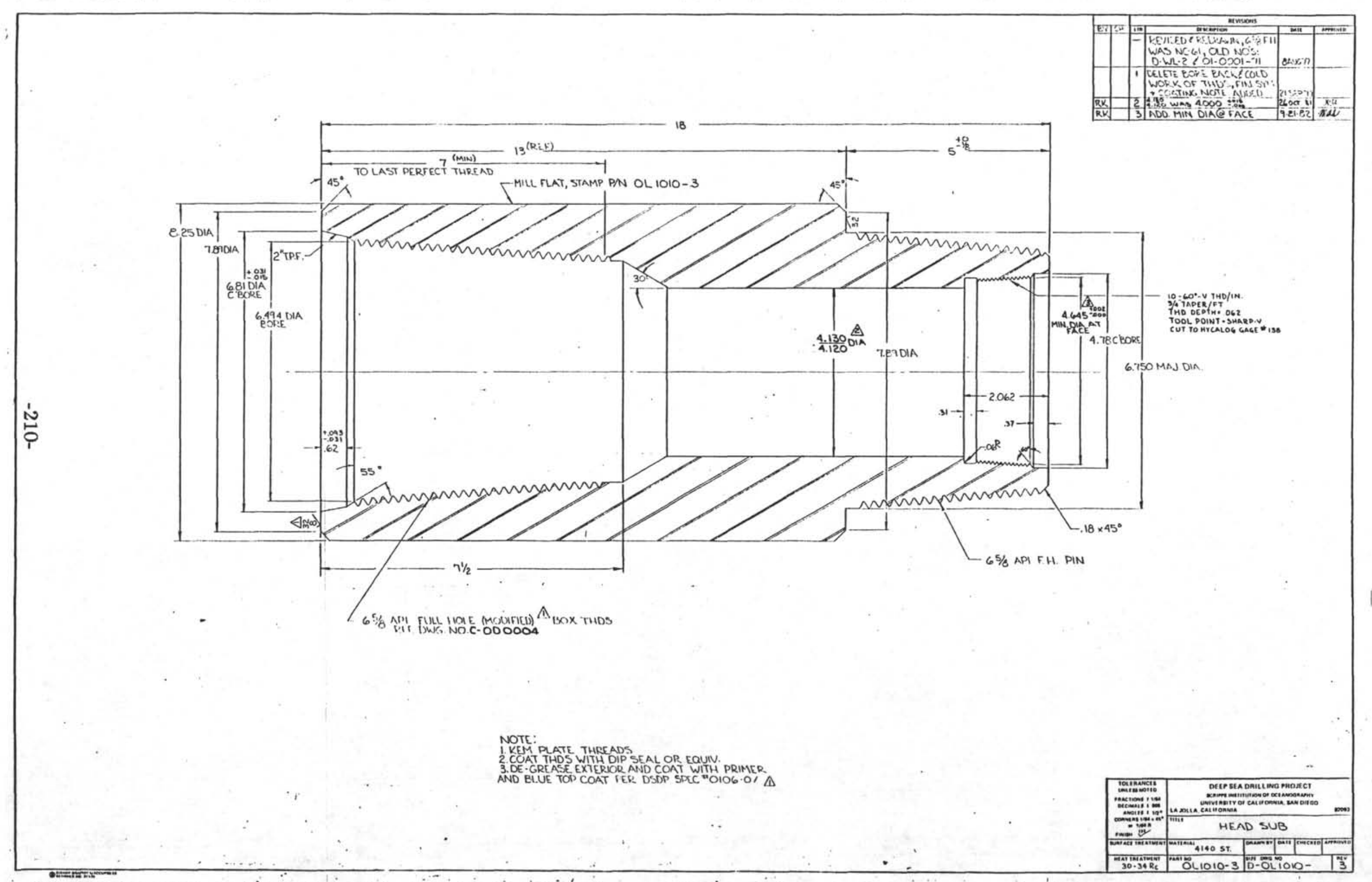




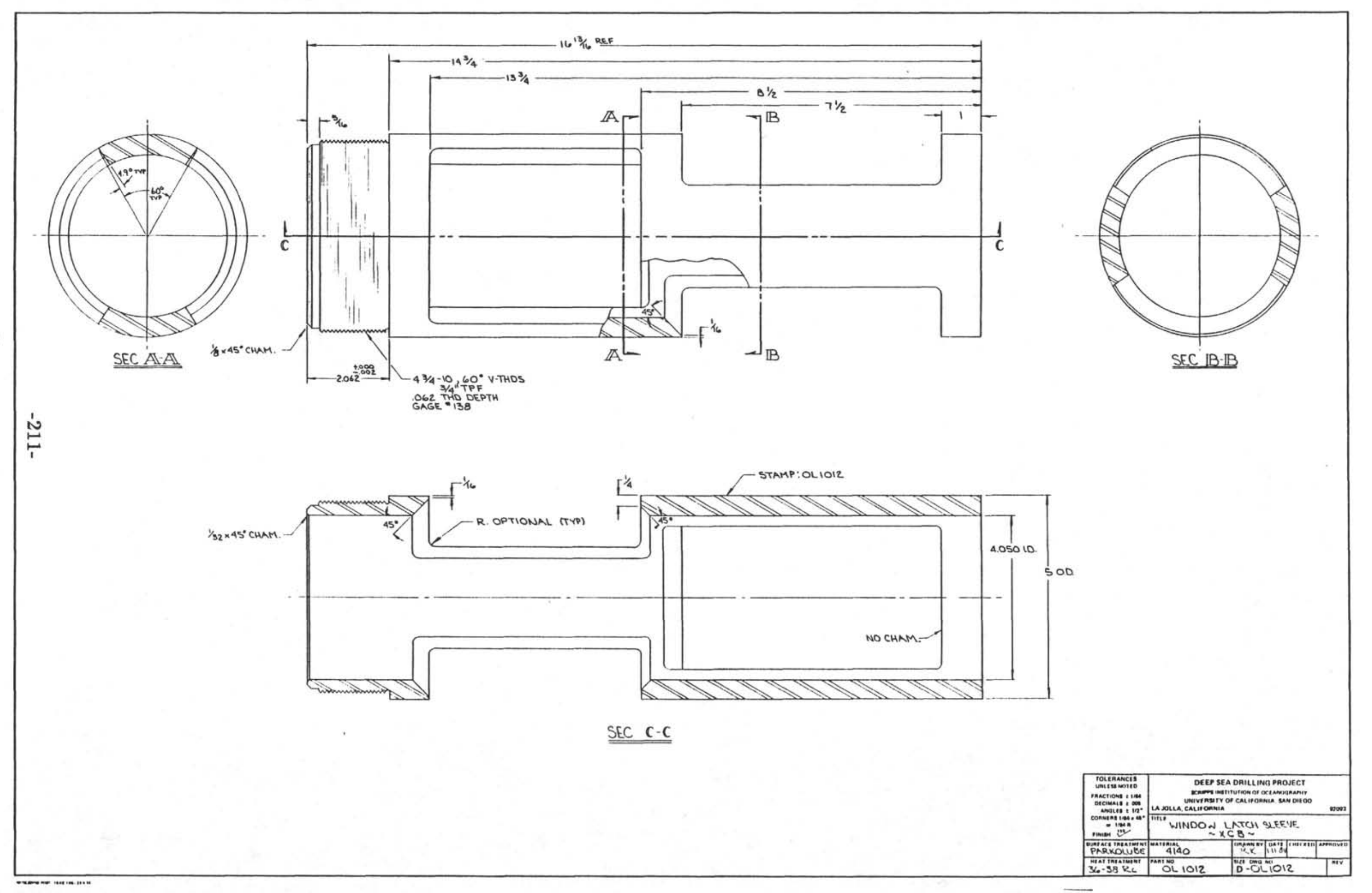




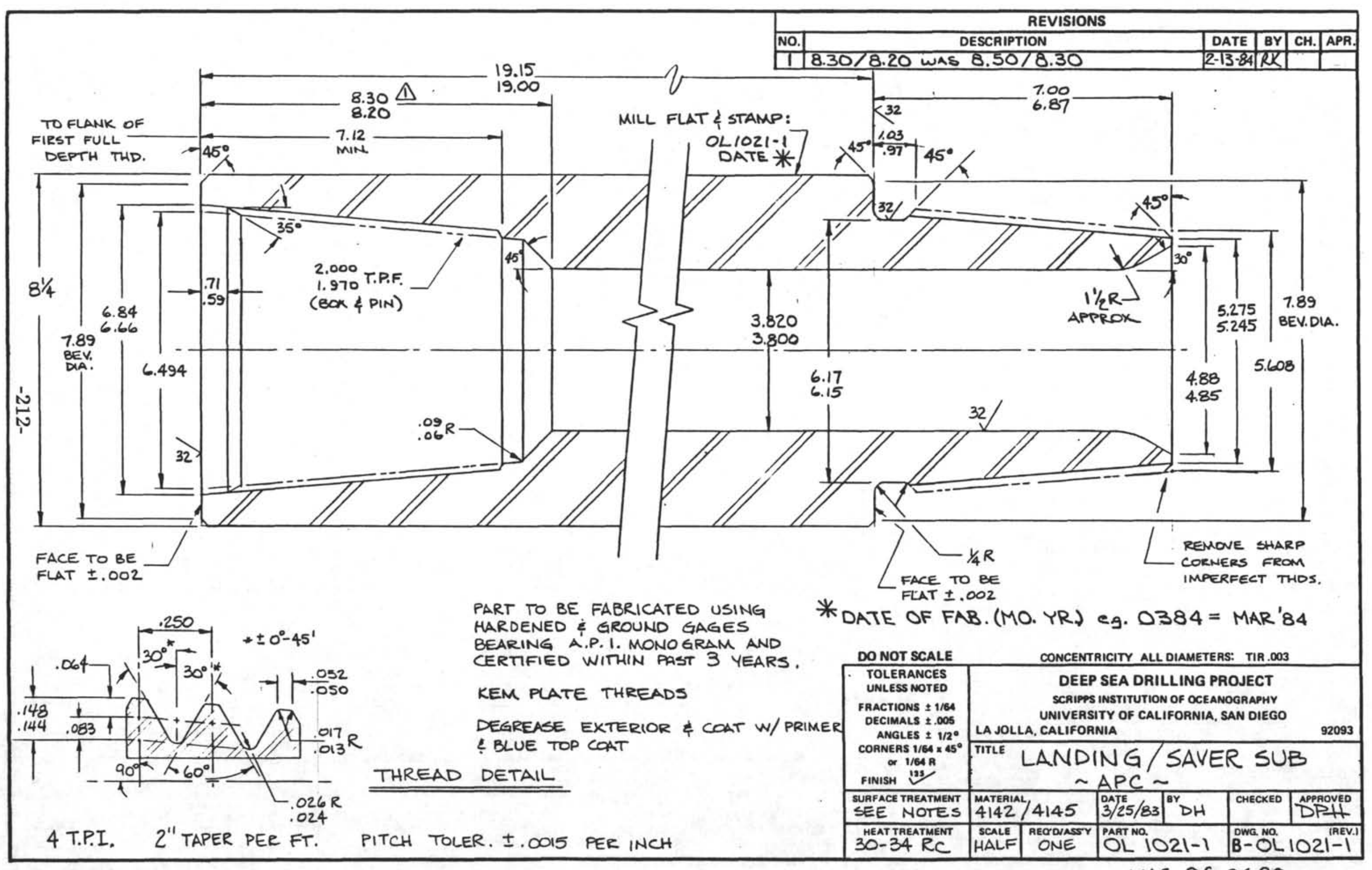

WAS OG 0620 


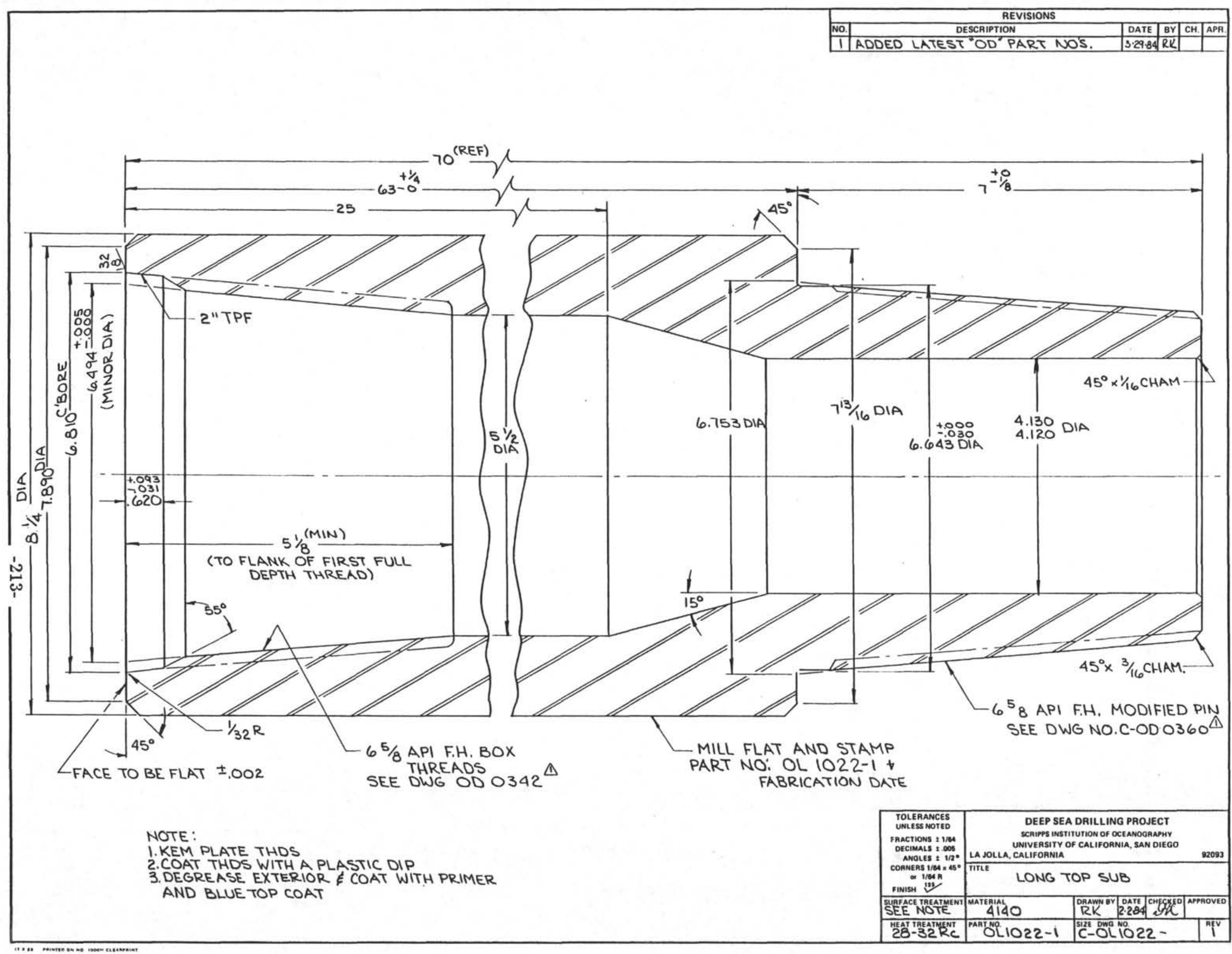




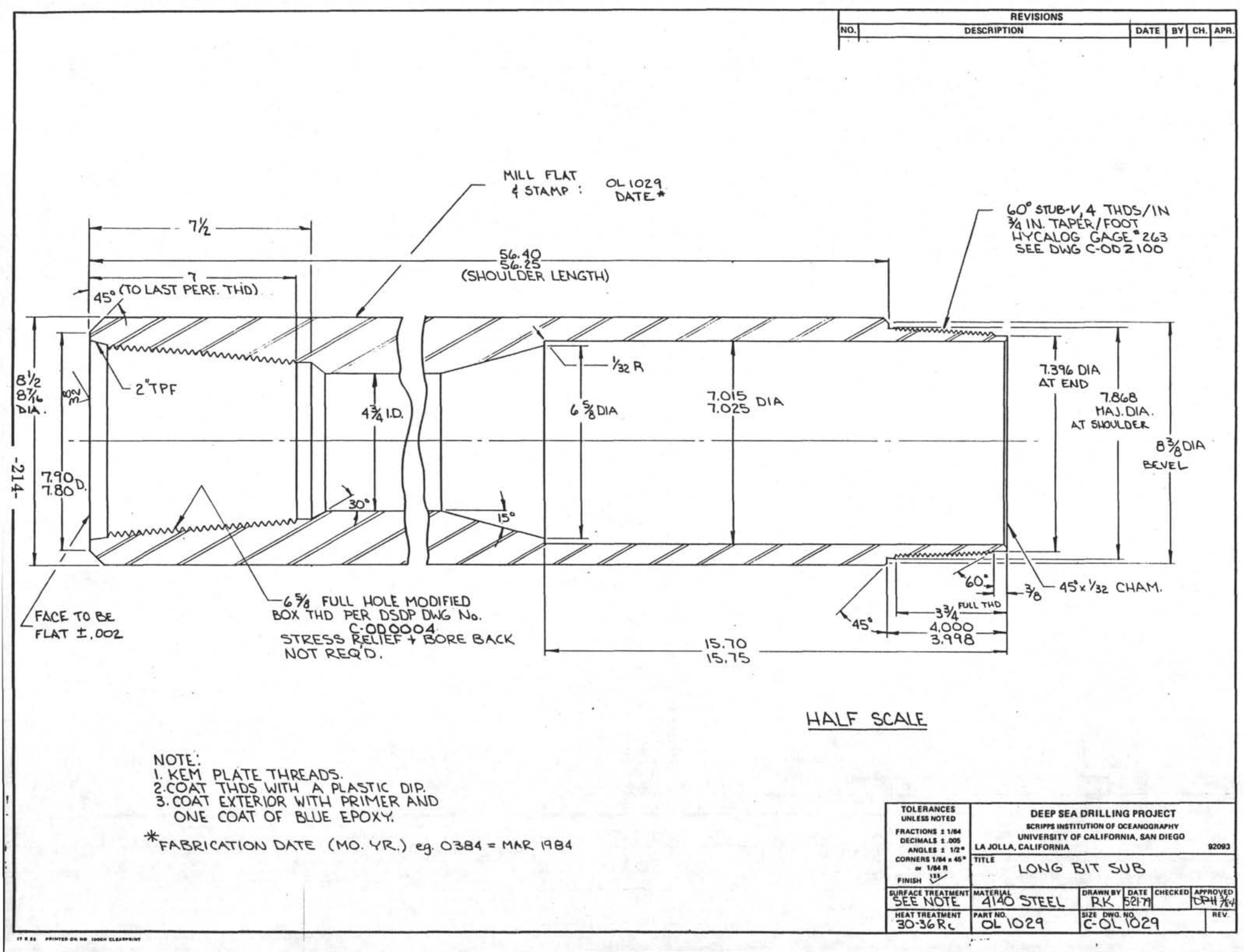




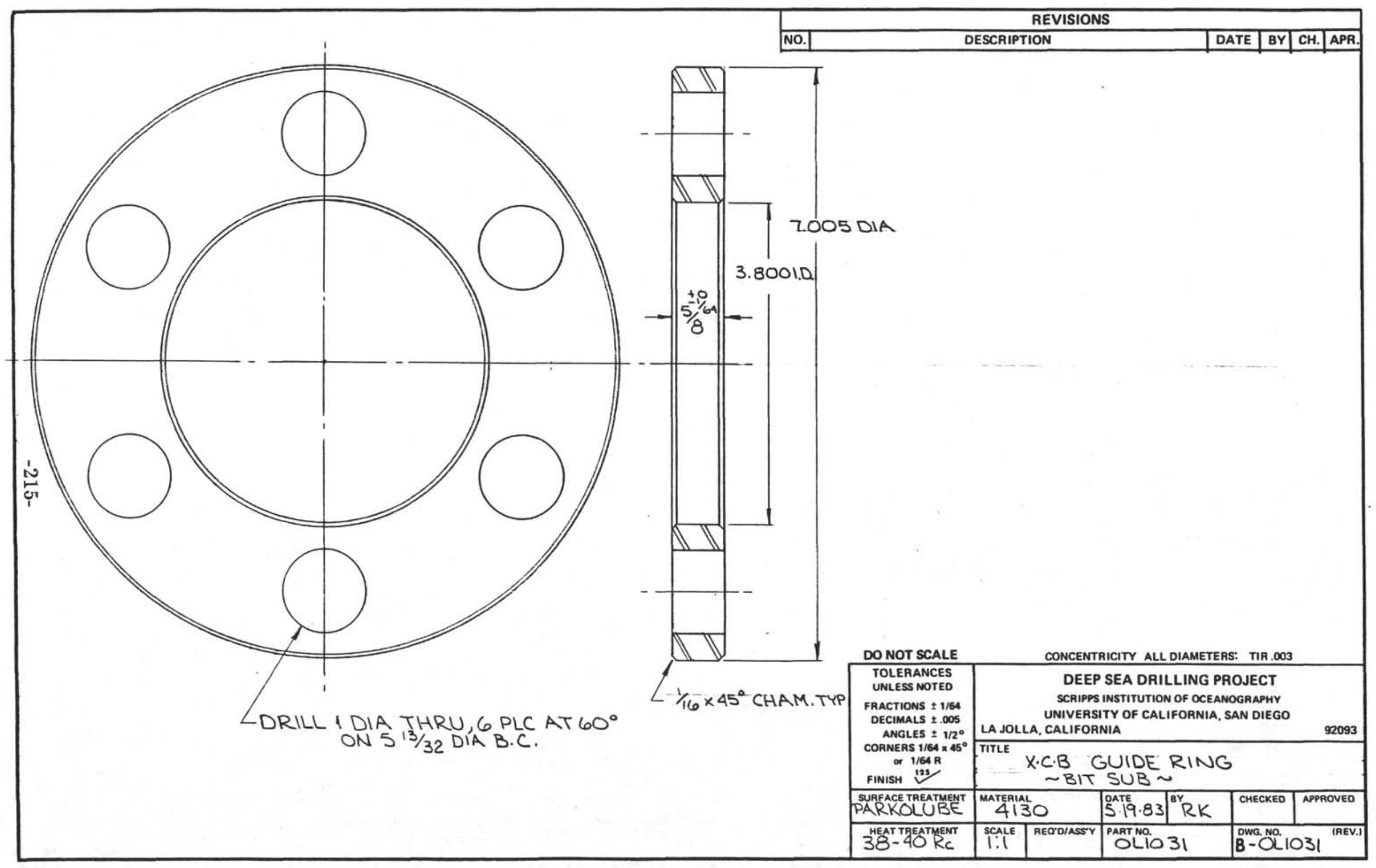




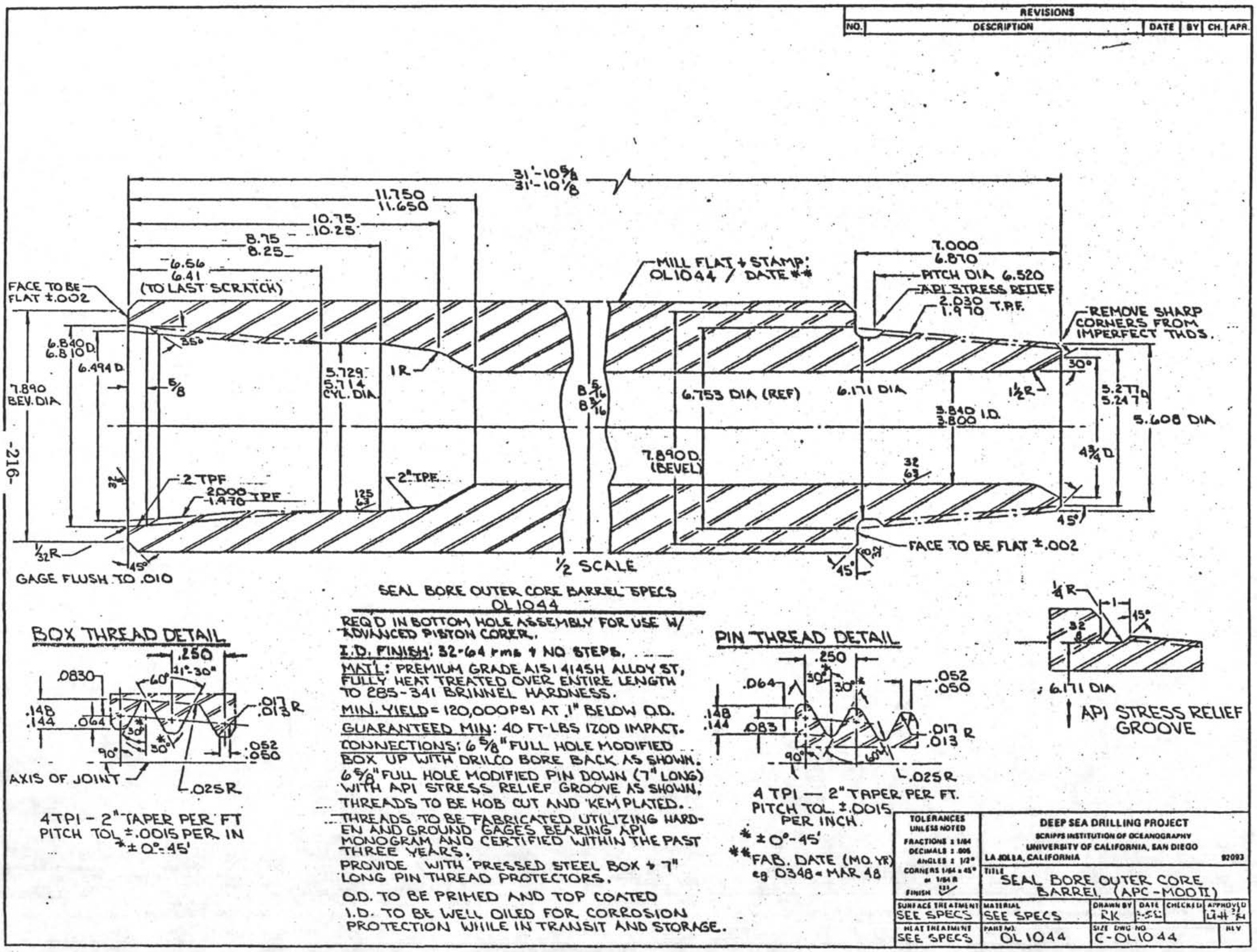


ELAPPER HIMGE PINS B FLAPER VALVE Egyision if

HEAT TRETHERT FOS SAE 4300

OBECCIIVE: Heat treat SAE 4340 steel to maxlmize low femperature trughness (charpy ter mpact eneray)

PRCCEDURE: Stress relleve: Approx Imately $1100^{\circ}$ f for 2 hours, atr cool Nartempering (narquencting)

A. Prehest to $1100^{\circ} \mathrm{F}$

B. Austentitize $4340 \mathrm{O} 1525^{\circ} \mathrm{F}$ approximately one hour

C. Quench in salt bath $0570^{\circ}$. Hold part unt11 temperature is unifom.

D. Place in $200-250^{\circ} \mathrm{F}$...1t bath. (2000\% is niminem temperature part

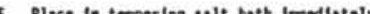

Ioppering

P. Temper $1000^{\circ} \mathrm{F}$ for two hours

6. OII quench (to prevent possibtility of temper mbirittlenent:

Burton W. Adns,
Deve lopeent Engineer

QEF?: Metal Handbook, Vo1. 2, Heat Treating, c10

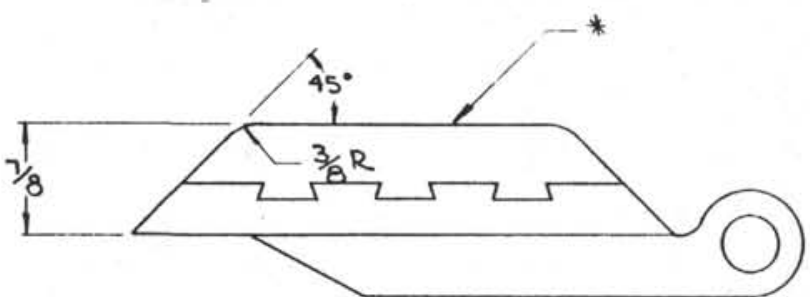
adiprene (POlyurathane) to be cast to a hardhess OF 55 DUROMETER D. MAX. DEVIATION \pm 5 D. MOCHA CURE. SUBSTRATE TO BE GRIT BLASTED AND PREPARED FOR MAX ADHESION, AFTER CASTING MACHINE TO FINAL CONFIGURATION

CAST PROCESS DONE. BY BROWII RUBBER DIVISION OF GLENCO 407 E. REDONDO BEACH BLVD, GARUEIIA. CALIFDRNIA, 90248 (213) $532-2980$

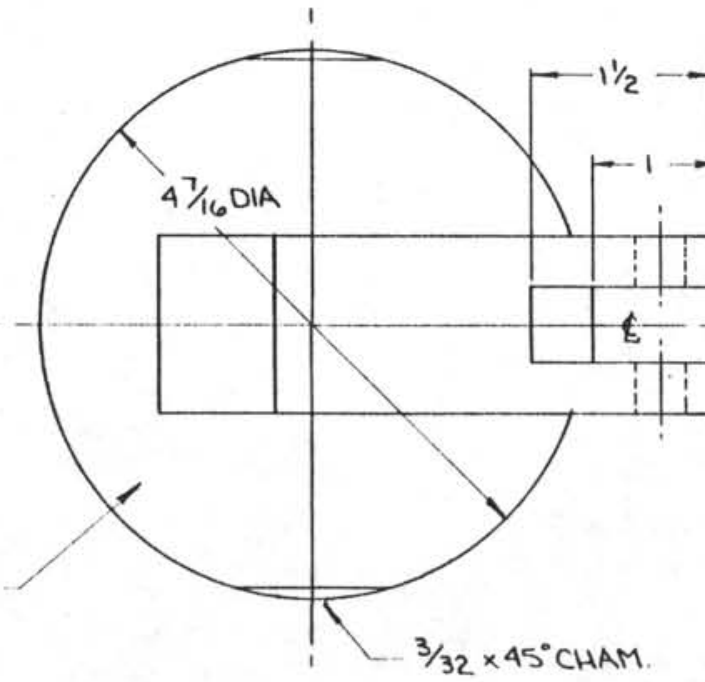

MAT'L:

6" DIA X I"LONG 4340 ALLOY HOT ROLLED ROD (ONE PIECE OF STOCK)

\begin{tabular}{|c|c|c|c|}
\hline \multirow{2}{*}{ 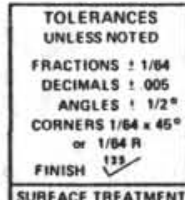 } & \multicolumn{2}{|c|}{ 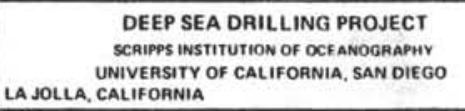 } & \multirow[t]{2}{*}{92093} \\
\hline & "IILE $\begin{array}{r}\text { PAD } \\
\sim \times C B \\
\end{array}$ & $\begin{array}{l}\text { ED FLAPPER: } \\
\text { OAT VALVE }\end{array}$ & \\
\hline SURFACE TREATMENT & MEYEIAL ABOVE. & 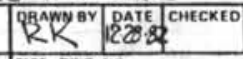 & APPAOY \\
\hline $\begin{array}{l}\text { HEAT THEA MENT } \\
36.40 \mathrm{R}_{C}\end{array}$ & OAT 1504 & $\begin{array}{l}\text { S12E OWa No } \\
\text { C-OL I'SOA- }\end{array}$ & $\begin{array}{l}\text { माv. } \\
1\end{array}$ \\
\hline
\end{tabular}

